\title{
Mongolia: Poverty Reduction Strategy Paper
}

Poverty Reduction Strategy Papers (PRSPs) are prepared by member countries in broad consultation with stakeholders and development partners, including the staffs of the World Bank and the IMF. Updated every three years with annual progress reports, they describe the country's macroeconomic, structural, and social policies in support of growth and poverty reduction, as well as associated external financing needs and major sources of financing. This country document for Mongolia, dated July 3, 2003, is being made available on the IMF website by agreement with the member country as a service to users of the IMF website.

To assist the IMF in evaluating the publication policy, reader comments are invited and may be sent by e-mail to publicationpolicy@imf.org.

Copies of this report are available to the public from

International Monetary Fund • Publication Services

$70019^{\text {th }}$ Street, N.W. • Washington, D.C. 20431

Telephone: (202) 623-7430 • Telefax: (202) 623-7201

E-mail: publications@imf.org • Internet: http://www.imf.org

Price: $\$ 15.00$ a copy

\section{International Monetary Fund \\ Washington, D.C.}





\section{GOVERNMENT OF MONGOLIA}

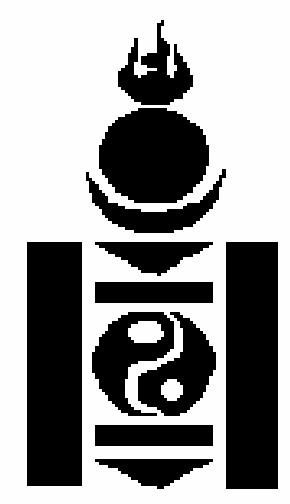

\section{ECONOMIC GROWTH SUPPORT and POVERTY REDUCTION STRATEGY}

ULAANBAATAR

July 3, 2003 


\section{Foreword}

We are pleased in present you the Economic (rowwlis Suppest and Poverly Reduction) Stralegy Paper developed by lise Government of Mongolia and that will play a critical role in Mongolia's developmont and prosperity.

Mongolia joined the World l3ank Group in 1091. Since a decade ago when Mongolia has irreversibly chosen the democracy and reform path and launched the market conomic reforms, the country is moving ahead to complete the transition process to the market economy boosting the gained accomplishments in the political democracy with the economic and social reforms.

The Government of Mongolia is working in a close conrtinat ion with the international financial institutions and the donor community to receive the support and assistance, to gain the eredit and trust from them in minimizing and overcoming the sugative consequences of the unfavorable external and internal factors.

The foreign aid has been playing a substantial role over the last 10 year period and it is likely that it will continue to have a significant role in the ceonomic development of the country in the coming yoars. Total 18 projects worth 312 Million US D have been committed to be undertaken with the support of the World Bank Group and cutrently, 8 projects have been successfully completed and 10 projects are on-going

There have been observed a notable economic growth in the economy of Mongolia sine 1994, however, the social development, namely the living standar ds of twe population bas not succeeded adequately. In the current context of drastically restuced real income of the population, pulled back indicators of the health and education achicvements, increased problems in the family lives, unemployment and crimes and in overall when the poverly has grown into a real social phenomenta, the development of the incdium term stralcgy that is directed to solve negative effects of the transition period and that will promote the ccononic growth and reduce poverly of the country has vitally come intes agenda

Therefore, bearing in mind the economic growit as the key prerequisite in pesverly and income inequality reduction, the ways for macroeconomic stablization, incerease of the market access and building of the favorable environment for private business and entreprencurship as woll as the policy priority to support the sustainable human develepment to speed up the economic growth have been identified and clearly out ined in the "Economic Gruwtl Support and Poverty Reduction Strategy Paper" developed by the Covermmont of "Mengolia upon the recommendations and kind support of the World Bank Group.

The fovernment is paying a due attention to harmonization of the state interventions with the market principles in boosting the sustainable livelihoods and poverty reduetion initjatives; 10 encourage a broader participation of the civil society not only in the secial projects and programs, but also in the policy formulation, inspementation and oversight of the broad macroeconomic and social issues. To enable a breader participation of the civil socicty in the decision-making process, the issues of economic growth, astamalide human development and governance have heen reflected in a holistic approach in this strategy papa. 
The development strategles of sectors in coming 3-4 years based on thein master plans and sector-specific projects and programs have been identified in the paper. The procoss of the paper formulation was also elosely interlinked with the major policy documents, including, the Government Action Program, PRGF Program, Rural Development Strategy, Social Sccior Development Master Plan, National Program on Gender Equality, Children Program, Millennium Develogment Goals.

The Government of Mongolia, private sector, civil society and denors lave a key role in the implementation of this paper. The Government of Mongolia considers that the protectim of the politionl, economic and social stability is the key precequisite to promote the conomic growth and to successfully implement the poverty reduction strategy.

Currently, the Govermment is completing the proparatory work though the technical assistance 10 receive the forcign aid in the framework of the Poverty Reduction S1rategy. The objectives of these technical assistances are to supjort the shift into the new public sector management and finance system, to adequately identify the incdium $1 \mathrm{crm}$ economic framework, to accelerate the civil service reforms, to enhance the quality of and aceess to the public services, 10 optimize the policy oversight system, to boost an economic growth, to build a business favorable climate, to improve risk managonen system and strengthen the partncrship between the Government and the civil socicty.

Taking this apportunity we would like to enphasize the crucial role to bo played by the support and assistance of the World Bank Group and other donots in achieving the aiorementioned objectives. Thereforc, it is vital to ensure the close coordination of the strategy paper with the policy and initiatives of other donor countries and international agencies, We shall pay a duc aitention to the effective arrangements and organizations of development programs and their adequate optinization at all stages of actions and to increase their efficiency,

Finally, on behalf of the Goverment of Mongolia we express the sincere acknowledgment to the international agencies and doner counrics fon lixil continuous support and essistance to Mongolia's efforts toward the denocraty and market economic reforms.

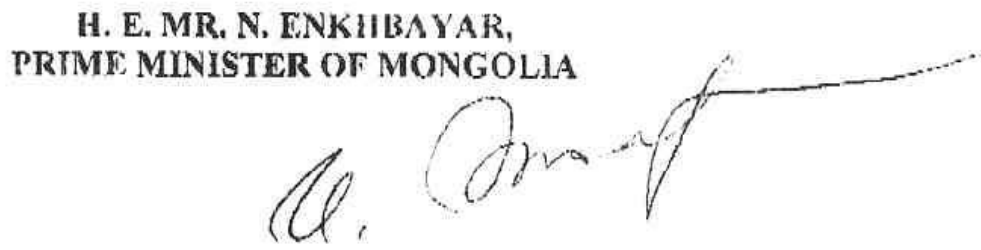




\section{Table of Contents}

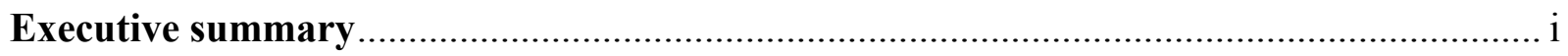

Overview of Economic and Social Development in the Past Decade ………………................. 6

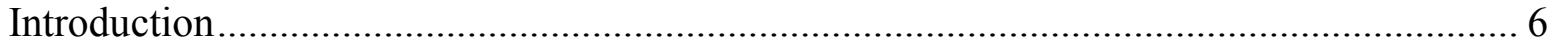

Chapter 1: THE TRANSITION PERIOD IN MONGOLIA ………....................................... 1

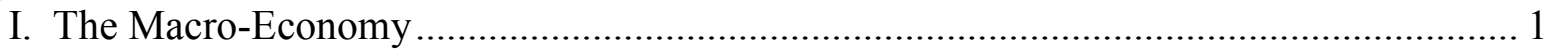

II. Demographic Trends drawn from the Household Income and Expenditure Survey ......... 4

III. The Poverty Situation in Mongolia........................................................................ 10

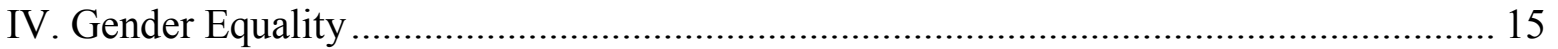

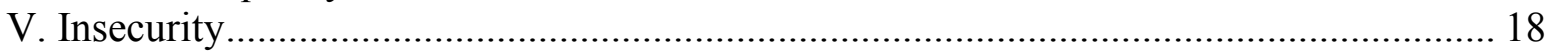

VI. Major Reasons for Poverty and Insecurity ……......................................................... 20

VII. Government Efforts to Reduce Poverty ....................................................................... 21

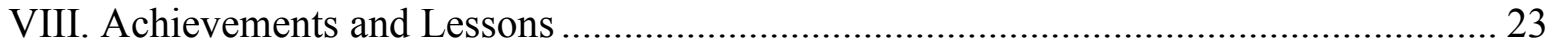

Chapter 2: ECONOMIC GROWTH SUPPORT AND POVERTY REDUCTION STRATEGY 25

I. Government Development Goals and Policy Priorities................................................ 25

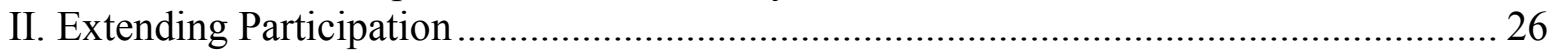

III. Sustainable Development and Pro-Poor Growth ........................................................... 28

IV. Acceleration of Economic Growth ........................................................................ 30

Chapter 3: $\quad$ PROMOTION OF ECONOMIC AND FINANCIAL SUSTAINABILITY ......... 38

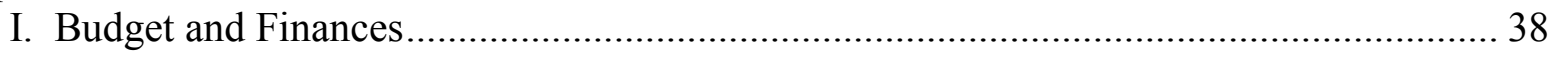

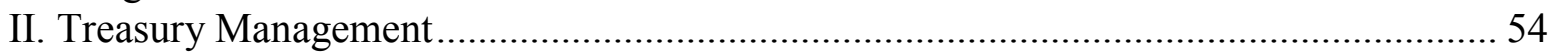

III. Balance of Payments ...................................................................................................... 57

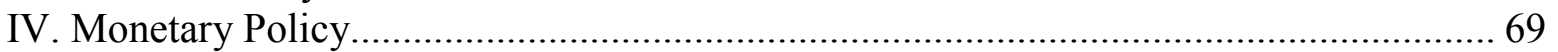

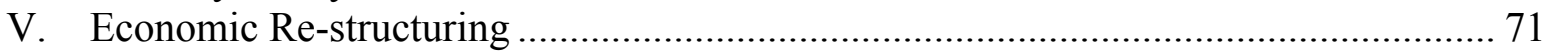

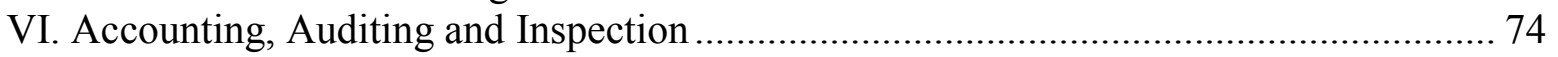

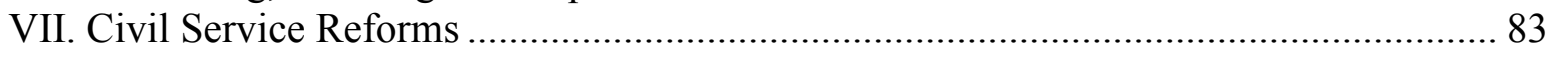

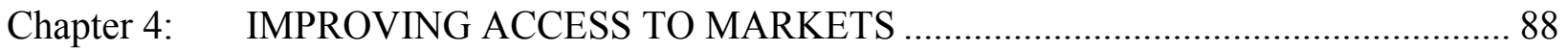

I. Creating a Favorable Operating Environment for Business ………................................ 88

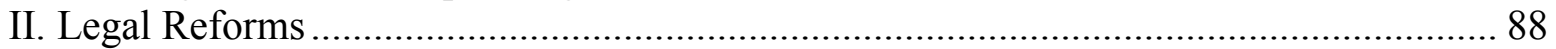

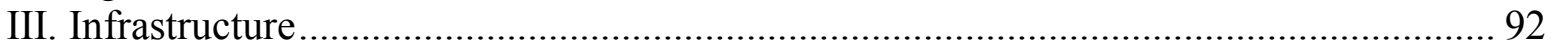

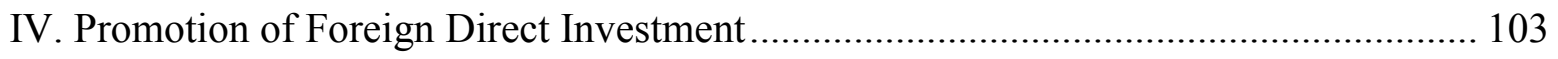

V. Improving Access to Markets ......................................................................................... 104

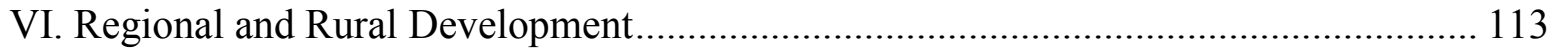

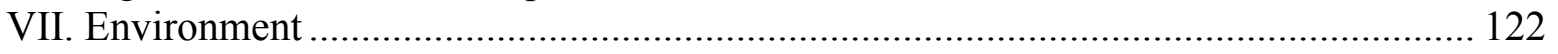

Chapter 5: ENSURING SUSTAINABLE HUMAN DEVELOPMENT ……….................. 125

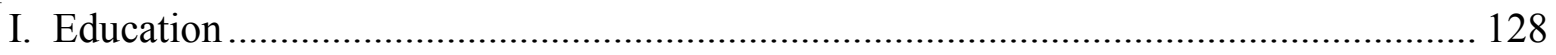

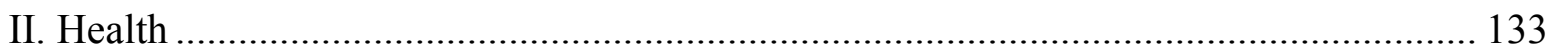

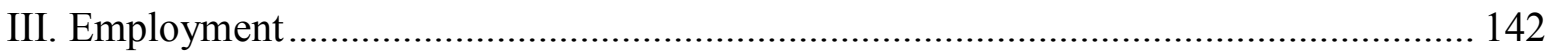

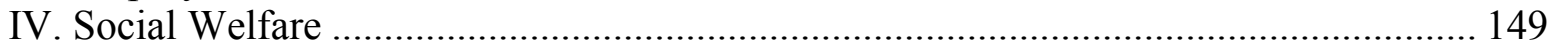

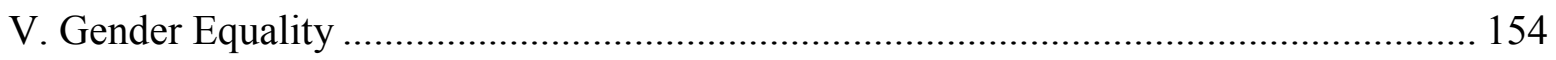


Chapter 6: IMPLEMENTING AND MONITORING THE STRATEGY ........................ 158

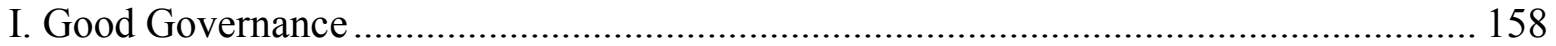

II. Implementation and Operational Management .................................................... 160

III. Extending Participation.............................................................................. 162

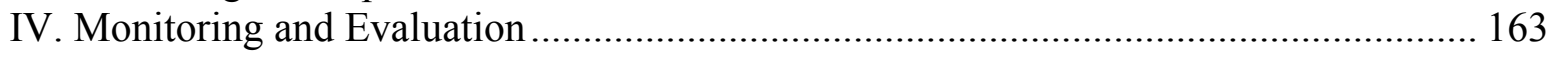


Tables

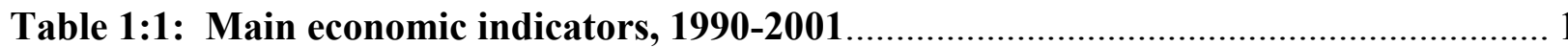

Table 1:2: Structure of average monthly total expenditure of household, national average,

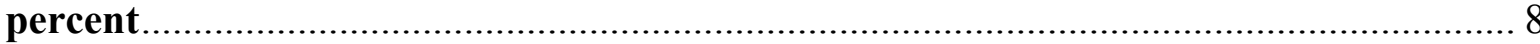

Table 1:3: Structure of average monthly total expenditure per household, by urban and

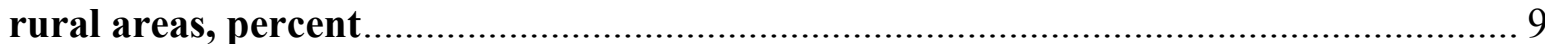

Table 1:4: Monthly expenditure per person, by residence ........................................... 9

Table 1:5: Monthly Adult Foodstuffs Consumption, national average, Kgs .................... 10

Table 1:6: Daily Adult Calorific Intake, national average ............................................ 10

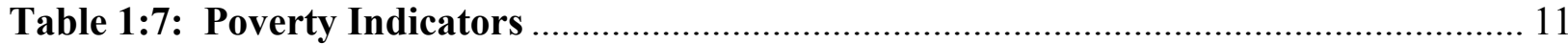

Table 1:8: Composition of Population by working age, and by location, as at 1998

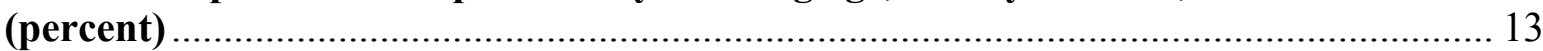

Table 1:9: The number of poor households, by head of household's gender and income

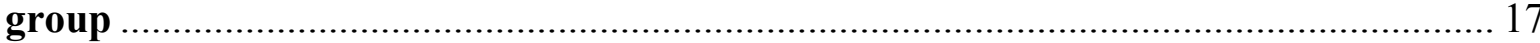

Table 1:10: The number of poor households, by head of household and location, as at 1998

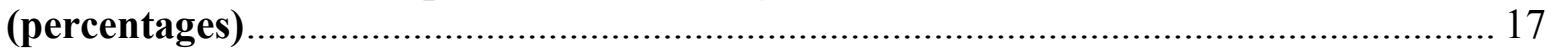

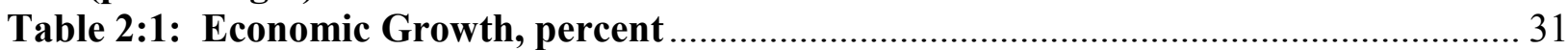

Table 2:2: High Scenario with Economic Growth of 6.0 Percent..................................... 33

Table 2:3: Main Assumptions on Newly Exploited Deposits ............................................ 34

Table 2:4: Base Scenario with Economic Growth of 5.5 Percent ................................... 35

Table 2:5: Investment at Current Prices, MNT billion (based on GDP estimated by

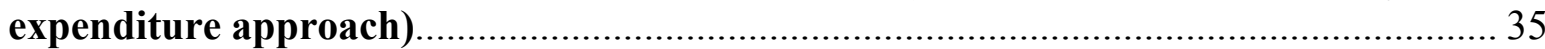

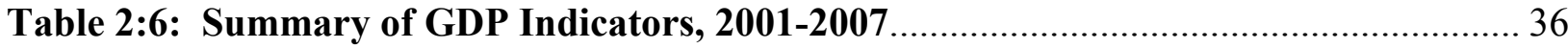

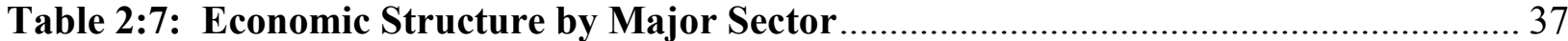

Table 3:1: The 'Financing Gap' as a Percentage of GDP .............................................. 44

Table 3:2. Fiscal Projections Outline as a percentage of GDP (Base Case) ...................... 45

Table 3:3: Budget Allocations to the Social Sector ......................................................... 46

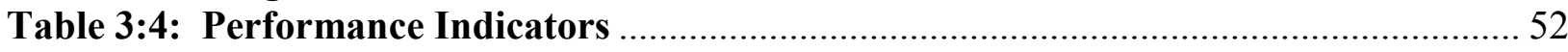

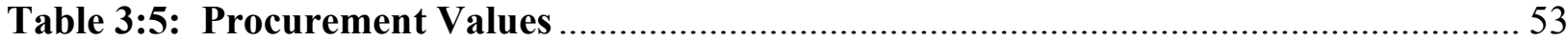

Table 3:6: Balance of Payments, million US\$, 1993-2002 …........................................... 61

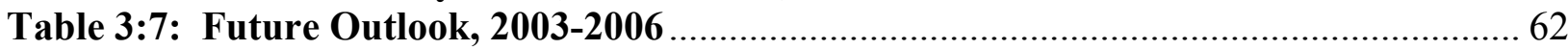

Table 3:8: Main Monetary Aggregates, 1998-2002, percent......................................... 69

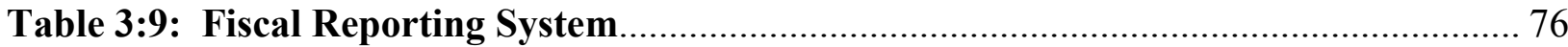

Table 3:10: Status of Accounting Reforms as at March 2003. ...................................... 77

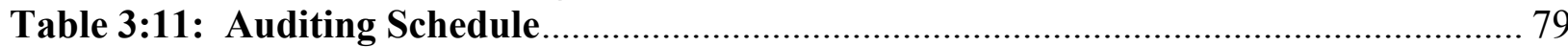

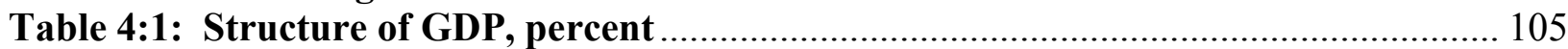

Table 4:2: Basic Economic Indicators by Region (as of 2000).................................... 114

Table 4:3: Livestock Husbandry's Share in Total Agricultural GDP (percent).............. 116

Table 4:4: Major Livestock Husbandry Products, thousand tons ................................ 117

Table 4:5: Investments in Livestock Husbandry, MNT million ................................... 117

Table 5:1: Fiscal Expenditures on the Social Sector..................................................... 127

Table 5:2: Preliminary Cost Estimates, US\$ thousands ............................................... 133

Table 5:3: Health Sector Financial Requirements Summary ........................................ 142 
Table 5:4: Employment Status of the Population at the year- end, 1995-2001, (thousand

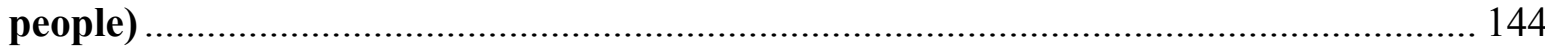

Table 5:5: Pensions met by the Social Insurance Fund, (as of January 1, 2003) ............... 151

Figures

Figure 2.1: Real Economic Growth, 1989-2002 ................................................................. 31

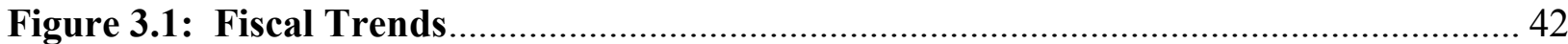

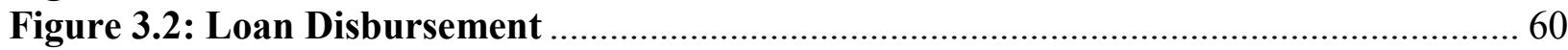

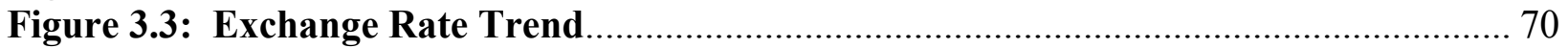

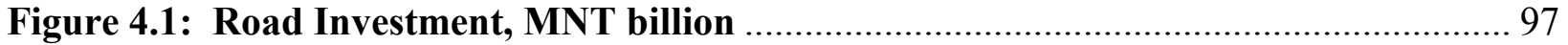

Boxes

Box 1-1: The impact of multifactor productivity on economic growth (empirical study) .... 2

Box 1-2: Sources of Information on Poverty …………................................................ 11

Box 4-1: Experience of the 'Wholesale Trade Network' pilot project ............................... 106

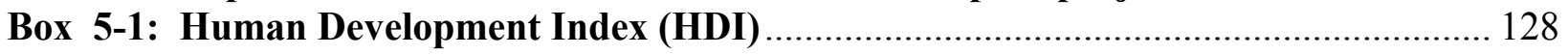




\section{Executive summary}

The Economic Growth and Poverty Reduction Strategy (EGPRS) is a strategy paper, which presents main policy directions of the government for the medium term with a focus on economic growth acceleration and poverty reduction efforts.

Since 1990 Mongolia has embarked on a path of building a democratic society which respects human rights and is committed to developing a market economy, undertaking sweeping changes and reforms touching all spheres of social life. Mongolia, with the assistance of international financial institutions and the wider donor community, has made substantial progress over the past decade of democratic restructuring in laying down sustainable macroeconomic foundations and creating a private sector-led open economy. For the medium term economic growth rate targeted at 5.5 per annum, which will be achieved through economic restructuring, including public sector reforms, improving public expenditure management and rationalization of social safety nets with clear implications on improving public service delivery.

The overall transitional transition period of Mongolia covered all spheres of life, and the past decade was a decade of securing foundations for market-based transactions and implementing policies oriented toward sustainable growth and poverty reduction. In 2002, economic growth reached 3.9 percent with modest increase compare to the previous 3 years. The results of the 1995 Living Standards Measurement Survey (LSMS) concluded that 36 percent of the total population of Mongolia was living in poverty. The 1998 LSMS showed a poverty level of 35.6 percent, with 39.4 percent for the urban population and 32.6 percent for the rural population. However, natural disasters occurred during last three years and intensive migration of rural population to the urban has led to changes in the spatial distribution of poor from rural localities to capital city and other large towns.

Based on the poverty diagnosis the government of Mongolia is implementing a series of policy reforms oriented to enhance economic growth and reduce poverty with more pro-poor orientation during last three years. In the medium term the Government will implement policies aimed at accelerating private sector-led economic growth through the stablisation of macroeconomy, low and stable inflation, development of free market competition, and appropriate monetary, credit and tax policies, thus raising the living standards of the population. A further central goal of the EGSPRS in the medium term will be redistribution of the benefits of growth to the population equally, with a distictly pro-poor focus. However, this distribution will not be done in a passive manner, but through implementing specific projects and programs aimed at increasing employment among the poor and the near-poor to take their own initiatives to improve their situation.

\section{Enhancement of economic growth and poverty reduction}

Carrying-out restructuring as well as reforms undertaken within the social and political sphere have became an essential resource for ensuring economic growth. The prevalence of the private sector in the economy is another major source for ensuring enhanced economic growth. The Government has set itself the goal of reducing poverty through higher economic growth, which 
will be based on active private sector participation and an export oriented trade policy. Regional and sustainable development concepts will be incorporated in the general economic growth strategy. In addition a stable macroeconomic situation, investment and the building of human capital factors will play a significant role in ensuring growth and sustainable human development. Moreover, the development of more efficient mechanisms of budget and financial management as well as reforms in the public sector will be another important ingredient in securing economic growth.

\section{Development framework}

The following are the priorities defined in short term within the framework of Mongolian development goals:

- to deepen the reforms for ensuring macroeconomic stability, and to intensify the restructuring process;

- to improve the health of the banking and financial sectors;

- to recover and develop national industry, to ensure economic growth through supporting export oriented industry;

- to support regional as well as rural development, to intensively develop infrastructure;

- to create an equitable environment for ensuring human development, to improve all levels of education, its quality, health service provision and its accessibility;

- to reduce unemployment and poverty, to generally improve the living standards of population;

- to ensure sustainable development and ecological balance, to mainstream nature conservation and environmental policies as priorities within regional socio-economic development;

- to speed up the land reforms;

- to reduce the air, water and soil pollution in large cities and settlements; to improve the living environment of the people through the reprocessing of waste;

- to improve governance to ensure human security;

- To create a fair, moral and democratic society that protects concepts of democracy, basic human rights and the freedom of each citizen;

- To mainstream gender dimensions in poverty interventions to promote gender equality.

\section{Private sector led growth support}

The Government of Mongolia aims to enhance economic growth and maintain sustainable livelihoods of the population based on three main pillars, namely macroeconomic stability, improving business climate, and human capital enhancement.

The Government places a focus improving Mongolian Laws and Legislation up to Year 2004, including institutional and economic management laws. The reforms in the economic legislation will be aimed to create favorable and competitive business environment for all types of enterprises, eliminate unnecessary licenses and other administrative impediments. In addition access to the financial resources will be expanded, especially for rural entities and SMEs. The government policy priorities should be re-oriented towards those population groups most affected by natural disasters through expanding financial and banking services in rural areas, 
developing small and middle-size enterprises, stabilisation and expansion of agricultural activities.

Development of energy, road, communication and information is of vital significance for creating a favorable environment for businesses. The energy sector development, a major foundation for the business expansion, will be to ensure sustainable development of the energy sector, create environment for efficient production of energy, increase the economic efficiency of the sector, support the use of renewable energy resources and commercialize, and furthermore privatize in a step-by-step manner state owned shareholding companies of the energy sector. In the medium term the transportation sector development will be focused on rural area road network expansion with active participation of local communities, enhancing competition among transport service providers, improving the technical capacity through replacement of engines, expansion of freight and transit capacity. While ICT sector will focus on (i) establishing the appropriate policy, legal and regulatory framework; (ii) developing the key telecommunications and information infrastructure necessary for providing access to reliable and affordable connectivity; (iii) establishing an economic and business framework for the utilization of ICTs in governance and other applications; and (iv) developing human resources to effectively utilize ICTs.

Another pillar for the economic growth support is promotion of foreign direct investment and external trade facilitation, including maintaining stability of regulatory framework, simplification of business licensing, effective utilization of mechanisms to strengthen its position in the international arena, protect its rights, and determine and facilitation of its foreign trade policies in line with global and regional development trends.

The medium term policy will be focused on expansion of sources of economic growth, in particular the government is giving priority to the development of processing industry based on domestic raw materials, mining and extraction, tourism, IT, and infrastructure.

Joint efforts aimed to accelerate economic growth and reduce poverty by the government alongside civil society and the private sector will be expanded.

\section{Economic restructuring}

The economic restructuring policy will be focused on privatization of large valuable entities, which enables an increase in the economic and financial efficiency of the companies, bringing in new technology, know-how and bridging them with new export markets. The restructuring in the energy sector will be continued by enhancing independent regulatory mechanisms, promoting private sector into the energy market, strengthening self-sustainability of energy companies and efficiency of their operations. Land reforms will be deepened to turn land into a productive asset to create opportunities for all people to create sustainable sources of income, in particular to implement land ownership and possession reforms. Social sectors restructuring, including education, health, culture and arts, will be carried out gradually without undermining public service delivery through management contract, management buyout, lease contracts. The reform measures will be supplemented by specific pro-poor measures to minimize negative consequences of the reform agenda. 


\section{Ensuring fiscal sustainability}

Improvement in the access and quality of public services, and ensuring fiscal sustainability in the medium term are the main expected outcomes of the public sector reforms, which are underway. The public sector reform will comprise of 6 components, namely, treasury management, budgeting, accounting and reporting, output based management and auditing. The legislative basis for the reform is the Public Sector Finance and Management Law, the Law on the Consolidated Budget and other legislative acts and programs issued in conformity with the above. Implementation of these laws and programs will enable improvement of budget planning, raising efficiency of fiscal expenditures, consequently releasing public resources for low-income people and enabling implementation of pro-poor policies. The medium term public sector reforms will be concentrated on carrying out comprehensive civil service reform aimed to increase accountability and credibility of civil servants, reporting and monitoring of performance based management. The securities market will be developed in accordance to the international standards to support economic growth through rationalization of the institutional framework, encouragement of private sector participation, increase their awareness. In line with reforms in the securities market activities the Trust fund law will be enforced. The insurance policy priorities will be focused on improving the legal environment, rationalization of management and enhancing monitoring of the insurance companies activities, expanding the types and coverage by the insurance activities, and introduction of international standards.

\section{Ensuring sustainable human development}

Although achievement of the sustainable livelihood and reduction of poverty depends on the level of economic growth, it is also closely associated and interrelated with the ensuring sustainable human development, improvement of the access to, and quality of public services, and creation of sound governance. The human development objectives as they relate to the economic growth and poverty reduction strategy, are aimed at creating income-generation opportunities for the poor, engaging them in decision-making processes and thus securing their social protection. The policies for social services are focused on priorities in education, health, social welfare and employment sectors, including improving basic service delivery with pro-poor focus, better targetting, enhancing professional capabilities of the service providers, introducing accredation system for the public and private institutions. A special focus will be on improving maternal and infant health care, rationalization of financing schemes. The social welfare system reforms will be aimed to create foundations for the pension system reforms, expanding coverage and monitoring of the insurance system, re-organizing the social assistance management through pursuing the principle of community based services and streamlining criteria for better targeting and service delivery based on new type of household assistance benefits.

Employment promotion activities will be aimed to enhance capacity of skills of people and labor market operation.

\section{Extending particpation}

Further participation of the civil society will be sought in the process of making adjustments to the PRSP after a certain period of time and ensuring its sustainable implementation. In particular, working groups could be formed at aimag and soum levels with civil society and business 
representation to monitor and intensify the process of implementation of the PRS. Also, nongovernmental organizations will be involved in monitoring and evaluation of the process of PRS implementation.

\section{Implementation and monitoring}

The overall implementation and monitoring of the EPSPRS will be coordinated by the MOFE. Within MOFE the Poverty Research Group will be a main acting body to coordinate implementation, monitoring and reporting for the EGSPRSP. The line ministries will be responsible for attaining of targets set for particular time period and implementation of specific programs within the framework of objectives. The local government and civil society will be involved through the working groups established during the I-PRSP dissemination. The progress report will be prepared on an annual basis and the strategy itself will be revised every three years and presented at the donor meetings to coordinate activities and funds of the donor community.

The prerequisite for the successful strategy is implementation of efficient monitoring and evaluation by two types of assessment, namely through monitoring benchmarks set by the government and civil society oversight. The Government, in order to monitor and evaluate the implementation of the poverty reduction strategy, will develop a system of appropriate tools and benchmarks for regular collection, monitoring, publishing of statistical indicators on the level of livelihood. However, civil society oversight, including NGOs, private sector, parliamentarians, citizens, donor representatives, will be conducted through various methods and approaches for monitoring and evaluation and the government will assist them in building of capacities to undertake monitoring and carry out the relevant assessments.

The government medium term main policy documents are the Government Action Plan, Medium term budget framework, the Socio-Economic Guidelines, sectoral papers and other policy papers / programs, signed agreements with international agencies. In addition following international practice the Government of Mongolia started an active participation in global initiatives such as PRSP process, MDG attainment, and Millennium Challenge account, specific programs to address greatest obstacles to the national development to spur economic growth and reduce poverty with an active participation of national stakeholders and coordination of external assistance. The MOFE will be a leading coordinating body to formulate, adopt, implement, and monitor these programs. Successful implementation of programs depends on efficient coordination of policy documents, reporting and alignment of processes, in particular the budgetary allocation in line with development priorities plays an important role in overall macroeconomic and sectoral management.

\section{Financial requirements .}

An implementation of the policy objectives included in the Economic Growth Support and Poverty Reduction Strategy requires resources equal to 40-45 percent of GDP per annum. These estimates are made based on targets included in the Medium term budget framework. 


\section{OVerview of Economic and Social Development in the Past Decade}

\section{Introduction}

Since 1990 Mongolia has embarked on a path of building a democratic society which respects human rights and is committed to developing a market economy, undertaking sweeping changes and reforms touching all spheres of social life. Mongolia, with the assistance of international financial institutions and the wider donor community, has made a substantial progress over the past decade of democratic restructuring in laying down sustainable macroeconomic foundations and creating a private sector-led open economy. The past decade was a decade when secure foundations for market-based transactions were formed, enabling the implementation of policies oriented toward sustainable growth and poverty reduction. GDP per capita grew from Tg 21.7 thousand in 1992 to Tg 187.1 thousand in 1995, to reach Tg 270.1 thousand in $2002^{1}$. Mongolia is now in 113th place among 173 countries ranked by their human development indicators ${ }^{2}$. Currently total Mongolian population reached 2.4 million with population density of 1.5 people per square kilometer and one third of population is concentrated in the capital city. The main stay of economy is nomadic style livestock. Currently there were 10 heads of livestock per capita.

Mongolia consists of 21 aimags and the capital city. The capital city Ulaanbaatar of Mongolia is a comprehensive administrative, territorial, economic and social complex with a special status and independent budget bearing specific functions, duties with own administration on a basis of the Constitution of Mongolia, Law on Legal Status of the capital city, Law on Territorial and Administration units as well as other relevant legal acts. The specific feature of the capital is concentration of one third of the total population and 40-50 percent of urbanization on 0.3 percent of the country's territory with the population density being 100 time more than the nation average, having 8-10 times more people compared to other cities of the country. Due to specifics of socio-economic development of Mongolia, in recent years the number of people migrating from the countryside to the capital has increased significantly, leading to increased demand for civil service such as school, kindergarten, hospital, public transportation, and energy.

\footnotetext{
${ }^{1}$ Statistical Yearbooks 1997, 2001

${ }^{2}$ Human Development Report, UNDP, 2002
} 


\section{CHAPTER 1: THE TRANSITION PERIOD IN MONGOLIA}

\section{The Macro-Economy}

1.1 The withdrawal of former Soviet Union assistance and collapse of COMECON left the Mongolian economy in an extremely difficult situation at the beginning of the 1990s. During 1990-1992, GDP decreased by more than 20 percent. The level of national savings rapidly declined, from about 35 percent of GDP in 1990 to 26 percent in 1995. Imports also decreased substantially, falling from US\$924 million in 1990 to US\$ 388.4 million in 1992. Inflation reached its peak of 325.5 percent in 1992, accompanied by growing unemployment. The number of the unemployed actively seeking jobs reached 54 thousand, as registered at the Labor Regulation Office. Multi-million rouble loans and assistance from the former Soviet Union abruptly ended in 1991.

1.2 To address this economic situation, the Government of Mongolia launched a series of reforms starting in 1991. These reforms included: the phased liberalization of state-controlled prices and tariffs, privatization of state owned enterprises, establishment of a two-tier banking system, liberalization of foreign trade, adoption of a floating exchange rate system, implementation of tight monetary and fiscal policies aimed at reducing inflation, adoption and enforcement of laws to encourage fair competition, and creating a favorable environment for private sector development. Since 1993, and as a result of the policies and actions undertaken by the Government, the economy began to recover.

Table 1:1: Main economic indicators, 1990-2001

\begin{tabular}{lrrrr|r|r|r|r|r|}
\hline & $\mathbf{1 9 9 0}$ & $\mathbf{1 9 9 2}$ & $\mathbf{1 9 9 5}$ & $\mathbf{1 9 9 7}$ & $\mathbf{1 9 9 9}$ & $\mathbf{2 0 0 0}$ & $\mathbf{2 0 0 1}$ & $\mathbf{2 0 0 2 *}$ \\
\hline Economic growth, percent & -2.5 & -9.5 & 6.3 & 4.0 & 3.2 & 1.1 & 1.0 & 3.9 \\
Inflation rate, percent & & 325.5 & 53.1 & 20.5 & 10.0 & 8.1 & 8.0 & 1.6 \\
Overall fiscal balance, in percent of GDP & -43.3 & -13.5 & -5.2 & -7.8 & -10.6 & -7.7 & -4.1 & -6.0 \\
Current fiscal balance, in percent of GDP & -8.8 & -1.7 & 6.2 & 1.6 & -0.3 & 3.1 & 5.0 & 4.4 \\
Exports (BOP), in million US dollars & & 368.0 & 473.3 & 451.5 & 454.2 & 535.8 & 521.5 & 524.0 \\
Imports (BOP), in million US dollars & & 400.0 & 415.3 & 468.3 & 512.8 & 614.5 & 637.7 & 690.7 \\
Exchange rate, 1US\$ =togrog & & & 473.6 & 813.2 & 1072.4 & 1097.0 & 1102.0 & 1125.0 \\
Net official international reserves, in & & 4.6 & 70.7 & 107.2 & 116.9 & 140.7 & 160.1 & 225.9 \\
million US dollars & & & & & & & & & \\
Unemployment rate, in percent & & 6.3 & 5.5 & 7.6 & 4.7 & 4.6 & 4.6 & 3.4 \\
\hline
\end{tabular}

* Preliminary

Source: Statistical Yearbook, Mongol bank Bulletin

1.3 Macroeconomic stabilization which emerged during 2000-2002 has led to gradual improvement in overall economic performance and creating fundamentals for poverty reduction. 
1.4 Economic growth: In the past decade GDP has fallen, but the economic situation was stabilized and the trend reversed from 1994 onward. The GDP growth rate increased to 2.3 percent in 1994 from a decline of 9.5 percent in 1992, and has remained positive since then. Importantly, the industrial sector (including the mining sector), which consistently declined at a rate of about 6 percent per annum revived, delivering 20 percent growth in 2002. The change brought up the share of this sector in GDP to 26.6 percent. In the same period, the major economic sector, agriculture, failed to realize its growth potential. The winters and springs of 1999-2002 brought extreme harsh climatic changes: droughts and excessive snowfalls led to Dzud which killed 3.5 million heads of livestock in 2000 and 4.7 million in 2001. In these years, 2.7-3.0 million female livestock miscarried. The total herd of 33.6 million heads of livestock in 1999 was reduced to 26.1 million in 2001, and 23.9 million by 2002. As a result, agricultural production fell, economic growth slowed and many thousands of herders were hit hard and left without any sources of income. This dependence on agriculture, the cornerstone of the economy, underlies the Mongolian people's vulnerability to climatic events. Economic growth of a mere 1.0 percent in 2001, and 3.9 percent for 2002 (preliminary estimates) is a direct result of such vulnerability. Empirical evidence suggests that if there were no Dzud effects, economic growth would have reached about 8 percent per annum in recent years.

1.5 Mongolia's economic base was fundamentally agricultural in character during the central planning period: between 1960 and 90 the economy was classified as agro-industrial. Equally in this period, all property was 100 percent owned by the state and cooperatives. Since 1990 however, restructuring and intensive privatization has led to fundamental changes in corporate structure and this along with changes in reporting, coverage and methodologies, is reflected in current summary statistics. Despite this process, whereby the economy is becoming more open, with capital and labor innovations brought by technological advance, the impact on the economy has not sufficient to lift performance; the contribution of GDP growth of these factors is estimated to be very low at only around 20 percent. This conclusion along with the estimated long term growth potential of the economy is derived from an empirical background paper prepared by the National University of Mongolia with financial support from the Japan International Cooperation Agency (see Box 1.1).

\section{Box 1-1: The impact of multifactor productivity on economic growth (empirical study)}

The objective of this study was to assess the contribution of the main factors of production to economic growth. In contrast to previous studies of economic growth carried out for Mongolia, human capital was considered as an independent causal variable. In addition a physical capital data set was developed in accordance with international standards The main conclusions are based on an analysis of data for the period 1980-2001. The study consisted of 2 parts: analysis and empirical evaluation of secondary and collected data - and second development of policy recommendations.

From the empirical evaluation study it was concluded that a 1 percentage increase in physical capital would contribute a 0.56 percent increase in growth, whilst 1 percentage increase in labor, a 0.29 percent increase in growth, and a 1 percentage growth in human capital would result in a 0.15 increase in economic growth. Yet our analysis of factor productivity also showed that the components of average economic growth in the period (totaling 0.5 percent) were capital -0.1 percent, labor 0.4 percent, and human capital 0.2 percent. Thus we can conclude that although the elasticity of capital is much higher, it has offered only a very small contribution to growth in recent years. Indeed, human capital has contributed twice as much to growth, as physical capital.

This contrasts somewhat with the experience of developed countries, where human capital has been found to 
be a very significant factor contributing to economic growth, but for Mongolia human capital appears to have an elasticity of only 0.15 . One of the reasons explaining the difference this might be that the wages of highly educated and qualified staff are kept below the value of their marginal product. Potentially therefore the underestimation of educational factors may be adversely affecting the allocation of resources, which in turn would result in lower economic growth in comparison with potential.

1.6 External economic factors: Factors such as the collapse of the former eastern-bloc economic cooperation and trade system (COMECON), a narrow export base deterioration of the terms of trade and the Asian financial crisis have upset Mongolia's external economic conditions and affected its balance of payments position. A foreign trade deficit of 32 million US dollars was recorded for 1992, this initially reversed to a large surplus balance of 102.6 million US dollars by 1994, but rebounded and from 1996 to deficits have averaged of 110 million US dollars. The abolition of customs duties in 1997 was the key causal factor underpinning the increase in imports. In 2001, the trade deficit was 169.9 million US dollars, with the current account deficit/excluding official transfers/ reaching about -16.6 percent of GDP. This can be traced directly to commodity price volatility on international markets. The market price of copper, which constituted 33 percent of export revenue in 1999, was 3000 US dollars per tone in 1995, it sharply in 1999 to 1480 US\$ per tone in 1999. The price recovered slightly in 2000, but again fell in 2001. These changes were accompanied by falling gold and cashmere prices on world markets. In addition, other factors such as the outbreak of food-and-mouth (FMD) disease resulted in an abrupt decrease in exports of raw agricultural materials to China, which has had a direct impact on the livelihoods of the rural population, particularly herders. Overall, a land locked location, remoteness from world infrastructure linkages, a narrow export structure, and poor international compositeness continue to impact unfavorably on Mongolia's terms of trade.

1.7 At the same time though, the gold price has grown steadily since September 2001, and net international reserves have increased substantially over the last decade from 4.6 million US dollars in 1992 to 40 million US dollars in 1994, and 160.1 million in 2001. By the end of 2002, net international reserves reached 225 million. A commitment to open economic policies during the transition period has led to a continual increase in donor aid. The outstanding debt of the Government reached about 84 percent of GDP at the end of 2002. Official development assistance worth 2.1 billion US dollars was received in the period 1991-2002, out of which 48 percent was represented by loans. As the country started to implement the open economy policy, the government jointly with international agencies and bilateral donors has organized 9 donor meetings with the active participation of the international community.

1.8 Financial and monetary sectors: Inflation has declined gradually since 1993, it reached 66.3 percent in 1994, averaged 27 percent between 1995 and 1999, 10 percent in 2000 and single-digit level (1.6 percent) by the end of 2002. Money supply has been increased steadily during recent years, its annual growth rate has fluctuated at around 27 percent. Bank lending rates remain approximately 35 percent p.a. This level of interest rates is not able to support production, services and economic growth. The budget has been in deficit in the past ten years, with loans from the banking system and foreign borrowings and assistance financing the fiscal gap.

1.9 Total budget revenues declined in 1998, mainly due to a sharp decline in corporate tax revenues and dividends due to a deterioration in terms of trade. This has had a harmful affect 
on the overall condition of the budget as the government failed to respond properly to falling revenues, and did not take serious action to improve public expenditure management. A crisis in the banking sector crisis was another factor that exacerbated the fiscal situation. Since 1996, 12 banks have gone bankrupt and the Government has been paying up to Tg 9 billion each year in interest payments for Government bonds which were issued to cover the losses of some of those banks. About 30 percent of total loans extended by commercial banks during 1996-99 were nonperforming loans.

1.10 Due to the unfavorable external environment and an excessive burden on public finances, the budget deficit as a percent of GDP has continually increased, from 7.7 percent in 1996 to 12.5 percent in 1998 and 10.6 percent in 1999 . Thus, the combination of the persistent falls in revenues and the excessive cost of economic restructuring have diverted already scarce resources from pro-poor programs and services. However, the budget deficit in the past two years declined, paving the way for financial stabilization. According to 2002 fiscal outturn the overall fiscal deficit was 6.0 percent of GDP with current surplus of 4.4 percent of GDP.

\section{Demographic Trends drawn from the Household Income and Expenditure Survey}

1.11 The Population and Housing Census of 2000 counted 2373.5 thousand people residing in Mongolia, of which 56.6 percent live in urban areas (with 32 percent of population concentrated in Ulaanbaatar city) and 43.4 percent who live in rural areas. Of the total population, 50.4 percent are women and 49.6 percent are men, and 35.8 percent of the population are children aged $0-14$. The population density is 1.5 persons per square $\mathrm{km}$, making Mongolia the least densely populated country in the World.

1.12 During the 1990s Mongolia's population growth averaged 1.4 percent per annum, with the total fertility rate remaining around 2.1 children per woman. The social and economic hardships that accompanied the transition were the main reasons for the decline in population growth. However, the fertility level of poor families is higher, and the structure of poor households is very young. For instance, within poor households 45 percent of their members are under age 15, while for the non-poor the proportion is 31 percent.

1.13 A set of monographs produced by the National Statistical Office drawing on the results of 2000 Population and Housing Census show that that the livelihood of people has undergone some changes.

1.14 Firstly, for example, the growth rate of the older population has remained lower than the total population over the last 20 years. The share occupied by elderly persons within the total population has been falling continuously. However, due to the favorable population growth conditions which have existed since the 1950s, the number of older people is projected to sharply increase between 2015 and 2020. Those born in the late 1950s and 1960s will move to the older age bracket in this period. According to median variant of the population projection based on 2000 population and housing census, the number of elderly people will increase by 16.2 percent or 20.1 thousand in 2005 compared to 2000, and by 28.7 percent or 35.6 thousand by 2010 . This strongly suggest a requirement for facilitating the implementing the updating of some articles of the State Law on Population, the Law on Elders and various provisions relating to discounted services and other related legal acts and programmers. 
1.15 Analysis of total national households as well as elderly households shows that the conventional type of household, with relatives and families living together still remains the mainstay. Of the total number of elderly people, 59.7 percent or 72.4 thousand are the head of their respective households. Of men who are head of household, 4,109 are single and the same position is found with the 8,453 women. Therefore, it is important that local administrations pay increased attention to the social issues and challenges facing single elderly people.

1.16 The willingness of the older population to work and participate in community work is quite high. The census revealed that one in every 9 older persons were working. Of the total older population 12.3 percent or 15.3 thousand are economically active. As a matter of fact, the economic activity rate is high all in rural areas, both for the total population and older persons. On the whole the older population is more involved in agriculture and especially in herding. In urban areas there is a shortage of jobs for older people and moreover, establishments are not willing to employ them. The government believes it is necessary therefore, to take clear and unambiguous actions in official statements and in ensuring state population policy is enforced and implemented at establishments of all types of organizations. The objectives of these policy statements are; the facilitation of a condition whereby older people especially of those aged up to 65 years can work taking advantage of their education and experience, hence making full use of investment made earlier into human resource development; making full use of their potential and capacity, passing on the rich life experience of elders to young generations; passing on traditional customs; encouraging elders to contribute to the country's development; and enabling them live to an active life and ensuring the accurate and proper recognition of their input and merits .

1.17 Secondly the monograph on Education produced in connection with the Population and Housing Census of 2000 witnesses that the literacy rate and educational level of the population have reached closer to the level of developed countries. This is due to greater attention paid by the Government of Mongolia towards the creation of a condition wherein children are fully enrolled in schooling and school drop-out rates are reduced. The Government took the action to establish a legal environment, which reflects well the country's current stage of social and economic development, and to enforce the laws.

1.18 The ratio of number boys to girls is low at all of the stages of schooling in Mongolia School enrolment reduces by 9.2 points from primary level to secondary level. In numerical terms 44.7 thousand children of whom 64.0 percent are boys are out of schooling at the age of secondary level attainment. This is related to the fact that boys from herder households have had higher school drop-out rate as since livestock privatization. This tendency has moderated in the recent years but it is still in evidence. Another reason for the higher number of school drop-outs amongst boys is that poor and very poor households force boys to contribute to family incomes; their earnings enabling the purchase of essential food-stuffs for other household members.

1.19 School drop-out rates particularly among boys has deepened the imbalance in the sex ratio in educational attainment. Further down the line, this might lead to a shortage of labor supply in particular economic sectors especially those, which due to their specific conditions, require inputs by the skills traditionally provided by men. 
1.20 The illiteracy rate amongst $15-19$ year olds rose by 2.2 points in 2000 on the 1989 figures. In 2000 this rate is 4.2 percent meaning that 8.4 thousand 15-19 year olds are illiterate. Of this figure, 5.6 thousand are boys and 2.8 thousand are girls.

1.21 For the 20-29 age brackets, 1.8 percent of the population aged were found to be illiterate in 1989 and this indicator rose by 0.5 points in 2000. A total of 5.3 thousand people of this age group are illiterate with men representing 60.4 percent of this figure.

1.22 In relation to housing; almost half of the 54,1149 households (51 percent) enumerated during the Census reside in Gers and 49 percent in houses. When this is compared with 1989 census result the proportion of households residing in Gers is down by 9.3 percent and that of households in houses is higher by 9.3 percent. Overall, 72 percent of urban households reside in houses and 78 percent of rural households live in a Ger.

1.23 According to 1989 census 2.7 percent of the total households living in a house lived in a flat whereas this indicator rose to 3.2 percent (an increase of 0.5 point) in 2000. Also 1.3 percent of the population lives in a non-designated house and 0.3 percent in trenches, corridors, roofs and forests.

1.24 Of total Ger households 56.9 percent have no access to electricity and 69.9 percent have no telephone. In rural areas these percentages are higher; 75.2 percent lack electricity and 98.9 percent have no telephone.

1.25 On Migration the census reveals that by the beginning of 200074.3 percent of the total permanent residents in Mongolia were living in their birth place and 25.7 percent of the total had migrated (moved to an area other than their place of birth) with 5 percent of which being return migrants (moved to another area and later returned to the place of origin).

1.26 Of the migrants 42.6 percent had migrated during the last three years - thus exposing the reality of intense migration which has taken place since the lifting of restrictions with the advent of the transition period in Mongolia.

1.27 Within the regions migration is highest in Khangai and lowest in western regions. A third of the people who took part in the inter-regional migration within Khangai moved to Orkhon aimag, making it the most attractive destination within this region. Recent statistics explain that there are 824.7 thousand people permanently residing in UB and almost one million people, including interim residents and incoming and outgoing guests, are residing, working and studying in the city. Just in recent 5 years the population has increased by over 70.0 thousand people through migration resulting in a significant rise of unplanned social service expenditures.

1.28 As for the central region, Darkhan-Uul aimag is the most attractive end-destination point. It absorbed about one third of the total in-migrants to this region. Net migration over the last five years has resulted in a 10 percent of increase in the population of 5 years of those aged and above in the capital city. Around 60 percent and 22.5 percent of the migrants from the western region moved to Ulaanbaatar and central region respectively. Of the total population enumerated during the census 13.7 percent had migrated during the last five years, mainly from the central and western regions. And almost 40 percent of them were 15-24 year olds - with the further break-down being 20 percent for 15-19 year olds and 19.6 percent for 20-24 year olds. 
1.29 It should be noted that the school enrolment of one year migrant children of 8 and 9 years is lower than their non-migrant peers. This might be associated with the fact either there is a shortage of schools in the destination place or in-migrants fail to get registered. Whereas households which moved to Ulaanbaatar city in 1999 were more likely to live in gers those who moved to the city after 1999 are more likely to reside in a house. When households moved to the capital city in 1999 and after 1999 are compared in terms of electricity the latter has poor access. Similarly, households which moved to Ulaanbaatar last year have poor access to telephone service than those migrated in 1999 . Of the households moved to the capital city 4.0 percent resident in non-designated housing while of the non-migrants this percentage is less than 2.

1.30 The population's migration has a number of causes and consequences. It affects the geographical distribution of population, on the one hand, by leading to concentration of population in Ulaanbaatar city and its outlying districts as well as in the central region and, on other hand, by sharply reducing the population levels and its distribution within other regions. Further it creates an imbalance of economic demand and supply - and presents challenges for social development.

1.31 In relation to marital status; the percentage of previously unmarried people aged 15 and above is some 8.9 percent and 11.2 percent higher for women and men respectively compared with 1979. The figures against 1989 levels are 8.3 and 7.4 points higher in the same order. This is related to the fact that young people particularly men, tend to get married later.

1.32 The proportion of divorced and separated people is also on the rise whereas that of the widowed population is declining. This can be explained by the fact that divorced men are more likely to remarry than divorced women and there the highest percentage of widowed population occurs in the 60 and above age group. In the older age groups, women are more preponderant since they live longer than men do.

1.33 The average age of marriage increased by one and half years in the census period 1979 to 1989 whilst it rose by two and half years between 1989 and 2000. However, men and women in urban areas get married one year later than their rural counterparts. From this it can be inferred that late marriage among men can be explained by many reasons like; getting prepared for family life under market economy conditions, economic preparedness, studies and other factors. In addition, the commitment, feeling of duties and life skills of the young population may well have changed.

1.34 In the context of all of the aforementioned, fertility, mortality and migration-borne changes and policy in the population arena have been incorporated in this economic growth and poverty reduction strategy paper through the line policies of health, gender, education, employment and other related areas.

1.35 Household Income and Expenditure. Changes in household incomes and expenditure in 1999-2002 are illustrated in the following by indicators such as monetary income, salary income, average salaries, monetary expenditure, savings etc. It is difficult to make comparisons between 1999-2000 household income and expenditure surveys (HIES). The 2002 HIES has used different sampling and methodology compared to the previous surveys which make difficult to make valid comparisons. The data for the 2002 HIES are preliminary. It is 
apparent that Household monetary income increased by 82 per cent in 2002 from 1999. However, the increase of monetary income in real terms was only a 54 percent. According to the Average Salary Survey, average salaries increased by 26 percent in 2002 from 1999 with the real increase being equal to 6 percent. Household monetary expenditure increased by 67 percent in 2002 from 1999 representing 41 percent in real terms.

1.36 Regarding Household expenditure; Indicators that better define changes in household living conditions are the household expenditure amount and expenditure structure measures. Average monthly household expenditure by expenditure item and structure as of 2000-2002 is shown in Table 2. For 2000-2002, the national average share of household monetary expenditure in total expenditure has declined, to 78.9 percent. This is related to an increase in consumption of food-stuffs prepared from household farms or own businesses and provided by others (families and friends) free-of- charge.

Table 1:2: Structure of average monthly total expenditure of household, national average, percent

\begin{tabular}{|l|l|r|r|r|}
\hline & Expenditure type & 2000 & 2001 & 2002 preliminary \\
\hline & Household expenditure - total & $\mathbf{1 0 0 . 0}$ & $\mathbf{1 0 0 . 0}$ & $\mathbf{1 0 0 . 0}$ \\
\hline $\mathbf{1}$ & Monetary expenditure - total & $\mathbf{9 3 . 9}$ & $\mathbf{9 1 . 9}$ & $\mathbf{7 8 . 9}$ \\
\hline & Food expenditure & 39.1 & 39.1 & 32.2 \\
\hline & Non-food expenditure & 31.7 & 27.0 & 26.3 \\
\hline & Service expenditure & 22.9 & 25.6 & 19.9 \\
\hline & Savings & 0.1 & 0.2 & 0.5 \\
\hline $\mathbf{2}$ & In-Kind contributions from others - total & $\mathbf{1 . 0}$ & $\mathbf{1 . 8}$ & $\mathbf{3 . 5}$ \\
\hline & Food expenditure & 0.3 & 0.7 & 1.9 \\
\hline & Non-food goods and service expenditure & 0.1 & 1.1 & 1.6 \\
\hline $\mathbf{3}$ & Foodstuff from household business & $\mathbf{5 . 1}$ & $\mathbf{6 . 3}$ & $\mathbf{1 7 . 6}$ \\
\hline
\end{tabular}

1.37 Table 1.3 shows changes in the household expenditure structure with different figures quoted for urban and rural areas. In 2000-2002, the share of monetary expenditure in total household expenditure declined in both urban and rural areas with an increase in food consumption from household farms. 
Table 1:3: Structure of average monthly total expenditure per household, by urban and rural areas, percent

\begin{tabular}{|l|l|r|r|r|r|r|r|}
\hline \multirow{2}{*}{ Expenditure type } & \multicolumn{3}{c|}{ Cities } & \multicolumn{3}{c|}{ Rural areas } \\
\cline { 3 - 7 } & 2000 & 2001 & $\begin{array}{c}2002 \\
\text { preliminary }\end{array}$ & 2000 & 2001 & $\begin{array}{c}2002 \\
\text { preliminary }\end{array}$ \\
\hline & Household expenditure - total & $\mathbf{1 0 0 . 0}$ & $\mathbf{1 0 0 . 0}$ & $\mathbf{1 0 0 . 0}$ & $\mathbf{1 0 0 . 0}$ & $\mathbf{1 0 0 . 0}$ & $\mathbf{1 0 0 . 0}$ \\
\hline $\mathbf{1}$ & Monetary expenditure - total & $\mathbf{9 8 . 4}$ & $\mathbf{9 7 . 6}$ & $\mathbf{9 2 . 8}$ & $\mathbf{8 7 . 8}$ & $\mathbf{8 2 . 0}$ & $\mathbf{6 8 . 2}$ \\
\hline & Food expenditure & 45.4 & 42.8 & 38.7 & 31.4 & 32.6 & 26.6 \\
\hline & Non-food expenditure & 27.6 & 24.8 & 28.8 & 36.4 & 30.8 & 24.8 \\
\hline & Service expenditure & 25.2 & 29.6 & 24.5 & 19.9 & 18.6 & 16.6 \\
\hline & Savings & 0.0 & 0.4 & 0.7 & 0.1 & 0.0 & 0.2 \\
\hline $\mathbf{2}$ & In-Kind Contributions from others - & $\mathbf{1 . 2}$ & $\mathbf{2 . 0}$ & $\mathbf{4 . 4}$ & $\mathbf{0 . 8}$ & $\mathbf{1 . 5}$ & $\mathbf{2 . 9}$ \\
& total & & & & & & 1.7 \\
\hline & Food expenditure & 0.3 & 0.5 & 2.3 & 0.4 & 1.0 & 1.2 \\
\hline & Non-food goods and service expenditure & 1.0 & 1.5 & 2.1 & 0.4 & 0.5 & $\mathbf{2 8 . 9}$ \\
\hline $\mathbf{3}$ & Foodstuff from household business & $\mathbf{0 . 4}$ & $\mathbf{0 . 4}$ & $\mathbf{2 . 8}$ & $\mathbf{1 1 . 4}$ & $\mathbf{1 6 . 5}$ & $\mathbf{2 8}$ \\
\hline
\end{tabular}

1.38 Another key indicator that reflects changes in the living standards of the population is consumption expenditure per person. A breakdown of expenditures per person for 1999 and 2002 is as set out below (Table 4). The analysis divides the households that responded to the survey, into 5 equal quintiles from the smallest to largest in terms of total expenditure per person.

Table 1:4: Monthly expenditure per person, by residence

\begin{tabular}{|l|r|r|r|r|r|r|}
\hline \multirow{3}{*}{ Group } & \multicolumn{2}{|c|}{ Nation average } & \multicolumn{2}{c|}{ Urban areas } & \multicolumn{2}{c|}{ Rural areas } \\
\cline { 2 - 7 } & 1999 & $\begin{array}{c}2002 \\
\text { preliminary }\end{array}$ & 1999 & $\begin{array}{c}2002 \\
\text { preliminary }\end{array}$ & \multicolumn{1}{c|}{1999} & $\begin{array}{c}2 \\
\text { preliminary }\end{array}$ \\
\hline I & 6398 & 57822 & 5319 & 59158 & 7205 & 56502 \\
\hline II & 11509 & 111376 & 10271 & 111438 & 12435 & 111414 \\
\hline III & 17101 & 167662 & 15738 & 167893 & 18121 & 167611 \\
\hline IV & 30002 & 252798 & 23841 & 253102 & 34612 & 252901 \\
\hline V & 47611 & 620786 & 52448 & 639294 & 43992 & 584648 \\
\hline
\end{tabular}

1.39 This underlines the fact that income distribution in Mongolia is likely becoming increasingly unequal.

1.40 Food consumption of the population. The amount of food consumption, nutritional value and ingredients of the food consumed by the population was estimated on the basis of monthly consumption of an average adult equivalent. The comparison of actual consumption and recommended consumption per month is shown in Table 5. The recommended consumption is taken from the recommended amount of food and nutritional intake of the population adopted by resolution Number A/318 of the Health and Social Welfare Minister of 1997. 
Table 1:5: Monthly Adult Foodstuffs Consumption, national average, Kgs

\begin{tabular}{|l|c|c|c|c|c|c|c|}
\hline \multicolumn{1}{|c|}{ Foodstuff } & Recommended & 1990 & 1995 & 1999 & 2000 & 2001 & 2002 \\
\hline $\begin{array}{l}\text { Meat and meat products } \\
\text { In meat equivalent }\end{array}$ & 6.9 & 8.1 & 8.1 & 9.4 & 10.0 & 8.1 & 8.6 \\
\hline $\begin{array}{l}\text { Milk and diary products } \\
\text { In milk equivalent }\end{array}$ & 10.2 & 9.8 & 10.5 & 12.2 & 10.9 & 8.4 & 10.5 \\
\hline Butter & 8.1 & 0.3 & 0.4 & 0.2 & 0.2 & 0.2 & 0.1 \\
\hline $\begin{array}{l}\text { Flour and flour products } \\
\text { In flour equivalent }\end{array}$ & 11.4 & 8.1 & 7.9 & 8.3 & 9.0 & 9.2 & 9.7 \\
\hline Rice & 1.35 & 1.1 & 0.7 & 0.8 & 1.2 & 1.3 & 1.5 \\
\hline $\begin{array}{l}\text { Candies and sugar } \\
\text { In sugar equivalent }\end{array}$ & 1.8 & 1.9 & 0.7 & 0.7 & 0.9 & 1.0 & 1.0 \\
\hline Fish and fish products & 0.12 & 0.1 & 0.1 & 0.0 & 0.0 & 0.2 & 0.1 \\
\hline Egg, pieces & 0.21 & 2.4 & 0.2 & 0.3 & 0.7 & 1.2 & 1.3 \\
\hline Potato & 3.6 & 1.9 & 0.9 & 1.4 & 1.8 & 2.2 & 2.6 \\
\hline Vegetables & 6 & 1.7 & 0.7 & 1.0 & 1.0 & 1.4 & 1.7 \\
\hline Fruit and berries & 0.4 & 0.8 & 0.0 & 0.2 & 0.3 & 0.3 & 0.4 \\
\hline Vegetable oil & 0.1 & 0.1 & 0.1 & 0.2 & 0.5 & 0.7 \\
\hline
\end{tabular}

1.41 In all years, all food-stuffs except meat and milk have been below the recommended level. As a result of natural disasters such as drought and dzud in recent years, the consumption of milk and meat products has declined in 2002 from 1999. Although the consumption of flour, rise, eggs, potatoes and vegetables has increased in 1999-2002, these figures are still below the recommended level. Especially, consumption of potatoes, vegetables and fruits which are significantly below the recommendation.

Table 1:6: Daily Adult Calorific Intake, national average

\begin{tabular}{|l|r|r|r|r|r|r|r|}
\hline & $\begin{array}{c}\text { Recomme } \\
\text { nded }\end{array}$ & \multicolumn{1}{|c|}{1990} & \multicolumn{1}{c|}{1995} & 1999 & 2000 & 2001 & 2002 \\
\hline Nutrition, kcal & 2731.18 & 2538.4 & 2277 & 2241.2 & 2462.3 & 2344.4 & 2697.0 \\
\hline Protein, g & 104.85 & 99.2 & 95.5 & 99.2 & 105.4 & 93.6 & 107.5 \\
\hline Oil, g & 76.23 & 85.3 & 87.1 & 83.6 & 90.1 & 78.4 & 98.2 \\
\hline Carbohydrate, g & 406.74 & 326.2 & 262.5 & 257.7 & 290.7 & 300.1 & 327.9 \\
\hline
\end{tabular}

$1.42 \quad$ Although the daily nutritional intake did not reach the recommended level in 19992001, in 2002 it increased because of high consumption of flour, flour products, eggs, potatoes and vegetables, all of which have a higher nutritional value. Also in 2002, protein and oils in food ingredients exceeded the recommended level.

\section{The Poverty Situation in Mongolia}

1.43 Definition. Poverty in Mongolia is defined using a the minimum living standards approach. According to the Law on Defining the Minimum Living Standards, the National Statistical Office determines the minimum levels differently by regions. Currently, the monetary equivalent of the poverty line ranges between $\mathrm{Tg} 19500$ to 25300 per capita per month depending on the region. Households with income less than 40 percent of the minimum living 
standards level and who are unable to provide for their basic food needs are defined as households in 'extreme poverty'.

Poverty assessment. The Government of Mongolia has conducted several living standards surveys with the support of international agencies.

1.44 From the various surveys conducted in Mongolia since 1995 (LSMS, PLSA), poverty was found to be preponderant among five categories of people; (i) single parent-headed households with many children, (ii) households with less than 100 heads of livestock (depending on the size and structure of the household), (iii) the unemployed, (iv) the uneducated (without basic education), (v) and specific vulnerable groups (elderly, disabled, street children and orphan children).

Table 1:7: Poverty Indicators

\begin{tabular}{|l|c|c|c|c|c|c|}
\hline \multirow{2}{*}{} & \multicolumn{2}{|l|}{ Poverty Incidence, P0 (\%) } & \multicolumn{2}{c|}{ Poverty Depth, P1 (\%) } & \multicolumn{2}{c|}{ Poverty Severity, P2 (Index) } \\
\cline { 2 - 7 } & 1995 & 1998 & 1995 & 1998 & 1995 & 1998 \\
\hline Urban & 38.5 & 39.4 & 12.2 & 13.9 & 5.7 & 7.1 \\
\hline Ulaanbaatar & 35.1 & 34.1 & 10.4 & 13 & 4.5 & 7.4 \\
\hline Rural & 33.1 & 32.6 & 8.9 & 9.8 & 3.6 & 4.4 \\
\hline Overall & 36.3 & 35.6 & 10.9 & 11.7 & 4.8 & 5.6 \\
\hline
\end{tabular}

Source: Living Standard Measurement Survey, 1998

1.45 The results of the 1995 Living Standards Measurement Survey (LSMS) concluded that 36 percent of the total population of Mongolia was living in poverty. The 1998 LSMS showed a poverty level of 35.6 percent, with 39.4 percent for the urban population and 32.6 percent for the rural population. This means that compared with 1995 , poverty has declined in Ulaanbaatar by 1998, whilst for other urban areas it has increased. The survey also showed that poverty was particularly concentrated in aimag centers, towns and other urban settlements. Methodology utilized in these surveys limit to conduct detailed comparisons of results in terms of spatial and population groups distribution.

\section{Box 1-2: Sources of Information on Poverty}

1. The Ministry of Labor first conducted a Poverty survey in 1995. The survey found that 13.2 percent of all households in Mongolia and 14.1 percent of the population were living in poverty.

2. In Mongolia the Household Income and Expenditure Survey has been conducted since 1966. As the number of households grew, the survey sample was expanded to include 1000-1500 respondents. The survey measures, in addition to incomes and expenditures of households, sources of income, patterns of consumption, living standards and helps define the minimum living standard. The Household Income and Expenditure Survey results are utilized as the basis for key statistical estimates, such as the poverty line, inflation and national accounts. The improvement of the survey's the methodology and the expansion of its is therefore a key priority for the Government. Currently, the National Statistical Office, with support from the World Bank and UNDP, is working to achieve these aims, a key part of this is the revision the questionnaire to include living standards-related questions to enable the estimation of poverty profile related statistics and enable the use of the survey results as the basic data in various analyses. Starting in 2002, the National Statistical Office has been conducting an expanded Household Income and Expenditure Survey, which is not comparable directly to the household income and expenditure surveys undertaken prior. The NSO is conducting Household Income and Expenditure Survey and Living Standards Measurement 
Survey with a new improved methodology. The Household Income and Expenditure/Living Standards Measurement Survey has 4 components which are:

1. Household income and expenditure survey/monthly/

2. Living standard measurement survey/quarterly/

3. Community questionnaire

4. Price questionnaire

For the HIES, a sample of 11,232 households in Ulaanbaatar city and 21 aimags is surveyed each year, at the rate of 2808 households per quarter. The integrated HIES-LSMS survey will visit 3744 households a year, at the rate of 936 households of surveyed HIES households per quarter or rotation approach is being utilized.

The expanded survey undertaken under the assistance of the international agencies is an integral part of comprehensive program to reform public sector, enhance economic growth and reduce poverty. The HIES is a main source for poverty reduction monitoring, attaining the MDGs, accomplishment of the MCA requirements.

3. The first survey to measure the living standards of the population was carried out in 1995 with the assistance of the World Bank. The survey sample included 1,500 households, which represents 0.3 percent of households in Mongolia. The second Living Standards Measurement Survey conducted by the National Statistical Office with the assistance of UNDP in 1998, and its results were widely disseminated. The survey became a standing component of published official statistics. The results of these two surveys are not however, directly comparable with one another.

4. The Participatory Living Standards Measurement Survey was conducted in 2000 with the assistance of the World Bank and other donor organizations to carry out a qualitative assessment of poverty. The survey provided an opportunity for the poor to make their voices heard to the Government about their concerns, and for policymakers to listen to their assessment and opinions about their quality of life, and assessment of Government's policies to improve their livelihoods. The objective of the survey was to enrich poverty statistics with qualitative information, and to provide information complementary to Poverty Assessment and Living Standard Measurement Surveys conducted in 1995 and 1998. The survey was the first ever survey in Mongolia to be conducted using participatory methods.

1.46 Although the level of poverty has not significantly risen during 1994-2000, the depth of poverty has increased and income inequality has worsened. The Gini coefficient increased from 0.31 percent in 1995 to 0.35 percent in 1998, demonstrating growing income inequality, particularly that of the poor. The depth index which measures the total consumption inequality of the poor population reached 10.9-11.7 percent, while the poverty severity index increased by 0.8 percentage points since 1995. According to the Participatory Living Standards Assessment, distinct population segments, the so-called "rich and poor" have emerged during 1992-1995, and more so in 1995-2000. Thus the gap between these two groups has continued to deepen. The survey also showed that a substantial proportion of urban population lies within the extremely poor category. The view that the number of middle-class households declined during 1992-1995 was supported by survey participants' responses that the number of poor and very poor households has grown. It is clear that income shortage is a major cause of poverty in Mongolia. The overwhelming majority of the poor live in gers, with 27-30 percent of them using water from unprotected wells for daily consumption.

1.47 The poor and employment. Poverty has a direct relation with employment. Out of total poor population of working age in urban areas, 27.3-38.8 percent are unemployed, while almost 60 percent of unemployed able bodied people of working age are poor. This is demonstrated by levels and composition of total household income. A third of household income comes from wages, pensions, benefits and incentives, over 20 percent comes from agriculture and non-agricultural production, another 30 percent from household business, and 10 percent are 
free gifts from others. This income composition largely depends on household location. For instance, 40-60 percent of income of the urban population is composed of wages, pensions and benefits, whereas in rural areas only 7 percent of the total income comes from this category, with over 60 percent coming from household business. However, the droughts and Dzud that occurred in the past years have left over 10 thousand herder households without any livestock, and many more thousands lost most of their livestock. As a result, members of these households fell into poverty, and many moved to urban centers, swelling the number of the urban poor.

Table 1:8: Composition of Population by working age, and by location, as at 1998 (percent)

\begin{tabular}{l|r|r|r|r|}
\hline \multicolumn{1}{|c|}{ By income groups } & Employed & Unemployed & \multicolumn{1}{c|}{ Other } & \multicolumn{1}{c|}{ Total } \\
\hline Rural & & & & \\
1. Very poor & 37.6 & 38.8 & 23.6 & 100.0 \\
2. Poor & 48.3 & 27.3 & 24.4 & 100.0 \\
3. Non-poor (low-income) & 49.9 & 19.3 & 30.8 & 100.0 \\
4. Non-poor (middle) & 55.2 & 13.2 & 31.6 & 100.0 \\
5. Non-poor (wealthy) & 58.6 & 9.0 & 32.4 & 100.0 \\
TOTAL & 49.8 & 21.4 & 28.8 & 100.0 \\
Urban & & & & \\
1. Very poor & 58.4 & 26.5 & 15.1 & 100.0 \\
2. Poor & 79.6 & 11.9 & 8.5 & 100.0 \\
3. Non-poor (low-income) & 83.3 & 6.5 & 10.1 & 99.9 \\
4. Non-poor (middle) & 81.3 & 7.2 & 11.5 & 100.0 \\
5. Non-poor (wealthy) & 80.8 & 4.4 & 14.8 & 100.0 \\
TOTAL & 77.9 & 10.3 & 11.8 & 100.0 \\
NATIONAL TOTAL & $\mathbf{6 5 . 0}$ & $\mathbf{1 5 . 4}$ & $\mathbf{1 9 . 6}$ & $\mathbf{1 0 0 . 0}$ \\
\hline Sorce: Ling Standar & & & &
\end{tabular}

Source: Living Standard Measurement Survey, 1998

1.48 Although, the poor are engaged in some types of economic activity, due to low incomes they are becoming more vulnerable. In other words, these people are mainly self employed, small traders, handicraft makers, and civil servants. The majority of extreme poor are unskilled and unemployed. Moreover cultural norms and mentalities dating to the socialist times have meant many within this group's exhibit ready-made mentalities, are welfare dependent, and lack their own initiative to escape their current conditions. 
Table 1:9: Distribution of Average Income by Consumption Groups (percentage)

\begin{tabular}{|c|c|c|c|c|c|c|c|c|c|c|c|c|}
\hline \multirow[b]{2}{*}{$\begin{array}{l}\text { Poverty } \\
\text { grouping }\end{array}$} & \multirow[b]{2}{*}{ 吾 } & \multicolumn{4}{|c|}{ Income in cash } & \multirow{2}{*}{ 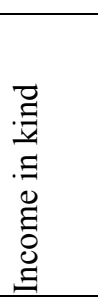 } & \multirow{2}{*}{ 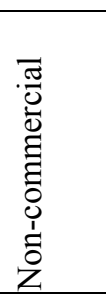 } & \multicolumn{2}{|c|}{$\begin{array}{l}\text { From } \\
\text { agriculture }\end{array}$} & \multirow{2}{*}{ 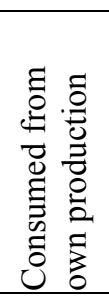 } & \multirow{2}{*}{ 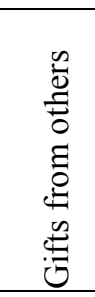 } & \multirow[b]{2}{*}{$\begin{array}{l}\frac{n}{\Delta} \\
\frac{\tilde{0}}{0}\end{array}$} \\
\hline & & $\begin{array}{l}\vec{\sigma} \\
0 \\
0\end{array}$ & $\begin{array}{l}8 \\
\substack{\infty \\
3 \\
3}\end{array}$ & 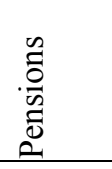 & $\begin{array}{l}\stackrel{n}{0} \\
\stackrel{0}{0} \\
\ddot{D}\end{array}$ & & & 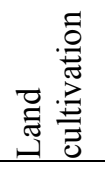 & 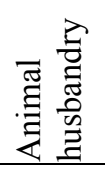 & & & \\
\hline $\begin{array}{l}\text { National } \\
\text { total } \\
\text { Very poor } \\
\text { Poor } \\
\text { Non poor (á) } \\
\text { Non poor (ä) } \\
\text { Non poor } \\
(\div) \\
\text { Average }\end{array}$ & $\begin{array}{l}100 \\
100 \\
100 \\
100 \\
100 \\
100\end{array}$ & $\begin{array}{l}50.6 \\
37 \\
32.1 \\
32.5 \\
29.4 \\
\mathbf{3 3}\end{array}$ & $\begin{array}{l}36 \\
29.1 \\
26.4 \\
27.6 \\
24.8 \\
\mathbf{2 7 . 2}\end{array}$ & $\begin{array}{l}11 \\
6.7 \\
4.9 \\
4.5 \\
4.2 \\
\mathbf{5 . 1}\end{array}$ & $\begin{array}{l}3.6 \\
1.3 \\
0.7 \\
0.4 \\
0.3 \\
\mathbf{0 . 7 5}\end{array}$ & $\begin{array}{l}0.8 \\
0.5 \\
0.4 \\
0.2 \\
0.1 \\
\mathbf{0 . 2 9}\end{array}$ & $\begin{array}{l}2.8 \\
5.4 \\
4 \\
9.9 \\
12.4 \\
\mathbf{8 . 5}\end{array}$ & $\begin{array}{l}0.2 \\
0.2 \\
0.3 \\
0.2 \\
0.2 \\
\mathbf{0 . 2}\end{array}$ & $\begin{array}{l}8.1 \\
12.8 \\
16.5 \\
16.1 \\
9.9 \\
\mathbf{1 3 . 3}\end{array}$ & $\begin{array}{l}21.1 \\
32.4 \\
34.1 \\
29.8 \\
28.8 \\
\mathbf{3 0 . 1}\end{array}$ & $\begin{array}{l}13 \\
8.7 \\
8.2 \\
7.7 \\
13.4 \\
\mathbf{1 0 . 1}\end{array}$ & $\begin{array}{l}3.4 \\
2.9 \\
4.5 \\
3.5 \\
5.9 \\
4.4\end{array}$ \\
\hline $\begin{array}{l}\text { Urban } \\
\text { Very poor } \\
\text { Poor } \\
\text { Non poor }(a ́) \\
\text { Non poor }(\text { ä) } \\
\text { Non poor } \\
(\div) \\
\text { Average }\end{array}$ & $\begin{array}{l}100 \\
100 \\
100 \\
100 \\
100 \\
100\end{array}$ & $\begin{array}{l}\quad 71.1 \\
61 \\
59.1 \\
57.1 \\
45 \\
\mathbf{5 4 . 6}\end{array}$ & $\begin{array}{c}52 \\
50.1 \\
51.2 \\
51.4 \\
40.5 \\
47.4\end{array}$ & $\begin{array}{l}15.3 \\
9 \\
6.9 \\
5.3 \\
4.2 \\
6.4\end{array}$ & $\begin{array}{l}3.8 \\
1.8 \\
1 \\
0.4 \\
0.3 \\
\mathbf{0 . 9}\end{array}$ & $\begin{array}{l}1.3 \\
1 \\
0.6 \\
0.2 \\
0.1 \\
\mathbf{0 . 4}\end{array}$ & $\begin{array}{l}\quad 4.9 \\
11.2 \\
9.4 \\
17.3 \\
22.1 \\
\mathbf{1 5 . 9}\end{array}$ & $\begin{array}{l}0.1 \\
0 \\
0.3 \\
0.1 \\
0.2 \\
\mathbf{0 . 2}\end{array}$ & $\begin{array}{l}1.4 \\
4.4 \\
3.1 \\
3 \\
1.2 \\
\mathbf{2 . 4}\end{array}$ & $\begin{array}{l}4.5 \\
5.9 \\
5.6 \\
4.2 \\
3.8 \\
4.5\end{array}$ & $\begin{array}{l}11.6 \\
12.6 \\
12.2 \\
11.5 \\
17.2 \\
\mathbf{1 3 . 8}\end{array}$ & $\begin{array}{l}5.1 \\
3.9 \\
9.6 \\
6.6 \\
10.4 \\
\mathbf{8 . 2}\end{array}$ \\
\hline $\begin{array}{l}\text { Rural } \\
\text { Very poor } \\
\text { Poor } \\
\text { Non poor (á) } \\
\text { Non poor }(\text { ä) } \\
\text { Non poor } \\
(\div) \\
\text { Average }\end{array}$ & $\begin{array}{l}100 \\
100 \\
100 \\
100 \\
100 \\
100\end{array}$ & $\begin{array}{l}25.8 \\
15.7 \\
13.6 \\
14.8 \\
13.3 \\
\mathbf{1 4 . 8}\end{array}$ & $\begin{array}{l}16.6 \\
10.3 \\
9.5 \\
10.4 \\
8.8 \\
10.1\end{array}$ & $\begin{array}{l}5.8 \\
4.6 \\
3.6 \\
3.9 \\
4.3 \\
4.1\end{array}$ & $\begin{array}{l}3.4 \\
0.8 \\
0.6 \\
0.5 \\
0.3 \\
0.6\end{array}$ & $\begin{array}{l}0.2 \\
0.1 \\
0.2 \\
0.2 \\
0.1 \\
0.2\end{array}$ & $\begin{array}{l}0.3 \\
0.4 \\
0.3 \\
4.5 \\
2.5 \\
2.3\end{array}$ & $\begin{array}{l}0.2 \\
0.4 \\
0.2 \\
0.4 \\
0.3 \\
0.3\end{array}$ & $\begin{array}{l}16.2 \\
20.2 \\
25.7 \\
25.6 \\
18.7 \\
22.6\end{array}$ & $\begin{array}{l}41.3 \\
56 \\
53.5 \\
48.4 \\
54.4 \\
51.7\end{array}$ & $\begin{array}{l}14.7 \\
5.3 \\
5.5 \\
4.9 \\
9.4 \\
7\end{array}$ & $\begin{array}{l}1.2 \\
2 \\
1 \\
1.2 \\
1.2 \\
1.2\end{array}$ \\
\hline
\end{tabular}

Source of information: Living standard measurement survey, 1998

1.49 The poor and social services. The cost of education and health services has become a heavy burden on poor families and, therefore, those families have almost no access to basic health and education services. For example, household expenditure on education increased by 4 to 5 times by 1998 compared with 1995, while its share in total non-food consumption expenditure increased by 9.3 percentage points. The lower the level of expenditure per household member, the higher the weight of food expenditure in total household expenditures. For instance, 72.6 percent of households with less than Tg 8000 expenditures per person spend over 70 percent 
of their expenditures on food, while only 22.6 percent of households with income per capita of $\operatorname{Tg} 60.1$ thousand allocate over 70 percent of their expenditures on food ${ }^{3}$.

1.50 The school enrollment rate for children of aged 8-15 years is 86.5 percent (girls 89.6 percent and boys 83.4 percent) and the drop-out rate is 2.8 percent (girls 2.4 percent and boys 3.2 percent). The drop-out rate is higher in rural areas -3.7 percent, as opposed to urban areas -1.4 percent. Out of the total number of children not attending school, 43.8 percent do not attend due to low living conditions and the need to work. This increase in drop out rates has become one of main reasons of chronic poverty in the country.

1.51 Wealthier households benefit more from health services than do poor households. Monthly expenditure on health services per person for different categories of expenditure groups is 9 times higher in high income households than that in very poor households. Frequency of visits by the poor to health centers has declined too. This take-up of health services by of the poor and malnutrition has led to an increase in the number of invalids, forcing more people to rely on social safety net benefits alone.

\section{Gender Equality}

\section{"Gender inequalities undermine the effectiveness of development policies in fundamental ways."}

1.52 Mongolia has a good enabling environment to promote gender equality. The Constitution grants equal rights to men and women. The government has committed itself to various international conventions on rights and the equality of women, and has established the National Council for Gender Equality in 2001 to monitor and support the implementation of policy and to promote women and gender equality. Civil society organizations and movements to promote women's rights and equality are active. Despite this positive environment, gender disparities still persist in all dimensions of poverty and specifically; access to economic opportunity, capacity to access public services, vulnerability to economic and domestic violence, and political empowerment.

1.53 Gender inequalities not only reflect disparities in the capabilities and opportunities of individual men and women, but they potentially hinder efforts to improve economic growth and reduce poverty. Government, civil society and development agencies have conducted a series of workshops and pieces of research on various aspects of gender and poverty. The key gender issues facing Mongolia identified through these workshops are:

1.54 Gender and Economic Opportunity: Due to the lack of gender sensitive approaches during the structural reform policies, it has been challenging to evaluate the negative and positive impacts these policies have had on men and women. The experience of the past decade shows that women were affected negatively and have become victims of poverty as a result of socioeconomic reform policies. Women, for example, were hit hard during structural reform and privatization which took place in the early 1990s. Many women working in light industries and services were transferred to the informal sector with little preparation. Woman faced difficulties

\footnotetext{
${ }^{3}$ Household Income and Expenditure Survey, Second quarter of 2002, NSO
} 
in obtaining get credit and in managing their households because they were left with no rights to own capital after privatization.

1.55 Some of the laws and regulations adopted were distinctly unfriendly to women. For instance, the Pension law that was approved in 1991 imposed conditions, which made it more likely that women would either be made redundant or encouraged to quit their jobs by stating that women with four or more children can receive state pensions early. The recently approved the Mongolian Land Law states that land will be given to the possession of household, while the Constitution stipulates this right is belong to the citizens of Mongolia. It is not clear whether and how the implementation of this law will affect men and women differently

1.56 Access to and the availability of credit and financial services, and hence the business environment are limited for women. Women work longer hours on household activities and have limited time to involve themselves in economic activities. Unpaid work never been evaluated and the contribution of the unpaid labor has never been calculated in the national accounts. Particularly in rural areas, livestock privatization and the movement from agricultural production towards household livestock herding, has resulted in and increased the level of unpaid family labor.

1.57 Opportunities for males and females in both employment and income, which are the main means of escaping poverty, are equal. Women in particular rely on the informal sector for income and employment. Discrimination against women by their age, gender, physical appearance and their childcare duties commitments needs be considered urgently.

1.58 Women have limited authority over privatized assets, registered in the name of the head of household, who is usually male. This in turn restricts women's ability to use such assets as collateral for loans and other business opportunities. Increased reliance on livestock herding, and the reduction of childcare services, has increased women's hours of unpaid domestic and productive work (not included in the national accounts) and limited time for women to engage in economic activities.

1.59 Gender and Access to Public Services: Mongolia's vast territory, low population density and poor infrastructure makes it difficult for all of the population to access to public services. Educational enrollment of both boys and girls is significantly lower today than in 1990, and boys' enrollment levels are low particularly in the higher grades. High maternal mortality rates reflect widespread problems of access and quality of health services, especially in rural areas, and this has a particularly negative effect on women. Closure of health care centers in rural areas, has lowered the quality and pushed up the cost of services, whilst also increasing the distance between providers and patients contribute to problems.

1.60 Gender and Vulnerability: High incidence of domestic violence threatens women's physical and emotional security. According to a study conducted in Ulaanbaatar, one third of women in Mongolia have experienced some form of domestic violence, and more than one-tenth have been beaten by their partners.

1.61 Since women's higher levels of unemployment and high reliance on the informal sector for employment and their livelihoods mean that many women fall outside of the state social 
protection and benefit system. Female-headed households are especially prone to poverty. For instance, 24.6 percent of very poor households and 18.3 percent of the total poor households are female-headed households, although female-headed households make up only around 12-13 percent of the total.

Table 1:9: The number of poor households, by head of household's gender and income group

\begin{tabular}{|l|c|c|}
\hline & Female-headed & Male-headed \\
\hline Very poor & 24.6 & 75.4 \\
\hline Poor & 18.3 & 81.7 \\
\hline Non-poor (low income) & 11.6 & 88.4 \\
\hline Non-poor (middle) & 13.5 & 86.5 \\
\hline Non-poor & 12.7 & 87.3 \\
\hline
\end{tabular}

Source: UNDP/NSO 1999

1.62 As poverty deepens, the number of female-headed households in poverty is growing because these households tend to have more children and are lower income-earners. In addition, divorces affect women more economically and physiologically, thus increasing their insecurity. Female-headed poor households are more concentrated in aimag centers and soums due to limited opportunities for them in the countryside to engage in business or to commute to urban centers for work. In addition they have poor access to the social safety net system.

1.63 Based on assessment of various data and reports, the Government has changed its approach to prioritizing equal rights for women in order to provide them with more opportunities. The new concept is based on securing gender equality, formulating and implementing new economic and social policies and programs. Many of the participants of the Regional Seminar on "From IPRSP to F-PRSP" organized in February-March 2002, have mentioned that "Education is important to reduce poverty. People need to be taught the living/ survival skills from a young age. Men are seldom given the opportunity to participate in various training programs".

Table 1:10: The number of poor households, by head of household and location, as at 1998 (percentages)

\begin{tabular}{|l|r|r|r|r|}
\hline $\begin{array}{l}\text { Household head, } \\
\text { by sex }\end{array}$ & Ulaanbaatar & Aimag centre & \multicolumn{1}{|c|}{ Soum } & \multicolumn{1}{|c|}{ Rural } \\
\hline Male & 21.4 & 39.1 & 28.5 & 25.2 \\
\hline Female & 43.8 & 53.2 & 51.7 & 23.6 \\
\hline
\end{tabular}

Source: Living Standard Measurement Survey, 1998

1.64 National Program on Gender Equality: One of important tasks of the Government of Mongolia is to provide an appropriate environment for gender equality in the fields of politics, economics and civil society, culture-and within the home to develop and implement appropriate gender sensitive policies in order to improve livelihoods and the quality of people's lives and promote human development. Studies and research indicate that gender equality exists in Mongolia to some extent. Therefore, the Government of Mongolia approved the National Program for Gender Equality in December 2002 in order to regulate these issues; making 
appropriate changes in the division of labor by lessening gender inequality in unemployment, effecting poverty reduction and equity in educational provision; counterbalancing gender inequality in politics, decision-making positions and in property relationships; and to formulate policies to decrease family violence in compliance with national economic and social policies. The National Program on Gender Equality sets goals and outlines activities for improving gender equality in:

Family welfare and development: to strengthen families and values, to ensure an equal burden is assumed by parents in child-rearing and domestic work; to address domestic violence through legislation and awareness rising; to balance rights and decision-making regarding household property, providing training and resources for poor families.

Economic relations: promote gender-sensitive macroeconomic policies and statistical monitoring and data collection to improve access to employment, health and social insurance, and ensure equality in domestic finances.

Rural development: improve rural education enrollment, particularly of boys, increase participation in regional development, reduce child and maternal mortality, provide equal opportunities for employment and small business activities

Empowerment and decision-making: develop enabling an environment for a greater level of women's representation in government decision-making both for elected and career positions.

Strengthening the national mechanism for achieving national gender equality objectives: establishment of national secretariat, gender based research, mainstreaming gender perspective into policies, programs, and budgeting, and improving monitoring/evaluation of gender-related goals and programs.

Implementing the National Program on Gender Equality will require support for strengthening the national secretariat and the overall mechanisms established for securing gender equality.

\section{Insecurity}

1.65 Participants in the Participatory Living Standards Assessment made clear interrelationship between poverty and insecurity. In addition to the economic insecurity the PLSA demonstrated the prevalence of other forms of insecurity: social, safety, environmental and physical.

1.66 Economic insecurity is expressed mainly in terms of unemployment and remoteness from the market. As a result, many households rely on pensions and benefits as their only reliable source of cash income. Investment involving communities and based on participatory initiatives, would mitigate the risks associated with agricultural production and will prevent the decline of the agricultural economy. Work insecurity and a lack of job vacancies has exacerbated poverty. 
Table 11. Employment Rate, at as 1998 (percent)*

\begin{tabular}{|c|c|c|c|c|c|}
\hline & Very poor & Poor & $\begin{array}{l}\text { Non-poor (low- } \\
\text { income) }\end{array}$ & $\begin{array}{c}\text { Non-poor } \\
\text { (middle) }\end{array}$ & Non-poor \\
\hline Urban & & & & & \\
\hline 1995 & 44.7 & 66.0 & 75.8 & 78.7 & 92.8 \\
\hline 1998 & 49.2 & 63.9 & 72.2 & 80.7 & 86.8 \\
\hline Rural & & & & & \\
\hline 1995 & 65.0 & 85.9 & 92.9 & 95.8 & 92.7 \\
\hline 1998 & 68.0 & 87.0 & 92.7 & 91.8 & 94.8 \\
\hline
\end{tabular}

*Share of employed population of working age in the total working age population

Source: Living Standard Measurement Survey, 1998

1.67 Environmental insecurity has a damaging effect of livestock husbandry. The effects of natural disasters, droughts, 'Dzud', forest fires and parasitic infestations have been made worse by a growing over-concentration on grazing pressure, as the numbers of herders and livestock increased while pastoral mobility has declined since 1990s. These primary environmental problems affect population living standards and cause poverty. Environmental insecurity particularly affects new herders, as well as the supply of raw materials to national industry and the export of raw materials. Unemployment and poverty are rising in rural areas. For instance, the total number of livestock has been continually increasing during 1994-1999. But the Dzud that occurred in the past years killed many animals, reducing the size of the herd to around 24 million animals by the end of 2002, which represents 29 percent less than in 1999 and 20 percent less than in 2000. At market prices, the value of the lost livestock is over Tg 270 billion. For Mongolia with its harsh climate, and the economic dominance of nomadic pastoralist population, the livelihood of the population is extremely vulnerable to environmental insecurity. Participants in the Regional Seminar on "From I-PRSP to F-PRSP" organized in February-March 2002, had intensive discussions about environmental and climatic difficulties and the lack of Government support to protect them.

1.68 Social insecurity leads to a weakening of traditional kinship relationships. Kinship has been weakening throughout the 1990s, while semi-commercial forms of intra-household transfers are increasing. The most vulnerable of all are those excluded from kinship and other social safety nets. In addition, as enterprises have closed leaving many people without a job, thus causing disruption and the lessening of friendship relations.

1.69 Many households are also prone to physical insecurities, particularly among the poorer groups. Unemployment and economic insecurity has led to widespread social malaise, alcohol abuse, a rising crime level, domestic violence and marital breakdowns. These insecurities create various shocks for households and lead them into stresses and poverty. For instance, 156 out of 10,000 adults over 18 have become victims of one or other form of violent crimes in 2001 (Statistical yearbook, 2001).

1.70 Economic crisis, social inequality, and breaking down of values and other negative trends in the society have created another type of vulnerable: street children. Street children live in the conditions lacking basic human needs in extreme poverty and begging. This unacceptable 
phenomenon is in contradiction with the basic rights of children and had a negative impact for the social progress and a matter of discussion of the international community moving beyond the national borders. The main reason for becoming "street" are as follows:

$\sim$ Absence of normal conditions of life at home

$\sim$ Subject of types of violence

$\sim$ Lack of love and care by parents

$\sim$ Having serious illness, health and physical development concerns

$\sim$ Malnutrition and physical weakness

$\sim$ Breaking ties with school or never attended school

$\sim$ Having difficult behavior

To address the issue of street children the city municipality has launched a comprehensive program aimed to return street children to their family environment and create a special environment for those who are lacking any care providers, including:

$\sim$ Adjust the status of special schools and pay attention to capacity and qualification building of teachers and social workers who work with children without adult supervision and have aggressive behavior as well as increase salaries of teachers and social workers.

$\sim$ Review the accountability system of parents who leave their children without supervision and introduce amendments to relevant laws.

$\sim$ Elaborate and undertake an appropriate policy for street youth who became adult and reached 18 being street children for a number of years since 1990.

\section{Major Reasons for Poverty and Insecurity}

1.71 The major reasons why a third of Mongolia's population is poor are determined as follows:

- The economy started to the transition without a clear articulated direction through a holistic approach. The shocks of the transition to a market economy have caused many industrial and service enterprises to close down, leading to lay-offs in excess of a thousand employees,

- Macroeconomic instability was deteriorated, especially in terms of increases of prices for domestic and imported goods, external shocks, banking crisis and slowing down of economic activities leading to income losses.

- Many thousands were given livestock during livestock privatization. However, a lack of experience in livestock herding and a lack of preparedness to climatic hardships made many of them lose their livestock, stripping them of their income sources,

- Many children who left their school during the initial transition years were left uneducated and without opportunities to work,

- Government transfers and social safety benefits to the people, which were large before 1990, were reduced substantially,

- Finally, the real incomes of the whole population have declined substantially.

1.72 These findings were also confirmed by the Participatory Living Standard Assessment Survey and participants in the Regional seminar on "From I-PRSP to F-PRSP", 2002. 


\section{Box 4. Forms of Insecurity and Vulnerability}

"The good life is to build your own life on his/her own way, make a decision independently him/herself on his/her own life, allow his/her children be educated and be healthy" as determined by a group of women from Bayanzurkh soum of Khuvsgul aimag

Another group of women from Khukhmorit sum of Govi-Altai aimag said that "We will be having a good life if we have good work, are healthy, have sufficient food and clothes, and be on the same path with the society".

Groups of men and women from Tuv aimag expressed their feelings and thoughts as follows: "A bad life means illiteracy of children and youth, suffering from illnesses, having a shortage in physical and mental needs and being uncertain on their future".

One poor lady from Sevrei sum of Unmugovi aimag said that "I'm heavily indebted and have lost control over the amount of the debt,- its like the number of stars in the sky".

\begin{tabular}{|l|l|}
\hline Economic & $\begin{array}{l}\text { Unemployment, remoteness from markets, unfavorable trade and commercial terms, } \\
\text { price instability, inability to pay wages, pensions and benefits on a timely basis, } \\
\text { cash shortages, loss of assets and indebtedness. }\end{array}$ \\
\hline Social & $\begin{array}{l}\text { Exclusion from communities, weakening of the kinship ties, hopelessness, inability } \\
\text { to work with others, inexperience of new herders }\end{array}$ \\
\hline Environmental & $\begin{array}{l}\text { Pasture over-grazing and degradation, lack of pasture, fighting for pastures, Dzud, } \\
\text { droughts, floods, dust and sand storms, steppe fires, invasion of insects, lack of } \\
\text { wells and places to settle in the winter }\end{array}$ \\
\hline Health & $\begin{array}{l}\text { Alcoholism, domestic violence, theft (especially theft of livestock), poor quality of } \\
\text { the drinking water, imported food, medication, deterioration of hygiene and health, } \\
\text { health risks due to prostitution }\end{array}$ \\
\hline Source: Participatory Living Standards Assessment, 2000
\end{tabular}

\section{Government Efforts to Reduce Poverty}

1.73 The National Poverty Alleviation Program. The Government of Mongolia, jointly with United Nations affiliated agencies, other international financial institutions and donor countries formulated and approved the National Poverty Alleviation Program (NPAP) in June 1994. The program was implemented until 2000. The main objectives of this multi-sectoral program, are based on principles of decentralization and public participation, were to reverse the declining trend of living standards and halt the human capital deprivation of the Mongolian population. Within the NPAP more than 13 thousand small scale projects have been undertaken in remote soums, horoos and bags to create temporary jobs in rural areas, to support pre-school and basic education, to improve basic medical services for the rural population, to provide technical training for adult disabled people by involving them in income generating activities, to provide education to disabled children through raising the incomes of vulnerable groups and the 
development of social infrastructure. The impetus for these projects came from the communities themselves, which is what made these projects distinctive.

1.74 Other programs and projects. Parallel to the National Poverty Alleviation Program the Government of Mongolia with the assistance of international banks, financial institutions, development organizations and donor countries has implemented a number of projects in health, education, infrastructure, and environmental sectors that directly and indirectly affect the living standards of the population. For example, 26 percent of foreign loans and assistance received during 1991-2001, amounting to 287 million US dollars, were spent on the social sector.

1.75 Employment. Approval of the Law on the Facilitation of Employment made an important contribution to the development of national industries and the reduction of unemployment. The Law clearly set out mechanisms to accomplish the Government's policy to support employment and financing mechanisms for a series of related actions. For example, the law requires that no less than 0.3 percent of annual budget revenues be allocated to the Employment Support Fund. According to this requirement, Tg 200 million was allocated to the Employment support fund from the central government budget in last two years. In addition, Tg 441.2 million was generated in the form of fees from expatriate workers in Mongolia in the second half of 2001. Out of the total revenue of $\mathrm{Tg} 641.2$ of the Fund, $\mathrm{Tg} 400$ million was allocated to 30 employment offices in aimags and capital city districts, enabling them to organize vocational training and to support employers, making important contributions to the effort to reduce unemployment. A total of 4.6 thousand citizens were trained in the first half of 2001, of which 41 percent were people with incomes under the minimum living standard level. Consistent with the policy of public works, 260 unemployed people, military servants and 240 convicts are engaged in construction works on the Millennium Road project.

1.76 Income generating activities: The National Program for Household Livelihood Support, financed by the IDA, was approved in 2001 and is being implemented as a follow-up to the National Poverty Alleviation Program. The main objectives of this program are to remove the poor households from poverty, and to prevent the non-poor low-income households from falling into poverty through mobilizing the economic and social resources necessary to support human and development capabilities. Implementation of the first stage of projects under this program started in the second half of 2002.

1.77 Poverty assessments showed that female-headed households are more likely to be affected by poverty and vulnerability. Parallel with sub-projects to increase the incomes of women within the National Poverty Alleviation Program, the Government developed and integrated the National Program on Advancement of Women, which is modified and replaced by the National program on gender equality adopted in December, 2002. The former program has included ambitious objectives to reduce poverty among women, but its implementation was not successful due to improper implementation mechanisms and financial difficulties (source: Program assessment report).

1.78 Small and medium size enterprise support projects in agriculture, implemented by the Government of Germany were quite successful among many projects and programs implemented to support employment and income generation in rural areas. 
1.79 In addition to special programs and projects, the Government of Mongolia implemented a series of increases in the wages of civil servants, other wages and pensions who are considered to be in the low-income group. In 2001-2002 pensions were increased by 41 percent on average, while the salaries of civil servants were increased by 23 percent.

VIII. Achievements and Lessons

1.80 Achievements. Although the rate of increase in poverty has slowed and its spread has been limited as a result of policy actions, poverty remains one of the critical problems facing Mongolia of today. The NPAP implementation has recorded the following achievements:

- Projects aimed at income generation activities and the creation of temporary jobs within public works, have secured increases of incomes of over 30 percent of poor households. Most of the participants have acquired skills and business knowledge, - and became more self confident and have escaped from poverty.

- In order to ensure the sustainable livelihoods of poor herder households over 2,200 herder households were given 107 thousand heads of livestock on a contract basis. In addition to the livestock re-stocking project, some herder households have diversified their activities by involving them in crop farming and support their livelihoods.

- Female participants have benefited more from income generation projects. For example, 65 percent of participants in income generating projects were female. At the same time female participants benefited from activities aimed to acquire skills on project development and management implemented by non-governmental organizations, rural health improvement projects, especially the maternal home restoration project.

- Community / public works projects have had a positive effect not only on creation of temporary employment, but have also had a long-term positive impact on the development of local economies. Bridges, roads, dams and irrigation canals have provided sustainable and long-term benefits to rural population. Also, projects for the supply of safe drinking water, public bath facilities, heating systems and waste removal have contributed to fostering a healthier and cheerful community life.

- Projects on strengthening basic and preschool education and rural health improvement have been implemented all over the country, with the effect of increasing school and kindergarten enrollment, reducing school dropouts and levels of infant mortality.

1.81 In addition to specific projects aimed at alleviating poverty, policy measures have been undertaken to maintain and enhance macroeconomic stability during the recent period. Macroeconomic stability enables the building of sustainable livelihoods of the population, in particular for those of the poor. Stabilization of inflation and currency rates, increases in foreign and domestic investment, restoration of national industries, strengthening of the public sector including fiscal management, improvement of the level and coordination of foreign loans and assistance helps improve the access and quality of social service delivery with a pro-poor focus. The objectives of raising living standards and reducing poverty amongst the population, especially in the rural areas, by improving infrastructure and fostering technological and scientific advances leading to increase of productivity are stated as one priorities of the Government's program. 
1.82 As a result of economic restructuring, the share of the private sector increased and it now accounts for over 70 percent of total GDP. The Mongolian economy has become more open, all citizens of Mongolia have the right and the opportunity to set their own personal goals for their lives and a favorable environment for the growth of private initiatives has been established.

1.83 Participants in the seminar organized in March in Bayankhongor aimag noted that "Now we learned what is poverty, what causes poverty and the ways to eliminate poverty". And that "Poverty is affected not only by national economic and social development, but also by the passive and submissive nature of the poor; we ourselves are not well organized."

1.84 Lessons. We have learned that programs and projects for poverty reduction and social welfare enhancement should be implemented in combination with a broad range of policies for sustainable economic growth, intensification of structural reforms, improvement of banking and financial services, as well as enhancement of social safety nets. It means that a poverty alleviation program, no matter how sound in its concepts and principles, may not eradicate poverty unless it is harmonized with and supported by broad-based social and economic projects and programs, policies oriented toward enhancing human capabilities, increasing employment, and enhancing economic growth.

1.85 The key objective of EGSPRS is the formulation, implementation and monitoring of poverty reduction and supporting the sustainable livelihoods of the population, the improvement in the targeting of social safety nets, - and the narrowing of the income gap between the rich and the poor and between urban and rural development. In addition poverty reduction efforts should be pro-poor oriented, and strategies should utilize efficient mechanisms to distribute the benefits of the growth to the poor.

1.86 Mongolia's extremely narrow structure of exports is very elastic to commodity price changes, leading to the economic vulnerabilities to externalities. The current level of economic growth is remains well below our requirements.

1.87 The banking system, which plays an important role in the economy, remains fragile. Competition is weak, resulting in persistently high interest rates and limiting access to domestic lending for the private sector. In addition the profitability of privatized enterprises is low, as human capacity and private sector management skills are not fully developed.

1.88 Components of good governance, such as transparency of government regulation, public policy management, monitoring, as well as participation of civil society are inadequate, leading to poor basic services in education and health, and in both poor quality and weak access to social safety nets.

1.89 In addition, past experience shows that besides targeting of programs to the poor, it is necessary to prevent vulnerable groups from slipping into poverty, within the overall poverty reduction framework. Thus the poverty reduction efforts should be directed not only to poor, but to people in danger of falling into poverty. 


\section{CHAPTER 2: ECONOMIC GROWTH SUPPORT AND POVERTY REDUCTION STRATEGY}

\section{Government Development Goals and Policy Priorities}

2.1 The Government has analyzed the economic situation since Mongolia adopted the market economy and defined its medium term economic and social development policies. Carrying-out restructuring as well as reforms undertaken within the social and political sphere have became an essential resource for ensuring economic growth. The prevalence of the private sector in the economy is another major source for ensuring enhanced economic growth. The Government has set itself the goal of reducing poverty through higher economic growth, which will be based on active private sector participation and an export oriented trade policy. Regional and sustainable development concepts will be incorporated in the general economic growth strategy.

2.2 In addition to the Government's pursuit of economic growth by using all possible and appropriate internal resources, it is also directing its strength to creating a sustainable livelihood, for all of the population and to reduce poverty through protecting nature and the environment based on the accomplishments of human civilization and improving social welfare. A stable macroeconomic situation, investment and the building of human capital factors will play a significant role in ensuring growth.

2.3 The Government of Mongolia will renovate techniques and technology, upgrade the processing of raw materials, rehabilitate the industrial processing sector, ensure sustainable development conditions, recover and develop the agricultural sector, increase investment in education and health sectors, ensure human development through supporting both foreign and local investment in all sectors and establishing favorable conditions for investment.

2.4 Besides reducing poverty within the country through ensuring higher economic growth, the policy on ensuring human development implemented in education, health and social welfare sectors will itself contribute and consolidate the economy's growth potential. Moreover, the development of more efficient mechanisms of budget and financial management as well as reforms in the public sector will be another important ingredient in securing economic growth.

2.5 The following are the priorities defined in short term within the framework of Mongolian development goals:

- to deepen the reforms for ensuring macroeconomic stability, and to intensify the restructuring process;

- to improve the health of the banking and financial sectors;

- to recover and develop national industry, to ensure economic growth through supporting export oriented industry;

- to support the regional as well as rural development, to intensively develop infrastructure;

- to create an equitable environment for ensuring human development, to improve all levels of education, its quality, health service provision and its accessibility;

- to reduce unemployment and poverty, to generally improve the living standards of population; 
- to ensure sustainable development and ecological balance, to mainstream nature conservation and environmental policies as priorities within regional socio-economic development;

- to speed up the land reforms;

- to reduce the air, water and soil pollution in large cities and settlements; to improve the living environment of the people through the reprocessing of waste;

- to improve governance to ensure human security;

- To create a fair, moral and democratic society that protects concepts of democracy, basic human rights and the freedom of each citizen;

- To mainstream gender dimensions in poverty interventions to promote gender equality.

2.6 At the beginning of the century the world has set itself global objectives to live without hunger and poverty in the next century. The Government of Mongolia has accepted the development goals set by the international community, and has committed itself to implementing them in the context of our country. With assistance of international agencies such as UNDP, ADB the Government has adopted and incorporated the MDGs in various policy documents.

2.7 The Government of Mongolia is working along its objectives of enhancing economic growth, poverty reduction and meeting specific development goals. In this framework, the Government of Mongolia is supporting the Millennium development goals, and has set its own Millennium Development Goals for achievement by 2015. The Government will endeavor to meet goals such as; the reduction in the number of people in extreme poverty by 25 percent by year 2005 , and by 50 percent by year 2015 , to provide universal primary education to all people and to reduce infant and child mortality by 50 percent by year 2005 with mainstreaming gender issues in poverty reducing efforts.

2.8 The Millennium Development goals have been incorporated in the EGSPRS, particularly in those sections dealing with health, education, employment, and other overall macro economic goals. These feature in the policy matrixes as well as monitoring section. Institutionally the government agencies jointly with civil society will undertake continuous monitoring of the process of achieving these goals, determined through annual plans and special reports during MDG implementation.

\section{Extending Participation}

2.9 In preparation of EGSPRS preparation the participatory approach is being utilized effectively, including all stakeholders. The government working group was a main coordinating body for the preparation of the strategy. Based on I-PRSP JSA and recommendations from the Mongolian cabinet and parliament, other donors the technical working group started an intensive and iterative process, including defining policy priorities by sectors, consultations, comments, coordinating with related domestic and donor funded projects. During the process of preparation the government has organized the donor consultation on energy, ICT, health, social welfare sectors and rural and UB city development laying a base for the sectoral policies. In addition the reforms in governance, including gender issues and legislative environment was discussed intensively under the UNDP support. At the final stage of the process the MOFE organized a round table discussion with Cabinet and Parliament members on policy priorities included in the 
EGSPRS and time table for implementation and monitoring. Besides government coordinated activities in order to support the PRSP process, the international community, in particular the World bank has organized several seminars workshops on economic growth, trade and poverty issues, pro-poor policies, public sector reforms among all stakeholders. UNICEF has initiated a monitoring approach with extensive focus on rural household's social sector services assess and quality which is intended to carry out in the further as one of main tools for monitoring of EPSPRS targets.

2.10 Extensive participation of non-government organizations was ensured, such as in conducting of research on specific issues and sectors, active participation in regional and consultative meetings, in sub-working groups as well as in the National Coordinating Committee. There are over 2500 non-governmental organizations currently in Mongolia. Compared to 1996, the number of NGOs increased 4.2 times. This was not only a qualitative growth. NGOs have matured financially, institutionally and in human capabilities. Most importantly, they became an active and responsible part of the development process. In the PRSP process, a working group comprising of representatives of 12 NGOs represented the civil society stakeholder and took an active part in the consultation process at all levels.

2.11 In order to broaden participation of the local governments and civil society in the process of development of the poverty reduction strategy, the first nation wide consultation in the form of series of regional seminars was organized in the first quarter of 2002 with assistance of the World Bank and the International Fund for Agricultural Development. During these seminars, participants assessed poverty and discussed possible ways to reduce poverty. Participants concluded that in addition to a reduction in living standards of Mongolians, there is growing income inequality. Although the Government with the assistance of international donors is providing quite a substantial support and assistance, results are unsatisfactory. The participants also proposed that in developing and implementing the poverty reduction strategy, the definition of poverty should be clarified, the poor should trained in life skills, and basic social services and the system of assistance for the poor, their targeting mechanisms should be improved. They also underlined that financial support should be provided based on resources and specifics of particular regions, through local cooperatives and other similar institutions and to those able to do business and to repay loans. Poverty will be effectively reduced if the poor are cared by more able people. They also underscored that job creation, development of small and medium enterprises, extension of infrastructure to connect rural areas with the market, expansion of financial services and effective environmental and disaster management should be key priorities of the Government. NGOs were an essential component of whole exercise: they were involved in preparation and organization of the regional seminars and took a substantive part in them. It is worth noting that one third of participants in each seminar were representatives of civil society. On the other hand, working groups participated in series of GDLN regional seminars organized by the World Bank Institute with subsequent internal discussions. During the PRSP consultative process, meetings discussed the Road map which is in essence an action plan for implementation of the strategy. Thus, local and national level teams made a good start for further in-depth involvement in the implementation phase of the EGPRS, in particular in contracting out some governmental functions as well as monitoring of this implementation. 
2.12 Series of consultative and business meetings as well as other events were organized on the national level. These consultations involved members of Parliament and the Cabinet, other high-ranking government officials on national and local levels, representatives of donor organizations, the private sector and non-government organizations, citizens, the poor and vulnerable in particular. Some of these participants including ministers, members of PRSP working group discussed their experience of the process on video and telephone conferences organized by the World Bank by sharing their views on specific issues, learnt experiences of other countries. Representatives of civil society presented their experience of PRSP process to the World Bank President stressing the wide presentation and consultations on specific as well as general issues on poverty and economic growth in Mongolia. Also, Mongolian representatives participated in international conferences and seminars on national poverty reduction strategies where they shared the process of the development of the PRSP in Mongolia and learnt from the experiences in other countries, which found its reflection in the Mongolian PRSP. All this greatly enhanced the quality of the PRSP.

2.13 The Poverty Research Group under the UNDP Poverty Research and Employment Facilitation project is continuing to operate as a unit to assist in addressing research and data gaps identified in the I-PRSP and its JSA through poverty research activities and developing recommendations for specific policy areas. The research in area of review of initial privatization policies, their impact on poor, of prevention of middle income groups from falling into vulnerability, of weather effects on environment and ways to approach sustainability of herders income have been sub-contracted to selected teams.

2.14 The specific project proposals, including Institutionalization of the participatory process, Improve pre-school education for the rural children, Improving participation of stakeholders and basic information, Support herders coalition have been screened by the National steering committee and main donors and proposed to PRSP Trust Fund.

\section{Sustainable Development and Pro-Poor Growth}

2.15 The Mongolian government's priorities are to accelerate economic growth and reduce poverty. Special focus is given to the involvement of poor people in development process through helping to improve their health and educational level, upgrade their skills, and most importantly the creation of a favorable environment for business development. Therefore one of the milestones of poverty reduction is acceleration of economic growth.

2.16 Pro-poor economic growth: Economic growth is the pre-requisite for poverty reduction, along with the narrowing of income inequality and, subsequently, ensuring sustainable development for the population. Mongolia's average GDP growth of 3.3 percent during 19951999 , and around 2 percent in the past 3 years is not sufficient to reduce poverty. Therefore, the central objective of the EGSPRS is to reduce poverty by increasing an economic growth to 5-6 percent per annum in the medium term. Sustainable high economic growth creates opportunities for the people to study, work and develop. However, the government and civil society should focus on efficient mechanism for channeling the benefits of higher growth to the poor. The Government will place emphasize on encouraging citizens' initiatives and creating a favorable economic and social environment in order to expand civil society participation in development. 
2.17 In the medium term the Government will implement policies aimed at accelerating private sector-led economic growth through the stabilization of macro economy, low inflation, development of free market competition, and appropriate monetary, credit and tax policies, thus raising the living standards of the population.

2.18 Economic growth will be enhanced by coordinating macroeconomic policies with policy priorities in the sectors and economic and social sector restructuring. Based on results of LSMS, the incidence of poverty was uneven in 1998. The depth of poverty was highest in aimag centers. Since then, natural disasters in the past three years greatly affected the livelihoods of herders. Therefore, the government policy priorities should be re-oriented towards those population groups most affected by natural disasters through expanding financial and banking services in rural areas, developing small and middle-size enterprises, stabilization and expansion of agricultural activities. Joint efforts aimed to accelerate economic growth and reduce poverty by the government alongside civil society and the private sector will be expanded.

2.19 Pro-poor allocation of resources. A further central goal of the EGSPRS in the medium term will be redistribution of the benefits of growth to the population equally, with a distinctly pro-poor focus. However, this distribution will not be done in a passive manner, but through implementing specific projects and programs aimed at increasing employment among the poor and the near-poor to take their own initiatives to improve their situation. As well, the Government will undertake economic restructuring consistent with building economic capacity, including public sector reforms, improving public expenditure management and the rationalization of social safety nets.

2.20 Ensuring comprehensiveness of the poverty reduction strategy. In addition to incorporating the main objectives of the economic growth acceleration and poverty reduction into long-term development policy documents, policies will be encompassed in national medium-term development programs and the medium term budget framework, as well as the annual Economic and Social Development Guidelines and budget proposals, thus ensuring consistency and comprehensiveness of implementation of the strategy with enhanced accountability and transparency.

2.21 To achieve this objective macroeconomic management and coordination is essential. Therefore it is important to develop a system of "outputs envelopes", which is consistent with new public sector management and finance environment and priorities of the macroeconomic and sectoral policies.

2.22 The long term vision of Mongolia's development is premised on a consensus of all stakeholders, including the government, civil society and the private sector. The business plan for the medium term of entities is becoming an efficient mechanism to link this long term development vision with sectoral priorities - feed back loops regarding financial resource issues is provided by a much improved medium term budget framework. This sequence of activities and their linking will provide a base for the formulation and implementation of pro-poor policies. The main objectives of the medium term plan will be included in the EGSPRS, and its implementation and monitoring will be done through annual Socio-Economic Guidelines. 


\section{Acceleration of Economic Growth}

2.23 Within the framework set by the strategy, the Government is giving priority to acceleration of economic growth, ensuring macroeconomic stabilization, further opening of markets and the creation of a favorable environment for business. We believe that the core objective of the economic growth and poverty reduction strategy is long-term macroeconomic stability. Macroeconomic stability is the cornerstone of economic growth enhancement and the increase in incomes of the population. The main engine of economic growth is private sector development, which is primarily based on privatization of state owned assets, improving business environment, enhancing business management, attraction of foreign investment and with overall enhancement of the macroeconomic stability.

2.24 Further, the Government will continue to support through policy measures, an open economy - and at the same time it will pursue a policy of accelerating the economic growth by attracting foreign investment and investing in efficient way. The Government will take measures to decrease the number of different kinds of trade permissions required, and simplify the overall procedure in order to support exports, industries and services in rural areas. It will pursue a policy of developing small and medium size enterprises, renovation of outdated technology, improving processing standards of raw materials and, therefore, boosting both production and the quality of the final product and increasing the number of small credit services. In relation to acceleration of economic growth, a favorable environment for service sector growth, particularly, development of the tourism sector, will be established.

2.25 The Poverty Reduction and Growth Facility Program, agreed between the Government of Mongolia and the IMF, is directed to ensure fiscal sustainability, to support private sector investment, to stabilize the macroeconomic situation and, hence, distribute the resources created as a result of economic growth for human development and poverty reduction. By implementing the PRGF, it is forecasted a solid basis for further economic development will be established and the economic growth is expected to be 5.5 - 7 percent in 2005-2008. Moreover, it is projected that the current account deficit of the balance of payment will be reduced to 6.7 percent of GDP in 2004 and, further, policy measures will be pursued to sustain it at the level of 6.5 percent.

2.26 Mongolia, with her vast territory and pristine nature, endowed with natural, in particular mineral resources, its advantageous geo-political position and the associated multifaceted international relations, relatively well-developed human resources and urbanization, has many advantages for development. However, Mongolia's economy is extremely vulnerable to climatic changes and the impact of external 'exogenous' shocks. The narrow base of the economy, the small size of the population, the distance from the sea and the other attendant problems of small economies also negatively affect national development. The main outcomes of this vulnerability are the sharp declines in prices of main export commodities and 'shocks' to the agricultural sector visited on the country in the past 2-3 years. Therefore, the implementation of any actions and mechanisms to accelerate economic growth in the medium term is only possible on the basis of careful study of these factors.

2.27 Overview of Mongolia's economic growth in last 10 years. During the transition period after 1990 when Mongolia began its transformation into a market economy, investments 
halted leading to an economic downturn; 1992 saw the largest decline a 9.5 per cent decrease in GDP from the previous year. This decline continued until 1993 when the economic downturn reversed.

Figure 2.1: Real Economic Growth, 1989-2002

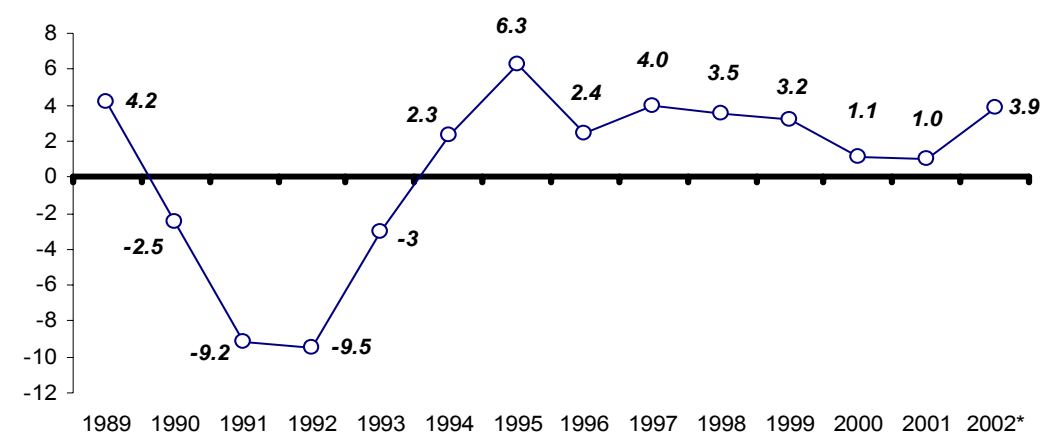

2.28 The economic growth trend in last 10 years can be split into 3 periods; 1993-1995, 1996-1999 and 2000-2002.

Table 2:1: Economic Growth, percent

\begin{tabular}{|l|c|c|c|}
\hline & $1993-1995$ & $1996-1999$ & $2000-2002$ \\
\hline Economic growth & 1.9 & 3.3 & 2.0 \\
\hline
\end{tabular}

2.29 Real terms economic growth was 1.1 per cent in 2000 and 1.0 per cent in 2001; and for 2002 it is expected to be at around 3.9 per cent. During the last 10 years, the growth rates of different sectors have not been stable due to structural changes in the economy, external economic conditions and climatic influences. In 1993-1999, growth in the primary sector of livestock husbandry was the main source of economic growth, yet the corresponding figures for industry, construction, transportation and communication remained unstable. In particular, growth of the industrial sector which declined by 6.4 per cent in 1993 recorded growth of 14.8 per cent in 1995. However, the sector experienced another decline of 3.6 per cent in 1996; yet in 1997-1999 it revived. The industrial sector, especially processing started its revival from 2000. Livestock husbandry which saw extensive growth between 1993-1999 comprising 36.8 per cent of GDP, declined by 16.6 percent in average due to unfavorable natural conditions. This resulted in an overall average economic growth rate of 2.0 per cent in between 2000 and 2002, in particular the processing sector delivered growth of 31.8 per cent in 2001, unprecedented since 1990. In 2002, its high growth continued at 22.1 per cent. In order to compile the requirements of Chinese external trade operations the technical standards MNS 4724:2001, MNS 3683:2001 have enforced for certain types of row materials, namely skins, wool.

2.30 The capital city UB is becoming one of chief contributors to economic growth. Almost 36 percent of Mongolia's GDP is produced in the capital; in 2001 the capital's GDP increased by 20 percent reaching MNT 426.9-bil. In GDP, industry, construction, hotel, dining 
hall, and financial services are delivering a more rapid growth. The share of the private sector on the capital's GDP has been increasing in recent years and hit on 71.2 percent. With the growth in production, in 2002 budget revenue increased by MNT 5.5-bil from previous year comprising 13.5 percent of the central budget.

2.31 Medium term government policy directions to enhance economic growth: Within the objective of attaining high economic growth in 2004-2007, the processing industry based on domestic raw materials, mining and extraction, tourism, IT, and infrastructure are considered to be main sources.

2.32 In the processing sector development livestock raw materials processing production, promoting export-oriented production of this type will be supported through SME's promotion and their efficient allocation and development in line with regional development principles. This includes cashmere products, meat, skins and hides, fur, flour productions, extraction of oil, and development of facilities to process the raw oil into petroleum products. In this regard, conditions to increase the extraction of oil will be provided.

2.33 For the mining sector, in order to utilize minerals and raw materials of Mongolia in the most effective and proper manner, measures will be taken to attract foreign and domestic investors into the mining sector and building favorable conditions for business operations. The government will encourage intensification of exploration, research and analysis works to open and utilize new deposits of minerals; and increases the extraction of gold, copper, coal, oil, zinc and other minerals. The production of final products with a high metal composition is a priority.

2.34 Within the framework of IT sector development, priority is given to IT sectors through expansion of internet services, establishment of a unified e-information network, thereby improve software and conditions for quality training of personnel, design and sale of software, development and export of e-information processing services.

2.35 Within tourism development priorities, the number of foreign tourists is to be increased significantly by establishing an environment for development of tourism in Mongolia, especially increasing the number of international flights and ensuring comfortable travel conditions. Hotel service quality will be raised to meet international standards. The comfort ability in tourist camps and entertainment activities will be ensured. There is a need to upgrade marketing efforts of Mongolia's tourism market. 2003 has been announced as to the year of visiting Mongolia - many important measures will be taken.

2.36 Regarding regions and infrastructure; a legal environment for regional development is to be established; priority is given to development of SME's in the countryside - for this purpose infrastructure such as transportation, communication, road, and energy will be developed to improve the business environment. Gradually shift to regional economic planning to narrow the development gap between cities and countryside. This will enable active participation of rural areas in market relations and establishment of favorable conditions for market and business development in the countryside.

2.37 In regard to livestock husbandry and land cultivation sectors, set the start for developing intensified livestock husbandry, improve the pasture management and water supply, 
assist in building up of security stock of feeds. Protection systems for livestock against natural and weather disasters, assistance in technical and technological innovations in land cultivation are needed to be enhanced, in particular introduction of new environmentally friendly technology in soil processing, support land cultivation, establishment of an appropriate weather system with extensive preventive measures, and livestock insurance system.

2.38 Medium term economic growth trends: Consistent with the above priorities of the government economic policy and activities, the economic growth rate for 2003-2007 has been estimated in three scenarios.

2.39 In 2003, the real growth of GDP is projected to be 5.2 per cent, in the mid-term or 2004-2007 6 percent, as a high scenario.

2.40 In this scenario for livestock husbandry and crop sectors are projected based on assumptions to have very favorable weather conditions resulting in their revival and thereby providing a growth to processing, food production, and weaving sectors. Projections to attain 6 per cent economic growth in 2004-2007 assumed that the agricultural sector would grow by on average 4.2 per cent, mining and extraction sector by 8 per cent, processing industry by $7.9-8.0$ per cent - the main foundation for the economic growth. Hotel and restaurant services -7.0 per cent growth.

Table 2:2: High Scenario with Economic Growth of 6.0 Percent.

\begin{tabular}{|l|c|c|c|c|r|r|r|r|r|}
\hline & 1999 & 2000 & 2001 & $2002^{*}$ & $2003^{* *}$ & $2004^{* *}$ & $2005^{* *}$ & $2006^{* *}$ & $2007^{* *}$ \\
\hline Agriculture, hunting, forestry & 4.2 & -14.9 & -18.5 & -10.5 & 4.0 & 4.2 & 4.2 & 4.2 & 4.2 \\
\hline Mining, extraction & 3.2 & 6.6 & 9.6 & -6.8 & 5.9 & 8.0 & 8.0 & 8.0 & 8.0 \\
\hline Processing & -2.8 & -3.3 & 31.8 & 22.1 & 7.3 & 8.1 & 7.9 & 7.9 & 8.0 \\
\hline Energy, water supply & 4.6 & 0.4 & 3.5 & 4.0 & 4.0 & 4.1 & 4.3 & 4.3 & 4.3 \\
\hline Construction & 1.6 & -14.6 & 10.8 & 11.1 & 8.0 & 8.0 & 7.0 & 7.0 & 7.0 \\
\hline $\begin{array}{l}\text { Wholesale and retail trade, } \\
\text { home appliances repair }\end{array}$ & 1.3 & 26.1 & 9.8 & 12.3 & 4.6 & 6.0 & 5.9 & 5.9 & 5.9 \\
\hline Hotel, restaurant & 8.7 & 13.2 & -6.9 & 0.5 & 7.0 & 7.0 & 7.0 & 7.0 & 7.0 \\
\hline $\begin{array}{l}\text { Transportation, warehouse, } \\
\text { communication }\end{array}$ & 6.1 & 25.2 & 14.9 & 17.1 & 6.7 & 6.9 & 7.0 & 7.0 & 7.0 \\
\hline $\begin{array}{l}\text { Finance and lending } \\
\text { institutions }\end{array}$ & 39.9 & 7.0 & 22.4 & 7.8 & 6.8 & 6.8 & 7.0 & 7.0 & 7.0 \\
\hline $\begin{array}{l}\text { Immovable property, business } \\
\text { service }\end{array}$ & -4.7 & 12.5 & 7.1 & 11.6 & 4.4 & 4.9 & 6.0 & 6.5 & 7.0 \\
\hline Public service & 1.5 & 3.5 & -5.7 & 5.5 & 2.1 & 2.1 & 2.1 & 2.1 & 2.1 \\
\hline Education & 4.6 & 3.2 & 1.3 & 0.8 & 4.5 & 4.5 & 4.5 & 4.5 & 4.5 \\
\hline Health, social welfare & 3.1 & -0.1 & 4.6 & 2.9 & 3.2 & 3.2 & 3.2 & 3.2 & 3.2 \\
\hline Social and private service & 0.5 & 57.1 & 10.4 & 9.1 & 6.0 & 7.0 & 6.0 & 6.0 & 6.0 \\
\hline $\begin{array}{l}\text { Indirect services of financial } \\
\text { institutions }\end{array}$ & 7.0 & 30.5 & 27.1 & -21.3 & 5.0 & 5.0 & 5.0 & 5.0 & 5.0 \\
\hline GDP (1995 prices) & 3.2 & 1.1 & 1.0 & 3.9 & 5.2 & 6.0 & 6.0 & 6.0 & 6.1 \\
\hline
\end{tabular}

* - expected actual

** - projections 
2.41 In this case for the medium term period external economic conditions are assumed to be extremely favorable. In addition, for mining and extraction sectors, some deposits, exploitation of which were planned to start, were considered as being exploited.

Table 2:3: Main Assumptions on Newly Exploited Deposits

\begin{tabular}{|l|l|l|l|l|l|}
\hline \multicolumn{1}{|c|}{ Factory } & \multicolumn{1}{|c|}{ Location } & \multicolumn{1}{c|}{$\begin{array}{c}\text { Operational } \\
\text { time }\end{array}$} & \multicolumn{1}{c|}{ Products } & \multicolumn{1}{c|}{$\begin{array}{c}\text { Annual } \\
\text { capacity }\end{array}$} & $\begin{array}{c}\text { Product value } \\
\text { USD mil }\end{array}$ \\
\hline $\begin{array}{l}\text { Boroo gold } \\
\text { factory }\end{array}$ & $\begin{array}{l}\text { Bayangol } \\
\text { soum, Selenge } \\
\text { aimag }\end{array}$ & 2005 & Gold & $1,500 \mathrm{~kg}$ & 15.0 \\
\hline $\begin{array}{l}\text { Toson gold } \\
\text { factory }\end{array}$ & $\begin{array}{l}\text { Zaamar soum, } \\
\text { Tuv aimag }\end{array}$ & 2003 & Gold & $800 \mathrm{~kg}$ & 8.0 \\
\hline $\begin{array}{l}\text { Tavt gold } \\
\text { factory }\end{array}$ & $\begin{array}{l}\text { Teshig soum, } \\
\text { Bulgan aimag }\end{array}$ & 2005 & Gold & $200-400 \mathrm{~kg}$ & 3.0 \\
\hline $\begin{array}{l}\text { Tumurtei Ovoo } \\
\text { zinc extraction } \\
\text { and enrichment } \\
\text { factory }\end{array}$ & $\begin{array}{l}\text { Baruun-urt } \\
\text { soum, } \\
\text { Suhbaatar } \\
\text { aimag }\end{array}$ & 2004 & $\begin{array}{l}\text { Zink } \\
\text { concentrate }\end{array}$ & 58,000 tons & 17.8 \\
\hline
\end{tabular}

2.42 The second or base scenario is a GDP growth of 5.5 per cent in the mid term. In this scenario, the growth of agriculture, mining, extraction and processing sectors were taken slightly below the ones used in the $1^{\text {st }}$ scenario.

In the $1^{\text {st }}$ scenario (high) the following growth rates were projected:

- $\quad$ Crop industry - 4

- $\quad$ Livestock husbandry - 4.3.

- Agriculture as a whole - 4.2

- Mining, extraction -8

- $\quad$ Processing - 8.0

$-$

In the $2^{\text {nd }}$ scenario (base):

- Crop industry - 4

- $\quad$ Livestock husbandry - 3.8

- Agriculture as a whole - 3.8

- Mining, extraction - 6.0-6.6

- Processing - 7.3-7.9 
Table 2:4: Base Scenario with Economic Growth of 5.5 Percent

\begin{tabular}{|l|c|c|c|c|c|c|c|c|c|}
\hline & 1999 & 2000 & 2001 & $\begin{array}{c}2002 \\
*\end{array}$ & $2003 * *$ & $2004 * *$ & $2005^{* *}$ & $2006^{* *}$ & $2007^{* *}$ \\
\hline Agriculture, hunting, forestry & 4.2 & -14.9 & -18.5 & -10.5 & 4.0 & 3.8 & 3.8 & 3.8 & 3.8 \\
\hline Mining, extraction & 3.2 & 6.6 & 9.6 & -6.8 & 5.9 & 6.0 & 6.6 & 6.6 & 6.6 \\
\hline Processing & -2.8 & -3.3 & 31.8 & 22.1 & 7.3 & 7.3 & 7.9 & 7.9 & 7.9 \\
\hline Energy, water supply & 4.6 & 0.4 & 3.5 & 4.0 & 4.0 & 4.1 & 4.3 & 4.3 & 4.3 \\
\hline Construction & 1.6 & -14.6 & 10.8 & 11.1 & 8.0 & 8.0 & 7.0 & 7.0 & 7.0 \\
\hline $\begin{array}{l}\text { Wholesale and retail trade, } \\
\text { home appliances repair }\end{array}$ & 1.3 & 26.1 & 9.8 & 12.3 & 4.6 & 5.0 & 5.0 & 5.0 & 5.0 \\
\hline Hotel, restaurant & 8.7 & 13.2 & -6.9 & 0.5 & 7.0 & 7.0 & 7.0 & 7.0 & 7.0 \\
\hline $\begin{array}{l}\text { Transportation, warehouse, } \\
\text { communication }\end{array}$ & 6.1 & 25.2 & 14.9 & 17.1 & 6.7 & 6.9 & 7.0 & 7.0 & 7.0 \\
\hline Finance and lending institutions & 39.9 & 7.0 & 22.4 & 7.8 & 6.8 & 6.8 & 7.0 & 7.0 & 7.0 \\
\hline $\begin{array}{l}\text { Immovable property, business } \\
\text { service }\end{array}$ & -4.7 & 12.5 & 7.1 & 11.6 & 4.4 & 4.9 & 6.0 & 6.5 & 7.0 \\
\hline Public service & 1.5 & 3.5 & -5.7 & 5.5 & 2.1 & 2.1 & 2.1 & 2.1 & 2.1 \\
\hline Education & 4.6 & 3.2 & 1.3 & 0.8 & 4.5 & 4.5 & 4.5 & 4.5 & 4.5 \\
\hline Health, social welfare & 3.1 & -0.1 & 4.6 & 2.9 & 3.2 & 3.2 & 3.2 & 3.2 & 3.2 \\
\hline Social and private service & 0.5 & 57.1 & 10.4 & 9.1 & 6.0 & 6.0 & 6.0 & 6.0 & 6.0 \\
\hline $\begin{array}{l}\text { Indirect services of financial } \\
\text { institutions }\end{array}$ & 7.0 & 30.5 & 27.1 & -21.3 & 5.0 & 5.0 & 5.0 & 5.0 & 5.0 \\
\hline GDP (1995 prices) & 3.2 & 1.1 & 1.0 & 3.9 & 5.2 & 5.3 & 5.5 & 5.5 & 5.5 \\
\hline
\end{tabular}

* - expected actual

** - projections

2.43 The $2^{\text {nd }}$ scenario is a scenario, which is more realistic by providing relatively less growth to mining and processing sectors. In this scenario the livestock has a normal loss and crop production and land cultivation a decent harvest. Regarding the external condition, it is the same as in 2000-2002.

2.44 Investment needs for the mid term are estimated as follows consistent with the economic growth trend.

Table 2:5: Investment at Current Prices, MNT billion (based on GDP estimated by expenditure approach)

\begin{tabular}{|c|c|c|c|c|c|c|}
\hline & 2002 & 2003 & 2004 & 2005 & 2006 & 2007 \\
\hline Total investment & 324.6 & 338.4 & 368.0 & 394.3 & 426.8 & 463.1 \\
\hline Domestic source & 114.6 & 124.1 & 141.3 & 156.4 & 175.3 & 197.7 \\
\hline Of which budget & 39.9 & 39.9 & 49.9 & 55.4 & 62.7 & 70.8 \\
\hline Foreign source & 210.0 & 214.3 & 226.7 & 237.9 & 251.5 & 265.3 \\
\hline \multicolumn{7}{|l|}{ Percentage in total investment } \\
\hline Domestic source & 35.3 & 36.7 & 38.4 & 39.7 & 41.1 & 42.7 \\
\hline Of which budget & 11.3 & 11.8 & 13.6 & 14.0 & 14.7 & 15.3 \\
\hline Foreign source & 64.7 & 63.3 & 61.6 & 60.3 & 58.9 & 57.3 \\
\hline Percentage of total investment in GDP & 23.0 & 23.3 & 23.7 & 23.9 & 23.8 & 23.9 \\
\hline Percentage of budget investment in GDP & 2.8 & 2.7 & 3.2 & 3.4 & 3.5 & 3.6 \\
\hline
\end{tabular}

2.45 In the mid term Mongolia needs investment that equals to 24 per cent of GDP, almost 60 per cent of which is projected to be financed from foreign sources. The government will meet 
its investment requirements by utilizing budget investments, donor country loans and aid, mainly in education, health, infrastructure sectors and promoting regional development, and attracting direct foreign investment into mining, processing, hotel, trading businesses.

2.46 The $3^{\text {rd }}$ scenario is the lower - case scenario with unfavorable situations for main economic sectors such as livestock husbandry and land cultivation. In this scenario the economic growth in the mid term is projected to be at 3.0-3.7 per cent. The risk exposure is continued in the agriculture - decline projected for up to 5 years in livestock husbandry and 4 years in crop industry. The main difference of this scenario from the $2^{\text {nd }}$ one is the processing sector in addition to livestock husbandry. In connection with the continued decline in the livestock husbandry, the processing industry is projected to grow by around 4.8 per cent assuming that main sub-sectors of the processing industry - food and weaving - will not deliver a decent growth. Furthermore, external condition is considered to be unfavorable, including continues commodity price volatility, declining world demand, political instability, outbreak human and animal diseases.

2.47 The above three scenarios provide for a conclusion that the economic growth in the mid term will be fluctuated at around $3-6$ percent subject to external and internal circumstances.

Table 2:6: Summary of GDP Indicators, 2001-2007

\begin{tabular}{|c|c|c|c|c|c|c|c|c|}
\hline & & 2001 & 2002 & 2003 & 2004 & 2005 & 2006 & 2007 \\
\hline \multirow{3}{*}{$\begin{array}{l}\text { GDP (current } \\
\text { prices, MNT } \\
\text { mil) }\end{array}$} & High & 1115641.4 & 1231330.2 & 1366089.3 & 1515894.5 & 1683093.6 & 1868921.7 & 2075343.8 \\
\hline & Base & 1115641.4 & 1231330.2 & 1362239.5 & 1508014.0 & 1669664.8 & 1849164.6 & 2049104.7 \\
\hline & Lower & 1115641.4 & 1231330.2 & 1362239.5 & 1477719.8 & 1606656.3 & 1749770.4 & 1909040.8 \\
\hline \multirow{3}{*}{$\begin{array}{c}\text { Growth rate, } \\
\text { percent }\end{array}$} & High & 9.50 & 10.37 & 10.94 & 10.97 & 11.03 & 11.04 & 11.04 \\
\hline & Base & 9.50 & 10.37 & 10.63 & 10.70 & 10.72 & 10.75 & 10.81 \\
\hline & Lower & 10.1 & 9.5 & 10.4 & 10.6 & 8.5 & 8.7 & 8.9 \\
\hline \multirow{3}{*}{$\begin{array}{l}\text { GDP (1995 } \\
\text { prices, MNT } \\
\text { mil) }\end{array}$} & High & 639013.0 & 664252.5 & 699046.4 & 740641.4 & 784880.1 & 832346.9 & 883014.2 \\
\hline & Base & 639013.0 & 664252.5 & 698614.4 & 735419.2 & 775553.2 & 818084.7 & 863152.4 \\
\hline & Lower & 639013.0 & 664252.5 & 698614.4 & 719429.0 & 743280.5 & 769291.7 & 797538.5 \\
\hline \multirow{3}{*}{$\begin{array}{c}\text { Growth rate, } \\
\text { percent }\end{array}$} & High & 1.03 & 3.95 & 5.24 & 5.95 & 5.97 & 6.05 & 6.09 \\
\hline & Base & 1.03 & 3.95 & 5.17 & 5.27 & 5.46 & 5.48 & 5.51 \\
\hline & Lower & 1.0 & 3.9 & 5.2 & 3.0 & 3.3 & 3.5 & 3.7 \\
\hline
\end{tabular}

2.48 The $2^{\text {nd }}$ scenario is considered to be the most consistent with the reality - no priority is given to any sector, risk in the agricultural sector is taken into account, growth of livestock husbandry is 1.7 points below the average growth recorded in 1996-1999 (normal loss without risk exposures).

2.49 The following table shows the composition of the mid-term economy by sectors under the $2^{\text {nd }}$ scenario: 
Table 2:7: Economic Structure by Major Sector

\begin{tabular}{|l|c|c|c|c|c|c|}
\hline & 2002 & 2003 & 2004 & 2005 & 2006 & 2007 \\
\hline Industry & $\mathbf{2 1 , 4}$ & $\mathbf{2 1 , 6}$ & $\mathbf{2 1 , 8}$ & $\mathbf{2 2 , 1}$ & $\mathbf{2 2 , 3}$ & $\mathbf{2 2 , 5}$ \\
\hline Agriculture & $\mathbf{2 0 , 7}$ & $\mathbf{2 0 , 5}$ & $\mathbf{2 0 , 2}$ & 19,9 & $\mathbf{1 9 , 6}$ & $\mathbf{1 9 , 3}$ \\
\hline Construction & $\mathbf{2 , 1}$ & $\mathbf{2 , 2}$ & $\mathbf{2 , 2}$ & $\mathbf{2 , 3}$ & $\mathbf{2 , 3}$ & $\mathbf{2 , 3}$ \\
\hline Transportation, communication & 14,0 & 14,1 & 14,2 & 14,3 & 14,5 & 14,6 \\
\hline $\begin{array}{l}\text { Trade, inventory and equipment } \\
\text { supplies }\end{array}$ & $\mathbf{2 7 , 6}$ & $\mathbf{2 7 , 6}$ & $\mathbf{2 7 , 5}$ & $\mathbf{2 7 , 5}$ & $\mathbf{2 7 , 5}$ & $\mathbf{2 7 , 5}$ \\
\hline Service & $\mathbf{1 4 , 2}$ & $\mathbf{1 4 , 1}$ & $\mathbf{1 4 , 0}$ & $\mathbf{1 4 , 0}$ & $\mathbf{1 3 , 9}$ & $\mathbf{1 3 , 8}$ \\
\hline
\end{tabular}

Source: MOFE

2.50 According to the $2^{\text {nd }}$ scenario the economic structure will not be changed much. Due to growth in mining and processing sectors percentage of industry in GDP will increase by 1.5 points with a decrease of agriculture share by 1.4 percentage points. 


\section{CHAPTER 3: PROMOTION OF ECONOMIC AND FINANCIAL SUSTAINABILITY}

3.1 At the first half of 1990, when Mongolia has made her first steps toward market economy relations, her macroeconomic situation was unstable, the economy was in recession that continued for a certain period of time. There was a gradual tendency toward macroeconomic stabilization in 1995-1999. However, not only the economic and financial crisis in South East Asia and overall economic slowdown in the world, but also the unstable internal political situation and unappropriate policy measures have affected Mongolian economy negatively.

\section{Budget and Finances}

3.2 In the early 1990's, the budget revenue constituted about 60 percent of GDP, but as a result of the economic crisis in Asia it dropped to 23.4-33.6 percent in 1995-1999. This was also affected by the following changes in the tax policy and legal environment in Mongolia. Measures taken in 1997-1999 within the taxation reform:

- Four-rate $(15,25,35$, and 40$)$ corporate income taxation was changed into two-rate (15 and 40).

- Five-rate $(2,15,27$, and 40$)$ personal income taxation was changed into three-rate $(10,20$, and 40).

- All import taxes were annulled except the import tax rate of 15 per cent on alcohol beverages.

- Import tax rate on flour and vegetables of 15 per cent was linked to seasonal pattern.

3.3 The taxation reform started in 2001 changing VAT rate to 15 per cent and increasing excise tax on alcoholic beverages and tobacco products by 50 percent with the aim of increasing budget income. The tax law on nullification of import duties was abolished imposing flat import duties on all imports. In addition, as a result of the Government's policy to improve the tax collection, revenue as of GDP has increased to 36 per cent in 2001-2003. By the mid of the last decade the economy started to experience the positive growth rates, averaging at 3.3 percent. Since the transition the economic performance has been slowed down, and signs of recovery emerged by the mid of the last decade only. However, due to external shocks, including commodity price fluctuations, East Asian and Russian crisis, the world overall economic slowdown and natural disasters overall economic growth was quite concervative at around 2 percent, downwarded mainly by livestock sector performance. Despite a low economic growth, last three years were period of extensive measures aimed to improve the public finances. Compare to overall deficit of over 10 percent by the end of the previous decade, fiscal deficit was reduced from 7.7 to 6 percent of GDP in 2000-2002. This strong performance was a result of sequenced policy measures aimed at enhancement of tax administration and expenditure management with strong focus on reduction of dependence of budget on banking sector, 
elimination of domestic and external arrears, enhancing efficiency of intergovernmental fiscal relations. During 2000-2002 the government reduced domestic arrears twice and reached -32.4 billion togrog.

3.4 A number of measures have been taken achieving notable results with a view to raise the tax collection process by expanding the tax base as stated in the Government's Action Plan, improve the tax imposition and control over the tax payments, rationalizing the tax debt workout management through strengthening the legal regulatory framework and to increase the real income of low-income citizen.

3.5 It is expected that the real annual income of citizen will increase by 1.2 billion MNT each year due to the decision to postpone the starting date for the tax imposition on the dividends, interest income received by permanent residents in Mongolia in order to promote personal savings, to January $1^{\text {st }}, 2005$.

3.6 As the next stage of reform the government has undertaken a series of decisive measures to enhance budget planning, execution and monitoring, enhance transparency of fiscal operations by transferring from yearly planning to medium term, linking policy priorities with budget resources, improving comprehensiveness of budget, rationalization of the system of norms, introduction of the Treasury Single Account (TSA) system, improving reporting system. In overall, in the medium term, fiscal and tax policies shall be directed to macroeconomic stabilization, including financial sustainability, improvement of the fiscal balance, expansion of access to and improvement in the quality of social services, increased pro-poor orientation of public expenditures. These reform measures were grounded in the Public Sector Finance and Management Law (PSMFL), which was passed by the Parliament in June 2002. The Parliament has discussed and adopted the next year's budget in a new manner not applied formerly consistent with the content of newly adopted laws.

- Budget financing and product payments are not dedicated for financing the budget institution, its staff and utility expenses, and will be provided in accordance with the performance results of their duties, tasks and subscriptions from the government.

- Budget expenditures and financing were distributed by expenditure items as well as by budget disposers or budgets were approved in bulk for each minister in charge of certain sectors.

- Next year's budget financing will be made based on contracts on product supply and results.

- During the years, budget financing can be changed subject to operational result reports from budget institutions.

- Sectors located in the countryside but carry out nation-wide activities will be financed from the central budget under a contract not from the local budget.

3.7 A tender selection process was initiated which led to the selection of 3 educational institutions to provide training to the civil servants at all levels on the new system for budget management. These institutions will conduct comprehensive on-site training and consultancy regarding the new system for budget management and involve about 8 thousand managers, general managers, and financial officers of 22 aimags and all the districts of the capital city for the period from May to July 2003. 
3.8 These training events conducted at the local level will create the human resources capacity needed for preparing the 2004 budget proposal in accordance with the requirements set forth in the PSFML.

3.9 As set forth in the law on management and financing of budget institutions, a new principle of financing is applied on all levels of the budget - contract on product supply and result agreement. As of the end of 2002, over 14.0 thousand economic entities operated in the capital and composed budget revenue of the capital; MNT 51.1-bil were mobilized to the capital budget and MNT 53.7-bil were spent on and financed operating cost of approx irately 500 entities in the field of education, health, culture, media, urban services and social order ending up with a budget deficit of MNT 73.9-million. Up to 2001 the capital city has had an independent budget capable to generate revenue to fund expenditures, however, in recent years the Ministry of Finance and Economy while developing a draft budget makes constant adjustments to the capital city budget so that deteriorating the independent status of the capital city budget.

3.10 Under this law, budget institutions on all levels and general disposers of aimag and UB city budget will prepare quarterly and annual reports on product supply including which services, on which quality level, and how were performed using budget funds.

3.11 Mongolia is just starting the implementation of this new principle, thus we set out implementation targets as follows:

- At primary stage: fully comprehend the law concept, correctly define products, measure supplied products in proper criteria, learn to prepare reports correctly and in a timely manner.

- Secondly: Fully mobilize opportunities to deliver services at a possible low cost and highest quality, decrease the cost of products and services.

- The Ministry of Finance and Economy has developed several procedures and Government decrees related to the enforcement of the law management and financing of budget institutions and is preparing their enforcement, namely:

- Definition and approval of output types as set forth in the law on central budget;

- Criteria for enforcement and outputs monitoring specified in the concerned contracts;

- Regulations concerning establishment of Government contingency fund and its allocation;

- Defining and authorization to the organization on disposal of budget saving generated during the fiscal year.

3.12 The PSMFL aims to strenghthen governance within the public sector, improve public sector performance, and clarify the roles, processes, and regulations governing the public sector performance. In accordance to the PSMFL the amendments were introduced into the concerned laws and legal regulations. The recent session of the Parliament ammended 78 laws, including the fundamental changes into the Consolidated Budget Law. According to the new system a series of and forms and regulations were adopted, namely Output contract, delegation of authorities, reports on outputs with concerned intsrutions, determinind of types and cost of outputs of public entity, business plan with comprehesive portfolio. All these regulations lay foundations 
for the deepening of public sector reforms aimed at improving public sector service delivery, its transparency and accountability.

3.13 If the major external shocks would not occur the fundamentals of macroeconomic stabilization will be maintained. Especially fiscal and public restructuring policy measures undertaken are conducive to the macroeconomic stability. The government has defined the following objectives with respect to the tax revenues for the purpose of ensuring the macroeconomic equilibrium for 2004-2006:

- To appropriately define the level of interdependence between economic growth and budget revenue; to intensify the tax imposition, collection and control within the legal framework; to further consolidate the progress of the last few years in terms of ensuring ongoing flow of budget financing;

- To relate the budget revenues and tax relations to the Civil Service Reform activities as well as the measures to be taken in the mid-term regarding the government's social policies and the need to ensure budget balance and stability;

- To implement measures to reduce the tax burden on the economy and the population to the reasonable level without following the tax policy consistent with the state budget revenue increase.

3.14 The percentage of budget revenues in GDP expected to be 37.4 percent in 2004, dropping to 36.3 percent in 2005-2006. In this connection, the following measures will be taken within the mid-term budget framework in the next three years with respect to taxation:

3.15 The tax burden on the economy was 29.2 percent according to the 2002 actual and the policy will be pursued in the next three years to maintain it at this level. The income from social insurance fee payments will be calculated in relation to the personal real and cash income growth and the activities to improve the level of employment. Thus in 2004-2006 it is expected that the personal revenues will increase by 15 billion MNT or by 27 percent compared to 2003. A system will be devised by which an excise tax is to be increase on cigarettes and it is expected that as a result the tax revenues will increase by about 3 billion MNT from 2004. It is expected that the revenues from land fees and payments will increase to a certain extent with the beginning of land privatization. The policy towards reduction of the higher rate of the corporate taxes will be reviewed and introduced since 2005 only if the accompanied by offsetting current expenditures cuts. This will as an initial step towards unification of the corporate tax level.

3.16 The restructuring in the social sector will be undertaken in accordance to the Main guidelines on restructuring and privatization of social sector adopted by the Parliament. The list of social entities to be restructured in the medium term is approved by the Cabinet.

3.17 Fiscal sustainability: The fiscal sustainability is a key for the macroeconomic stability. Years of 1997-99 were a period of lower revenue accumulation due to poor tax policy, business collapse, external shocks, and Asian financial crisis. In addition the public expenditure management was poor, in particular in area of expenditure control and wage policy. In overall the budget performance was poor with large fiscal deficit and instability. The general structure of the Mongolia's budget for 1993-2003 was as follows: 
Table 9. Macro fiscal performance, 1993-2003 (as a percentage of GDP)

\begin{tabular}{llllllllllll}
\hline & 1993 & 1994 & 1995 & 1996 & 1997 & 1998 & 1999 & 2000 & 2001 & 2002 & $2003^{*}$ \\
\hline Budget revenue & 30.2 & 31.1 & 25.6 & 24.8 & 25.5 & 27.6 & 27.2 & 33.6 & 38.9 & 38.8 & 36.3 \\
\hline $\begin{array}{l}\text { Budget expenditures, } \\
\text { net lending }\end{array}$ & 28.3 & 26.8 & 26.8 & 32.7 & 34.5 & 41.9 & 39.4 & 41.1 & 43.3 & 44.8 & 42.6 \\
\hline Current expenditures & 25.5 & 18.4 & 23.7 & 22.1 & 23.1 & 27.2 & 26.7 & 30.1 & 32.4 & 33.8 & 31.9 \\
\hline Interest payments & 1.2 & 0.6 & 0.4 & 0.7 & 2.5 & 1.4 & 1.9 & 1.7 & 1.5 & 1.6 & 1.5 \\
\hline $\begin{array}{l}\text { Current budget surplus } \\
(+)\end{array}$ & 1.9 & 2.9 & 6.2 & 4.0 & 1.6 & -0.7 & -0.2 & 3.1 & 5.6 & 4.4 & 3.8 \\
$\begin{array}{l}\text { Overall budget deficit } \\
(-)\end{array}$ & -14.6 & -19.8 & -5.9 & -7.9 & -9.1 & -14.3 & -12.1 & -7.5 & -4.5 & -6.0 & -6.2 \\
\hline *plan & & & & & & & & & & & \\
\hline
\end{tabular}

3.18 Mongolia has attained a remarkable success in reducing the budget deficit in last 10 years. In 1994 the budget deficit constituted 19.8 per cent of GDP; however we managed to reduce it in succeeding years down to 6.0 per cent in 2002. Although the current expenditure of the budget was increasing in terms of amount and percentage in the total expenditure, direct subsidies to state-owned enterprises had been reduced 3 times in 1995-2000.

Figure 3.1: Fiscal Trends

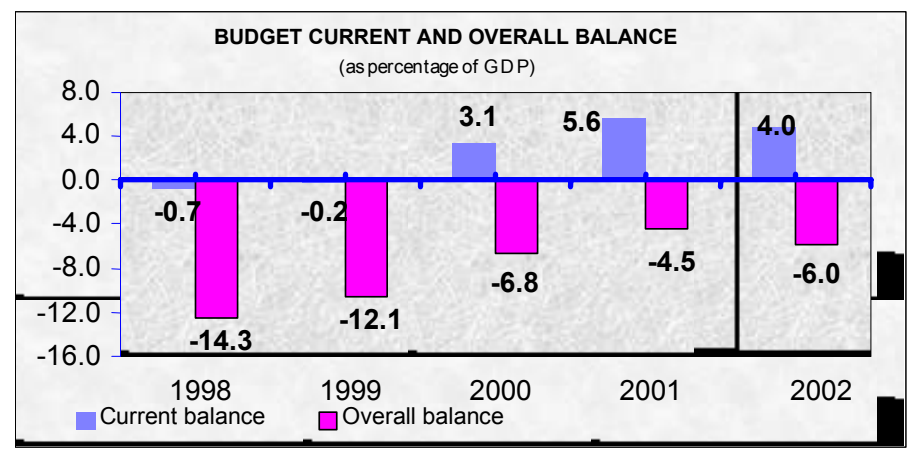

3.19 Since 2001 the government started fundamental changes in area of public expenditure management with aim to enhance tranparency, accountability and improving service delivery. As an outcome of implemented policy actions on fiscal sustainability from 2001-2002, the fiscal macroeconomic indicators were improved, current budget was with positive number and expenditure financing supervision was upgraded.

3.20 As a result of efficient measures and actions undertaken by the Government on ensuring the fiscal sustainability, improving tax collection process and implementing rational tax policy, the fiscal sustainability has been improved from the second half of the 2000, access and quality of public services has been improved. The newly established Government (August 2000) undertook a series of decisive measures to improve the tax collection, repayment of domestic and foreign arrears, enhancement of fiscal discipline. As the first step the government repaid lending to the Mongolbank worth 12 billion togrogs. Further, as result of the above measures the arrears in wage bill of 8.2 billion togrog was retired and inter-agency arrears were reduced substantially. By the end of 2002, 16 aimags out of 21 have nullified their arrears. The Public Sector Financing and Management Law was adopted by the Parliament in June 2002 and enforced from $1^{\text {st }}$ of 
January of 2003 in order to speed up fiscal reforms. 2003 budgeting was drafted according to the Public Sector Financial Management Law and start from 1 January 2003 the budget is enforced. The VAT has been increased by two points reaching 15.0 percent and enforced, and excise tax on alcoholic beverages and tobacco products has been increased by 50 percent as well as customs tax by two points reaching 7.0 percent (The customs tax is being enforced within one year).

3.21 The intergovernmental transfer system was modified based on new equalization model: of 80 percent of excise VAT and 50 percent of special excise tax centralization and a reallocation based on various criteria. Key indicators of last 5 years of the capital's budget and finance show that tax collections from corporate and individual income taxes have been increasing from year to year, but with the amendment into the Taxation law effective 2001 most part of VAT, effective 2002 corporate income and excise taxes, and effective 2003 individual income tax collections are mobilized to the central budget changing the budget structure of the capital and leaving its with a less budget base. Under the law on administration and financing of budget institutions, General portfolio manager of the capital or the Mayor shall bear the following duties and mobilize funds required for performance of his/her duties from local sources:

1. Enhance infrastructure of local property, do road maintenance

2. Ensure the smooth running of water supply purifying facility

3. Take environmental protection measures and do furnishment, expansion and reform

4. Build flood barriers, fight against soil wear

5. Ensure the public sanitation, remove and destroy trash

6. Protect from fire

7. Destroy damage-causing animals

8. Fight against animal decease and deceases transferred from animals to humans, take preventative measures

However, education, culture, health, labor, social welfare, social security delivery and prevention measures are being supplied to the Government on a contractual basis under a new structure. Under the structure, the capital budget revenue is comprised of revenues with limited source that are imposed on one specific object such as immovable property tax, vehicle tax, stamp duty, land payments, rent for utilization of water, forest and minerals. This reflects the requisite to take actions towards identifying additional sources of revenues and expanding the tax base.

3.22 As a result of the measures aimed to maintain macroeconomic stabilization the macro fiscal indicators for 2001-2002 have improved substantially. The following Table describes the financing gap filling for the period of 1997-2003. 
Table 3:1: The 'Financing Gap' as a Percentage of GDP

\begin{tabular}{|l|c|c|c|c|c|c|c|}
\hline & $\mathbf{1 9 9 7}$ & $\mathbf{1 9 9 8}$ & $\mathbf{1 9 9 9}$ & $\mathbf{2 0 0 0}$ & $\mathbf{2 0 0 1}$ & $\mathbf{2 0 0 2}$ & $\begin{array}{c}\mathbf{2 0 0 3} \\
\text { budget }\end{array}$ \\
\hline Total budget deficit & $\mathbf{- 9 . 1}$ & $\mathbf{- 1 4 . 3}$ & $\mathbf{- 1 1 . 9}$ & $\mathbf{- 7 . 5}$ & $\mathbf{- 4 . 5}$ & $\mathbf{- 6 . 0}$ & $\mathbf{- 6 . 2}$ \\
\hline & & & & & & & \\
Budget deficit financing & 9.1 & 14.3 & 11.9 & 7.5 & 4.5 & 6.0 & 6.2 \\
\hline Foreign resources (net) & 10.5 & 8.9 & 10.1 & 6.4 & 6.4 & 6.7 & 7.3 \\
\hline - Project loans & 8.3 & 9.5 & 9.4 & 6.0 & 6.1 & 6.6 & 6.7 \\
\hline - Program loans & 4.5 & 0.9 & 1.8 & 1.3 & 2.1 & 1.3 & 2.1 \\
\hline - Amortization & -2.2 & -1.5 & -1.1 & -0.9 & -1.7 & -1.2 & -1.5 \\
\hline Domestic resources (net) & -1.5 & 5.4 & 1.8 & 1.2 & -1.9 & -0.7 & -1.1 \\
\hline - privatization receipts & 0.0 & 0.0 & 0.0 & 0.7 & 0.5 & 1.4 & 1.1 \\
\hline - Monetizing Govt. Rest. Bonds & 0.0 & 0.0 & 0.0 & 0.2 & -1.3 & -1.1 & -0.8 \\
\hline - IMF (net) & 0.0 & 0.0 & 0.4 & 0.7 & 0.5 & -0.2 & 0.6 \\
\hline - banking system & -1.5 & 5.4 & 1.3 & -0.5 & -1.5 & -0.8 & -2.0 \\
\hline - non banking system & 0.0 & 0.0 & 0.0 & 0.0 & -0.2 & 0.0 & 0.0 \\
\hline *Plan & & & & & & &
\end{tabular}

3.23 As indicated in the Table 20, the fiscal deficit for 1997-1999 was primarily financed from the external resources, namely financial loans. Domestic resources, such as loans the banking sector, especially from Mongol bank were also utilized. Due to over reliance on the domestic sources for financing the fiscal deficit, the "crowding out effect" took place. However, the Government's initiative to reduce the government credit from the banking sector and to finance the monthly and quarterly deficit through issuing short-term bonds have successfully implemented in 200-2002. The fiscal deficit for 2002 was financed, basically from the external project loans, extended to the Government of Mongolia on a concessional basis.

3.24 Based on EGSPRS and preliminary consultations with IMF, key indicators of the budget in its mid-term projection for 2004-2006 are projected to be on the following levels provided Mongolia's GDP growth reaches 5.3 percent in 2004 and 5.5 percent in 2005-2006: 
Table 3:2. Fiscal Projections Outline as a percentage of GDP (Base Case)

\begin{tabular}{|c|c|c|c|c|c|c|}
\hline & 2002 & 2003* & $2003 * *$ & $2004 * * *$ & $2005 * * *$ & $2006 * * *$ \\
\hline Total revenue and grants & 38.8 & 36.3 & 37.0 & 37.4 & 36.3 & 36.3 \\
\hline Tax revenue & 29.2 & 27.4 & 28.7 & 29.4 & 28.4 & 28.5 \\
\hline Non-tax revenue & 9.0 & 8.3 & 7.7 & 7.5 & 7.4 & 7.3 \\
\hline Grants & 0.6 & 0.6 & 0.6 & 0.5 & 0.5 & 0.5 \\
\hline Total expenditure and net lending & 44.8 & 42.6 & 43.0 & 43.3 & 41.8 & 40.8 \\
\hline Current expenditure & 33.8 & 31.9 & 31.9 & 31.8 & 31.0 & 30.4 \\
\hline Goods and services & 23.2 & 21.3 & 21.1 & 21.5 & 21.1 & 20.9 \\
\hline Wages and salaries & 8.5 & 8.6 & 8.5 & 8.5 & 8.4 & 8.3 \\
\hline Purchase of G\&S & 14.7 & 12.7 & 12.7 & 13.0 & 12.7 & 12.6 \\
\hline Interest payment & 1.6 & 1.5 & 1.4 & 1.3 & 1.2 & 1.1 \\
\hline Subsidies and transfers & 8.9 & 9.2 & 9.3 & 9.0 & 8.8 & 8.4 \\
\hline Capital expenditure & 5.5 & 4.8 & 4.8 & 5.1 & 4.9 & 5.3 \\
\hline Net lending & 5.5 & 5.9 & 6.3 & 6.3 & 5.9 & 5.1 \\
\hline Current budget surplus (+) & 4.4 & 3.8 & 4.5 & 5.0 & 4.7 & 5.4 \\
\hline Overall budget deficit (-) & -6.0 & -6.2 & -6.0 & -5.9 & -5.5 & -4.5 \\
\hline
\end{tabular}

** Expected Outturn

$* * * \mathrm{MTBF}$

3.25 In the mid-term, total budget expenditures and net lending to GDP ratio will be reduced steadily. For instance, by 2002 total expenditures constituted 44.8 per cent of GDP, which is targeted to drop to 43.3 per cent in 2004, and 41.8 in 2005 . This will be attained through the following measures by the Government:

- Restructure some self-sufficient units of education, health and culture sectors into selffinanced institutions, transform them into state owned entities, or contract out some services, and privatize;

- Carry out the civil service structural reform in phases, downsize the Government expenditures;

- Reduce subsidies to state-owned entities;

- Optimize the ODA utilization, in particular improve targeting an efficiency of loans extended from donor countries and international financial institutions, as one of key factors of economic growth through amendment the existing legislation on foreign investment and loans, and maintain debt level of Mongolia at manageable ratios.

3.26 The surplus of the current budget was 4.4 percent in 2002, and this will be kept above 4.7-5.4 percent in 2004-2006 for potential funding of domestic investment. The overall budget deficit will not exceed 5.9 percent of GDP in 2004 and 5.5-4.5 percent in 2005-2006.

3.27 Resource allocation. The credible public sector policy flow from a consensus of policy priorities with budget and official development assistance allocation. Therefore the Government Action Plan considers being a primary policy document which identifies the main directions of policy for the medium which were transferred into the sectoral strategies, projects and programs. The current fiscal reform aims to strengthen the linkage between policy-making with budget allocation, in particular with focus on pro-poor measures. 
Table 3:3: Budget Allocations to the Social Sector

\begin{tabular}{|lcccccc|}
\hline & $\mathbf{1 9 9 7}$ & $\mathbf{1 9 9 8}$ & $\mathbf{1 9 9 9}$ & $\mathbf{2 0 0 0}$ & $\mathbf{2 0 0 1}$ & $\mathbf{2 0 0 2}$ \\
\hline 1. Expenditure ratio to GDP & & & & & & \\
Education & 5.6 & 7.1 & 7.0 & 8.1 & 9.0 & 8.5 \\
Health & 3.4 & 4.0 & 3.9 & 4.5 & 5.3 & 4.4 \\
Social welfare & 5.1 & 6.3 & 6.5 & 7.5 & 7.7 & 7.7 \\
\hline 2. Expenditure ratio to total budget & expenditure & & & & \\
Education & 16.2 & 17.1 & 17.8 & 19.1 & 20.6 & 19.8 \\
Health & 9.9 & 9.6 & 9.8 & 10.7 & 12.2 & 10.3 \\
Social welfare & 14.9 & 15.1 & 16.4 & 17.7 & 17.7 & 17.9 \\
\hline
\end{tabular}

3.28 Since 2000 the Government has focused its attention on the education sector, thus providing to one child of poor and herder families with free university education and dormitory fees, improving the educational environment, the budget allocation for this sector has been increased during last three years. The education and health sector financing is planned based on the expenditure norms per student or service person, and the financing of schools with many students is done sufficiently. These norms have been in force since 1998 and depending on the price changes, they have being increased annually. Despite, there are some cases when the allocated normative expenditure is not sufficient and lack of in remote schools with a small number of students and in soums hospitals with a small population. It is a common situation when children of wealthy families with a large number of livestock go to study in province and capital schools, whereas, the children of poor families stay to study at soum schools. Therefore, the expenditure allocation must taken into account and be advanced, while children from poor families will be given an opportunity to study and health services for poor improved. In the medium term, the share of education and health sector to GDP will be increased gradually as result of comprehensive public sector reforms. This will be an opportunity for poor and midlevel people to raise their income resources, thus building a basis for poverty reduction. Although, there is a need to increase the pension rates, the government will not grant any pension increase for short-term, but in 2004 the government will expand options to rationalize public expenditures and increase pension's level not more than the inflation rate. In addition the government will continue pursue policy of insurance, in particular pension reforms in terms of coverage and level in accordance to the employment expansion. The measures to secure individual pension account funding will implemented. In the medium term the policy will be reoriented more towards pro-poor directions. Therefore, in the medium term the ratio of education, health and social welfare expenditures to GDP will be increased slightly with clear shift of resource allocation in line with policy priorities.

3.29 Despite that financial capacity of UB city has being strengthened there are still constraints to finance the renovation and modernization of engineering facilities and premises of public transportation, urban service, lighting, education, health and social order protection institutions the facilities of the city have become obsolete accumulating many pressing problems related to economic, social and urbanization issues.

3.30 The health sector financial sustainability depends not only on rational allocation of budget resources, but on efficiency of the Health Insurance Fund functioning, because majority of its financing are premiums paid by the government for the vulnerable groups, including low income people, invalids, children and elderly. However pro-poor allocation resources under the 
Health Insurance Scheme are an essential element of financing reforms in the health sector. So for the medium term the challenge is to use resource more efficiently without undermining the quality of service delivery and target spending more towards poor.

3.31 Cash transfer programs under the Mongolian social protection system are one of the old structured payments in terms their administrating and targeting. Currently 18 percent of public expenditures transferred to population as pensions and benefits. However, despite this high ratio the amount per capita is very small due to poor targeting. The average pension is around US\$ 22 per person, which can afford the minimum living standard only, while the average benefit is even much lower with wide coverage. So for the medium term the policy priority will be centered on pension reforms and cash transfer system restructuring based on household support type.

3.32 In addition to pro-poor programs income gradation system was expanded: people with an income less that 36000 tugriks were not imposed by tax and this level was extended up to 48000 tugriks in order to increase the income of the population and people with low income. Moreover, it is decided not to impose a tax on bond share benefit, apportionment income and savings interest rate income from 1st January 2005.

3.33 The fiscal sustainability and transparency are major requisite for reaching objectives announced from the Government such as ensuring macroeconomic stabilization, facilitating economic growth and reducing poverty. An objective has been put to keep the budget deficit at 6 percent and less. In the medium term, the fiscal and tax policies shall be directed to macroeconomic stabilization, including financial sustainability, establishment of a favorable environment for developing private sector, improvement of fiscal balance, expansion of access to and improvement in the quality of social services, increased pro-poor orientation of public expenditures. With the purpose to establish an efficient budget expenditure system, the Government is working in cooperation with $\mathrm{WB}$ and $\mathrm{ADB}$ on formulating a comprehensive plan for public sector reform, which information is based on WB public expenditure management review. An intensive implementation of the medium term budget reforms will enable improvement of budget planning, raising efficiency of fiscal expenditure and, consequently, releasing public resources for low-income people.

3.34 Improvement in the access and quality of public services, and ensuring fiscal sustainability in the are the main expected outcomes of the public sector reforms which are underway. The public sector reform will comprise of 6 components, namely, treasury management, budgeting, accounting and reporting, output based management and auditing. The legislative basis for the reform is the Public Sector Finance and Management Law, the Law on the Consolidated Budget and other legislative acts and programs issued in conformity with the above. Implementation of these laws and programs will enable improvement of budget planning, raising efficiency of fiscal expenditures, consequently releasing public resources for low-income people and enabling implementation of pro-poor policies. The support of international organizations, donors is important to implement the above laws and regulations, and reforms.

3.35 Fiscal reforms. The Fiscal reforms were not fully undertaken during 1996-1999. Several important measures were undertaken during 2000-2003. First of all, in order to ensure the transparency and reporting of fiscal expenditure financing, the Treasury Single Account 
system was introduced to budget entities. "Zero balance" accounting system was piloted in 10 state organizations. In area of reporting the monthly reports are produced in accordance to GFS methodology. The preparation for the procurement of the comprehensive program GFMIS is underway. The Government is drafting a comprehensive program to implement the public sector reforms, including civil service reforms. From 1 January 2003, the line ministries have started to use outcome-based agreement on experimental basis.

3.36 The primary objective of the fiscal reforms is to reduce unproductive current expenditure based on improving budget formulation, monitoring and execution, undertaking credible civil service reforms, improving service delivery with a pro-poor orientation, and enhancing transparency and accountability. To improve transparency and accountability, contracts for public works, such as road building and major infrastructures, will avoid exchangebased financing arrangements such as the granting of mineral extraction rights in return for construction work.

3.37 The tax reforms aimed to utilise the tax as a powerful mechanizm for economic growth support, optimizing demand and supply side of the economy, rather than revenue accummulation tool. The tax reforms implementation is focused on expansion of tax base, reduction of various tax exemptions and holidays and creation a fair environment for the tax payers.

3.38 Within the framework of the Regional development concept the intergovernmental relations will be optimized to reduce rural and urban development disparities and support income generation and service delivery for rural residents. In this regard the local government accountability and civil socity participation will be enhanced.

3.39 The new fiscal system based on PSMFL creates incentives for budget managers to be involved in the whole budget cycle, including formulation, execution, monitoring, reporting. Moreover, the process improves link between budget and sectoral policy priorities with focus on pro-poor orientation.

3.40 Reforms in reporting system are implemented through introduction of GFS methodology and procurement of GIFMS.

3.41 Medium Term Budget Framework is powerful tool to enhance fiscal governance to manage poverty reduction efforts in the country. It becomes a center for the public finance management. Medium Term Budget Framework (MTBF) - an efficient mechanizm to link policy priorities with financial resources allocation and accountability. The institutionalisation and development of adequate MTFE is long term process which requires capacities and commitments from all budget executors. The PSMFL is a legal background for its development, adoption and implementation.

3.42 As the priority measures the Government has initiated a formulation and approval of the Medium-term Fiscal Statement (MTFS), which is an essential part of the MTEF. During last 2 years the Political Steering Committee as an governing body for MTFS approval, which now legalised as the Parliament. Development of accurate forward estimates is another component 
of MTEF, which requires capacity building among policy makers. Another area of concern is building of capacity to manage an efficient allocation of resources in line with policy priorities.

3.43 Fiscal expenditure management Within the framework of fiscal reforms, the fiscal expenditure management, which was within the responsibility of the Ministry of Finance and Economy, within the city and province Governor's office, has been transferred to sector management and commenced its activities since 2003. The fiscal expenditure management reform has been restructured in such a way that ministers of branch ministries have become the General budget managers and have the right to formulate and utilize the budget, thereinafter, to establish an output based contract and to finance delivered products and services. From February 2003 the finance and economic units were established within major ministries incorporating with budget planning and financing through sector ministries. In the medium term, according to the Public Management and Finance Law, the Ministry of Finance and Economy and General budget managers will have the right to monitor financial and non-financial operations of budget organizations and evaluate their performance. Action will be undertaken to build and strengthen the capacity of General budget manager and their working units during 2003-2005.

3.44 As part of the public sector reform, in the medium term the Government will improve the management and efficiency of public expenditures, based on output based evaluation. Within the framework of these actions, the Government will work to strengthen public expenditure management by undertaking civil service reform, commercialisation of the some social services, reforms in the social insurance and pension systems and further detailing the financing standards. In order to maintain the achieved level of financial sustainability the government and monetary authorities will rule out any quasi fiscal activities and granting an increase of civil servants wages unless the crediable civil service reforms with comprehensive human resource management data base will be introduced. In addition evaluation criteria and feasibility analysis for foreign and domestically financed projects will be enhanced.

3.45 The Ministry of Finance and Economy and General budget managers (Other ministries and heads of local governments) are required to produce detailed plans, prepare a set of manuals with specific rules, regulations and implementation guidelines for the implementation. The key priority is strengthening of the capacity of all relevant civil servants regarding PSMFL implementation, output delivery contracts for each ministry and organization, its monitoring, analysis and evaluation.

3.46 Sequencing of reforms process: Implementation of the Public Finance and Management Law and the public sector reform will be carried out in three phases:

- Preparatory phase

- The first phase: Introducing output-based management system

- The second phase: Transfer of authority.

3.47 An appropriate determining of actions of reform process in the public sector reform and their sequencing is essential element of improving of public expenditure management, making the civil service more compact and more capable, and improving the access to and the quality of the public service. 
3.48 In the first stage of budget and financial reform, the medium term budget statement will be formulated in 2003. It is planned to draft a full fiscal reform strategy from 2004. Within the framenwork of above two actions, public service reform program will be drafted. Moreover, depending on the capacity of business entities in education, culture, health and social welfare sectors to restructure social sector, intensification of reforms and financial independence, these entities will be commercialized.

3.49 The Government will define detailed asset and financial calculations as well as local and foreign resources required for public sector reform strategy. In connection with the implementation of public sector reform, the transfer of authority will be implemented in the next stage.

3.50 Government procurement. One of major changes occurred in the Government's scope of duties was the purchase of goods and services needed by the public sector from the open market under contracts with the private sector.

3.51 With the transformation of Mongolia into market economy in 1990, an urgent need to build a public sector procurement system consistent with the market economy was on the table. Issues of efficient, economy-wise and transparent spending of tax payers or public funds, mutual reporting on spending, and improving liability principles covered all areas of social life facing requests and requirements from the community.

3.52 In order to regulate this issue, a procedure was adopted by a joint resolution of Finance and Infrastructure Ministers in 1996. However, the procedure was used only in selection of construction work contractors plus it could not become a common procedure for all line ministries - adopted only by Ministers of Finance and Infrastructure. Government organizations were making their procurements from a limited range of vendors which was in breach of the principle of efficient, economy-wise and transparent spending of public funds.

3.53 The Government of Mongolia in cooperation with ADB started a reform of Government procurement in 1999 with a purpose of establishing a system that provides saving, efficiency and fairness in state and local funds spending and ensuring the fair and transparent operation of the Government.

3.54 In order to build up a foundation of this brand new system, introduction of which is being started nation-wide, three key goals are being implemented in phases at first hand. Firstly, establishment of a legal framework for regulation of government procurement consistent with the market economy. Secondly, build up the capacity of government organizations to do procurement. Thirdly, establishment and enhancement of the management, monitoring and regulation structure.

3.55 A law on selecting contractors of goods and service to be procured by state and local budget funds was adopted in April of 2000 by the Parliament and entered into force in May of 2000. Key law enforcement procedures such as the Special Procedure on Selecting contractors, Special Procedure on Selecting Consultants, Ethical Norms of civil servants involved in procurement were adopted by Government Decree No. 1001 in June of 2000. In 2001-2003 6 more procedures have been adopted. In addition the Minister of Finance and Economics has 
approved 15 procedures, instructions and standards. These procedures are inevitably necessary in enforcement of the law.

3.56 Thereby, a legal framework for public sector procurement consistent with international standards was established in Mongolia backing up the principles of efficiency, economy, transparency and fairness in spending of budget funds. Methodological, technical, management and organizational issues of efficient organization of tender selections was defined on a professional level.

3.57 The law on management and financing of budget institutions adopted with the purpose of facilitating the budget reform and changing the budget expenditure into an efficient form stipulates that government procurement shall be carried out under selection, which reconfirmed the importance of the law.

3.58 Although the legal environment was provided the Government did not have personal capacity - trained and experienced in government procurement and to enforce the operational laws and procedures - in place like other countries transiting from the socialist economy to a market one. This has resulted in misunderstanding, mal-enforcement or non-enforcement, inability to apply the laws, miss-selection of contractors, thereby increasing the government cost, prolonging the government project implementation, disgracing of the government reputation among the public, and violation of the laws due to intentional actions or lack of knowledge and skills.

3.59 In order to enhance the capacity of civil servants, the Government adopted a mid-term training program for government procurement in September of 2001. Under this program, elementary and intermediate level training was conducted in 2001-2002 for relevant staff in all government organizations. The training in-depth covered technical issues such as new procurement structure, basic info on the legislation, procurement methods and techniques, preparation of tender documentation, organization and assessment of tenders, granting the authority to make contracts. Under the program, higher level training will be conducted in 2003.

3.60 The Ministry of Finance and Economy is taking measures to improve the technical and personnel capacity of subscribers, attaching more importance to developing a transparent and efficient information database. The database is directed towards implementing projects of subscribers, especially upgrading the organization and monitoring of procurement, data processing, and autoimmunization of and making exchange systems more reliable. Within this task, the following software has been developed in collaboration with ADB project.

1. Launched a website of government procurement

2. Developed a registry software of suppliers and contractors

3. Developed a monitoring system for procurement, initial version of project management database software.

3.61 The Government is giving a great importance to building an optimal management, regulation and monitoring structure consistent with the new system. The Procurement Policy and Regulation Division is set up under the Ministry of Finance and Economy by government decree 
No. 75 of 2001, with main duties to develop procurement policies, provide professional and methodological management to contractors, ensure and monitor the law enforcement.

3.62 The division is a qualified unit in charge of policy and regulation matters of government procurement and should assist in meeting objectives and provide necessary policy recommendations to the Minister of Finance and Economy with regard to issues assigned to him under the government procurement law.

3.63 One of duties of the division is a resolution of complaints regarding contractor selection on the prior-to-court level. However, the fact that the department is under the law enforcement structure poses a conflict in performing the above duty. Thus with the purpose of enhancing the monitoring of law enforcement and strengthening the status of the division it was moved to direct supervision of the Minister to be in charge of procurement policy development by a Finance and Economy Minister resolution from October 1, 2002.

3.64 In the future, there is a need to enhance the organizational structure, status, functions and personnel of the unit. As a result of the above mentioned measures, most organizations in all government levels are implementing the law. According to a survey of MOFE, government organization have organized 1,371 tenders and procured MNT 328.7 billion worth of goods and services in last 2 years.

Table 3:4: Performance Indicators

\begin{tabular}{|l|l|l|l|l|}
\hline \multicolumn{1}{|c|}{ Year } & \multicolumn{1}{|c|}{ No. of Tenders } & \multicolumn{1}{|c|}{$\begin{array}{c}\text { Total budgeted } \\
\text { cost (MNT Bn) }\end{array}$} & $\begin{array}{c}\text { Contract value } \\
\text { (MNT Bn) }\end{array}$ & \multicolumn{1}{c|}{$\begin{array}{c}\text { Difference } \\
\text { (surplus) } \\
\text { (MNT Bn) }\end{array}$} \\
\hline 2001 & 620 & 150.3 & 144.7 & 5.5 \\
\hline 2002 & 751 & 178.4 & 162.8 & 8.3 \\
\hline Total & 1,371 & 328.7 & 307.5 & 13.8 \\
\hline
\end{tabular}

3.65 The above table shows that government organization saved a total of MNT 13.8 billion in their procurement. Subscribers have gotten accustomed to procure construction and road works, building renovation and rehabilitation, equipment, medicine, and uniforms through tender selection. Tenders by sectors were as follows: 
Table 3:5: Procurement Values

\begin{tabular}{|l|l|l|l|l|l|}
\hline & Sector & $\begin{array}{l}2001 \\
(\text { MNT Bn) }\end{array}$ & $\begin{array}{l}2002 \\
(\text { MNT Bn })\end{array}$ & $\begin{array}{l}\text { Total } \\
\text { (MNT Bn) }\end{array}$ & Percentage \\
\hline 1 & Environment & 1.2 & 1.6 & 1.8 & 0.6 \\
\hline 2 & Defense & 2.7 & 2.7 & 5.4 & 1.6 \\
\hline 3 & Education, culture, science & 4.0 & 8.4 & 12.4 & 3.8 \\
\hline 4 & Foreign affairs & 1.5 & 0.4 & 1.9 & 0.6 \\
\hline 5 & Infrastructure & 96.6 & 118.5 & 215.1 & 65.4 \\
\hline 6 & Social welfare & 0.2 & 0.5 & 0.7 & 0.2 \\
\hline 7 & Finance and economic activities & 7.1 & 3.0 & 10.1 & 3.1 \\
\hline 8 & Production and trade & 1.4 & 2.0 & 3.4 & 1.1 \\
\hline 9 & Justice and internal affairs & 10.7 & 8.2 & 18.8 & 5.7 \\
\hline 10 & Food and agriculture & 1.3 & 4.6 & 5.9 & 1.8 \\
\hline 11 & Health & 0.8 & 2.8 & 3.6 & 1.1 \\
\hline 12 & Fully and partially state-owned & 13.6 & 12.8 & 26.4 & 8.0 \\
\hline 13 & Aimags and countryside & 8.7 & 12.6 & 21.3 & 6.5 \\
\hline 14 & Other & 1.6 & 0.4 & 2.0 & 0.6 \\
\hline & Total & 150.3 & 178.4 & 328.7 & 100 \\
\hline
\end{tabular}

3.66 Although it has been 3 years since the law adoption, its enforcement does not meet the requirement. In the enforcement of the law, it is difficult to fully enforce it in some sectors and organizations, and there is a need to update the law. On the other hand, the procurement legislation is good as it is consistent with international standards and covers key procurement principles; however, its weakness is management, organization, monitoring and liability structure of procurement is not provided clearly. These weaknesses pose problems in the successful implementation and monitoring of the law.

3.67 The fact that the enforcement of the law could not reach the desirable level is on one hand related to knowledge and skills of government staff and organization of procurement, but on the other hand there are some problems and difficulties encountered in the enforcement as well as the above-mentioned weaknesses of the law.

3.68 Thus the following measures have to be taken in order to improve procurement system and make procurement activities efficient and transparent:

- Enhance the legal environment of procurement;

- Amend the law and make it simple. The existing law stipulates the rate and ceiling price for procurement which lessens the law's flexibility;

- In-depth indicate the management, organizational structure, monitoring and liability implications;

- Update procedures and regulations that should accompany the law. Ensure the law's flexibility with amendments to procedures and regulations;

- Clearly define the tender committee, its composition, structure, operating principles, and liability. 
3.69 In order to ensure the law enforcement and upgrading the monitoring mechanism, upgrade the status of the procurement policy department in charge of procurement policies and regulation with main duty to monitor the law enforcement and transform into an independent professional office.

- Intensify actions to improve the capacity of staff in government organizations.

- Regular training for procurement staff, abroad training to strengthen their knowledge and skills.

- Include a discipline of Government Procurement in the curriculum of state officer's retraining and universities.

3.70 In 2001-2002 the Government of Mongolia has procured MNT 90 billion worth of goods and services through tenders using loans and aids from donor countries and international organizations. The lack of knowledge of procurement procedures of respective donors of Government staff conducting procurement with donor funds is resulting to prolonged procurement time and delay of project implementation. Furthermore because donor countries and international institutions have own procurement procedures government procurement staff lose time to learn these procedures posing difficulties in efficient and timely running of procurement activities. The main reason why Mongolia is in the lowest place in Asia Pacific in terms of donor funds utilization level and the implementation of projects is extended for a longer time is that procurement is not done according to the plan. Thus in order to solve this problem government staff should be taught the procedure of donors and procurement procedures have to be unified to ensure the timely implementation of projects.

\section{Treasury Management}

3.71 The Mongolian Government Action Plan states that "the system of cash management of the Treasury will be improved". Prior to 2000 the Treasury unit was operated at the ministry of Finance, however the different ministries and commercial banks administrated treasury main functions.

3.72 Due to inadequate quality of budget performance reports or failure to meet the reporting deadlines, the requirements set at decision-making were not met. In addition the functions of the budget formulation and execution were administrated by the Fiscal Department of the MOFE, which undermined accountability and transparency of fiscal activities.

3.73 Financial transactions of public (budgetary) organizations at the central and local levels were made through accounts opened at different banks lead to the poor monitoring and reporting, which lack coordination of payments resulting in accumulating of external and internal arrears and dependency on banking system.

3.74 Due to poor reporting system including a multiple accounts for public entity in various banks, poor technical capacity of MOF and other budgetary bodies the annual budget reporting was delayed, in some cases the annual reports were consolidated in September-October with subsequent discussion at the Parliament in November. The delayed reports were useless for utilization in policymaking process. 
3.75 The public entities have had a multiple number accounts at various banks without any permission or monitoring by the MOFE.

3.76 The account census of 2001 showed that out of total 5475 organizations, 1192 organizations hold more than one account, and this accounted for 21 percent of the total number of organizations. Public entities with more than 5 accounts comprise 11.6 percent or 139 organizations.

3.77 A tendency to overspend the budgeted funds for unplanned measures by budgetary organizations seems to become a customary and conventional practice. For instance, as 2001 budget performance indicated, the expenditure for purchase of furniture and the like exceeded the planned amount by 4 times, and twice as much as planned was spent for repair activities.

3.78 The PRGF program concluded between the government of Mongolia and the IMF puts greater emphasis on establishing a treasury system, which aims to introduce centralized payment system based on the Single Treasury Account (TSA) principles.

3.79 Based on IMF recommendations the system was introduced on phased manner with pilot period at 11 entities. The legal background was the cabinet decision Number 132 of 2001. The piloting indicated that "zero balance" account system is contradicted with Mongol bank regulation on "Interbank clearing procedure". Therefore the centralized ledger system was introduced as a base for the TSA in Mongolia. The main aim of the system is establishment of an efficient treasury system with the core principle of unified, centralized payment and settlement relying upon the system of STA. It means that public funds are secured from various risks and prevent the unplanned expenditures.

3.80 Within framework of the fiscal reforms and government cash management the Integrated treasury system and structure has been established nationwide as of July 1, 2002. The treasury system structure encompasses the Department of Treasury Management and Coordination at MOFE, treasury departments at the municipality, aimag and district governments and treasury representatives in soums. The structure covers 331 soums of 21 aimags and 9 districts of the city municipality with total number of 2660 public entities. The TSA came into effect by closing the numerous accounts of budgetary organizations at commercial banks and opening under their respective names a current account to counteract with the Government's central budget.

3.81 Under the government decree of Mongolia Treasury department was established and is carrying out its activities in UB and districts effective from July 1, 2002. With the transition to the centralized treasury accounts system, a possibility to utilize the idling balance in budget accounts was provided enhancing the accounting control. This has produced relevant results in upgrading the bookkeeping quality of municipal finance, ensuring the enforcement of the law on budget and other legislation, reducing inefficient cost by enhancing the budget discipline, elimination of room for emergence of new arrears and debts, halting the financing of unplanned expenditures, and eliminating over-spending of the budget.

3.82 The new system shall see to preventing excessive concentration at the MOFE the power of decision-making on fund/financial allocations and shall strictly abide by rights and 
powers granted by legislation. A treasury department shall be established in the structure of local state administrative organizations, and the local governments shall preserve their powers granted by budget law to approve, dispose, discuss the performance of and make decisions on its budget.

3.83 Since November 1, 2002, "Oracle" payment and settlement system has been installed at treasury departments and offices of 21 aimags, which are connected to the central treasury on a Dial-up regime.

3.84 The main progress of transferring to the TSA can be summarized as following:

- A direct control of whether the tax revenues to the state central and local budgets are spent within the framework of the budget law has become possible. This creates possibilities to eradicate non-planned expenditures, budget overspending and abuse of budget funds.

- Conditions have been created for improving fiscal/budget planning. The need for budgetary organizations to realistically assess needs and correctly determine their income and revenues has emerged. In other words, we now have clearer understanding about the mistakes and errors made in the process of budget planning.

- Conditions have been created for timely, prompt and accurate issuance of budget performance reports and data. Basically, it becomes possible to process and release monthly budget performance report for budgetary organizations directly at the treasury.

- Fiscal cash planning and management have dramatically improved. The account balances of central budget organizations are now being used for ensuring the implementation of the budget.

3.85 The full TSA creates an opportunity to full computerization of fiscal operations. So local authority have expressed concerns not to increase the number of staff, but their capacity to deal with book-keeping and reporting using computer software.

The following measures desired to enhance TSA transferring for the medium term:

\section{Extending all government accounts to TSA in BOM will be completed}

- Social Security Funds

- Government agencies

- Special accounts for international loans and aids.

\section{Effective cash management system will be fully implemented}

- Improved planning

- Financial asset and liability management

- Budget allocation based on procurement of goods and services

\section{Budget control will be improved}

- Increased accountability of budget general governors for budget preparation and execution

- Significant step to improve financial reporting and internal control of budget entities 
- Improved commitment and expenditure control

\section{Accounting practices of budget entities will comply with international standards.}

- Reporting financial assets and liabilities

- Audited financial statements

- Revaluating real assets

- Cost accounting

\section{Treasury information system will be implemented}

- Extending information system to possible soums

- GFMIS to central and local Treasury offices

- International remittance will be implemented by the first quarter of 2003

- Treasury divisions in soums with reliable power resources will be connected with aimag Treasury divisions from April, 2003.

- Budget entities will be connected with Treasury offices to make banking and payment transactions

- Prior tasks to implement online payment processing system will be completed

- Possibility of cash transactions in local level will be studied as to prepare proposal.

- Payroll system should be changed to introduce

3.86 These arrangements will be implemented to strengthen TSA as to improve transparency of budget expenditure and reporting. Thus, reporting of money spent of poverty will be transparent and resources will increase.

3.87 The above mentioned objectives will be fully adopted by the UB city municipality, in particular the whole budgeting process starting from budget planning and up to review, adoption, funding disbursements, spending and reporting will be inter-related through the single treasury management system. In addition, manual operations will be reduced and public participation in the budget execution and enforcement of financial legislation will be expanded, leading to transparent monitoring and implementation process.

\section{Balance of Payments}

3.88 Trade balance. Our trade balance was positive only in 1997, but in all the other financial years it was negative. Until 2001, the trade balance was calculated with 10 percent adjustments on import value. However, this adjustment factor was reduced to 5 percent for 2002 data, and it will be eliminated from 2003 to reflect the ongoing improvement in the coverage of import data by customs.

3.89 The percentage of exported goods and services to GDP was the highest in 1993 and equaled 93.1 percent, whereas, the import equaled 96 percent. In consequent years this percentage was steadily falling reaching its lowest level in 1995 when the export was 43.7 percent and the import reached 44.8 percent. Further trend shows that the both import and export has increased, however, the import has risen at faster pace than the export. Preliminary estimates indicate that the export and import equaled 63.9 percent and 85.4 percent of GDP accordingly in year of 2002 . 
3.90 The percentage of trade deficit on our goods and services to GDP has been increasing significantly in recent years and it has reached its highest level of -20.6 percent in the preliminary estimates of the year of 2002. In 1997 the percentage was 2.6 percent and positively contributed to GDP. The positive international economic environment and the high revenues from our main exported goods such as copper $/ \$ 211.4$ million USD/ and gold $/ \$ 117.0$ million $\mathrm{USD} /$ are the direct contributors to higher GDP. However, in the recent years the export of our traditionally exported products has reduced and the international market prices as well as the demand for our main exported goods, which make up the most of our export, has decreased causing lower export revenues. In addition, by becoming a member of World Trade Organization, we adopted the policy of trade liberalization, which also encourages foreign investments to increase productions and to develop domestic infrastructure. This policy has increased the level of import further increasing the trade deficit.

3.91 In 1993 the service turnover was 55.5 million USD and increased to 107.5 million USD in 1997 and to $\$ 378.4$ million USD by the preliminary estimates of 2002, 3.6 times more than 1997. Liberalization of the economy, increase of tourism, development of communication sector, insurance, financial services as well as passenger and air transportation sectors are the main factors of the increased service revenues.

3.92 The number of people studying abroad has increased. They usually work during their spare time fulfilling not only their needs but also their families at home by wiring funds to them from overseas. Improving their standard of living by working abroad has become common today and number of personal money transfer has increased. The financial institutions such as banks were quick to offer new services for these new customers. As a result, the statistical and financial reporting of such institution has become more accurate and comprehensive. In the year of 2002, the total of 64.4 million USD was wired from overseas which was a very positive contributor to the increased standard of living from previous years, especially from the years from 1993 through 1995 when personal money transfers were almost nonexistent and, in some occasions, were even negative. In the near future, it is estimated that the volume of official transfers from overseas will be stable, over $\$ 70$ million USD a year.

3.93 These money transfers are recovering certain percentage of our cash flow deficit. Official transfers of $\$ 47.7$ million USD, the lowest, was used 1997 and the aid of $\$ 107.4$ million USD, the highest, was used in 2001. In all the other years, this non-returnable aid was pretty much at same level and it did not change much. The volume of official transfers is projected to decrease in the mid-term future estimates.

3.94 Personal money transfers along with foreign aid and other official transfers are written as direct revenue. This practice is one sided and some economist argue that, in order to see the real value of foreign economic trade, these transfers need to be subtracted from current balance. In that case, the current balance comes out negative for the years from 1993 to 2002, except the year of 1997. For instance, it was -7.7 percent of GDP in 1993, 1.9 percent in 1997, 13.2 percent in 1999, and by preliminary estimates of the year 2002 this deficit equals -16.1 percent of GDP. In the mid-term future estimates the current balance deficit projected to be -11.5 percent of GDP in 2006. 
3.95 The current balance with official transfers included has been positive for years from 1993 to 1997, except the year of 1996, and became negative starting from 1998 to this date. For instance, the current balance was positive 6.2 percent in 1997 and by preliminary estimates of 2002 it is at the level which decreases GDP, -9.5 percent.

3.96 The negative balance caused by the increase of international trade deficit even though the official transfer has increased. With the trade deficit of expected to level off in the period ahead it is expected to narrow the current account deficit to 6-7 percent over the medium term.

3.97 Capital account. The Government is currently working on reduction of national debt burden, assuring on-time loan interest payment through cooperation and talks with major lender countries. The Government of Mongolia is paying specific attention on improvement of management of foreign aid and loans. Analysis of the performance for last 10 years indicates that the capital account was negative during 1994 to 1995 and it reached \$157.5 million USD in 2002. The capital account was $\$ 4.2$ million USD while direct foreign investments equaled $\$ 7.7$ million USD in 1993. If Mongolia utilized \$60.9 million USD of foreign loans, the due payment on the major debt came out $\$ 21.5$ million USD, the short-term capital equaled $-\$ 42.9$ million USD. Whereas, in 1994 capital account was negative and it amounted $-\$ 39.0$ million USD due to following factors. Namely, the due payment on the major debt was $\$ 52.3$ million USD, shortterm capital totaled $-\$ 52.8$ million USD causing a significant increase of payment balance. The capital account equaled $-\$ 16.9$ million USD in 1995. In addition, \$18.7 million US dollars were channeled in from foreign countries and organizations as long- and short-term trade loans to private and other entities. The direct investments increased to $\$ 9.8$ million USD. In 1996, the capital account was $\$ 41.3$ million USD and Mongolia's use of foreign debt increased to $\$ 84.2$ million USD and payment on major debt decreased from previous year to \$39.4 million USD. In 1997 , the capital account became $\$ 27.0$ million USD. The use of foreign debt reached its highest level, \$142.2 million USD. Also, the short-term capital reached its highest level, $-\$ 77.3$ million USD and it is bad indicator in the sense of being short-term. The capital account increased to $\$ 128.6$ million USD in 1998. Mongolia's use of foreign debt was \$101.2 million USD, the short and long-term debt to private and other entities from foreign countries and organizations reached \$21.2 million USD in 1998. Short-term capital reached \$4.5 million USD indicating some stabilization in 1998. In the period of 1999 through 2001 the capital account was gradually growing from $\$ 69.1$ to 109 million USD and reached its highest level, $\$ 157$ million USD, by 2002.

3.98 Mongolia has disbursed 87.1 million US dollars of concessional loan in the year of 2002, which was allocated as follows: 23.4 percent went to economic development of communication sector, 1.8 percent to manufacturing and construction, 15.8 percent to mining industry, 1.9 percent to agriculture, 16.1 percent to transportation, 7.3 percent to energy and 22.1 percent to improvement of other sectors. 10 million USD was disbursed to public service.

3.99 In the current year \$21.5 million USD was paid off for debt reduction, the most of which went to due payment to Russian Federation 19.5 percent, to Japan 13.9 percent Germany 5.1 percent. Our country's outstanding foreign debt balance totaled \$984.9 million USD in 2002. 
3.100 The most of the Government loans came from ADB 30.4 percent, The World Bank 16.5 percent, Korea 18.5 percent, Japan 16.0 percent accordingly and totaled to 84.1 percent of all used up loans.

3.101 Private and other entity's short and long-term loans from foreign countries and international organizations equaled to $\$ 98.2$ million USD.

Figure 3.2: Loan Disbursement

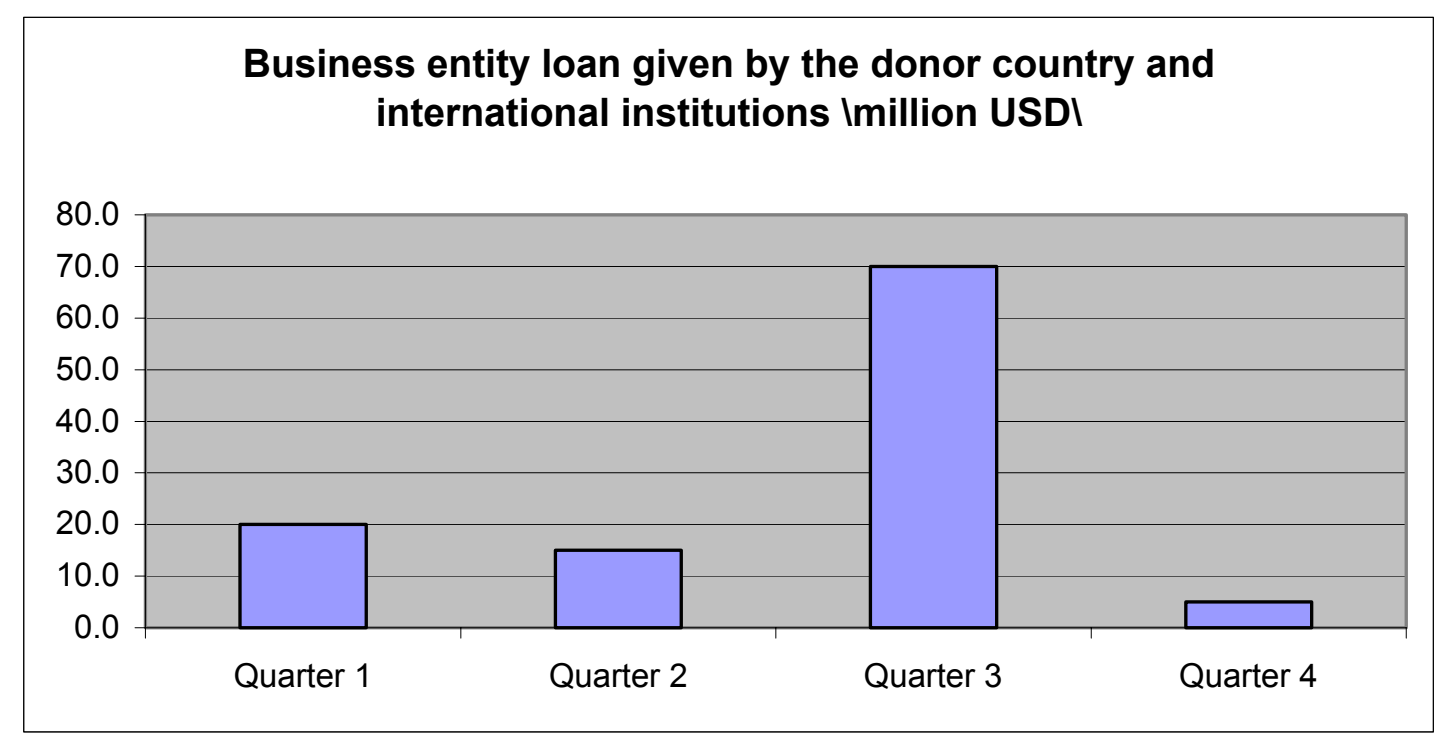

3.102 According to the reports issued by the Foreign Direct Investment Coordinating Agency, $\$ 172.5$ million US dollars were registered to be invested in Mongolia. The companies with Chinese participation \$134.8 million USD, with Korean participation \$14.9 million USD and with Canadian participation $\$ 5.9$ million USD accordingly has applied and been issued licenses approving the proposed capital investments. In the period from 1990 to 2002 there were 2399 joint- and independent companies newly registered, 387 of which registered in 2002 alone. Out of 387 newly registered companies 121 registered in trade and restaurant sector, 21 in tourism, 34 companies in construction sectors accordingly. 51.9 percent of all foreign investment is going to trade and construction businesses, another 23.1 percent to mining industry including exploration, research and mining itself. The volume of foreign investments has increased from 2001 due to government's policy encouraging foreign investments.

3.103 Overall balance. The performance data for last 10 years indicate that only in 1996, 2001 the payment balance were negative, in all other years the balance was positive. The payment balance is being calculated by the IMF's method utilizing the World Bank's directions. In the future, the capital account values will be maintained without sudden changes and, with decrease of current balance debt, the total balance will be positive.

3.104 The payment balance deficit is compensated from foreign currency reserve and loans provided by IMF. 
Table 3:6: Balance of Payments, million US\$, 1993-2002

\begin{tabular}{|l|l|l|l|l|l|l|l|l|}
\hline & $\mathbf{1 9 9 5}$ & $\mathbf{1 9 9 6}$ & $\mathbf{1 9 9 7}$ & $\mathbf{1 9 9 8}$ & $\mathbf{1 9 9 9}$ & $\mathbf{2 0 0 0}$ & $\mathbf{2 0 0 1}$ & $\mathbf{2 0 0 2}$ \\
\hline Trade balance & -22.0 & -87.4 & 30.2 & -120.1 & -113.1 & -140.1 & -169.9 & -228.8 \\
\hline $\begin{array}{l}\text { CAB including official } \\
\text { transfers }\end{array}$ & 38.9 & -36.9 & 68.0 & -75.5 & -57.8 & -69.9 & -61.7 & -105.0 \\
\hline Capital account & -16.9 & 41.3 & 27.0 & 128.6 & 69.1 & 89.8 & 109.9 & 157.5 \\
\hline Overall balance & 33.4 & -22.5 & 54.8 & 1.6 & 40.9 & 1.0 & -15.9 & 66.5 \\
\hline
\end{tabular}

3.105 Trade deficit projected to narrow gradually towards a level of 10 percent of GDP in the mid-term future. This projection is based on following assumptions such as stable growth of production, successful implementation of government policies and programs, expansion of economic and international cooperation, positive international economy and favorable foreign conditions. In order to increase export and to improve an infrastructure, the stable macroeconomics conditions need to be set. To set satisfactory domestic conditions it is essential to pay attention to the following:

- Setting a policy supporting export oriented, value added, knowledge and new technology based production

- Marketing exported goods, establishing market research, creating exported goods technology and information centers, improving research potential, involving private companies and supporting their inputs and initiations

- Improving credit management policy through enhancement of collaboration between Mongol bank (Central Bank) and other commercial banks

- Establishing favorable conditions for the external trade activities through enhancement of tax law enforcement, implementation programs oriented to explore new export markets

- Enhance enforcement of international standards to improve quality of products for the exports

3.106 To improve the management of capital payment balance account, more advanced debt management practice and better utilization of foreign aid will be initiated and implemented, especially the government and monetary authority will rule out any quasi-fiscal activities unless it has been stated in the medium term investment programs and other related policy documents. The accounting / reporting system will be improved in line with international standards. To better manage and regulate donors' activities, legal environment for foreign official development assistance will be established as well as determination of development and external financing priorities will be optimized in line with fiscal and debt sustainability. Mongolia's external sustainability is projected to be at the manageable if the debt and fiscal management practice will be improved in line with overall public sector reforms. In the medium term the foreign direct investments expected to increase. The country's long-term development trend defining regional development views, integrated energy system development program, "Millennium Road" projects are becoming the fundamental documents defining main development priorities. The various studies suggest that tourism, transportation, communication, banking, insurance, professional and business service sectors are main potential areas for foreign investments, so in the near future more attention will be paid in outlining new policies and regulations to attract investors in these sectors of economic growth. 
Table 3:7: Future Outlook, 2003-2006

\begin{tabular}{|l|l|l|l|l|}
\hline & 2003 & 2004 & 2005 & 2006 \\
\hline Trade balance & -215.5 & -198.9 & -195.7 & -210.2 \\
\hline CAB, including official transfers & -106.9 & -92.5 & -91.4 & -101.5 \\
\hline Capital account & 115.2 & 117.3 & 122.6 & 131.1 \\
\hline Overall balance & 8.2 & 25.0 & 31.4 & 29.3 \\
\hline
\end{tabular}

3.107 Challenges: It is difficult to collect information on volume as well as utilization of loans given to private and other entities by foreign countries and international organizations. To resolve this problem the private and public entities need to include information on the usage of foreign loans and total loan volume in their yearly financial reports. This information needs to be further processed, registered and summarized as a report.

3.108 Information on direct foreign investments is collected using the data provided by foreign trade agencies. Usually, the data is simply the registration records of licenses issued to the parties intending to invest. Therefore, it is hard to give precise estimates on foreign investments and to resolve this matter all involved parties need to collaborate with each other and develop integrated information network.

3.109 The payment balance calculation is based on double entry method and based on the assumption that the total of funds coming in and out needs to be equal to zero, so is the forecast error. However, in the reality the errors do occur and the main reasons for errors are unfocused statistical data and lack of systematic data. For instance, the data provided by customs on the imported goods arising from foreign investment, aid and loans usually differ from the total registered. Even though foreign investments licensed before coming in, not all the investments come in to the county in actual amount specified in the license, so it also creates an error. Moreover, the serving statistical data is collected from limited circles. Besides, the loans from foreign countries and international organizations to private sector currently are not being registered completely.

3.110 External sector management. Like other developing countries Mongolia has been resolving pressing economic and social issues and creating conditions for ensuring the sustainable living of the population using foreign credits and aid to cover the resource shortage faced in this phase of the country's development. Since the 1990's Mongolia has received a total of USD 2.1 billion credits and aid from foreign countries and international institutions, 48 per cent of which was concessional loans. Since 1991 to the end of 2002 Mongolia has received a total of USD 1.25 billion credits and paid USD 265.3 million for principal and USD 86.3 million for interest and fee payments.

3.111 As of the end of 2002, Mongolia's outstanding principal debt due to foreign countries and international financial institutions amounted to USD 984.9 million, which is expected to equal to 88.9 per cent of GDP in 2002. Under international principles, the ratio of the NPV of external debt to GDP, which determines the debt burden, was 58.4 per cent at the end of 2002. Debt due to Asian Development Bank constitutes 37.4 per cent of the Mongolia's total external debt, Japan - 22.7 per cent, World Bank - 18.3 per cent, Germany - 6.2 per cent, and International Monetary Fund -4.3 per cent.

The growth of external debt of Mongolia in last 10 years is shown on Figure 4. 


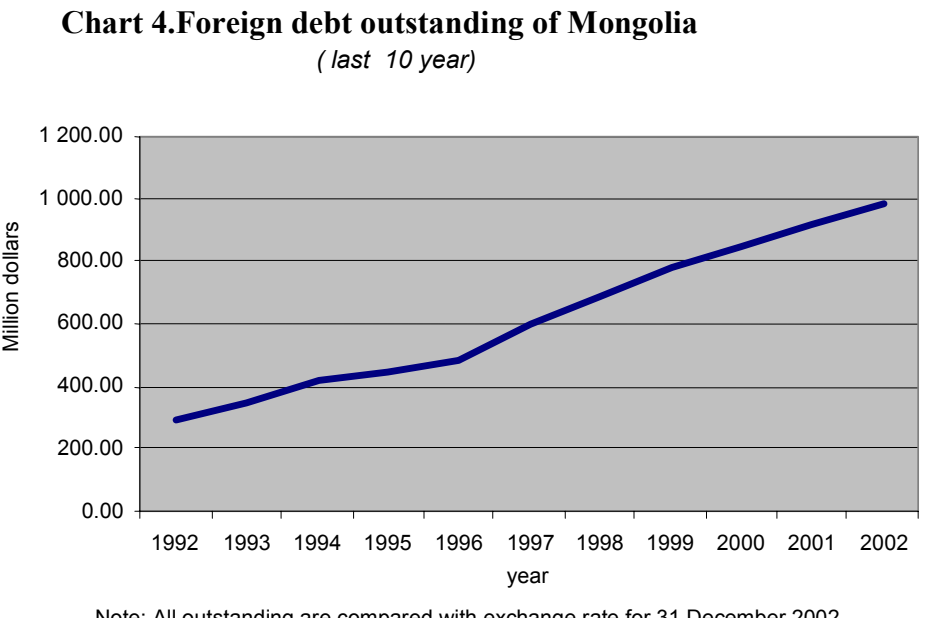

38.4 per cent of the total external debt of Mongolia is bilateral concessional loans, 57.3 per cent multilateral concessional loans, and 4.3 per cent IMF loans (Figure 5).

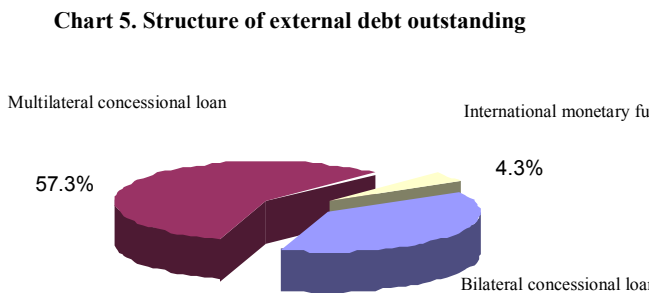

$38.4 \%$

3.112 Mongolia has disbursed MNT 98.0 billion equivalent concessional loans from donor countries and international financial institutions out of projected MNT 104.6 billion in 2002. The disbursement rate of project loans was 98.5 percent of originally planned. In addition 67.3 percent or MNT 65.9 billion of total loans disbursed in 2002 was classified as project loans, 16.1 per cent or MNT 15.8 billion as transport loans, while 16.6 per cent or MNT 16.3 billion as financial loans. Chart 6 shows the composition of external loans disbursed in 2002. 


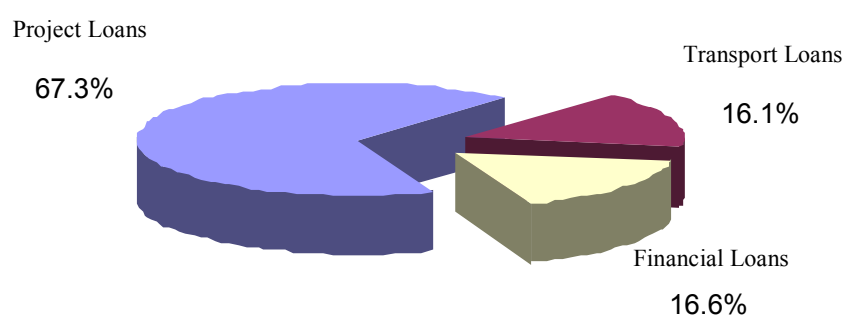

Let's look at external debt outstanding of Mongolia by economic sectors.

Chart 7. The structure of foreign debt outstanding at the end of 2002

(byeconomic sectors)

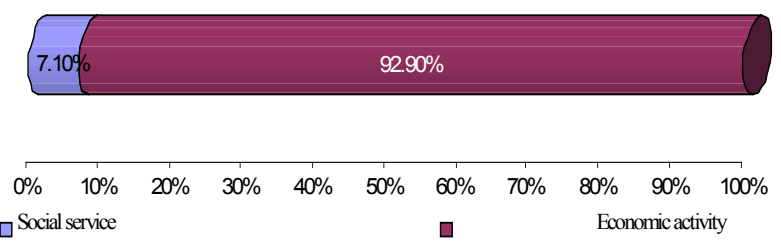

The structure of social service

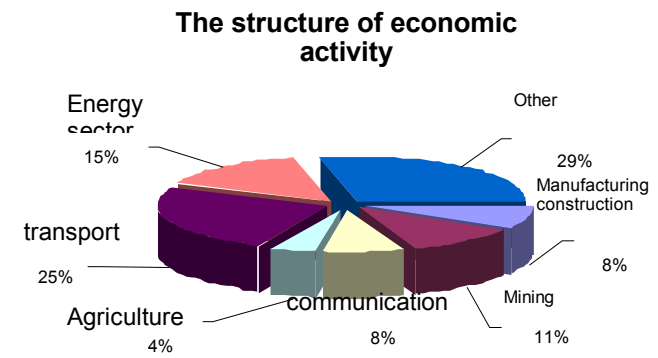

3.113 The above figures present that majority of loans has been disbursed for economic related activities, namely transportation, energy, and mining to a greater extent.

3.114 External debt service. Mongolia has paid a total of USD 265.3 million for principal and USD 86.3 million for interest and fee payments to donor countries and international financial institutions as credit service fee for all loans obtained since 1991. The chart 8 shows the comparison of debt servicing payments converted from credit original currencies into USD at the 2002 year-end exchange rate. 


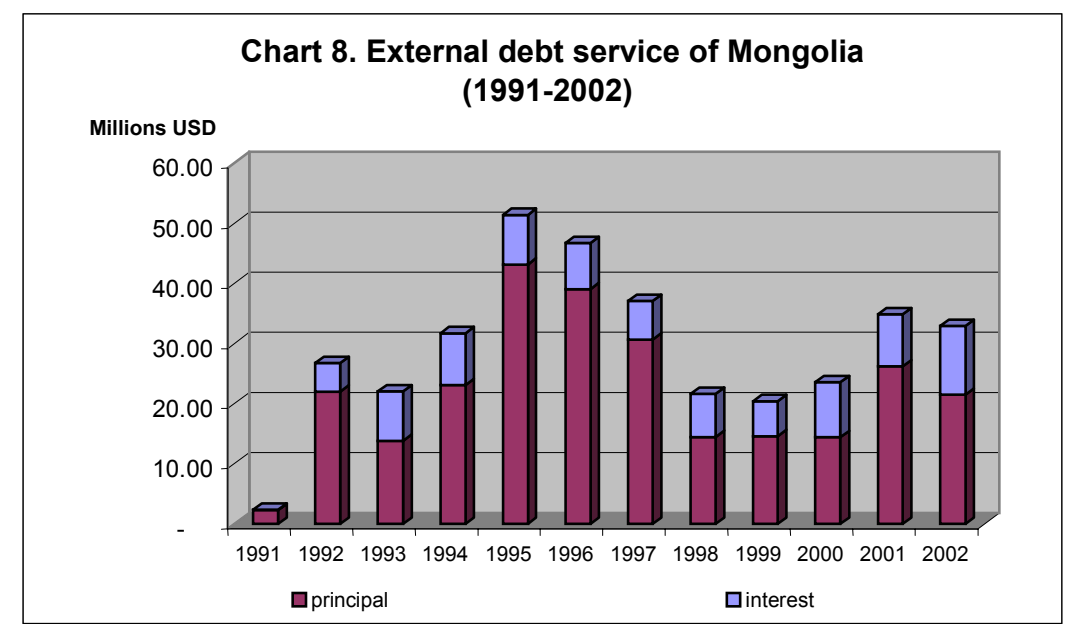

3.115 It can be seen from the table that the debt service of Mongolia were very high in 1992-1997 as a result of short-term commercial borrowings at high interest rate in the beginning of the 1990's, payments of which had been a significant burden. It is essential for Mongolia to not make commercial borrowings.

3.116 In 2002, Mongolia repaid a total of MNT 37.0 billion equivalent loans to donor countries and international financial institutions in original currencies, including MNT 12.8 billion (34.7 percent) for interest and MNT 24.2 billion (65.3 per cent) for amortization. The repayment increased by MNT 4.6 billion as the amortization of nine new loans started in 2002. Majority of the total debt service in 2002 was paid to IMF (25.0 per cent), Japan (21.1 per cent), Russia (18.7 per cent) and ADB (10.9 per cent). Mongolia has been repaying concessional loans issued by donor countries and international financial institutions on a timely basis.

3.117 An amount of USD 6.1 million due in foreign currency out of USD 10.2 million due in 2002 were paid to Russia as payment of current debt. Out of which USD 4.1 million to be paid in commodities was postponed due to tender issues in Russia. It was repaid early in 2003. As a result, Mongolia retired all external arrears in 2002. The external debt sustainability analysis of Mongolia indicates that debt levels are at the manageable level, however debt related issues are still remain one of main areas of economic management. In order to improve the external debt management, the Government of Mongolia established a Debt Management Division under the Treasury Management Regulation Department of MOFE in 2001. The division has created data base with all records concerning individual loans borrowed since 1990s with specification of onlending agreements. Around 73 per cent or USD 912 million of government loans from donor countries and international financial institutions had been transferred on-lending arrangements.

3.118 Revenue from on-lending agreements plays an important role in repayment of external debt. However, the principle of recovering external debt payments from repayments of loans extended under domestic on-lending arrangements is not sufficient. As a result, the repayment has improved delivering USD 5.5 million repayments in 2002. Under World Bank Fiscal TA, an international tender for debt management accounting software was announced in 2001. UNDP has been qualified in the tender and signed a contract in June of 2001. UNDP started the installation of Debt Management and Financial Analysis System /DMFAS/ in September of 2001, which was accompanied by a consultant. During the initial phase of the 
project all data had to be input; the task was accomplished during the period of 8 months. By May of 2002 the database was preliminarily completed. UNDP counts this project as one of the success stories. The success of the project was determined by efforts of the Debt Management Department of MOFE to a greater extent. One of progresses of DMFAS was linking MOFE to Mongol bank in one network. Some notable accomplishments are:

- Improved loans and debt registration;

- Created a basis for the debt sustainability analysis

- With utilization of DMFAS, Mongolia became able to monitor debt sustainability and debt burden, and a comprehensive system for debt management was established.

3.119 Although DMFAS included a series of data on external debt of Mongolia and is running smoothly to date, there are some problems too. The most important is statistics on grants received by the Government from donor countries and international financial institutions is under covered, undermining the debt management and data availability on external sector.

3.120 Our policy is to upgrade the debt management, including its repayment not posing additional burden on the budget, and improve the efficiency of external debt. The following actions have to be taken with regard to external debt:

- Mongolia should be receive loans only on concessional basis;

- An external debt strategy has to be developed;

- Do the following estimations and debt sustainability study with focus on:

- Repayment capacity. The impact of additional external debt service payments for new loans on budget income and expenditure, and external trade balance, repayments from borrowers under domestic on-lending etc.

- Endogenous economic benefit. What portion of the loan will be spent domestically and what portion used abroad during the course of loan utilization project, how many jobs will be created, in what timeframe outcomes are expected etc.

- Priority support to sectors with significant contribution to the economy. For today, it would be effective to use the loan for development of export-oriented sectors.

- Build a favorable legal framework for external debt, improve accounting and reporting system in line with international methodology.

- A liability mechanism has to be established with regard to the Council for ODA coordination. Staff of the council proposes a loan to the Government and Parliament, but there is a lack of proper monitoring on utilization and efficiency. Thus, if the loan had low efficiency a monitoring mechanism for liability has to be in place.

3.121 For the purpose of trimming external debt burden, a policy is to investigate all possible aid sources and complete debt servicing basis. In the mid-term, debt service shall not exceed 10 per cent of GDP. Therefore, the utilization of foreign loans and aid shall be improved by further enhancing the registration and information data base on external debt, creating a legal framework for boosting the credit regulation, effectively identifying sectors that should be beneficiaries of credit and aid, and effectively administering with the priority policy. 
3.122 Prior to making a transition into market relations, like other socialist countries Mongolia had received significant credits from Russia and some countries in Eastern Europe. As of 2002, Mongolia has generally resolved debt issues with all countries except Russia. The Government of Mongolia is making negotiations with Government of the respective countries to regulate convertible ruble debt and inherited receivables formed during the old structure; with some countries the negotiations are going well enough. Namely, Mongolia had an experience of negotiating on USD 1.00: 14.5 convertible rubles. Debt issues with Hungary, Czech, and Germany have been resolved and under process are negotiations with Poland, Bulgaria and Slovakia.

3.123 In the early 1990's, the Government of Mongolia has negotiated with the Government of Russia discussed the "big debt" and agreed to extend the debt term not accruing interest. To date, there is information that Mongolia's debt due to Russia amounts to 10.2 billion convertible rubles. Much effort was made towards resolving the debt issue in last two years, but no ultimate agreement has not been made yet. Consequent to high-level negotiations between Mongolia and Russia the following four basic principles to guide the debt regulation had been agreed upon:

- Take into account the historic situation of debt formation

- Consider the real potentials of Mongolia's economy, apply internationally accepted approaches in debt regulation

- Consider the traditional friendly cooperation and relations between the two countries in debt regulation

- Promote investments towards increasing export capacity of Mongolia

3.124 MOFE is continuing negotiations with the Ministry of Finance of the Russian Federation on the technical level.

3.125 The long run external debt management policy is aimed to reduce gradually government borrowing and attract more direct foreign investment in business sectors. This will result in reduced debt payment burden on the budget, more funds dedicated to the poor and improve public service delivery, especially in the social sector.

3.126 The mid-term policy of foreign economic relations is defined as to continuing the open policy and using diversity of mutually beneficial cooperation methods and mechanisms.

3.127 Aid coordination. The donor community is playing a critical role in assisting to build democracy, in intensifying the transition to the market economy, in ensuring good governance, in improving the living standards of the people and in reducing poverty.

3.128 Today, Mongolia is reaching more mature stages of transition and the country is now becoming more focused on determining priorities and strategies for longer term social and economic development.

3.129 Between 1991 and 2001, gross disbursements of all types of ODA (made by the international donor community were US \$2.1 billion. 52.4 percent of total ODA disbursements represent grants and 47.6 percent represent concessional loans. 
3.130 The Government has undertaken a series of measures to optimize aid coordination and management based on lessons and experiences of previous years in managing aid, including:

- Institutional framework: the amendment in the law on the Government mandates the MOFE with responsibilities for collecting and integrating information, concluding contracts and agreements, and conducting overall management of ODA;

- Regulatory framework: changes made to the composition and functions of the Foreign Investment and Aid Coordination Council.

- Legal framework: A draft law on ODA initiated by the MOFE, which develops the legal/administrative framework for aid coordination with a specific focus on strengthening of Government internal coordination and management in utilizing aid.

- A modern debt management database with the support of the World Bank is under installation at the MOFE, which will sustain working contacts with donors and improve debt service management.

3.131 The Government places importance on the relationships between core macro policies and ODA policy, which includes its work with donors:

- Moving to a three year fiscal planning framework will require close consultation and coordination with donors in terms of the medium term and annual policy and measures as the movement to three year expenditure planning intensifies;

- To maintain fiscal sustainability a careful selection and disbursement of concessional foreign borrowings, increase of grant level will be undertaken; and

- Higher potential public debt and public debt service levels in the medium term indicate there is a case for close scrutiny of new borrowings and pursuit of higher grant elements of ODA.

The Government is undertaking as series of measures to improve policy toward better aid coordination, namely:

- The Government of Mongolia fully supports the major international initiatives toward better use of ODA and appeals to the international donor community to critically review the portfolio of loans and grants so kindly provided by the international financial institutions, particularly with a view to decreasing debt levels and raising grant elements. Donor support and cooperation with the Government is called for in this regard. The balance of loans and grant provided by ADB and World Bank is 95/5 and 90/10, therefore, it is proposed that lenders reduce this sharp gap and gradually make closer the balance between loans and grants.

- Government policy in terms of the composition of aid is to substantially increase the volume of grant aid in the social sector, including, health and education and to gradually reduce the volume of loans in this sector.

- Furthermore, Mongolia is seeking to use ODA to promote more active involvement in regional cooperation. Mongolia is strongly interested in participation and implementation of regional projects and programs.

- Stronger private sector and civil society participation is promoted in issues that can be dealt through the private investments rather than the ODA. 


\section{Monetary Policy}

3.132 The main objective of the long and medium-term monetary policy is to strengthen macroeconomic and financial stabilization, to create a growth-enabling monetary and financial environment, to deepen financial intermediation, and to expand the scope of financial and banking services. The Government will continue to pursue the floating exchange rate policy, with the exchange rate adjusted in accordance with the balance of payments and foreign currency demand and supply on the interbank market. The inflation level will be maintained at 5 percent in the medium-term, and net official international reserves will be increased to reach 18 weeks of imports.

Table 3:8: Main Monetary Aggregates, 1998-2002, percent

\begin{tabular}{|l|c|c|c|c|c|}
\hline & 1998 & 1999 & 2000 & 2001 & 2002 \\
\hline Money supply to GDP & 20.5 & 23.8 & 24.8 & 29.7 & 38.2 \\
\hline Deposits to GDP & 10.4 & 11.4 & 12.3 & 12.3 & 23.0 \\
\hline Loan outstanding to GDP & 10.5 & 8.4 & 6.5 & 6.5 & 18.8 \\
\hline Non-performing loan to GDP & 3.8 & 4.6 & 1.5 & 1.5 & 1.3 \\
\hline
\end{tabular}

3.133 The price level stabilized in recent years, declining since the second half of 2002. The year-on-year change in consumer prices was negative and by the end of the year reached 2 percent. Within the framework Economic Growth Support and Poverty Reduction Strategy, the Government will pursue the flexible monetary policy to ensure the money demand which is lacking in the economy and control the level of money supply without boosting inflation rate. The Government will improve consistency between monetary policy tools and efficient policy on Central Bank bills.

3.134 Despite pronounced seasonal patterns in the Mongolian economy and, subsequently, consumption, the annual inflation in the past years stabilized at single digits. This has a large positive effect on the livelihoods of the population, including the poor.

3.135 The Government has put an objective to maintain the inflation rate at 5 percent in the medium-term. Incorporated to implement the efficient monetary policy and to keep money reserve growth at an appropriate level. Moreover, the Government will continue to pursue a policy to improve the supply of commodities of the population.

3.136 The nominal exchange rate of togrog against the US dollar has also leveled out. The exchange rate is expected to reach togrog 1125 per US dollar by the end of 2002, which means 2-percent depreciation on the year earlier. 
Figure 3.3: Exchange Rate Trend

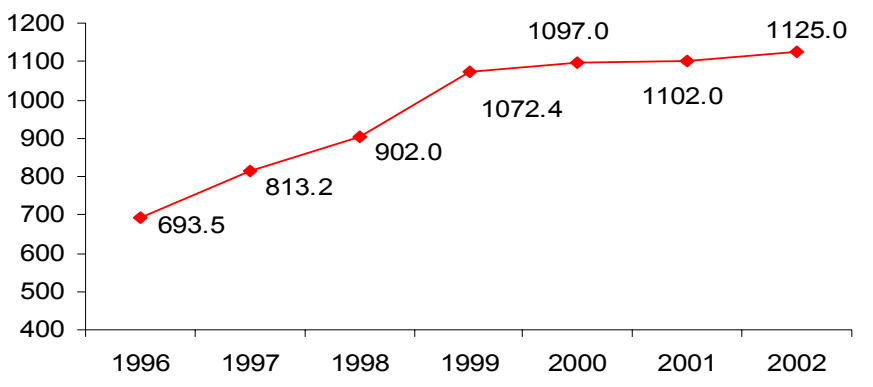

3.137 The Central bank's policy focuses on adequate linking of money supply management with the stabilization of inflation and exchange rate. Money supply grew by 42 percent in 2002, compared with the previous year, while foreign and domestic currency deposits increased by 55 62 percent. Despite high growth of money supply, some positive developments arise in the composition of money supply, and the confidence in the banking system is growing continuously. As the economic activities have being activated, the demand for credit continues to expand. Currently, the average lending interest rates are 35 percent. Therefore, it is necessary to pursue credit and monetary policy to support economic activities, enhance competition among banks to reduce interest rates. In implementing the medium-term exchange rate policy, the Government will consider that appreciation of the domestic currency leads to erosion of competitiveness of our export products on the world markets, increase in unproductive imports and negative effects on the ability to repay external borrowing in the future. The Government will implement its monetary policy accordingly:

- Raise placement and interest rate of BOM bills,

- Enhance monitoring of on-lending activities,

- Upgrade supervisory and prudential framework,

- Restrain from any issuance of payments or loan guarantees for third parties, unless it has been included in government medium term policy documents or annual budgets.

3.138 Financial and banking system. The major indicators of financial intermediation, such as share of broad money, credit and deposits to GDP are gradually growing, indicating the deepening of financial intermediation in the economy. By the end of 2002, 16 banks and about 60 non-bank financial institutions operate in Mongolia with 502 branches. Although 85 percent of these institutions are located outside Ulaanbaatar, only 13 percent of loans were issued to borrowers in rural areas, pointing to a growing financial concentration. A recent survey conducted by the Bank of Mongolia showed that small businesses and rural customers have inadequate access to credit.

3.139 As a result of implementing policy directed toward expansion of financial services in rural areas, the Law on Non-bank Financial Institutions has been adopted by the end of year 2002 and legal amendments, supporting the development of saving and credit cooperatives, were 
made in the Cooperatives Law and are enforced. The activities of bank and financial intermediaries will be expanded within this legal framework.

3.140 One of the priority policies to expand monetary and financial intermediation is to encourage foreign and domestic investors to facilitate fair competition, to introduce new services, update the technology and improve supervisory mechanisms. As well, steps will be taken to expand financial services in rural areas, including measures to support activities of the non-bank financial institutions and saving-credit cooperatives. Privatization of state or partially owned commercial banks will be intensified in accordance with the privatization program, after completing the necessary preparation. The Trade and Development bank, one of the largest banks of Mongolia, and the Agricultural Bank, which has many branches in rural areas, were privatized in 2002 and at the beginning of year 2003 respectively.

3.141 Accesses to credit and interest rates level have an exceptional importance for business, particularly for development of small and middle-size enterprises. Therefore, actions will be taken to expand competition in order to reduce nominal interest rates on loans, to maintain real interest rates positive, and to reduce the flow of money outside banks. The policy of reducing the large gap between deposit and lending interest rates will be intensified by channeling liquid assets of individuals, companies and organizations to banks. The expansion of banking and financial services, and improvement of service quality will upgrade money flow in the rural areas, thus affecting on creation of job opportunities and activation of economic activities in the regions and increase income of rural population, in particular poor.

3.142 Banks' internal supervision will be enhanced in accordance with international standards, external auditing will be strengthened, transparency of information will be ensured and mechanisms of credit risk-sharing between banks will be introduced.

3.143 In order to reduce money flow outside banks the new types of cash transactions will be introduced, and non-cash management network will be established at the national level.

3.144 The Parliament of Mongolia has adopted the Main guidelines for the development of the securities market for the medium term, including separation of functions of the Stock exchange and Securities payments and savings center, revise recording criteria - requirements for securities, introduce needed amendments to the legal environment, encourage participation of citizens in the securities market operations, increase their awareness. In line with reforms in the securities market activities the Trust fund law will be enforced.

3.145 The insurance policy priorities will be focused on improving the legal environment, rationalization of management and enhancing monitoring of the insurance companies activities, expanding the types and coverage by the insurance activities, introduction of international standards.

\section{Economic Re-structuring}

3.146 Creation of economic structure based on the private sector and subsequently increasing economic efficiency is one of the Government priorities in its policy to accelerate economic growth. The Government will, therefore, increase the private sector's share in the 
economy to 80 percent, while improving the composition of the industrial sector and exports. With this purpose, the Government will accelerate the privatization process with special focus on most valued companies and take actions to improve efficiency of already privatized enterprises.

3.147 A constructive solution towards privatization of large, valuable entities that play a major role in the Mongolian economy will have an important impact on further economic development. The Government's policy will be focused to privatize these companies to strategic investors that will be capable of increasing economic and financial efficiency of the companies, bringing in new technology, know-how and bridging them with new export markets.

3.148 Restructuring will start with commercialization of the energy sector, a strategic sector for the economy. With adoption of the new Energy Law by Parliament in 2001, the legal base for restructuring in energy sector was established. The Government of Mongolia believes that the condition for enabling independent regulatory mechanisms, for promoting private sector into energy market, for introducing competitive environment in energy sector has been created, and important steps were implemented.

3.149 The Government will strengthen self-sustainability of energy companies and will accelerate the energy sector reforms. Energy sector restructuring will be stepped up, its monitoring will be improved, costs will be reduced by ensuring that companies directly collect their payments from customers, without intermediaries, thus eliminating various commissions. The distribution grid that deals with customers will be privatized, and non-technical losses and internal consumption of energy will be cut down.

3.150 In the context of the Government's objective of turning land into a productive asset, the Government will expand opportunities for the people, including the rural and the poor population, to enable their engagement in business activities and thus create sustainable sources of income. The Government will undertake steps to implement land ownership and possession reforms. In this process the main focus will be on long-term leases, improvement of the land fee system and using the land as an incentive to develop production and crop farming. As well, the focus will be on using the land reform as the basis of economic growth sources. The implementation of the recently approved Law on Land and Law on Land Ownership will be stepped up, and the process of giving land to Mongolians for ownership will be started on the basis of detailed land registration and cadastral surveys. An effective pastoral management system will be created, considering the dependence of rural residents on the land and nature.

3.151 Social sectors restructuring, including education, health, culture and arts, will be carried out in a way that would not damage the access and quality of government services. The Government will encourage the various methods of restructuring, including management contract, management buyout, lease contracts in privatization of state owned educational institutions, hospitals, and cultural institutions, as well as encourage sustainable and high-quality services of private educational, health and cultural institutions. This process will be mainly guided by the Guidelines of restructuring and privatization in social sector approved by the Parliament. During the reforms the Government's special pro-poor measures will be undertaken to minimize negative consequences of reform agenda. 
3.152 In the medium term the city transport privatization will be continued and competition will be expanded in the transport services.

3.153 Local property will continue to undergone re-structuring in line with the overall privatization process. Following objectives and principles set forth in the general guidelines of state property privatization in 2001-2004 adopted by Parliament decree No. 10 of 2001 and General guidelines for reforms and privatization in the social sector adopted by decree No. 56 of 2002, the specific targets were set for UB city municipality to increase the participation of the private sector in socio-economic sector, promoting competition, improving the economic efficiency, and creating sources of investment.

3.154 In 200335 immovable properties will be privatized. Within the launching of social sector privatization, preparations are being made to privatize some institutions in the education and health sector, public transportation, housing utility services, heating kilns, media under management contract as pilot.

3.155 In implementing the restructuring policies to ensure that gender equality will be provided, and increase equal access for men and women to benefits from socio-economic policy through out gender analysis in the policies and programs related to structural changes in the socio-economic arena will be carried out. Therefore there is a need to conduct gender analysis on impacts of land reforms and actions should be taken to reduce negative effects. In particular, depending on external and local asset flow and allocation, it is affecting the livelihood of women in some ways. Therefore, in order to undertake restructuring in the economy, there is a need to conduct gender analysis on impacts of land reforms, labor relations, restructuring in the social sector and fiscal reforms should be taken to ensure gender balance and implement the National Program for Ensuring Gender Equality. Based on previous experience, the Government will pursue a long and medium term policy to ensure the social guarantee and avoiding poverty during the restructuring process in the economy.

3.156 The medium term private sector led growth objective will be reached through deepening of restructuring and reforms in the various sectors of economy and social development, including energy, land, civil service, pensions, and taxes. The above areas of restructuring is along term and painful process affecting welfare of people, especially vulnerable groups. Therefore addressing the negative consequences and mitigating risks associated with restructuring is one of the areas of government concerns. The government has undertaken a number of initiatives to analyze impact of privatization and restructuring with assistance of the international agencies. The Mongolian government jointly with the World Bank started to implement a comprehensive program towards public sector reforms. USAID has initiated a series of studies on energy sector restructuring and development. However, the above mentioned reform policies have a different impact on population groups welfare. Therefore in the medium term there is a need to evaluate impact of policy reforms with gender mainstreaming with participation of various stakeholders, including international experts, academics, and policy makers. 


\section{Accounting, Auditing and Inspection}

3.157 Accounting. Since Mongolia's transition to the market economy, for the first time the Law on Accounting was passed in 1993. The main objective of this Law was to introduce the International Accounting Standards (IAS) in Mongolia. At that time the prestige of accounting profession had fallen down and there was widespread understanding that accounting is not such a useful activity and there were no qualified experts familiar with the IAS. Therefore in 1993 with the financing of the World Bank and in 1995 with the financing of the ADB three projects were implemented leading to the provision of systematic training on the IAS to the key professionals and teachers.

3.158 The 1996 version of the IAS was translated and disseminated in 1998, but soon thereafter it underwent major revisions and eventually was not considered satisfactory. On the other hand a number of methodical instructions and manuals were produced by the MOFE in relation to the introduction of the IAS.

3.159 The curriculum of universities and colleges underwent changes in 1996 to include teaching of the IAS.

3.160 There are nearly 30 thousand accountants in Mongolia and one-third of them have been involved in 2-3 weeks training on the IAS.

3.161 In 1993-2000 no concrete actions were taken by the government to transfer the accounting systems of the budget entities and local financial institutions to the IAS. In 1999 the methodical instructions on transferring the accounting systems of the budget entities to the IAS began to be developed within the framework of the WB Fiscal Technical Assistance Project, but the process was rather slow.

3.162 In 2001 a national inspection was conducted into the accounts of all the enterprises and budget entities in Mongolia. The results of this inspection showed that all the budget entities had not transferred to the IAS, more than 30 per cent of the enterprises had not kept accounts, produced financial statements and had relationship with the taxation authorities, almost 40 per cent of them had not collected receipts for their transactions, and 27 per cent of the enterprises had introduced the IAS.

3.163 The government has made relevant conclusions and took some important measures, one of which was to make amendments to and renew the Law of Accounting in December 2001. The revised Law provided for all the budget entities and enterprises to transfer to the IAS. In some instances, it was found that some enterprises and budget entities would issue financial statements without keeping accounts, therefore, the revised Law provided for detailed procedures for accounting and also specified that each enterprise or budget entity should hire a full-time or part-time professional accountant. Also, the Law defines the rights and responsibilities of the accountants in terms of not violating the Law and not recording transactions without valid primary documentation. According to the Law, state accounting inspectors were established with 
the function of conducting inspections and imposing penalties. In order to accelerate the process of implementation of the Law, the year 2002 was announced as the Year of Improving the Accounting System and a government Program for Developing the Accounting System for 20022004 was developed and approved. The Government Action Plan provided that the introduction of the IAS should cover at least 50 per cent of all the enterprises in 2002, 70 per cent- in 2003 and 90 per cent- in 2004. The level of availability of primary level documentation should reach at least 80 per cent in 2003 and from 2003 all the budget entities should transfer to the IAS.

3.164 In 200234 new methodologies and instructions were developed by the MOFE which led to the formation of an appropriate legal and regulatory framework for implementing the Law of Accounting. Also sufficient methodologies and instructions were provided to the business sector on the introduction of the IAS.

3.165 One of the notable achievements in 2002 was the introduction of the IAS in the stateowned enterprises and joint-stock companies. 55 per cent of the enterprises complied with the IAS. The remaining 45 per cent represent mainly small enterprises and this poses a critical challenge for us.

3.166 In 2002 within the WB Fiscal TA Project the Procedures for Transferring the Accounting Systems of Budget entities to the IAS were approved and these procedures are being enforced effective as of 1st January 2003.

3.167 In September 2002 training was organized on the above procedures for 60 consultant teachers leading to almost 2000 training events organized with the assistance of these consultant teachers in October and November 2002, which involved about 50 per cent of the accountants who needed to be trained. The new instructions and accounting formats have been delivered to all the budget entities.

3.168 These instructions and formats were developed in accordance with the Public Sector Financial Management Law, which requires the government to develop the Annual Financial Statements according to the IAS. Also, the Law defined the deadlines for issuing the financial statements as follows: 
Table 3:9: Fiscal Reporting System

\begin{tabular}{|c|c|c|}
\hline Reporting institution and type of reports & Deadline & User \\
\hline $\begin{array}{l}\text { 1. Budget entities } \\
\text { Structure of the financial statements } \\
\text { a. Balance Sheet } \\
\text { b. Statement of Financial Outcomes } \\
\text { c. Statement of Cash flows } \\
\text { d. Statement of Property Movement } \\
\text { e. }\end{array}$ & $\begin{array}{l}15 \text { February of the } \\
\text { following year }\end{array}$ & $\begin{array}{l}\text { Budget General } \\
\text { manager }\end{array}$ \\
\hline $\begin{array}{l}\text { 2. Budget General Manager } \\
\text { The structure of the Financial Statements is the same as } \\
\text { for the budget entities }\end{array}$ & $\begin{array}{l}20 \text { February of the } \\
\text { following year }\end{array}$ & MOFE \\
\hline $\begin{array}{l}\text { 3. MOFE } \\
\text { The Financial Statements of the government: } \\
\text { a. Statement of Financial Outcomes } \\
\text { b. Balance Sheet } \\
\text { c. Statement of Cash flows } \\
\text { d. Statement of Property Movement } \\
\text { e. Notes }\end{array}$ & $\begin{array}{l}20 \text { March of the following } \\
\text { year }\end{array}$ & $\begin{array}{l}\text { State Great } \\
\text { Khural } \\
\text { (Parliament) }\end{array}$ \\
\hline $\begin{array}{l}\text { 4. State Owned Enterprises } \\
\text { The structure of the FS is the same as for the budget } \\
\text { entities }\end{array}$ & $\begin{array}{l}10 \text { February of the } \\
\text { following year }\end{array}$ & MOFE \\
\hline
\end{tabular}

3.169 Instructions for transferring the treasury accounts to the accrual basis in 2003 have been developed. In April it is planned to conduct a workshop for the Treasury accountants on these instructions. However the requirement to transfer the Treasury to the accrual basis in 2004 became binding with the passing of the Public Sector Financial Management Law.

3.170 There is a need to appropriately evaluate the capital assets and to correctly determine the depreciation costs in order to determine the level of outputs of budget entities, to fully reflect the output costs as well as to show the economic capabilities of the budget entities.

3.171 Although methodologies are being developed on conducting a census, revaluation of state properties, reflecting the values in the accounts, establishing depreciation norms, there are many methodological challenges which need to be addressed. In particular, a number of issues should be solved such as what kind of properties are to be included in the census, how to convert the value of immovable properties such as the buildings procured in the previous years at varied prices to the current value, what should be the basis for evaluation of state-owned enterprises to be included in the TSA.

3.172 The central Treasury accounts and the financial statements do not reflect state-owned enterprises, budget entities, public roads and bridges and other items. This applies to the provincial levels as well. This situation prevents the demonstration of the economic potential of the government and hampers the implementation of the financing law.

According to the inspections conducted in 2001, all state-owned enterprises and businesses with state ownership have transferred to the IAS. 
3.173 The March 2003 situation of public sector accounting is as follows:

Table 3:10: Status of Accounting Reforms as at March 2003.

\begin{tabular}{|l|l|}
\hline & \multicolumn{1}{|c|}{ Introduction of IAS } \\
\hline 1. State-owned enterprises & Fully introduced the IAS \\
\hline 2. Budget bodies & $\begin{array}{l}\text { Began to introduce the IAS and switch to the } \\
\text { accrual basis }\end{array}$ \\
\hline 3. Treasury accounts & $\begin{array}{l}\text { To switch to the modified accrual basis in 2003 } \\
\text { and to the accrual basis or the IAS in 2004 }\end{array}$ \\
\hline
\end{tabular}

3.174 It is not possible to produce the Financial Statements of the Public Sector because 3 accounting bases are used. Furthermore, it will be time and effort consuming to consolidate the financial outcomes of budget entities in the Government Financial Statements. However, it is hoped that in 2004 the said challenges can be overcome.

3.175 The International Accounting Standards for the Public Sector are being currently translated and it is hoped that the translation will be complete in 2003.

3.176 A national inspection of accounting was conducted in March 2003. The outcomes of the inspection are to be discussed in April 2004 at Accountants' Conferences at the aimag/city level and in June 2003 at the National Accountants' Conference. The positive results from these Conferences will provide further critical impetus to the improvement of the government accounting practices.

3.177 It is planned to train about 2000 accountants of budget entities who have not yet participated in the previous training events.

3.178 There is also a need to involve the Accountants-in-Chief of the aimag treasury departments and Budget General Managers.

3.179 There is a need to immediately conduct an inventory and revaluation of state properties and to register the properties in the accounts of relevant budget entities and the treasury accounts by their current value; to introduce the practice of calculating the depreciation costs and for this to develop the methodology and instructions to be applied throughout the country.

3.180 A methodology will be developed on recording the budget entity outputs and costs in the accounts.

3.181 The MOFE will provide the accountants of budget entities with individual assistance on introducing the IAS by sending experts to give on-site training and to help upgrade the accounts of at least 10 entities in each aimag and at least 500 in the country to the exemplary level.

3.182 The full version of the International Accounting Standards for the public sector will be fully translated, published and disseminated to all the entities. 
3.183 Auditing. Until 2003 the function of fiscal regulation audits was fulfilled by the State Inspection Committee, the Financial Inspection Department of the MOFE and the Sector Inspection Departments at line Ministries (Environment, Health, etc.)

3.184 The State Inspection Committee operated under the Parliament and fulfilled the functions of financial inspection, performance inspection, inspection of the ethics of civil servants.

3.185 The State Inspection Committee did not conduct inspection for any entity and was mainly engaged in financial inspection, disclosure of discrepancies and irregularities and imposition of fines.

3.186 The Financial Inspection Department of the MOFE conducted scheduled financial inspection into the activities of budget entities and state-owned enterprises. It had a function of conducting financial inspection and disclosing irregularities and problems in their financial activities.

3.187 The inspection departments at line Ministries conducted investigation into the harmful effects of sectoral production and service technologies on the environment and population.

3.188 There was a considerable overlap of activities of the above inspection institutions demonstrated by the fact that one economic entity could have several inspection organizations coming to conduct investigation at one time or receive a series of inspection visits one following the other. It was not uncommon that after an investigation and evaluation of the State Inspection Committee, the subsequent inspection of the Financial Audit Department revealed a considerable number of irregularities.

3.189 In January 2003 two laws were passed simultaneously, namely the State Audit Law and the State Inspection Law, followed by the restructuring of the State Inspection Committee into the National Audit Department.

3.190 The National Audit Department conducts the following two types of audits according to the Law:

- audits of the Financial Statements

- Performance audits

3.191 The Professional Control Agency has the following duties:

- Control over the implementation of the laws

- Proposing improvements in the control legislation

3.192 Also a State Professional Control Agency was established under the Prime Minister's Office thus merging 11 inspection agencies with various functions, which used to operate under the various sectoral ministries. The Financial Inspection Department of the MOFE was also included in the structure of the State Professional Control Agency. 
3.193 With the above structural changes taking place, the National Audit Department assumed a function of conducting audits and issuing conclusions according to the international auditing standards on the financial statements of the Ministries, agencies, state-owned enterprises and economic entities with state ownership. The National Audit Department conducts the following audits according to the PSFML:

Table 3:11: Auditing Schedule

\begin{tabular}{|c|c|c|c|c|}
\hline Government agency & Auditor & $\begin{array}{l}\text { Deadline for submission } \\
\text { of FS to the Auditor }\end{array}$ & Deadline for Audit & $\begin{array}{l}\text { User of the Audit } \\
\text { Conclusions }\end{array}$ \\
\hline 1. Budget entity & $\begin{array}{l}\text { National Audit } \\
\text { Department }\end{array}$ & $\begin{array}{l}15 \text { February of the } \\
\text { following year }\end{array}$ & Within one month & $\begin{array}{l}\text { Budget General } \\
\text { Managers and } \\
\text { MOFE }\end{array}$ \\
\hline 2. Local Governors & $\begin{array}{l}\text { Local auditing } \\
\text { institutions }\end{array}$ & $\begin{array}{l}20 \text { February of the } \\
\text { following year }\end{array}$ & Within one month & MOFE \\
\hline 3. Government & $\begin{array}{l}\text { National Audit } \\
\text { Department }\end{array}$ & $\begin{array}{l}20 \text { March of the } \\
\text { following year }\end{array}$ & Within one month & $\begin{array}{l}\text { State Great } \\
\text { Khural } \\
\text { (Parliament) }\end{array}$ \\
\hline $\begin{array}{l}\text { 4. State-owned } \\
\text { Enterprises }\end{array}$ & $\begin{array}{l}\text { National Audit } \\
\text { Department }\end{array}$ & $\begin{array}{l}20 \text { February of the } \\
\text { following year }\end{array}$ & $\begin{array}{l}\text { By } 1^{\text {st }} \text { January of } \\
\text { the following year }\end{array}$ & $\begin{array}{l}\text { Board of } \\
\text { Directors }\end{array}$ \\
\hline
\end{tabular}

3.194 However, the State Audit Law does not provide solution for all the issues and there are areas where some controversies are likely to arise, namely:

1. The National Audit Department is not authorized to impose payment of compensation or fines in the event of disclosure of substantial irregularities and mistakes while conducting the audit. In such cases is it sufficient only to issue an audit conclusion where these irregularities will be stated? This question is not explicit in the Law.

2. The accounts of private enterprises are done by the Certified Public Accountants and accountants with auditing license. However, the audit of large state-owned enterprises is to be done by the National Audit Department Inspectors, who are not qualified accountants. This does not comply with international practice and is not acceptable for other clients.

3. Audit is an independent and impartial investigation. However, can an audit conducted in a state-owned enterprise by a state organization be considered as impartial and independent from the point of view of a third party?

4. After the National Audit Department conducts an audit and issues a positive conclusion, it may be possible that the subsequent financial inspection of the Professional Control Agency could reveal substantial discrepancies. In this event the National Audit Department does not bear any responsibility.

5. It is not explicit also if the National Audit Department shall be liable if it makes mistakes in the auditing of the financial statements of the enterprises with state ownership and a situation arises similar to the bankruptcy of Enron Co. 
Thus the activities of the National Audit Department can be considered as impartial for the public organizations, but cannot ensure independent and dispassionate point of view for the enterprises with state ownership.

6. The responsibility of reviewing and allocating the budgets of all the Ministries, agencies and other budget entities of Mongolia, of reviewing and accepting their financial statements, lies with the Ministry of Finance and Economy. Therefore, the audit conclusions of the National Audit Department are to be submitted to the MOFE. In the event the MOFE considers the conclusions unreasonable, there will be a need to repeat the audit inspection or to appoint an expert group to investigate the way the auditing was handled. However, the National Audit Department is a parliamentary body, yet it has to be responsible before a lower institution. This may create a contradictory situation in the management relations. Thus some difficulties may arise in the implementation of the Auditing Law.

- There is a need to review and refine the State Audit Law.

- The management of the local branches of the National Audit Department should be changed and replaced by the qualified accountants.

- The International Auditing Standards should be translated, published and disseminated to the auditors.

- There is a need to develop, obtain approval for and implement terms of reference and manuals for auditing activities as well as internal standards for the state financial audits.

- A broad training program is to be implemented for upgrading the knowledge and skills of the financial inspectors of the Professional Control Agency.

- The government programs are to be audited in 2003 which will allow the auditors to gain sufficient experience.

3.195 State Supervision: Since 1991, the supervision offices had operated under various structures and organization, and were mostly within the structures of policy sectors and departments.

3.196 Founding upon resolution \#32 of September 1, 2000 of the Parliament on "Reforming the state administrative system and revising the general scheme of structure", and according to the Government resolution \#139 of September 6, the following regulatory agencies were established. These were:

- "Infrastructure Supervision Office" within the functions to be managed by the Minister of Infrastructure;

- "State Labor and Social Protection Supervision Office" within the functions managed by the Minister of Social Protection and Labor

- "State Financial Supervision Office" under the functions managed by the Minister for Finance and Economy

- "State Supervision Office for Trade and Industry" under the functions managed by the Minister of Trade and Industry 
- "State Supervision Office for Food Security and Agriculture" under the functions to be managed by the Minister for Food and Agriculture

- "Environmental Protection Office" under the functions managed by the Minister for Environment

- "State Health Supervision Office" under the functions managed by the Minister for Health

- "State Education, Culture and Science Supervision Office" under the functions managed by the Minister for Education, Culture and Science. These agencies performed their respective functions and duties as described below.

3.197 The Infrastructure Supervision Office performed such core functions as to ensure the implementation and enforcement of the pertinent legislation in the area of auto-transport, tourism, construction, geodesy, analysis and inspection of flight and related technical issues and cases, communication, fuel and energy, and to eradicate revealed shortcomings and violations. The number of staff under the Office was 66 persons.

3.198 The Labor and Social Protection Supervision Office with the staff of 28 persons ensured the implementation of the labor and social protection legislation and provided monitoring and control over enforcement of hygienic requirements, labor standards and conditions; formulation and spending of all types of funds, grants and credits to the social protection sector.

3.199 State Financial Supervision Office carried out factual inspection over the formulation and spending of the state central and local budgets, special purpose funds, utilization of loans and grants taken through government lines; financial and accounting practices of the state fully and partially owned entities and public organizations, their financial statements, utilization, conservation and efficiency of property utilization; issued conclusions and assessments based on the inspection, and enforced measures to ensure eradication of revealed shortcomings and implementation of pertinent legislation. The number of staff at the Office was 200 persons.

3.200 The State Trade and Industry Supervision Office worked to ensure the implementation of geology, mining, trade, industry and services legislation; developed rules and procedures, consistent with international standards and practices on mineral exploration and exploitation, on trade, industry and service activities, and on oil products, and provided control over the security and safety of utilization and storage of explosives, explosion tools and devices, control over rehabilitation of lands, undergone mineral exploration and exploitation activities, and over returning geologically explored and exploited areas.

3.201 The State Food Security and Agriculture Supervision Office worked to ensure the implementation and enforcement of laws and legislation on veterinary services, plant quarantine and control, legislation on meeting the quality requirements for livestock breeding, cultivated plants and protecting the health of herds and cultivated plants and on meeting safety and hygienic requirements for food products.

3.202 Environmental Protection Office enforced legislation on protection of Specially Protected Areas and other legislation on environment and ecology, and performed duties to eradicate revealed violations and shortcomings. 
3.203 The State Health Supervision Office supervised over the activities of health, border health, epidemiologists, pharmacy and medical treatment areas and enforced the implementation of legislation in these spheres. Under the Office, there were laboratories where analysis and tests were carried out to support the assessment and evaluations made by Office inspectors.

3.204 The State Supervision Office for Education, Culture and Science worked to ensure the implementation of laws and legislation in primary, secondary and high education, science, technology, professional education, culture and arts. Like other Offices, it was authorized to take necessary measures to eradicate revealed shortcomings and violations.

3.205 The duties of these Offices in the local areas were carried out by the Financial Supervision Department, Environmental Supervision Department and Specialized Supervision Departments in the structure of the local Governments. The Specialized Supervision Department, which is the Government Regulatory Agency, was newly established according to the Parliament resolution number 58 of 2002 "Concerning revised approval of general scheme of framework and organizational structure of state administrative organizations" and the Government resolution number 162 of 2002 "Concerning the establishment of state regulatory and implementing agencies".

3.206 The overall objective of the State Specialized Supervision Department is to enhance the Government responsibility, improve the efficiency and results of its activities with regard to the population by supervising the enforcement and implementation of legislation.

3.207 Within this framework the purpose of the Specialized Supervision Department is to ensure the enforcement and implementation of rules, regulations, norms and standards established by the law and state authorized organizations for public observance in sectors such as finance, insurance, social welfare, health, living environment, research of communicable diseases, pharmaceutics, health, labor, education, culture, science, radiation, environment, geodesy, mapping, standards, quality, measurement, contraction, roads, energy, communications, tourism, transportation, geology, mining, industry, trade, veterinary, growth, protection of plants, seeds, quarantine on food production and technology.

3.208 The state specialized supervision on the territory of Mongolia shall be implemented by the State Specialized Supervision Department, state general inspector, state senior inspector, state inspector, a local and border organization in charge of specialized supervision, state senior inspector, state inspector and environment inspector.

3.209 The State Specialized Supervision Agency has a vertically integrated management and has its offices in 21 aimags and districts of the capital city. These offices have two departments and 1 division.

3.210 The State Specialized Supervision Agency employs altogether 1250 state inspectors at national level, of which 320 are placed in the center, 290 in the capital city, 560 in the aimags and local governments, and 120 in border supervision offices.

3.211 Difficulties and bottlenecks encountered in the process of implementation of supervision: 
- Specialized supervision at national level necessitates a cohesive inspection information at the system-wide level. Besides, it involves communication with public organizations, which necessitates establishment of a unified computer network. The financial resources to resolve this issue represent a problem.

- Because the supervision offices were attached to the ministries and, thus, financed from the ministries' budget, they could not build sufficient material base of their own. The limited budget was barely enough for current expenditures, and the supply of computers and other equipment, necessary for supervision purposes is not sufficient. Local inspectors do not have computer access, and few computers in use are obsolete. Supervision offices do not have funds to purchase necessary technical equipment and devices. The situation is likely to persist.

- Provision 9.2.3. of the Law on State supervision prescribes: "undertaking measures to train, re-train specialized supervisors, and to create conducive working environment and guarantee social welfare of specialized supervisors". As was mentioned above, at the system level, 1250 inspectors are employed. Totality of the inspectors has not been covered in training activities on market principles, and no re-training activities are carried out.

- It becomes imperative to train state supervisors in foreign languages, professional, computer and technical trainings. This is pertinent also to newly employed inspectors.

- In the process of supervision and enforcement of legislation, there occur many incidents, which reveal the need to improve and streamline legal provisions. It is necessary to establish an information and research center where the inspectors could study cases and do research. This is a legitimate and timely requirement for regular up gradation of the professional qualifications of specialized supervisors.

3.212 Our inspectors operate in all sectors and undertake relevant measures to enforce and supervise implementation of laws and legislation, and to rectify violations and shortcomings. In that process state inspectors encounter many forms of illegal practices and operations. Thus, it is necessary to create conditions conducive to encouraging honest and just discharge of duties and prevent corruption and bribery among supervisors.

3.213 Provision 11.1.1. of the Law on State Supervision stipulates that "in case state inspectors use public transportation (except taxis) in the process of discharging their official duties, the payment for public transportation shall be compensated to the inspectors according to the relevant procedures." However, there are no financial resources to implement this provision of the law, and there are no possibilities to provide transportation to the local supervision offices and departments.

\section{Civil Service Reforms}

3.214 Civil service. Mongolia has started its transition to the market economy since 1990 and has been undertaking privatization processes and establishing an economic system with domination of the private sector. In parallel with these developments the structure of the administrative system, which plans and regulates the economy has been changed and the role of the public administration has been significantly modified. In conjunction with this, the reduction of public sector employees has been conducted several times since March 1990. Since 1994 an 
effort to properly identify the role of the public sector in the market economic conditions has been taken, and a project on the "Reforms in the Public Administration and Civil Service" was implemented with support from the Swedish government. Under this project the public sector structure was changed in 1996 to having 9 ministries and over 60 agencies. Each ministry was to have the Minister, the Sate Secretary, departments and divisions. In 2000 the number of ministries were increased to 12, and a position of the Deputy Minister was adopted. But still the civil service, public administration and special civil service agencies have performed some government duties and services. Ministries, agencies and the Governor's offices in aimags and the Capital City cannot develop adequately their strategic plans, and terms of reference for certain positions are remaining unclear.

- Due to the shortcomings in identification of an adequate number of civil servants to sustain the quality and accessibility of public services rendered by the State to the citizens, the resources for civil service vacancies, wages' fund and social protection measures cannot be appropriately reflected in the state budget.

- There is a shortage of necessary information needed for evaluation and assessment of the current situation with the public sector human resources, also the grass-root public organizations don't fully include data on the employed civil servants into the statistical reports on the number of employees and developments in the civil service. Then the employment in the higher level of civil service is not stable.

- No procedure on selection of the management level civil servants was adopted, so there is an absence of a proper mechanism of selection, and the civil servants lack of competence and expertise.

- Also there are still many cases when the issue with registration of the people, who passed the Civil Service Qualification Exams, and their appointment to the open vacancies in government institutions is not transparent and fair.

- There is a lack of objective criteria on identification of the civil servants' performance and level of professionalism. So the subjective attitude of managers plays an important role in promotion of employees. In addition, there is no legal environment is established for receipt, revision and resolution of citizens' complaints regarding the civil service employment issue.

- No internal monitoring methodology or mechanism is built in any level of public service, and there is a lack of an appropriate integrated system to identify the performance measurement of ministries, agencies and local administration institutions, to plan, report and evaluate their performance, as well as to reward or make them accountable for the actions taken by the civil servants.

- Although it is needed to employ in the public service only the people with a bachelor's or higher level of education, there are more than 15,000 civil servants, who have just a basic or special secondary education and who need further training in public management.

- There is only one state funded institution training civil servants and improving their qualifications- the Academy of Management. But its capacity, accessibility of the training and boarding facilities, level of refurbishment, services and students' vacancies are not satisfactory to meet the current needs.

3.215 The medium term budget reform policy will support economic growth by providing the financing needed for deepening the structural changes in the civil service and social sectors, and should become an integrated approach that provides economic guarantees for the people released from the civil service, reduces poverty and reforms the budget management process. 
However, in order to maintain fiscal sustainability the government will not undertake any measures to increase civil servants' wages in 2003, and increases for later years will depend on implementation of the broad-based civil service reform program.

3.216 One of the main objectives of the mid-term public sector reforms is to improve budget management, specifically to get certain civil service duties performed by other institutions on the basis of contracts and agreements, to commercialize the public sector, to eliminate overlaps in the vacancies and structures, to take strategic approaches in mid and long term budget planning, to link it to the pertinent development policies, to increase effectiveness of resource management and to improve the openness and transparency of the financial and functional performance measurement and monitoring systems.

3.217 The civil service reform or the introduction of a new model of result-based management is considered to be an inevitable part of the public sector reformations. The civil service reform aims to achieve maximum results at the minimum expenses, without decreasing quality and accessibility of public service. The reform shall cover the state administration, public service and special government agencies. In conjunction with this the privatization and structural changes of the social sector should be undertaken in line with main guidelines and list of institutions adopted by the Cabinet. Because the implementation of the government policies on poverty reduction can be assessed through the achievements in the health, education and social welfare sectors, a special importance should be attached to the reforms in planning and implementation of these sectors' budgets. Potential negative conclusions of the public sector reforms should be foreseen in advance, and it is needed to prevent from the increase of poverty through rendering support to these sectors based on the specific criteria. Therefore, effective measures to identify the products to be provided by the state funded organizations, to conclude performance contracts, to monitor implementation of these contracts, to assess and evaluate the results, as well as to reward or make accountable for the performances shall be systematically put in place. For the implementation of the civil service reforms the following measures shall be taken in the coming years:

- Not to appoint people to the vacant positions.

- To retire the civil servants, who reached the retirement age,

- To develop a procedure on allocation of the relevant allowances to people voluntarily leaving the civil service,

- To shift to the system of contracting outside performers to fulfill some duties and services,

- To reform the structure of ministries, agencies and Governor's offices of aimags and the Capital City,

- To shift to the principle of self-financing at the appropriate organizations,

- To implement the privatization, changes and reforms in the social sector according to the recommendations issued by the State Great Hural.

Within the mid-term reform of the civil service the following objectives shall be reached:

- A human resources planning capacity will be established for the purpose of supporting the economic growth; 
- To develop at an adequate level strategic business plans of ministries, agencies and all level state funded organizations in the aimags and the Capital City, to approve and implement the procedures on identification of the terms of reference and job duties for the civil service positions;

- To identify the personnel needs in the civil service, to develop standardized methodology of human resources planning that would meet the requirements, and to introduce this methodology to some ministries and aimags;

- To identify, assess and evaluate the situations with the human resources in the civil service based on the synthesizing of the detailed civil servants' registers provided by the aimags, the Capital City and ministries;

- To train the staff in charge of human resources information issues, to provide state funded organizations with necessary equipment and to develop a capacity to effectively plan and regulate the location and movement of civil servants.

- A new information system on the civil service human resources management (with the appropriate criteria) will be established.

- To renovate and utilize the civil service human resources information indicators that would comply with contemporary international standards;

- To develop with involvement of the World Bank experts a program software on the civil service human resources information management that meets the international standards and could be utilized in both Mongolian and English languages;

- To create an integrated countrywide information network on the civil service human resources.

- To establish an integrated system of collecting and synthesizing realistic data from all level public institutions through installing a new information technology network on human resources information covering all public institutions.

- A system on selection of all-level civil servants based on the principles of openness, transparency and merit encouragement will be put in place.

- To establish according to the relevant laws a Commission on selection of civil service managers;

- To create properly a pool of candidates, who passed the civil service manager selection exams, and to organize in a fair manner a process of nomination to these positions that would meet the legal requirements;

- To renovate the procedures on professional examination given to the candidates to the civil service positions based on the principles of openness and transparency, and to get the procedures adopted and implemented by the Civil Service Council;

- To develop and approve a standardized and integrated procedure on assessment and evaluation of the job performance and professional qualification of all level civil service managers that have concluded performance contracts.

- A legal ground will be established for resolution of complaints related to the promotion of civil servants. 
- To study in details the criteria for promotion and ranking of civil servants, and based on the research findings to develop and approve a procedure regulating this issue;

- To create a legal ground for resolution of the complaints and conflicts raised in connection to the promotion of civil servants;

- Competence and skills of civil servants will be improved in line with the reforms and developments in the public sector.

- To study and identify the training needs of all level civil servants in conjunction with the mid-term strategies by utilizing the conceptual, quantitative and other indicators;

- To develop and implement an integrated policy on internal and external training of civil servants;

- To organize gradual measures on involvement of the managers of all-level public administration and local self-governing bodies into the in-service training in 2003-2006 according to the "Program on supporting the training, knowledge and skills in the civil service" approved by the Government Decree 96 of 1999.

3.218 Conclusion. The Government will ensure the macroeconomic stability in the long and medium terms, reduce poverty and increase economic growth as a result of restructuring and reforms at levels of public sector. One of the main priorities of the strategy is to avoid and prevent from poverty and eliminate negative consequences of restructuring and reform process. The reforms to be undertaken in the public sector shall not only ensure fiscal sustainability and improve public expenditure efficiency, but also increase asset resources to promote the quality and access of public services for poor. The fiscal sustainability is the basis to ensure macroeconomic stability. The stabilization of prices and the exchange rate, increasing economic growth, and reducing and eliminating the trade deficit in long and medium terms will establish a stable macroeconomic situation. By implementing the public sector reform policy, the Government will use its own resources and receive the technical assistance of international organizations. 


\section{CHAPTER 4: IMPROVING ACCESS TO MARKETS}

\section{Creating a Favorable Operating Environment for Business}

4.1 Since 1990s when Mongolia started to transfer to market economy, many important actions have been taken to set up a favorable environment for development of private sector. The reforms in the strategy and state sector being done to ensure sustainable macroeconomic situation are also factors of the favorable environment.

4.2 To set up a favorable environment for running business aimed to accelerate economic growth based on private sector for long and medium-term is a priority in the policy of the Government of Mongolia. The Government has been implementing the policy and taking actions to create economic favorable conditions to run small and medium businesses and manufacturing and challenge people's activeness and initiatives particularly in rural areas by ensuring the macroeconomic stabilization, keeping inflation rate stable and expanding foreign and domestic markets.

\section{Legal Reforms}

4.3 Background. Legal reforms and their impact are important for successful implementation of the reforms which are taking place in our society.

4.4 It can be said that the creation of rational legal environment to regulate new relations in the society and to enhance and reform laws and regulations, has started with the ratification of the Constitution of Mongolia in 1992 according to the concepts stated in this document.

4.5 The process of legal reforms in Mongolia can be divided into 2 basic stages: first one is 1992-1998 - from the ratification of the Constitution of Mongolia until the ratification of Program on Legal reforms, and second one is since 1998 up to present. During the first stage of the legal reform, between 1992-1998, a stock of important measures pertaining to securing the state's sovereignty and independence, safeguarding human rights and liberties and other measures in the social, economic and political areas were undertaken in conformity with the principles and ideals of the Constitution. Particularly, a number of laws, to name but few Election Law, Law on the Legal Status of the Parliament, of the President, of the Government respectively, law on territorial and administrative units, law on budget, defense, laws directed at improving the regulation of border and customs relations, were enacted. On economic arena, Privatization law, Economic Entities Law, Law on Bankruptcy, Taxation, Banking, Law on Restricting Unfair Competition constitute just a fraction of economic laws. 
4.6 The provision of the Constitution of Mongolia which states that all forms of property are equal established the basis of development of private sector. In 1990-2000 the was Company adopted and improved due to a number of amendments. The Law on Restriction of Unfair Competition has been followed since 1994. The actions to reduce a number of licenses and restrictions which have to be obtained in order to run business by private sector enterprises are being taken lately. During this period, the Parliament adopted about 180 separate laws, changed and amended over 200 laws and joined about 60 international treaties and conventions.

4.7 In 1998, with the view to deepen the legal reform and approach legal reform within a planned and cohesive policy framework, the Parliament approved the Legal Reform Program. The approval of this Program marked the start of the second phase of the Legal Reform in Mongolia.

4.8 According to this program, general guidelines to improve Mongolian laws and legislation up to the year 2000 were approved, and within this task, it prescribed to adopt 118 laws, of which 70 bills have been approved.

4.9 The particular document states that "The objective of the legal reform in Mongolia is, with the view to implement the goal to develop humane, civic democratic society in Mongolia, and according to the principles and ideals, proclaimed by the Constitution, to define basic activity lines to be implemented by all-level state organizations and state officials and create favorable legal basis and environment to ensure political, social and economic development and progress of Mongolia”.

4.10 Then, in 2001, the Parliament approved the basic guidelines to improve Mongolian laws and legislation up until 2004. The guidelines direct to adopt 136 laws, of which over 60 laws have been enacted.

4.11 The actions to decrease the fees and inspections in customs have been taken since 2002 when the resolution on reduction of a number of licenses to conduct manufacturing and services was issued. Hence the legal environment has become more favorable. In 2001 the Parliament adopted the Law to Support Employment, Law on Exporting and Importing Labor Forces respectively with the aim to create legal basis for state policies and operations on employment promotion, and define their types, forms and scopes, and to establish legal grounds for organizations to support and promote employment.

4.12 Within the social policy framework, the Law on Health Insurance of Citizens was approved in 2002. Founding upon the provision of the Government's Action Plan to "ensure independent development of the health insurance system", this law was enacted with the view to improve the health insurance system, efficiently link the health insurance fund formulation, allocations and spending with the specifics, policies and strategies of the sector, and ensure that every citizen holding health insurance gets the benefits of the insurance.

4.13 Besides, the Parliament revised the Package of Laws on Education, on Primary and Secondary Education, on Tertiary Education, on Vocational Education and Training. Among these, the Law on Vocational Education and Training is a new law, which determines the objectives, content, structure, management and organization of vocational education and 
regulates relations pertaining to provision of education, upgrading professional and vocational capacities and organizing vocational training. In the period prior to the adoption of the law, state vocational training policies were, to some extent, neglected. In that sense, this new law has become an important measure to educate and improve the living standards of mid and below level population.

4.14 In 2003 the Parliament adopted General Guidelines on the social sector reform and privatization. These Guidelines were approved with the view to increase private sector participation in social sector, promote competition and increase the efficiency and quality of services adjusting to the needs and demands of the population. The Guidelines fully identify the principles, forms, coverage and measures pertaining to social sector reform and privatization.

4.15 Although many laws addressing poverty, unemployment, public utilities and health issues within the social policy framework are being enacted, there is still a need to improve and revise these laws. Particularly, the issues on health insurance of poor citizens, minimum wages and minimum subsistence level need to be revisited, and their pertinent laws should be revised, which altogether would greatly contribute to alleviation and reduction of poverty.

4.16 The year of 2002 has been a year of reform and changes for the judicial branch. In 2002 a host of measures were implemented with the aim to improve the legal basis for judiciary organizations, introducing changes in the functions and organization of law enforcement organizations, which further grow into wider measures directed towards securing public order, safeguarding and consolidating human rights and liberties. Particularly, the Civil Code, Criminal Code, Law on Court Procedures of Civil Cases, Criminal Procedures Law, Law on Courts, Law on Court Decision Enforcement have been revised, and changes and amendments were made to the Laws on Prosecution Organization, on Advocacy, on Notary, and on Police Organizations.

4.17 Substantial amount of work was done to improve economic laws, law on budget and finance. Particularly, laws on Securities Market Law, Non-Bank Financial Operations, Law on Free Zones, Law on Altanbulag Free Trade Zone and the Law on Introducing Changes and Amendments to the Cooperatives Law have been adopted.

4.18 The Law on Public Sector Finance and Management was adopted in 2002. The objective of this law is to increase the efficiency of fiscal expenditure, create optimal fiscal management system, improve the productivity of public organizations, ensure transparency of fiscal expenditures, increase the accountability of budget managers and clarify the powers and responsibilities of local administrative organizations.

4.19 It is worth emphasizing that the issue to combat corruption has been an important component of the state policies. In this respect, in 2001 National Program to Combat Corruption was adopted and the National Council was appointed. The 1996 law on Corruption was not adequately implemented. Civil participation, their support and assistance are critical in achieving sustainable success in the combat against corruption. That's why, this program was approved as a long-term policy, which brings together and combines the efforts of the state and the civil society to fight corruption. The objective of the program is to build conducive environment and conditions to fight corruption, stimulate a social atmosphere intolerant to corruption, prevent 
corruption relying upon the cooperation between the state, civil society and the private sector, which lead to eradication of reasons, causes and conditions nurturing corruption.

4.20 One of the measures carried out to reduce bureaucracy and red-tape in state organizations assigned to combat corruption and to support economic activities of citizens and legal bodies was the adoption of the Law on Licensing Economic Activities. According to this law, the number of Incenses required to set up a business was reduced from over 600 licenses was reduced to 95. This is how the legal environment to run business has been created.

4.21 Advertising and implementation of laws and regulations. The consideration and input of public opinions in the development of draft laws is one of the main concerns. This issue has been regulated by the laws on drafting and presentation of laws and other decisions of the Parliament of Mongolia. An initiator of a law is eligible to take opinions of scholars, nongovernmental organizations and citizens on a draft of a law. Also the law authorizes the Parliament of Mongolia to make final resolution when a law draft is being put for the public discussion.

4.22 Except the mentioned law, there are no legal acts to regulate this issue. The time has come to develop sustainable mechanisms to receive public comments in drafting laws, which adequately respond to and meet public needs and requirements.

4.23 Innovative approach is needed for better publicizing and advertising adopted laws and legislation. Although a large number of laws are being enacted by the state, advertisement and publicizing of these laws are inadequate, and that's why the laws fail to play their designated roles in the society. This is especially a concern in rural areas, with the major reasons for inadequate advertisement being financial shortages and fiscal constraints. Besides, lack of initiative and commitment on the side of public organizations and officers has also something to do with inadequate advertisement of laws.

4.24 Medium term objectives: The Government's Action Plan, the Legal Reform Program, General Guidelines to Improve Mongolian Laws and Legislation up to Year 2004 and the SocioEconomic Guidelines for 2003 and other policy documents will be the leading documents to be guided by in our further efforts to deepen the legal reform and improve laws and legislation of Mongolia.

4.25 The immediate goals to be pursued within the legal reform and strengthening of governance will with be "to advocate human rights and develop conducive environment for peaceful and free development of people through deepening the legal reform and strengthening good governance for human security". Within this framework, specific attention will be given to developing and presenting for Parliament approval of the laws, prescribed by the General Guidelines to Improve Mongolian Laws and Legislation up to year 2004.

4.26 Increased attention will be posed for advertising and ensuring the implementation of approved laws. Particularly, Socio-Economic Guidelines for 2003 (also merited in medium term policy matrix attached to this document) state:"...availability, quality and efficiency of legal manuals designated for economic entities and citizens' legal knowledge, will be improved, and organization of legal advertisement will be optimized in proper ways; especially, efforts will be 
made to publish and deliver legal manuals to soums and bag level residents". Also, "enforcement and implementation of newly adopted laws on judiciary will be promptly organized, and in conformity with them, the rules, procedures and organization of court and judiciary organizations will be reformed".

4.27 Within the framework of the policy objective to reform the public administrative organizations, measures are being undertaken to change and amend the Law on Administrative and Territorial Units, and their Management, elaborate a draft Law on Legal Status of Ministries and Agencies and reform the operational standards, rules, instructions and procedures of public service.

4.28 At the moment, the draft laws on Registration of Legal Entities, on Arbitration and the law on Selection Procedures for Lawyers, initiated by the Government, are being prepared for discussion of the Parliament. The Government is working to elaborate draft Laws on Insurance, on Bankruptcy, on Non-Profit Legal Entities, on Registration of Immovable Assets and on the Fund to Recover for the Losses Incurred by Crimes. The basic sectors of infrastructure such as energy, roads and communications play a significant role in running of economic activities in order to accelerate the economic growth and alleviation of poverty. Therefore, infrastructure is the main accelerator of the economic growth and gives an opportunity to create income among people, particularly for poor people.

\section{Infrastructure}

4.29 Development of energy, road, communication and information is of vital significance for creating favorable environment for businesses. It can be said that this is one of the specific features of Mongolia. Mongolia has a small population sparsely located throughout the territories. That's why the material base per square $\mathrm{km}$ is extremely small.

4.30 Energy supply. Mongolia's energy sector comprises of the Central Energy Grid (CEG), western and eastern energy network, diesel power stations and thermo-power stations. CEG covers 11 aimag centers and 102 soum centers; Western Energy Network covers 3 aimag centers, 8 soum centers; aimag energy systems cover 12 soums and 3 soums are connected to a thermal Power Station. In this way, the Central energy system covers 44 soums, and the rest soums are provided with energy from small-scale local diesel stations. They have been rehabilitated through grant aid by the Government of Japan. Because of geographic location and different level of income, the soum energy supply and volume vary by soums. Thus the Mongolian energy sector comprises of the CEG, Eastern energy system, Western energy system, local diesel stations and thermal power stations that supply energy to aimags and soums which are not connected to the CEG.

4.31 As of today over 40 percent of the central region and over 50 percent of the total population are supplied with energy from the Central Energy System (CES).

4.32 The Central energy system operates 7 power stations, of which 2 are located in the countryside, with total installed capacity of $764 \mathrm{Mwt}$. 
4.33 Mongolia operates $1044 \mathrm{~km}$ long $220 \mathrm{kwt}$ electricity transmission line, $2500 \mathrm{~km}$ long $110 \mathrm{kwt}$ transmission line and over $4000 \mathrm{~km}$ long $35 \mathrm{kwt}$ transmission line respectively. There are also 5 substations for $220 \mathrm{kwt}$, over 150 substations for $35 \mathrm{kwt}$ and $110 \mathrm{kwt}$.

4.34 The 36 mwt thermal PowerStation, located in the Dornod aimag center, started supplying energy to Suhbaatar aimag center through the Choibalsan-Baruun-Urt electricity transmission line, thus laying down the foundation to small, independent energy supply in the eastern part of Mongolia.

4.35 Dalanzadgad 6 Mwt thermal station was put into operation in 2000, thanks to which the Umnogovi aimag center and the adjacent soum centers and tourist camps acquired a reliable source of energy.

4.36 Diesel stations are used in soums, not connected to the central energy system. Diesel stations are expensive to purchase and costly to maintain. Thus, the soum residents consume energy during the daytime for a limited number of hours. Hospitals, schools and other organizations barely survive winters; small industries which use energy also cannot support and maintain their regular, uninterrupted operation. Herders, who account for about 40 percent of the population, are basically not provided with energy, and only 10 percent of herding households have small-scale electricity generators capable to produce energy for electric lamps and other minor use. That's why the households which are not supplied with energy and heat, are likely to impoverish.

4.37 Aids and loans received by the government are spent for repair and rehabilitation of power stations, however, the system employs obsolete technology, runs costly lines with huge technical losses and seriously threatening natural environment. Produced heat and energy are expensive and low-income citizens as well as small entities encounter difficulties with their energy affordability.

4.38 Mongolia's energy sector is the vital part of Mongolia's infrastructure, economy and the society. It is clear to anyone that the country's social, economic, regional and other sectoral development is directly associated with the operation of the energy sector.

4.39 Improving infrastructure, in particular, creating a reliable energy system is the basic precondition for reducing poverty and supporting regional development.

4.40 Because of the tough price control for many years, the energy sector is not able to cover its expenditures with its revenues. The sector is incapable to finance its investment, technological renovation and repair works, and received the lion share of foreign aid and credits.

4.41 In 1992-2000, 400 million USD worth foreign loans and aid were spent for partial rehabilitation and supply of spare parts. These efforts resulted in some recovery of the sector, showing signs of stabilization, however, the crisis situation has not been completely eradicated.

4.42 Fifty per cent (50) of the population is supplied with energy from the central energy system. The central energy grid is strongly centralized and is 100 percent owned by state. The system has weak capacities to regulate generation, transmission, distribution and supply of energy, has difficulties with the pursuit of flexible tariff and price system consistent with market 
principles, has poor collection, has duplication of managerial efforts, is under constant financial constraints, bound in numerous arrears' webs and undergoes huge technical losses. Under such circumstances, there was an urgent need for creation of a legal environment for a structural reform and transfer the system to a commercial regime. In 2001, the Parliament approved Energy Law, and the Government has started its enforcement. In this regard, important steps have been taken to transfer the system to market principles, create independent state regulatory mechanism, create conditions for private sector to enter the energy system and create legal environment for promoting competition in the sector.

4.43 A crucial part of the energy sector restructuring has been the creation of an independent regulatory mechanism - establishment of the Energy Regulatory Authority, which enabled investment and operation by new domestic and foreign economic entities. Creation of an independent regulatory environment has created conducive environment for generating, transmitting, distributing and supplying energy at cheap prices, promoting competition and increasing the efficiency of energy services.

4.44 State owned energy entities have been dismantled according to their lines of business and in their place 18 state owned shareholding companies and companies with limited liabilities have been established. The shares of these companies are owned by the Ministry if Infrastructure, State Property Committee, Ministry of Finance and Economy according to the provisions of relevant legislation.

4.45 A number of initiatives are being done with the view to attract private investment in the energy sector. Such activities include settling arrears among users, distribution companies, power stations and co amines; bringing the tariffs to the level where the stations could recover the costs with revenues; reducing the distribution line losses, improving collections and introducing latest techniques and technologies in improving the payment invoicing and claiming system.

4.46 A working group, formed by the joint order of the Minister of Infrastructure and the Chairman of the State Property Committee \#214/155 of 2002 is elaborating the policy to increase private sector participation in the sector and the policy of privatization.

4.47 In 2003, we are planning to privatize "Ulaanbaatar \#2 power station" SC, "DarhanSelenge electricity distribution network" SC, and planning "Ulaanbaatar electricity distribution network" SC for privatization. In 2002 energy construction "Altai" state owned enterprise of Hovd aimag was privatized in an auction, and in 2003, "Baganuur thermal Station" SC and "Nalaih Thermal Station" have been privatized on the basis of management contract. Energy law was adopted in 2001 and 18 energy shareholding companies have been established, which was a significant step. Besides, the energy price was liberalized, and measures were undertaken to raise energy prices. All diesel stations of soums not connected to power stations have been rehabilitated in 2000-2002 with the assistance of Japan. Every year 400-600 km long electricity transmission lines are being built with the state budget funds and measures have been taken to connect aimags and soums to the central energy system.

4.48 Several measures have been undertaken in 2000-2002 to construct hydro-power stations using cheap, less-costly water resources, and to resolve their financial resources issues. 
However, the work undertaken to fully supply rural areas with reliable energy sources, electrification of herding households, establishing united energy networks, and fully meeting energy demand remain cumbersome. These difficulties in their turn represent barriers in developing SMEs in rural areas, generating employment, and reducing poverty.

4.49 Coal is the main energy source for Mongolia. Coalmines are operating under the full or partial ownership of the state in the form of shareholding companies. Coal is sold of the prices set by the Board of Directors of the coalmine.

4.50 Mongolian coalmines are placer deposits (surface mines), and the technical renovation which began in mid 90s at larger mines has been basically completed in 2002 .

4.51 As some coal mines deposits have been utilized extensively for long time, especially in regions with highly populated and industrial concentration, their deposits are near to exhaustion and mines are technologically outdated. One of them is Shariin gol mine, located in the Central region. To continue to maintain reliable coal supply of the main economic region, technological renovation at coal mines continues, and new coal exploration activities are carried out in Darhan and Selenge aimags. As a result, preparations are made to exploit Ulaan Ovoo mine deposit, which is vital for this particular region's economic and social development. In particular, coalmines play certain role in supplying coal to poor citizens. Specifically, a policy to supply poor people in settled and urban areas with cheap coal is to be pursued.

4.52 There have elapsed two years since a procedure was established to settle the arrears that had been accumulated prior to October 2000 within a given schedule and to pay on each occasion for the supply of coal delivered after that period (after October). This procedure has proven to be useful as no more arrears have emerged. Full collection of energy consumption bills is very pertinent to the recovery and settlement of all arrears. The arrears that had been accumulated before October 2000 were reduced by 7 billion tugrogs as of February 2003, reducing by 41 percent. In this way, Ulaanbaatar 3 and Darhan Erdenet power stations have fully paid off their arrears.

4.53 The major mid and long term policy for the energy sector will be to ensure sustainable development of the energy sector, create environment for efficient production of energy, increase the economic efficiency of the sector, support the use of renewable energy resources and commercialize, and furthermore privatize in a step-by-step manner state owned shareholding companies of the energy sector.

4.54 The "Mongolia Sustainable Energy Sector Development Strategy Plan for 20022010" approved by Government Resolution \#140 on July, 2002, shall be implemented stage-bystage. The Mongolia Sustainable Energy Sector Development Strategy Plan for 2002-2010 was elaborated with the assistance of donors and is a policy paper, consistent with the EGSPRS.

4.55 The strategy to ensure sustainable development of the energy sector for the period between 2002-2010 is based found upon the following principles. These include:

4.56 By strengthening financial independence of the sector, to ensure that the energy sector provides an impetus for the country's economic and social development, to mitigate and gradually eradicate the sector's burden for the state budget 
4.57 By implementing the sector's structural reform, to commercialize the sector and increase the participation of the private sector

4.58 By improving the structure, organization and managerial capacities, to ensure successful transition of the sector to the market relations

4.59 By improving the supply of energy and creating a pricing mechanism tied to the subsistence level, to ensure that the users in rural areas and low-income clients benefit from the restructuring of the sector

4.60 By conserving the energy, to increase efficiency and ensure environmental sustainability.

4.61 With the aim to increase the efficiency of the energy sector and accelerate economic growth the utilization of cheap energy resources will be expanded. Within the framework of this policy, hydropower stations will be constructed in rural areas and the length of electricity lines will be extended.

4.62 Most of the arrears in the energy sector involve household use of energy, especially by low-income users. Given this reality, a flexible energy price and tariff system will be elaborated and introduced. In doing so, a policy to provide for the minimum energy and heat needs of poor citizens shall be pursued. In relation with this, possibilities to reduce the impact of the energy and oil products' price increase on poor people's livelihood shall be studied. The energy distribution network shall be privatized at the first order and the collection of sales will be improved.

4.63 With the aim to ensure accessibility of public services to the rural population, in particular, to the remote soums and settlements; to develop small and medium size enterprises, and meet the household needs of citizens, the renewable energy resources will be broadly used. In this way, energy sector development shall speed up economic growth, create jobs, and thus, play a leading role in poverty reduction.

4.64 Transportation. Mongolian transportation services consist mainly of auto, air and railways services.

4.65 Auto roads, bridges. Mongolia has $11,063 \mathrm{~km}$ of national roads, $1,317.6 \mathrm{~km}$ or 12 per cent of which asphalted, 1,379 $\mathrm{km}$ or 12.5 per cent gravel, and the remaining natural soil roads. The Government is directing its policy towards building new roads, rehabilitation of existing roads, and improving the road utilization. Under a structural reform in the road sector carried out by the Government, road construction and rehabilitation and maintenance entities have been split into 2 sections: rehabilitation and maintenance section left under the state ownership, road construction - privatized. With this reform road and bridge rehabilitation and maintenance work is done by entities with small set-up. In addition, certain sections of road are contracted out to individuals for rehabilitation and maintenance, and it is giving results. Due to poor road condition much time is lost, and high costs are incurred; this poses a difficulty in running a business in the countryside and developing market relations. In 2001, the Parliament of Mongolia adopted a great project "Millennium road" to build a horizontal road from the west of the country to the east and 5 vertical roads. The development of these roads will expand not only 
regional but also Mongolia's foreign trade and cooperation and enable the link to unified network of Euro-Asia infrastructure, thereby gain an access to sea as well as to trans-Asia highway.

4.66 The $200 \mathrm{~km}$ vicinity of the Millennium road is estimated to cover $1 / 3$ of the territory, 77 per cent of the population and 72 per cent of central settlements.

4.67 In view of fast development of political and economic relations between Russia and China, the volume of goods and passengers transported through the territory of Mongolia is increasing rapidly. Auto-transportation from Russia to China through Kazakhstan is $539 \mathrm{~km}$ longer than through Mongolia.

4.68 Owing to utilization of loans and aid from donor countries and international financial institutions such as Japan, World Bank, ADB, and Kuwait Foundation in the road sector, equipment and technology used in road construction has been upgraded to a certain level with increases in the capacity, but much remains to be done in road and bridge construction works still remain much.

4.69 In planning rehabilitation and maintenance funds for national roads, funds are distributed on the basis of technical utilization level. Road fund sources are used for rehabilitation and maintenance of national roads and road facilities.

4.70 Within the Millennium road project, asphalting of the UB-Baganuur road and road rehabilitation at big hills and bridge construction in the west is underway. With financial support from large foreign donors the $400 \mathrm{~km}$ UB-Suhbaatar-Altanbulag road is being improved, and the $200 \mathrm{~km}$ Nalaih-Choir asphalted road built. With credit funds from the Kuwait Foundation, the $184 \mathrm{~km}$ Darhan-Erdenet road is being built, under a World Bank project western direction roads are being improved and the $420 \mathrm{~km}$ UB-Arvaineer road renovated. In this manner, the road construction work was significantly facilitated in 2000-2002 with funding increased at the same time.

Figure 4.1: Road Investment, MNT billion

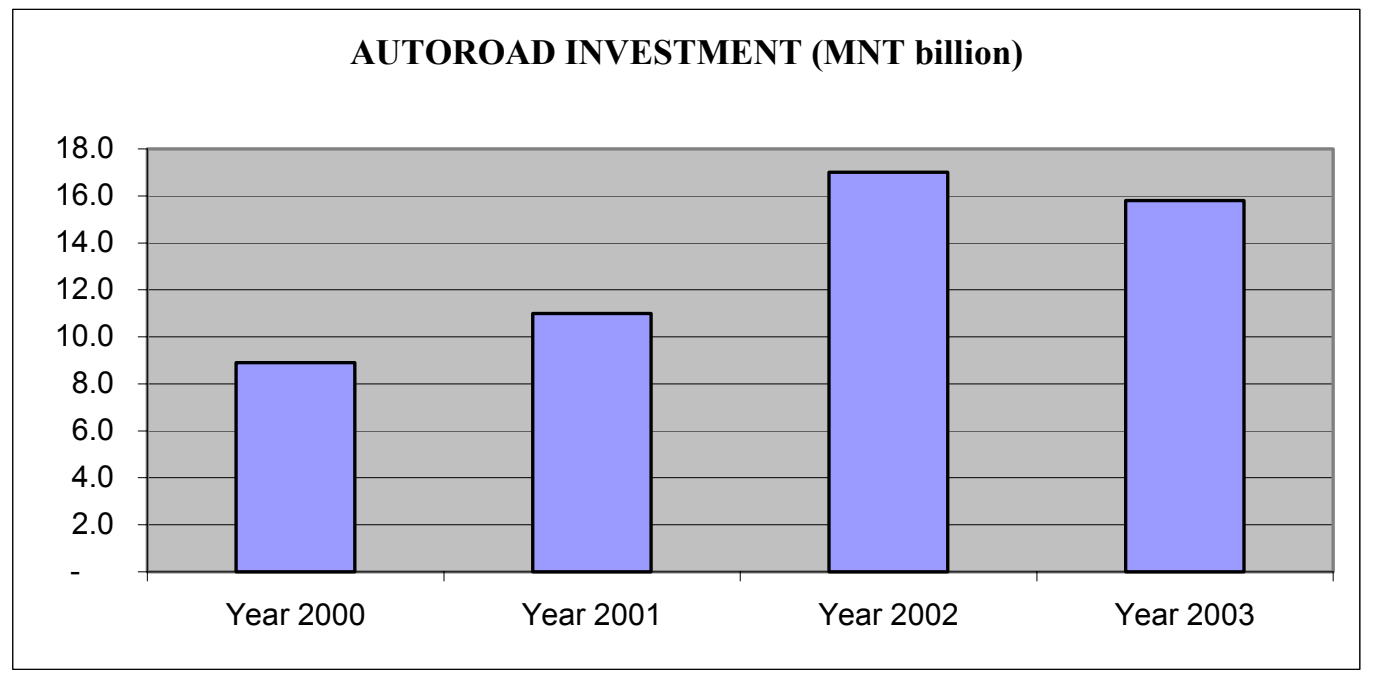


4.71 Blue-print and documentation for the $140 \mathrm{~km}$ Erdenet-Bulgan-Murun and $220 \mathrm{~km}$ Baganuur-Undurhaan roads have been developed. Facilitation of road construction was accompanied by increased road rehabilitation and maintenance involving hundreds of unemployed local people, which is making contributions to poverty reduction.

4.72 In this fashion, improvement of road and transportation services is being a factor in poverty reduction, especially by bringing herders closer to the market, delivering social and public services to the population, and creating numerous new jobs in the countryside. Many cases of traffic incidents because of bad road, imperfect car, and unskilled driver is also another factor of poverty. As roads and bridges play an important part in bringing regions together by developing transportation infrastructure and ensuring its reliability and security, the Government is attaching dear to de sector importance. Good roads would significantly save cost and promote business operations.

4.73 One of priority goals of the Government in the mid and long-term is improvement of the inter-city road network and continuation of construction of vertical and horizontal roads. This road network is considered to become a development basis for auto transportation and facilitate the development of local economies along the road and their effective partaking in market relations providing for an environment for business development in the rural areas and increasing the income source of the population and access to domestic and foreign markets. Income of poor individuals will be increased by creating jobs through extensive partaking of unemployed and local people in road and bridge construction work.

4.74 Efforts and attention of individuals will be mobilized towards construction of lowcost roads, especially rehabilitation and maintenance of roads and bridges involving the poor and increasing their income.

4.75 Contracting out rehabilitation and maintenance works in city and local roads and bridges will be continued increasing the input from individuals and private sector.

4.76 Auto transportation. Mongolia has over 140,000 vehicles; all vehicles except those owned by 3 public transportation pools, 1 trolleybus pool, and few numbers of state administrative offices and state-owned factories have been privatized.

4.77 Inter-country and inter-city passenger transportation is carried out under tender selection. State-ordered freight transportation is carried out by auto transportation pools transformed into joint stock companies.

4.78 Public transportation of UB city is provided by 250 buses and 90 trolleybuses of 4 state-owned companies, 220 large-scale and 1,800 small-scale buses owned by individuals and private companies. Most of them are outdated in terms of utilization timeframe.

4.79 In order to promote the replacement of obsolete out-of-standard buses amendments to the law on customs tariffs and VAT were made last October.

4.80 Several foreign investment companies are rendering taxi services in the UB city public transportation. 
4.81 Under Government decree No. 8 of 2002, the government of UB city was assigned with the duty to organize management privatization of state-owned companies such as Autobus2, Autobus-3 and Electronic transportation. Privatization work of Autobus-3 companies has been launched.

4.82 In inter-city passenger transportation over 30 entities are offering 60 routes from UB to the countryside. According to resolution No. 115 of Deputy Infrastructure Minister of 2002 local governors have been sent the generic operating rules of aimag and UB city transportation regulation offices and sample agreement between Aimag and City governor and Head of transportation regulation office and provided with relevant advice and instructions. Transportation regulation offices had been established to put in order individuals and entities engaged in passenger transportation and regulate their services. It is worth noting that this has enabled the restoration of passenger transportation and postal delivery from aimag centers to soums which was cancelled in last 10 years.

4.83 UB is the crossroad of national passenger transportation, but still does not have passenger transportation terminals consistent with modern standards. Although the road connecting UB and big cities is being built and rehabilitated, the vehicles used in transportation do not satisfy the passenger comfort requirements.

4.84 Technical and technological reform in the transportation sector is being implemented through WB and NDF funded projects to reduce harmful factors of vehicle utilization on people and the environment, establish an optimal structure that ensures the security of technical utilization and traffic, and technical monitoring networks for policy enforcement purposes. Under the projects, vehicle technical monitoring review and diagnosis centers will be established in UB, Darhan, Erdenet and aimag centers.

4.85 Railway transportation. Initially established in 1949 as joint venture of Mongolia and Russian, Mongolia Railway is now executing 90 per cent of national freight turnover with 1,815 $\mathrm{km}$ of railways connecting Russia, China and big domestic industrial cities.

4.86 The railways have accomplished a lot of work in the field of renovating engine facility pools, improving rails, increasing the capacity, strengthening the technical capacity of border ports, upgrading repair technology of communication and engine facilities. Examples are an installed optic cable network along the railway in 2000, which enabled the establishment of a unified communication network and communication of production.

4.87 Freight turnover was 133.8 tones in 1995, in 2002 it has increased 23.1 times. At a conference on agreement of railway freight shipment by the International railway cooperation Organization it was agreed that 4.6 million tons of transit freight would be transported through Mongolia by railways. This shows that Mongolian railways' competitiveness in the main-land transportation network has improved significantly. However, there are still many constraints such as our railway was built in a fast manner after World War II, too many turns, steep ups and downs, one road for 2 way traffic, limited transmittance capacity, small capacity of roads and engines. All these limit the possibility to increase the turnover of transit freight through Mongolia. 
4.88 In the mid-term, a Master plan for railways will be developed, and priority actions will be carried out to carry on the replacement of engine pool and expand the freight and transit capacity.

4.89 Air transportation. 100 percent state owned MIAT, private companies such as Hangaird, Central Mongolian Aviation, Mon, and foreign investment companies Tengeriyn ulaach, Blue sky are operating in the aviation sector of Mongolia. Although private and foreign investment aviation companies are operating they do not have sufficient technical capacity to compete with MIAT and offer regular domestic and international regular flights.

4.90 Mongolia has 22 airports, of which Buaynt-Uhaa and Ulgiy airports serve international flights. The Buaynt-Uhaa airport is the door of Mongolia to foreign countries as well as cross-road of local flights. With development of tourism and increasing number of tourists, there is a need to increase the number of international flights and airplanes.

4.91 The Government is attaching a significant importance to attracting foreign investment into the aviation sector and to replace the plane pool and expand operations of MIAT. However without a competition in domestic and international flights of Mongolia's aviation there is a risk of emergence of price monopoly in one company and no progress in the service quality. Therefore, the government is implementing a policy of privatizing the aviation. In coming years actions will be taken as to replacing the plane pool of domestic flights, increasing international flights, adding more planes, and privatizing MIAT.

4.92 Information and Communication Technologies (ICT) The Government of Mongolia recognizes that ICTs have an important role to play in its development. They offer a platform for building and applying knowledge; facilitate participation in trade for isolated communities and SMEs as well as corporations; are critically important for national competitiveness; and allow for improved delivery of public services. As a result these technologies offer the opportunity for accelerated economic growth and poverty alleviation. The input of ICT in the Mongolian economy is increasing. In particular, the share of ICT sector in GDP was 1.44 in 1995 reaching 5.3 in 2000. In 2001-2002 ICT sector paid over 10 percent of tax income of the budget and 7.0 percent of VAT collections.

4.93 The Government of Mongolia approved the Medium Term Strategy for the Development of the ICT sector and an Action Plan for its implementation in January 2002. Further, the Government also approved the Communications Law of 2001 and has established the Communications Regulatory Commission to regulate the telecom sector. The ICT Department has also been established within the Ministry of Infrastructure. The Government of Mongolia implemented policy and regulatory framework for building the appropriate regulatory and management structure, and renovation of the backbone telecommunications network.

4.94 The first law on Communications was passed in 1995; in line with developments and market situation in ICT the law updated in 2001 and provided for establishment of an independent regulatory institution and a fund for universal service obligation. This was an 
important step towards supporting private investment and fair competition and is appreciated by international ICT organizations. The Parliament of Mongolia passed a policy document called "Vision until 2010 for ICT sector of Mongolia" in February 2000. The main objective of this document is to ".build a community based on knowledge and mental capacity and improve the living standards o the people.".

4.95 The Government of Mongolia's mid -term ICT strategy identifies harnessing the potential of ICTs as a key driver of development and is supported by four pillars which include (i) establishing the appropriate policy, legal and regulatory framework; (ii) developing the key telecommunications and information infrastructure necessary for providing access to reliable and affordable connectivity; (iii) establishing an economic and business framework for the utilization of ICTs in governance and other applications; and (iv) developing human resources to effectively utilize ICTs.

4.96 In order to develop the information infrastructure in Mongolia, the Government places priority on: (i) developing government capacity to lead and implement a national ICT program; (ii) establishing a policy and regulatory framework that encourages the competitive provision of affordable and reliable telecommunications infrastructure and services; (iii) establishing an appropriate legal and regulatory framework for the development of e-services; (iv) further privatizing Mongolia Telecom (v) digitizing the transmission network between aimags and soums, to enable internet connectivity; (vi) establishing appropriate institutional and regulatory frameworks for public-private partnerships in the provision of rural access to ICTs; and (vii) to increasingly utilize ICTs, especially the Internet in the social services sector, with a focus on education and health.

4.97 As part of the objective to develop human resources, the Government intends to (i) mainstream IT into the education curriculum; (ii) organize schemes to provide basic knowledge of IT to the population, to support primary, intermediary and advanced IT courses and centers using economic policies, tax policies and other policies, and to enable broad enrollment/ involvement of the population in such training; and (iii) develop distance learning based on ICT, to create a system of acquiring formal education through open training programs, to support training centers that conduct training in the use of electronic text books.

4.98 As part of the objective to support the development of business and the private sector, the Government intends to create a favorable policy and regulatory environment for ICT related private sector led development.

4.99 Mongolia has made considerable progress in developing its information and communications infrastructure in recent years, particularly in the availability of modern basic service and cellular services. The number of main lines grew from 3.5 per 100 inhabitants in 1996 to 5.4 in 2002. The number of cellular subscribers grew from 1800 in 1996 to 235,000 in 2002 with the licensing of two operators.. The Internet service market is fully liberalized and there are approximately 50000 internet users of the Internet. A number of licensed VSAT service providers also provide various value added services such as managed network services, which allow businesses to utilize ICTs. Approximately $80 \%$ of the current fixed network infrastructure is digitized. Further, Mongolia Railways also owns fibre optic infrastructure. This provides the opportunity to provide affordable bandwidth while increasing returns on state 
owned assets and investments. GOM will ensure that the policy and regulatory environment allows for fair and competitive provision of infrastructure and services. The challenge Mongolia faces is to increase rural access to ICT infrastructure and services. Nation-wide there are 2,052 soum-bagh radio communications operation. Over 120 settlements are connected to the central energy supply, 105 soum communications offices are installed with solar power systems.

4.100 Mongolia will ensure that the policy and regulatory environment allows for fair and competitive provision of infrastructure and services. The challenge Mongolia faces is to increase rural access to ICT infrastructure and services.

4.101 As the broadcast media has an important role to play in the development of Mongolia by providing information to its citizens, and the poor in particular, the equipment of radio and TV studios will be improved and transmission systems and stations for TV broadcasting will be upgraded. Within this framework, we will start broadcasting of the 4 domestic digital TV (including the National TV) and 4 FM radio channels in all of whole Mongolia in the end of 2003.

4.102 Postal services are provided by Mongol Post, a state-owned entity, through its officers in aimag centers, 19 branches in UB and 328 branches in soums covering the entire territory of Mongolia. Mongol Post is engaged in the business of printing of various types of postal and parcel marks, trading of them on domestic and international markets, postal box services, passenger transportation, postal and parcel trading, international call, fax and e-mail services in some branches in UB in collaboration with Telecom Mongolia.

4.103 Implementation of short and medium term strategy on ICT and infrastructure development will create one of the prerequisite for establishment of knowledge based society, introduction of new types of services and applications, ensuring sustainable and rural development, improvement of access to education and public/social services, and ensuring balanced level of regional development, and poverty reduction.

4.104 The Government of Mongolia's short to medium term priorities for the ICT sector are as follows:

- Develop and implement a Universal Service Fund to provide access in rural and periurban areas of Mongolia.

- Implement policies (economic/fiscal/tax) and design incentives to encourage adoption and use of ICTs in businesses, the social sectors, civil society.

- Strengthen CRC's capacity to adequately regulate the telecommunications sector and create a pro-competitive environment for the private sector led development of Mongolia's information and communications infrastructure.

- Improve regulatory framework for the introduction and widespread use of new services /IP enabled services, transit data transfer, call-back, and its interconnection \& tariff issues.

- Create the enabling environment in order to improve availability of IT services including E-learning, Tele-medicine, and national information databases.

- Increase usage of ICT for the economic growth /industry, financial sector, Agriculture/ such as introduce ICT applications in social-economic sector 
- Increase the potential and results of basic and complementary research studies in the ICT sector

- Broaden and deepen regulatory reform /cyber laws, and others/

- Implement e-commerce and e-services/applications for all sectors,

- Develop and implement the Concept on DTH (Digital-To-Home) Distance-learning and education, distance-medicine and national registry.

\section{Promotion of Foreign Direct Investment}

4.105 Since the transition to free market economy starting in 1990 about 2300 business entities representing 70 countries and with more than USD 800 million of paid-in capital were created. About one third of them are operating in mining industry and 20 percent in the light industry. Such increase in investment helps to accelerate economic growth, to develop export industry, to introduce new equipment and technology, to strengthen human resource capacity and thus to increase competitiveness of Mongolian goods and products. Several measures were taken during the last two years in order to attract and encourage foreign investment, to create favorable environment as well as to sustain macro economic stability Technological equipment and machinery imported by foreign investors who will run export oriented production are relieved from import and custom duties. Also the Law on Foreign Investment was amended in 2002 by creating legal grounds for business entities with foreign investment to conclude sustainability agreements. Measures were taken towards relieving business income tax imposed on the government portion of outputs produced by business entity with foreign investment who operate under the product sharing agreement in the area of oil industry. Year 2002 was declared as the Year of Encouraging Foreign investment and September 2002, Investor's Forum was organized. The forum was attended by 300 delegations representing 40 countries. Within the 3 months after the forum agreements were concluded that would increase amount of foreign investment in the country by USD 150 million. Despite the fact that foreign investment has been increased, its legal environment is improved and support to the foreign investors is boosted. The 8 significant projects were not implemented to the extent that would show concrete results. There is still a need to improve the business environment for operation of the business entities with foreign investment.

4.106 The strategy to increase foreign investment in the longer term will be aimed at accelerating economic growth and its capacity increasing income of the population and speeding up the development of the country.

4.107 In the near future the focus will be on creating an environment that will allow to increase foreign investment. Measures will be taken to prepare skilled workers with technical knowledge who will be able to work at the business entities with foreign investment. Condition will be created for foreign investors to operate freely but in orderly manner.

4.108 Through simplifying licensing system with respect to different products and services related to foreign investment, support will be rendered to both export industry and business owners in rural areas. 
4.109 In overall foreign direct investment will be attracted effectively to all areas of processing and services, however, investment in the mining sector will be the priority. The FDI support is one of ways to improve living standards through creation of new work places, increase of the citizen's income and thus will contribute to reduction of poverty.

\section{Improving Access to Markets}

4.110 The domestic commodities market. The basis of the Mongolian industrial sector is formed mainly by the primary processing industry (wool, cashmere, leather, etc.) that processes the key outputs of the livestock sector, a few plants that are mining and producing mineral concentrates, some enterprises in sewing, knitting, food, printing, wooden products and construction materials. Starting from $1990 \mathrm{~s}$, privatization was carried out in a chaotic way, without clear policies and guidelines. The consequences were demolished chains of inputs and output between industries, most leading enterprises experienced shortages of working capital and were cut off from their markets. As a result, many of these enterprises stayed idle and shed many workers, cutting their sources of income.

4.111 Weakness of most light agro-processing and food industries, lack of their competitiveness and inability to reach substantial export markets are the major obstacles for resolving the above issues. Herders' terms of trade is continually declining, with the growth in prices of herder-supplied commodities being 33.2 percentage points lower than the growth in prices of commodities they buy, in 2001 compared with 1995. Development of small and middle-size agro-processing industries in rural areas increases opportunities for local people to be engaged in economic activities with seasonal variations and generate income. The SMEs are considered to be an efficient approach to diversify the agricultural activities. The Government in the past 2-3 years announced the priority sectors such as mining, manufacturing, tourism and IT sectors as part of its policy to restore national industries. The Government also developed specific programs such as Meat, Gold, Cereals, Fallow, and implemented them in partnership with the private sector. Projects to strengthen the management of privatized enterprises and access to information and markets are being implemented with assistance of donors. Actions taken by the Government with the assistance of the Government of Germany and the World Bank to develop competitive small and middle-size enterprises have been very successful and have made substantial progress in expanding import-substituting industries and creating new jobs. In the period of over one year recently some wool, leather, tannery and construction industries are starting to show signs of recovery. Collection of various herbs and medical plants and their primary processing for the traditional medicine, considered to be one of vital components for the income generating and human and animal health care activities. By the end of 2002, in accordance to the preliminary statistics, manufacturing sector growth reached 29 percent. As a result, the share of the industrial sector in GDP reached 27 percent of GDP in 2002. 
Table 4:1: Structure of GDP, percent

\begin{tabular}{|l|r|r|r|r|r|r|r|}
\hline & \multicolumn{1}{|c|}{1993} & \multicolumn{1}{|c|}{1995} & \multicolumn{1}{|c|}{1996} & \multicolumn{1}{|c|}{1999} & \multicolumn{1}{|c|}{2000} & \multicolumn{1}{c|}{2001} & \multicolumn{1}{c|}{2002} \\
\hline Industry & 30.9 & 25.8 & 18.6 & 18.2 & 20.0 & 20.1 & 21.4 \\
\hline Mining and quarrying & & 12.0 & 10.4 & 8.6 & 11.5 & 9.0 & 8.6 \\
\hline Manufacturing & & 12.1 & 5.9 & 5.9 & 6.1 & 8.1 & 9.5 \\
\hline & & & & & & & \\
Electricity, gas and water supply & & 1.8 & 2.2 & 3.6 & 2.4 & 3.0 & 3.3 \\
\hline Agriculture & 35.1 & 38.0 & 43.8 & 37.0 & 29.1 & 24.9 & 20.7 \\
\hline Construction & 1.6 & 1.7 & 2.8 & 2.5 & 1.9 & 2.0 & 2.1 \\
\hline Transport, communication & 4.6 & 6.4 & 7.4 & 9.2 & 11.0 & 13.0 & 14.0 \\
\hline Trade, material and techniques & & & & & & & \\
supplies & 16.0 & 17.0 & 16.7 & 20.7 & 24.0 & 26.7 & 27.6 \\
\hline Service activities & 11.8 & 11.1 & 10.8 & 12.5 & 13.9 & 13.4 & 14.2 \\
\hline GDP /at current prices/ & 100.0 & 100.0 & 100.0 & 100.0 & 100.0 & 100.0 & 100.0 \\
\hline
\end{tabular}

Source: NSO

4.112 Operations of large and medium sized food processing plants are becoming stable for the last few years, and new small plants are being set up, therefore there is a trend for indicators of this industry to grow.

4.113 Productions of meat, milk, flour and baking plants are steadily on the rise and with introduction of progressive technology and new packaging the competitiveness of domestic food processing plants increased and their safety and quality indicators are getting better.

4.114 Exports of meat, meat products and vodka have increased and processors are working actively to open new export markets besides the traditional markets.

4.115 The Government is actively cooperating with the private sector, the civil society and foreign partners to connect the growing industries with external and domestic markets, as part of its policy to support private sector-led economic growth. A marketing system based on an infrastructure that enables better movement of goods is lacking. This system would serve to develop domestic trade and to improve the match between the supply and demand of commodities and consumer goods by connecting rural and urban areas and providing industries with better access to raw materials. Its outcomes will be a reduction of the gap in prices of consumer goods between rural and urban areas and a reduction in the time, effort and costs incurred by herders though buying agricultural products and raw materials directly from them. The Government is undertaking a pilot implementation of the Wholesale trade network program in Orkhon, Khentii and Bayanhongor aimags, and will expand the system to other aimags in the medium term, depending on their market sizes. The main objective of the network is to assist creation of a channel to buy agricultural products from herders and delivery of consumer goods to them. The Wholesale Trade Network program will have important implications for a reduction of inflation, creation of a stable business environment and ensuring food security. 
Box 4-1: Experience of the 'Wholesale Trade Network' pilot project

Advantages:

- Better information access and price risk management

- Reduction of cost of business, especially transport cost

- Facilitation of the goods storage leading to better selling opportunities and safety

- Improved choices, food security and price offer

\section{Challenges:}

- Encouragement of local business in the selection process

- Improvement of facilities for storage and selling

- Expansion of competitiveness and coverage to other administrative units

4.116 Information access is one of important criteria for improving the market access and business profitability. Therefore, the core area of industrial policy is better information supply to rural areas with active participation of private sector facilities, including e-commerce dissemination facilities. Using the scope of the wholesale trade network and other channels, dissemination of information about foreign and domestic markets and basic business knowledge is a priority area of the policy to increase production and poor people will be involved to great extent in this Program and conditions for delivering business information shall be created.

4.117 Currently, processing industries in rural areas are very weak with the exception of cashmere processing industries. However, since recently, there is a market tendency for establishment of small and middle-size enterprises and more intensive competition. According to the National Statistical Office, of 407 agro-processing enterprises in Mongolia, 75.8 percent are located in areas with relatively developed infrastructure and proximity to markets, such as cities of Ulaanbaatar, Darkhan, Erdenet and Selenge and Tuv aimags. Of the enterprises, 29.7 percent operate in meat processing, 27.3 percent in dairy production, 7.4 percent in leather processing, 1 percent in production of oil and fat, 31.4 percent in flour production, 1.7 percent in vegetable and fruit processing and 1.5 percent in production of silage and fodder. Most of them are small and middle-size with less than 50 employees. The study indicated that out of total food companies, 58.1 percent use less than 50 percent of their capacity.

4.118 The cashmere processing of Mongolia is one promising industry and becomes one of sources of growth for the medium term. Mongolia ranks as the second among producers of raw cashmere. The government jointly with private sector will encourage expansion of processing of raw cashmere and improve their competitiveness in order to explore possibilities to participate at the international market.

4.119 Maturing markets, growing business incomes and profits, operating non-agricultural small and middle-size enterprises and shrinking flows of rural-to-urban migration are impossible without accessible financial services in rural areas. The macroeconomic policy, in particular financial sector policy will be oriented towards intensification of financial flows to the rural areas aimed to expand access to financial services in far reaching areas. The effective way to 
create favorable environment for expansion of financial services is the introduction of competitiveness to the rural banking and financial services through establishing non-bank financial institutions, credit - saving cooperatives, and insurance institutions. Currently there are 63 non-bank financial institutions in rural and urban areas. Therefore the government supports activities and sustainability of those institutions, which have short term impact on population livelihoods.

4.120 The Government jointly with private sector and foreign partners have organized activities to promote commodities and products produced by local producers through extensive advertisement, enhancing capacity by introducing new management and technological innovations, auctioning. These types of activities are important initiatives for rural people providing them opportunities to participate of actively in business activities and better access to market. This initiative plays a canalization role for rural poor as part of the process of empowerment. These activities are mainly managed and undertaken by close partnership of state, private sector and citizens.

4.121 One of the challenges of the national industry is utilization of outdated technologies and equipment. Therefore, the objective of the Government is to develop small and middle-size enterprises with new technologies and export orientation, and to build their capacity and competitiveness to enter international export markets. For the medium term the objective is to utilize fully resources of agricultural materials such as skins, hides, wool, cashmere, and increase their value added through deepening the processing. In addition the environmentally friendly technology for the cashmere will be upgraded to reach international standards and compete at the international market. The goal for cashmere processing industry is to increase quality of raw material, to strengthen its raw material procurement system and to increase export of cashmere products. For these purposes the following measures will be taken:

- Animal productivity will be improved through introducing animal tax based on age and sex of the animals, thus quality of the raw material will be improved;

- Banking and financial services devoted for procurement of raw material will be developed, cooperation among herders, processors and traders will be ensured and trade risks will be reduced;

- Management of enterprises and plants will be improved and cooperation with international organizations with respect to increasing foreign markets will be pursued thus increasing exports.

4.122 The goal for the food processing industry is to develop small and medium sized plants with modern technology and to supply the population with safe food and to increase their competitiveness by offering ecologically clean products. The mid-term policy is to increase production and diversity of food products aimed at preventing from the lack of and regulating microorganisms, developing infant food, to increase quality of meat and meat product to the world standard and to increase exports.

4.123 The government will implement policy to support artisan small industry in rural areas based on specific resources and skills of the particular region. The vocational training programs in the rural areas will include measures to select types of artisan skills particular to the community, disseminate the concerned skills and information on access to markets with extensive involvement of poor. This will maintain traditional skills and disseminate among 
younger generation. It is considered that promotion of these small industries, in particular which focus on artisan skills, are suitable to Mongolian feature of nomadic lifestyle and assist to create small businesses in rural areas with a wide involvement of poor and vulnerable groups.

4.124 One of the main sources of economic growth in the medium term beside the agroprocessing industries is development of textile production with higher value added. However, for medium term mining industry will continue to be a major source for economic growth in the country and will be supported as priority sectors.

4.125 For the medium term it is expected that the new mining will be explored and factories will be built by domestic and foreign investors, such as Tomortein zinc processing factory, Boroo gold mining company. In addition new mining in copper, gold, silver, and oil exploration will be started. Currently it is explored 80 types of minerals and 6000 deposits, out of which only 160 are under the utilization. It is estimated that 75 percent of Mongolian land has not been investigated by geological exploration. The geological survey has been slowed down due to financial constraints. The geological survey and exploration work will be expanded and for the medium term, budget allocation for the geological survey will be increased by 70 percent compare to the year 2002 .

4.126 The legal basis for the business running in mining sector is quite stable and favorable. Therefore the Government intensifies implementation of legal provisions concerning natural resources survey, in particular minerals, environmental assessments, and exploration / processing stages.

4.127 Recently the tax law was amended to support the mining companies through imposition of differentiated rates for royalty payment, which depends on types of deposits. In addition in the frame of gold liberalization value added tax was removed from the gold sell. The stability contract, which signed between the Government and big investors, became one of important mechanisms to attract foreign investment to the economy. Some tax holidays and exemptions are in force concerning priority sectors. These major legal provisions are main basis for the stable business environment. In addition to stable legal environment the infrastructure development is primary condition for successful business, investment attraction and market access in the country.

4.128 The medium term policy objectives will focus on increase of value added in the mining sector, especially copper concentrate will be processed into final product and exported. Because the mining companies are operated in the rural areas mainly, they play an important role income generation for rural population, in particular poor, whilst involving them in economic growth acceleration process.

4.129 Tourism. Currently there are 130 tour camps with 6400 beds, 260 large and small hotels with 7000 beds and 400 hundred tour operating companies in this country. In 2002 Mongolia was visited by 230188 foreigners out of which 198057 were tourists. It was 20 percent increase compared to the previous year, or 56 percent increase compared to 1990 and in 2002 the total revenue of the industry has reached USD 130,1 million. 
4.130 In order to create favorable legal environment for the tourism industry the Parliament has adopted in 2000 new Law on Tourism and for the purposes of assisting the tourism entities to increase their financial capacity and supporting investment in this area the Government has exempted the industry from VAT. 5 percent of the advertising costs was exempt from business income tax, however, this was increased up to 10 percent and it serves as an example of real assistance to the tourism industry. A decision was adopted not to oblige visitors traveling to Mongolia for less than 30 days to be registered with respective authorities and agreements are reached with some countries to allow visa discounts for their citizens.

4.131 Mongolia is consistently taking part in large international tourism exhibitions and fairs organized abroad in order to study international markets, to attract foreign tourists and to promote Mongolia to other countries. This include:

- CBI exhibition and fair organized in Utrecht, Netherlands,

- CMT exhibition organized in Stuttgart, Germany,

- ITB exhibition and fair organized in Berlin, Germany and

- WTM exhibition and fair organized in London, UK.

4.132 In addition, in order to assist tourism companies to find new partners we have organized "Discovery Mongolia" exhibition in 2002 and "Year of visiting Mongolia" promotional tour in 2003 in Japan. As a result of decision to oblige Representative Offices of the MIAT company to run tourism promotion of Mongolia, such activities are being conducted through MIAT offices in Korea, Japan, PRC, Taiwan, Germany, Italy, France, Netherlands, USA, Canada and Russian Federation.

4.133 In order to increase the types of tourism products and create new routes, tourism representative offices are being created in main client markets in Japan, Korea and other countries and study being undertaken with respect to offering offices in PRC, Germany, UK and Russia. To supply with necessary information those who want to travel to Mongolia, English and Japanese websites were created and works commenced to set up tourism information database.

4.134 Mongolia's active cooperation on international arena such as participation in "Tumen River Regional Development Program" implemented under the sponsorship of World Tourism Organization and UNDP, international exhibitions and fairs organized by Asia Pacific Tourism Association and other international organizations which Mongolia has joined as member, cooperation with international experts working on studies related to tourism industry, provision of comments with respect to measures planned in the future, exchange of information etc serve as beneficial steps towards promoting Mongolia, developing tourism industry and to bringing it up to the world standard. During the Investors Forum that was organized in September of last year in Mongolia.

4.135 In order to bring the quality of tourism industry up to the international standards, to establish ratings of hotels and tour camps and to introduce new service standards the Minister of Infrastructure by his Decrees numbered 133, 134 and 135 of 2001 approved "Procedure for licensing and rating hotel works and services", "Professional classification and rating of guides", and "Procedure for licensing guides", the board of National Center of Standardization and Measurement by its Resolution No.93 approved "Quality Rating and Principle Requirements and 
Standards for Tourism Centers", and the Cabinet by its Resolution No.69 approved "Rules of State Control over the Tourism Industry".

4.136 A core curriculum for tertiary program in tourism studies was developed for purposes of developing human resources in the area of tourism industry, to develop professional cadres and to increase their professional skills. Number of training seminars aimed at retraining current workers of tourism industry, increasing their skills and providing them with necessary information are being organized together with development programs active in Mongolia. So far a number of tertiary institutions preparing different types of professionals for the tourism industry.

4.137 With the approval of "Procedure for gathering, spending and exerting control over the tourism fund" by Resolution No.200 of the Cabinet in 2001, the "Tourism Fund" set up and is in operation since then. Creation of the fund will support different projects included in the General Plan for the development of the National Tourism Industry and promotion of Mongolia abroad and within the country.

4.138 We are confident that announcement of 2003 as "Year of visiting Mongolia" will not only promote Mongolia worldwide, but it will also accelerate the development of "the smokeless industry" of tourism and will allow to bring the industry up to the world standards.

4.139 Within the preparation to this year a theme song was written and special videos, websites and CDs on history and culture of Mongolia were issued and works to establish tourist street, information center and nomadic cultural institutions are commenced in Ulaanbaatar. Expansion of tourism industry will allow to create conditions for expansion of other service industries such as transportation, communication, hotels and restaurants which make small part of the GDP and therefore improve the structure of the economy. For the last several years Mongolian Government has paid special attention to the development of tourism industry and has determined the main direction of its policy for years 1995-2005 and with the help of European Union and the Government of Japan has developed the Master Plan for development of tourism industry until year of 2015.

4.140 The general strategy for developing national tourism industry in Mongolia was defined in the Master Plan as following:

- development of cultural and historical tours;

- increase in numbers and improvement of new types of tourism products;

- strengthening management and organizational structure of tourism industry;

- development of human resources.

4.141 As part of regional development strategy until 2005, the foundations for the Mongolian tourism were to be established by strengthening tourism centers in Ulaanbaatar, Kharkhorin and Omnogobi and by developing tourism of unique interests in Khovsgol, Khentii and Olgii areas. Mongolia has a potential to attract foreign tourists and visitors by using its historical and cultural resources, nomadic culture, untouched nature and the reputation for being as a birth place of Chingis Khaan who was named as Man of Millennium. Strategic goals of developing this industry are, - taking measures aimed at developing an independent economic 
industry, improving its structure and organization and intensifying external promotional activities. In order to implement these goals following measures shall be taken: general plan for developing tourism until year 2010 will be implemented, measures will be taken to improve management and organization of the industry, infrastructure for tourism in Ulaanbaatar, Kharkhorin, Omnogobi and Khovsgol will be developed, legal foundations for expansion of tourism and bringing of its quality up to the international standards will be created. Within the mid term strategy of developing the tourism industry the following measures will be taken:

- measures reflected in General Plan for National Tourism Industry will be implemented step by step;

- structure and organization of local administration unit in charge of the tourism industry will be improved;

- infrastructure for the tourism will be developed based on regional strategies;

- ecological tourism will have priority support and types and routes of tours will be increased;

- domestic tourism will be intensified;

- preparation, vocational and retraining of mid level cadres of the tourism industry will be improved;

- the level and quality and types of services will be improved and brought up to international standards;

- international routes will be organized to allow tourists who visit close to the border areas of neighboring countries to visit Mongolia;

4.142 External trade. Foreign trade has traditionally played a very important role for Mongolia because of specifics of Mongolia's economic development. Since 1990s during the transition to the market economy, foreign trade was liberalized and Mongolia's traditional export markets dissolved, causing a breakdown of the processing industries, rapid outdating of their technologies and shortage of management skills to produce competitive products, impacting on rapid decline of exports. As a result, exports are dominated by a few products, such as copper concentrate, cashmere and cashmere products and textiles. An open economy policy, earlier liberalization of trade, removal of main tariff and non-tariff barriers have become important steps towards foreign trade expansion. About 80 percent of exports go to a few countries, including China, Russia, US, Japan and Korea. Therefore, the Government focuses on efficient utilization of tools and mechanisms of the World Trade Organization, other regional trade arrangements and bilateral agreements, whilst improving potentials of domestic market.

4.143 International competitiveness will be strengthened by increasing the levels of processing of agricultural products and raw materials, by producing final goods and improving the quality of our products. Exports of meat products will be expanded by introducing modern processing technologies. In addition, meat and meat products industries will be expanded. Except for the wood and goat skins underpinned by the environmental, ecological reasons and considerations about structure of the livestock, all Mongolian export items will be free from any tariff and non-tariff barriers, and in the further the government will not impose any tax restrictions on exports.

4.144 The membership of Mongolia in the World Trade Organization in 1997 became an important step of the Mongolian Government to strengthen its position on international arena, 
protect its rights, and determine and facilitation its foreign trade policies in line with global development trends. It also enabled Mongolia to exercise favorable treatment of trade activities with other members of WTO. Therefore, the Government will actively participate in activities of the WTO, particularly protecting the interests of Mongolia by exercising various preferential treatments for agricultural products and service sectors. As other developing countries, the developed countries provide most favorable nations treatment for the textile industries. The most favorable nations treatment is provided by the USA on Mongolian textiles, which will be negotiated to extend in the future round. In addition the Government aims to extend this treatment to the European market too. In the medium term, the Government will pay close attention to implementation of the Doha agreement. As well, the Government will select specific, internationally competitive products, which meet international standards and include them into various agreements to be concluded under the WTO arrangements. Under the frame WTO trade facilitation efforts the technical barriers will be removed through bringing the national standards closer to international levels, and step up its actions in quality assessment of standards of domestic and foreign products entering the market.

4.145 The landlocked geographical location has a negative impact on the terms of trade. The Government will, therefore, study possibilities of protection of interests of landlocked countries and actively work on the international level to reduce transportation costs. For instance, the Government will intensify the tripartite negotiations regarding transit transportation with Russia and China, and will use the General Agreement on Transit Transportation to be signed as a result of these negotiations to protect Mongolia's interests in the region.

4.146 An appropriate level of customs tariffs is essential for creation of a favorable trade environment. By 1998, the level of import taxes was reduced to a "free-trade level" compares to other countries customs duties. Although this was not an easy decision for a small market and a small economy like Mongolia, the move played an important role in substantial increasing the supply of production and consumption markets. Currently, most imported goods are taxes at 5 percent, with a few products such as technological equipment of foreign companies in priority sectors being exempted from the import tax. In order to continue to maintain current scope of Mongolian trade liberalization in the medium term the government will not place any barriers for external trade activities.

4.147 The Government will aim to facilitate trade through more effective government regulation. Under the frame of trade facilitation the institutional and organizational structure was modified to eliminate overlapping and bureaucracy. The favorable environment for foreign trade will be deepened by rationalization of non-tariff regulation of production and trade. The foreign trade efficient facilitation will improve supply in the economy, leading to overall increase of income of population. Poor and vulnerable groups will have better access to the consumer goods at affordable prices.

4.148 Free trade zones play a significant role in the reduction of disparities in rural and urban development and raising the living standards of the population as part of implementation of the concept on regional development. A legislative framework enabling various types of free zones, including trade, production, agricultural, tourism and services and economic zones was created. Altanbulag and Zamyn-Uud will be the pilot free zones. In establishing the free zones, the Government will be relying on the existing resources and capabilities. 


\section{Regional and Rural Development}

\section{Regional Development}

4.149 The Parliament of Mongolia ratified the main concepts of the regional development in June 2001. The purpose of these concepts is to decentralize over-concentration of population by rational utilization of the natural, agricultural, land and human resources, acceleration of the economic growth and social development and setting up favorable conditions to minimize difference in development between cities and rural areas. The basis of the implementation of the strategy on poverty alleviation is to apply the main principles of the concepts into all spheres in order to accelerate the economic growth. According to the concepts of the regional development, all citizen of a particular region will be given equal opportunities to study, to live, to access to information and to take an active part in social life. They also will be able to enjoy education, health, cultural, information and social services in the equal basis. The development of legal environment to support regional development has to be done in a medium-term period aimed to determine priority directions of the strategy of the development of a particular region and to ensure the policy to improve banking, financial and infrastructure network of a particular region

"We are located far from the market, therefore the retailers come to us themselves. But they communicate with the people differently depending on how wealthy people are and how many cattle they own. If there is no much of cattle in the house, to they would just pass by this family. So some herders look for retailers in binoculars and go the houses where retailers have stayed for a night.

Although we know that they have cash, they never do business for cash. Instead they give us goods for our cattle. But sometimes, in case if they deal with wealthy families for big deals, they use cash. They select and take the best animals, but they give us so little. It is difficult and not fair to do business with them. We really miss an old network of sales with agents which used to serve us." These are the words of the group of men in Dashbalbar sum of Dornod aimag.

4.150 Therefore there is a necessity to link the regional development and issues of rural population and poverty. The main goal of the strategy of the rural development in Mongolia is to set up all conditions for human development in all spheres and to ensure prosper life of people. The fact, that in most areas of our country more than 10 kinds of natural disasters, such as drought, dzud, snow and windy storms, fires in forests, etc., are taking place frequently, and their occurrence is increasing, is negatively influencing on agriculture and manufacture, and the people in rural areas are facing serious natural problems and suffering economically and in health.

4.151 There are more than five thousand hectares of crop land around the capital. Compared with 1998, average arable land of the last 2 years declined in 2002. This is related to the inactive participation of the citizens in implementation of the Green Revolution Program. Looking at the expected performance of 2002, potato and vegetables were planted in 2050 hectares of land. In order to increase city food supply, employment and to decrease poverty, it is required to effectively use the opportunities and to increase the crop land. Another source of food supply is to deal with fruit business. The City municipality is planning to encourage fruit planting and to 
bring the business in the same level of 8.4 tones as it was during 1998-1999. As of 2002, there are 208 agricultural enterprises, out of which, there are 59 enterprises deal with livestock separately or in combination with crop production. Most of employees, $(70.6 \%)$ of those enterprises deal with crop production and the livestock is considered as household business. These household businesses and enterprises provide $100 \%$ of milk and meat product needs, $70 \%$ of flour, $55 \%$ of potato and vegetable and $10 \%$ of eggs by their products. Some main food products such as candy, fruit, butter and sunflower oil etc are imported. Generally, role of the agricultural enterprises is very low in providing food consumption of the capital city since the entrepreneurs afford to supply only their family consumptions.

Table 4:2: Basic Economic Indicators by Region (as of 2000)

\begin{tabular}{|c|c|c|c|c|c|c|c|c|c|}
\hline & $\begin{array}{l}\text { Percent } \\
\text { tage in } \\
\text { popula } \\
\text { tion }\end{array}$ & $\begin{array}{l}\text { Percen } \\
\text { tage in } \\
\text { territory }\end{array}$ & $\begin{array}{l}\text { Percen } \\
\text { tage in } \\
\text { cattle }\end{array}$ & $\begin{array}{l}\text { Percen } \\
\text { tage in } \\
\text { wool }\end{array}$ & $\begin{array}{l}\text { Percen } \\
\text { tage in } \\
\text { produc } \\
\text { tion }\end{array}$ & $\begin{array}{l}\text { Occurren } \\
\text { ce of } \\
\text { dzud }\end{array}$ & $\begin{array}{l}\text { Infra- } \\
\text { structure } \\
\text { Supply }\end{array}$ & $\begin{array}{l}\text { Watering } \\
\text { of fields }\end{array}$ & $\begin{array}{l}\text { Local } \\
\text { budget } \\
\text { capacity }\end{array}$ \\
\hline $\begin{array}{l}\text { 1.Western } \\
\text { region }\end{array}$ & $\begin{array}{l}450.0 \\
\text { thous.per }\end{array}$ & $\begin{array}{c}41705.4 \\
\text { thous. } \\
\text { hectares }\end{array}$ & $\begin{array}{l}8702.4 \\
\text { thous. } \\
\text { head }\end{array}$ & $\begin{array}{l}956 \\
\text { òonnes }\end{array}$ & $\begin{array}{l}10069.9 \\
\text { mln.tug }\end{array}$ & $25-30 \%$ & $31.5 \%$ & 0.13 coff & $17.9 \%$ \\
\hline Bayan-Ulgii & 22.5 & 11.4 & 15.1 & 15.3 & 0 & $20-30$ & 23.5 & 0.11 & 23.1 \\
\hline Gobi-Altai & 15.2 & 33.9 & 23.4 & 29.4 & 90 & $20-30$ & 34.5 & 0.15 & 11.9 \\
\hline Zavkhan & 20.8 & 19.8 & 22.3 & 16.5 & 0 & $40-50$ & 29.3 & 0.11 & 16.3 \\
\hline Uvs & 20.6 & 16.7 & 18.1 & 16.4 & 0 & $30-40$ & 33.6 & 0.13 & 19.2 \\
\hline Khovd & 20.9 & 18.2 & 21.1 & 22.4 & 10 & $20-30$ & 36.7 & 0.14 & 18.9 \\
\hline $\begin{array}{l}\text { 2.Khangai } \\
\text { region }\end{array}$ & $\begin{array}{l}554.2 \\
\text { thous.per }\end{array}$ & $\begin{array}{c}38439.3 \\
\text { thous. } \\
\text { hectares }\end{array}$ & $\begin{array}{l}10711.7 \\
\text { thous. } \\
\text { head }\end{array}$ & - & $\begin{array}{l}203240 \\
\text { mln.tug }\end{array}$ & $30-40 \%$ & & 0.26 & $35.2 \%$ \\
\hline Arkhangai & 17.6 & 14.4 & 20.7 & - & 2.1 & - & - & 0.26 & 30.1 \\
\hline $\begin{array}{l}\text { Bayan- } \\
\text { khongor }\end{array}$ & 15.4 & 30.2 & 22.2 & - & 1 & - & - & 0.19 & 17.3 \\
\hline Bulgan & 11.3 & 12.6 & 14.2 & - & 0.7 & - & - & 0.37 & 28.6 \\
\hline $\begin{array}{l}\text { Uvur- } \\
\text { Khangai }\end{array}$ & 20.4 & 0.2 & 20.2 & - & 3.8 & - & - & 0.2 & 27.1 \\
\hline Khuvsgul & 21.6 & 16.4 & 21.1 & - & 0.7 & - & - & 0.3 & 20.2 \\
\hline Orkhon & 13.7 & 26.2 & 1.6 & - & 91.7 & - & - & 4 & 84.6 \\
\hline $\begin{array}{l}\text { 3. Central } \\
\text { region }\end{array}$ & $\begin{array}{l}445.3 \\
\text { thous.per }\end{array}$ & $\begin{array}{c}47355.9 \\
\text { thous. } \\
\text { hectares }\end{array}$ & $\begin{array}{l}6792.7 \\
\text { thous. } \\
\text { head }\end{array}$ & $\begin{array}{l}665.8 \\
\text { òonnes }\end{array}$ & $\begin{array}{l}87429.2 \\
\text { ñàỹ òõãơã }\end{array}$ & $20-25 \%$ & $46.1 \%$ & & $49.8 \%$ \\
\hline Dornogovi & 11.5 & 1.1 & 15.3 & 15.2 & 1.9 & $13-20$ & 35.2 & - & 43.5 \\
\hline Dundgovi & 11.5 & 0.7 & 18.9 & 19.9 & 1.1 & $20-30$ & 35.5 & - & 25.4 \\
\hline Umnugovi & 10.5 & 23.1 & 21.9 & 36.5 & 0.9 & $13-20$ & 47.8 & - & 23.7 \\
\hline Selenge & 22.7 & 15.8 & 9.6 & 6.2 & - & $20-30$ & 69.3 & - & 60.4 \\
\hline Tuv & 22 & 34.9 & 29.8 & 18.5 & 17.3 & $30-40$ & 42.5 & - & 58.3 \\
\hline Darkhan-Uul & 19 & 8.7 & 2.9 & 2.2 & 53.9 & $13-20$ & - & - & 59 \\
\hline $\begin{array}{l}\text { Govi- } \\
\text { Sumber }\end{array}$ & 2.8 & 15.7 & 1.6 & 1.4 & 21.5 & $13-20$ & 46.6 & - & 43.6 \\
\hline $\begin{array}{l}\text { 4. Eastern } \\
\text { region }\end{array}$ & $\begin{array}{l}201.5 \\
\text { thous.per }\end{array}$ & $\begin{array}{c}28621.0 \\
\text { thous. } \\
\text { hectares }\end{array}$ & $\begin{array}{l}3790.1 \\
\text { thous. } \\
\text { head }\end{array}$ & & $\begin{array}{l}4251.5 \\
\text { mln.tug }\end{array}$ & $35-45 \%$ & $40.5 \%$ & 0.63 & $21 \%$ \\
\hline Dornod & 36.8 & 43.2 & 21.8 & - & 32.4 & $30-35$ & 25.6 & 1.31 & 26.8 \\
\hline Sukhbaatar & 27.8 & 28.7 & 39.4 & - & 29.5 & $40-50$ & 36.5 & 0.28 & 12.6 \\
\hline Khentii & 35.4 & 28.1 & 38.8 & - & 38.1 & $30-40$ & 59.5 & 0.31 & 22.6 \\
\hline Ulaanbaatar & $\begin{array}{l}786.5 \text { ì̈í. } \\
\tilde{O}_{¿ i}\end{array}$ & & & & $\begin{array}{l}574.2 \\
\text { bln.tug }\end{array}$ & & & & \\
\hline
\end{tabular}

4.152 To ensure sustainable growth of income of rural people, especially poor ones, to increase an access and quality of social services and to ensure sustainable conditions of 
utilization of natural resources and environment are the priority goals for the medium term and they can be defined as follows:

- Within framework of the Regional development concept to enhance institutional capabilities in terms of legal regulations.

- Within framework of the Regional development concept to define the strategy of the development for every region.

- To develop cattle-breeding sector, to stop the decrease of farming and put efforts on its recovery.

- To improve agricultural marketing, agro-business and manufacturing in order to increase non-agricultural income.

- To undertake policy to mitigate adverse effects of the natural disasters, including land reforms

- To protect environment, to ensure appropriate utilization of natural resources.

- To improve rural infrastructure.

4.153 These goals are stated in the related chapters of this document on the strategy to alleviate poverty and to accelerate economic growth, and this chapter briefly covers the strategic issues such as expansion of opportunities to increase agricultural manufacturing, management of natural resources and income of rural people, and improvement of capability of citizens. The strategy of rural development was developed with assistance of the World Bank in 2002.

4.154 The urbanization process has rapidly taken place in the capital city during the recent years, which leads to over concentration of population and industries and rapid growth of urban population. In 2002, Ulaanbaatar's population amounted to 817.6 thousand or about 32 percent of the country's total population. 48.7 percent of Ulaanbaatar's population or about 35,000 households live in ger districts. Massive settlement of population and increased density have an adverse impact on health of city residents and lead to distortion of a healthy and safe environment for human living, especially, in ger districts of the capital city. Therefore, priority objective for UB city ger district is to define and implement the policy of restructuring gers, traditional housing reflecting the distinctive feature of Mongolia from other capital cities in the world, into comfortable housing block with welcome living conditions within the urban development strategy.

\section{Livestock husbandry}

4.155 The main foundation of Mongolia's economy, pasturing livestock husbandry still plays an important role in the economy, employment and export revenues of Mongolia. To date, almost one third of GDP, employment and export revenues is comprised of revenues from livestock husbandry. In 1990 when the country transited from the centrally planned economy to a market economy, the livestock was transferred from state and cooperative ownership directly to private. With the change of livestock ownership the state policy had to be changed too. Although the state policy regarding livestock husbandry has changed since then, livestock husbandry still remains the key mean of the country's economy and living of people while increasing the importance of the sector. 
4.156 In 1990, 68.2 percent of total livestock was in state and cooperative ownership; now 97.2percent of it is in private ownership. The growth of GDP was 2.4-4.0 percent in 1996-1999 with the growth of livestock husbandry production being 4.2-6.4 percent. However, due to natural disasters, drought and dzud, livestock husbandry production declined by 16.8 percent in 2000 and 18.5 percent in 2001, which has resulted in a drop of the amount of milk and diary products per capita.

Table 4:3: Livestock Husbandry's Share in Total Agricultural GDP (percent)

\begin{tabular}{|l|c|c|c|c|c|c|c|c|c|}
\hline Indicator & 1992 & 1993 & 1994 & 1995 & 1996 & 1997 & 1998 & 1999 & 2000 \\
\hline $\begin{array}{l}\text { Share of agricultural sector in } \\
\text { GDP }\end{array}$ & 31.7 & 35.9 & 37.1 & 38.0 & 36.8 & 34.6 & 37.5 & 37.0 & 33.4 \\
\hline $\begin{array}{l}\text { Share of livestock husbandry } \\
\text { in agricultural sector }\end{array}$ & 81.7 & 76.7 & 85.7 & 85.2 & 86.8 & 86.5 & 87.7 & 89.8 & 87.6 \\
\hline
\end{tabular}

Source: Statistics book of Mongolia

4.157 In recent years the share of agricultural sector in GDP and share of livestock husbandry -derived output in agricultural sector have been stable. However, the figure dropped in 2000-2001. Summer during these years was very dry which led to poor grass-yield in pastures and low harvest, plus in winter excessive snowfalls killed 3.5 million heads of livestock in 2000 and 4.7 million in 2001. Thousands of female livestock miss-carried, reducing the number of youngsters per 100 heads.

4.158 Livestock activities continue to be one of main sources of livelihoods in the capital city. In 2001, there were 221.4 thousands heads of livestock registered. Recent declining trend in livestock number is attributed to the high cost required to protect and keep animals lowering capacity of pasture outside the city. This fact means there is no more possibility to deal with traditional pastoral livestock around the city. There are 7496 herder families in the capital city, of which 3976 families have less than 10 livestock, 1606 families have up to 30 livestock, 1422 up to $100,481-100-500$ and 11 families have up to 1000 livestock. In terms of the livestock structure, they are more cattle in the center of the town. However, the herders who live outside the town prefer to have sheep and goat. In addition, there are 1134 pigs and 38573 birds. Looking at the research work of the scientists and experts, in order to provide annual family consumption, the herder families should at least have 300 livestock. Only 34.8 percent of the capital city herders have an appropriate number of livestock that can provide their family consumption and the remaining part deal with the livestock business just to supply their daily needs. Factors like poor agricultural development of the capital city and migration of country herders to the capital are considered as one of the reasons to mechanically increase the city poverty. Therefore, these problems are to be decided in consistent with the regional development policy.

4.159 In accordance with Regional Development Concept, the strategic objective of the UB city is to develop the capital as one independent region with all kinds of services, enterprises, information technology and with internationally ranked banking and financial network. Therefore, to develop and implement a development program for settled, semi-settled intensified livestock husbandry, food and agricultural production with less climatic risk in support of livestock husbandry is becoming one of priority objectives in livestock rising in UB city. 
Table 4:4: Major Livestock Husbandry Products, thousand tons

\begin{tabular}{|l|l|l|l|l|l|l|l|l|l|}
\hline \multicolumn{1}{|c|}{ Indicator } & \multicolumn{1}{c|}{1992} & \multicolumn{1}{c|}{1993} & 1994 & \multicolumn{1}{c|}{1995} & \multicolumn{1}{c|}{1996} & \multicolumn{1}{|c|}{1997} & \multicolumn{1}{c|}{1998} & 1999 & \multicolumn{1}{c|}{2000} \\
\hline Meat (slaughter weight) & 251.2 & 216.1 & 203.9 & 211.7 & 259.9 & 240.5 & 268.3 & 289.0 & 310.6 \\
\hline Of which beef & 75.7 & 64.5 & 64.4 & 69.4 & 90.0 & 86.6 & 99.3 & 104.6 & 113.4 \\
\hline Mutton and goat & 116.3 & 112.5 & 111.9 & 111.5 & 121.3 & 104.4 & 120.2 & 128.9 & 120.0 \\
\hline Pork & 1.8 & 0.7 & 0.7 & 0.6 & 0.3 & 0.2 & 0.2 & 0.3 & 0.9 \\
\hline Sheep wool & 21.0 & 20.8 & 19.6 & 19.6 & 19.5 & 18.3 & 20.1 & 20.9 & 21.7 \\
\hline Cashmere & 1.4 & 1.3 & 1.8 & 2.1 & 2.5 & 2.6 & 2.9 & 3.3 & 3.3 \\
\hline Milk & 308.1 & 292.9 & 312.5 & 369.0 & 369.8 & 418.6 & 430.8 & 467.0 & 375.6 \\
\hline Egg (mil pcs) & 18.6 & 10.0 & 3.6 & 3.5 & 4.9 & 6.1 & 8.5 & 9.6 & 6.7 \\
\hline
\end{tabular}

Source: Statistics book of Mongolia

4.160 Prior to transition to the market economy on average 7.6 million herds of livestock or over 480.0 tones of meat by living weight were produced for consumption per year nation-wide. 40 percent of total meat consumed was mutton, 30 percent beef, 10 percent horse, 10 percent goat and 4 percent camel.

4.161 The meat production has been declining till 1994; from 1995 it revived delivering a steady growth trend, mainly owing to meat exports. The Government of Mongolia announced 2001 the year of "promoting domestic production" and thanks to economic supports provided to livestock husbandry-derived products processing, domestic producers are showing a revival. As of present, there are 220 meat processing factories with capacity of 62,000 tones per year operating in one shift, 19 of which are licensed to export.

4.162 There are over 10 large- and 200 small-scale milk processors and diary producers. Furthermore, 46 wool processing, 70 hide and skin processing, 48 cashmere processing, and 37 weaving productions. Livestock husbandry raw materials can be processed for export purposes provided that these productions revive their operations.

Table 4:5: Investments in Livestock Husbandry, MNT million

\begin{tabular}{|c|c|c|c|c|c|c|c|c|c|}
\hline & Investment & 1990 & 1995 & 1996 & 1997 & 1998 & 1999 & 2000 & 2001 \\
\hline 1 & $\begin{array}{l}\text { Measures of improving } \\
\text { health of livestock and } \\
\text { preventative measures }\end{array}$ & 668.0 & 870.0 & 900.0 & 1900.0 & 1900.0 & 1900.0 & 2100.0 & 2900.0 \\
\hline 2 & $\begin{array}{l}\text { Establishment of basic } \\
\text { fodder pool }\end{array}$ & & & & 74.9 & 89.2 & 103.5 & 29.3 & 1720.9 \\
\hline 3 & $\begin{array}{l}\text { Preventative measures from } \\
\text { insects and rodents in } \\
\text { pastures }\end{array}$ & 10.0 & 16.0 & 150.0 & 200.0 & 200. & 300.0 & 450.0 & 600.0 \\
\hline 4 & $\begin{array}{l}\text { Improvement of water } \\
\text { supply in pastures }\end{array}$ & & & & & 260.0 & 300.0 & 426.0 & 466.0 \\
\hline 5 & $\begin{array}{l}\text { Recovery of losses caused } \\
\text { by natural disasters, } \\
\text { drought and dzud (livestock } \\
\text { provision) }\end{array}$ & & & & & & & $\begin{array}{l}1300.0 \\
*\end{array}$ & \\
\hline 6 & $\begin{array}{l}\text { Assistance in fighting } \\
\text { natural disasters and dzud }\end{array}$ & & & & & & 437.4 & 1900.0 & 71.8 \\
\hline 7 & $\begin{array}{l}\text { Fighting against epidemic } \\
\text { decease of livestock }\end{array}$ & & & & & 0.4 & & & 753.7 \\
\hline
\end{tabular}

Source: Data from Ministry of Food and Agriculture

* MNT 1,300.0-mil have been used to provide livestock to herders in 5 aimags that were left without livestock and with few livestock as a result of natural disasters and dzud. 
4.163 A total of MNT 6.9-bil have been used for making livestock healthy and preventative measures in last three years, ranging between MNT 1.9-bil to MNT 2.9-bil per year, involving 37-38 thousand herds of livestock every year, a total of 127,800 herds of livestock.

4.164 With the aim of recovering the loss caused by natural disasters, draught and dzud, herders are being provided with livestock under credits and aid from donors and international institutions. In this regard, MNT 1.3-bil, a long-term credit from World Bank, has been used for provision of 103,400 herds of livestock to 1,728 households in 33 soums of 5 aimags, and from UN Agricultural Fund 767,000 herds to 1,276 households in 2 aimags.

According to a sample survey conducted among herders in 1998, average income of one herder household was MNT 500,200, MNT 41,700 per month. At that time, average annual income of herder households with more than 2,000 herds of livestock was MNT 4.5-mil.

4.165 Findings of surveys conducted by scientific organizations in 2000-2001 among business-type herder households with more than 1,000 herds of livestock show that 94.8percent of total household's cash income is generated from livestock husbandry, 1.1percent from other production, 3.4percent from pensions and benefits. This proves the fact that today's herders engage only in one business - livestock production - and that their income is extremely dependent on nature and climate, making their income and living unstable. Annual cash income of herder households is MNT 4.6-mil, expense MNT 4.5-mil.

4.166 The breakdown of household income by product type is as follows: 59.5percent goat, 23.3percent sheep, 10.4percent camel, 2.9percent horse. Pasturing livestock husbandry is dependent on natural and climatic changes and have low productivity. During the course of transition into the market economy the above mentioned traditional livestock production methods and operations left unchanged being only household economy to meet consumption needs. Promotion of livestock husbandry has worsened, and not marketing structure has been established. During the structural change that took place in transitional economy, many people were laid off significantly increasing the number of people left with no option but to go to the countryside and engage in livestock production to support their living. In the beginning of the 1990 's the number of herder households amounted to 190,000 with 25.8-mil herds of livestock, while in 2000 it has doubled with 33-mil herds of livestock. However, 85 per cent of herder households have less than 200 herds, 63 per cent less than 100. Households with too small livestock husbandry lack force in preparing hay and fodder, transporting, obtaining veterinary and other services, accessing markets to sell their products, and overcoming natural disasters and price risk, and are extremely vulnerable to poverty. The number of experienced herders has dropped breaking the system of introducing leading experience in livestock husbandry and training replacing generation of herders. It was estimated that a herder household has to have $300-400$ herds of livestock to meet its basic needs.

4.167 Concentration of herds at one place due to increased number of herds and insufficient water supply in pastures is leading to pasture overgrazing. In addition over-concentration of herds in reserve pastures for dzud and drought results in hoof-dzud. As a result of all these herds are being killed in large numbers. 
4.168 Relating to number of herds and productivity, the difference between rich and poor is becoming larger; poverty and social welfare of herder households is being addressed critically. As of 2000, only 10.6 per cent of herder households had electricity and 12.8 per cent TV sets. The scatter redness of herders poses a difficulty in delivering social services to them. As a result of transitional economic crisis, drop in financing of education and health services from the budget complicates the resolution of herders' social issues.

4.169 The above situation has been addressed by the Government, and it is implementing programs towards improving the living of herders and rural people by facilitating pasture livestock husbandry, developing intensified livestock husbandry in certain regions to meet domestic needs, and steadily increasing exports of livestock husbandry derived raw materials and products within the "Guidelines of the state policy on countryside". Examples are "National program for enhancing livestock quality and breeding", "Livestock health program", "National program for assisting in protecting livestock from dzud and drought", "National water program", "White revolution", "Cashmere", "Wool" programs. The budget each years allocates MNT 3-5bil funds for livestock health protection, feed provision, fighting against pasture insects and rodents, improving water supply, livestock provision, helping dzud and drought sufferers, and halting infectious decease. These projects and programs are directed towards improving the living of herders and reducing rural poverty.

4.170 In addition to above programs, livestock provision projects carried out in two aimags with support from donors were successful. However, there is a need to make the risk protection system for herders available, and capture opportunities of increasing non-livestock income.

4.171 Long and mid-term livestock husbandry development goals are to effectively protect herder property and income by creating the risk management capacity to protect from natural, climatic and infectious factors, and taking into account specifics and advantages of regions, to ensure the sustainable development of the sector by facilitating livestock husbandry, including introduction of the relevant livestock insurance scheme based on indexation system.

4.172 Increased opportunities for engaging in other small production, cultivating potatoes and vegetables, and processing livestock raw materials through fostering ordinary forms of cooperation among herders, strengthening the required capacity, providing support in the form of training, micro loans and financial services will reduce risks present in herder's living.

4.173 The direction is to fully utilize the capacity to solve pressing issues of herders with their own initiatives and joint efforts by supporting their cooperative work and cooperation. This would be consistent with the principle of triumphing over the readiness mindset applied in poverty reduction and modern development trend of promoting initiatives from the bottom not from top. Promotion of cooperation among herders will be done through supporting voluntary initiatives from the bottom and unofficial organizational structure of traditional neighborhood groups.

- Improve the quality and access of veterinary service

- Risk prevention information system, capacity to react, and disaster management. 
4.174 Secondly, making livestock healthy is one of priority goals of livestock husbandry, and first of all an interest to make their herds healthy will be provoked in herders.

Intensifying of livestock husbandry will be carried out in two directions: (1) improve Mongolian livestock with local best breed livestock that well fits into local conditions and has high productivity, and (2) develop intensified and semi-intensified farmer businesses with the capacity to survive in the market located close to feed reserves and markets. The movement of many households from general and supporting agricultural activities into livestock herding has increased women's hours of unpaid domestic work, in carrying out milking and the processing dairy products, whilst also caring for children (not included in the national accounts). This has meant women have limited time to engage in other economic activities. A majority herdsmen usually work on their own property but have no license for household production, no banking facilities account and often lack the basic tools for farming. This new dependence on a herding lifestyle effects children too, as they themselves have to make a sufficient contribution to the household and the raising of livestock. Coordinating with the relevant agencies and civil society to ensure equal opportunities and benefits for men and women - as well as reducing any possible social and economic risks.

\section{Crop Farming}

4.175 Before 1990 the crop farming sector's output was 700,000-880,000 tones of crop, 100,000-120,000 tones of potato, and 500,000-700,000 tones of livestock fodder. Before 1990 land cultivation sector's policy was to fully meet domestic demand for crop, potato, vegetables, and livestock fodder as well as to export while in 1990-1996 consistent with the principle of the closer the property the better its operation, land cultivation entities were transformed into joint stock companies with state ownership. Land cultivation production dropped significantly due to reduced direct and indirect support from the Government, unwelcome economic situation during the beginning of the transition period (fast growth of import prices, inflation, high interest rates, wrong lending policy, banking and financial crisis) and lack of management skills and capacity to run the business in the market economy. According to official records there are 1.2 million hectares of land for LC, but actual of 2001 showed that 217,600 hectares of land were used for crop, potato, vegetable and feeds production and 275,400 hectares for crop land preparation, which totals the LC land to 497,000 hectares. This means that 707,000 hectares were left unused.

According to 2001 results, in 2001:

$\begin{array}{lll} & \text { Output of LC } & \text { Domestic demand covered } \\ \text { Wheat } & 150,200 \text { tones } & 34 \text { percent } \\ \text { Potato } & 58,000 \text { tones } & 42 \text { percent } \\ \text { Vegetables } & 44,500 \text { tones } & 46 \text { percent } \\ \text { Feeds } & 1,700 \text { tones } & 4.0 \text { percent }\end{array}$

4.176 The Government has adopted a Program for reviving the crop production and is providing support as to granting certain concessions and credits. In addition, jointly with governments of donor countries it is implementing projects such as KP-1 for improvement of food supply (to supply flour, rise and wheat) and KP-2 for increasing food production (to supply import inputs of great lack in land cultivation such as tractors, combiners, agricultural trailers 
etc.) under which 40-50 tractors and combiners are provided each year via long-term credits. Although the Government has set out the revival of land cultivation as priority objective in agriculture, the policy and programs could not achieve desirable success as a consequence of natural factors.

4.177 Until 1995, the government has been controlling prices of main crop products such as wheat, flour, and bread taking preventative measures from abrupt rises. This had a real impact on the sector downturn.

4.178 From 1996, the Government set out the main policy of the crop farming sector as to finalization of privatization of all state-owned entities in the sector. In addition, for the purpose of increasing the state support, confessional credits had been extended through state owned commercial banks and oil supply entities.

4.179 For the aim of reducing unemployment and poverty in rural areas, increasing household income, and promoting individuals and households cultivating potato and vegetables, the Government adopted a "Green revolution" program. The program is organizing training in all aimags and soums on how to cultivate, tender and consume vegetables and is giving support to increasing the production and consumption; but the domestic production supplies only 4345 percent of potato and vegetable demand and less than 6 percent of berries.

4.180 In 2001, the government adopted a "Seeds" sub-program and disbursed MNT 1.8-bil from the KP-1 fund, under the "Urinsh 2001" project MNT 2.5-bil in 2001 and MNT 2.5-bil in 2002 under repayment conditions. But as a result of drought in last consecutive 4 years the harvest was lost making most of companies non-capable of repaying the credit.

4.181 In this way, since the transition into the market economy, the Government has been taking measures to revive the LC production as to extending significant amounts of credit for preparation of crop land, modernization of equipment pools, and purchase of seeds. But the companies that never had enough working capital and accrued huge debt could not get decent harvest due to unwelcome climatic changes, especially consecutive droughts in recent years.

4.182 Therefore, a working group was set up in the Ministry to propose a principle change in the land cultivation policy, and in cooperation with scientific organizations prepared a draft on state policy towards land cultivation.

4.183 Ensuring the security of crop, a food product strategically important to living of the entire population, especially of the poor bracket, is one of priority objectives. A goal is set out to improve the flour supply to the population and ensure the reliable supply by reviving the crop production, utilizing the capacity of flour production at its maximum and reducing the import risk. Sustainable development of the crop production will not only assure the living of over 60,000 crop producers, but also reduce the livestock risk by creating a reliable source of livestock feed. Therefore, the mid- and long-term strategy for the crop production is to revive the sector as well as to develop highly productive intensified and mechanized crop production by refining technologies, introducing technologies with less soil damage, developing seeds production, increasing harvest yield, cropping elite seeds, and establishing irrigated production. In other words, the objective is to get high yield harvest and meet domestic demand. Production 
of livestock fodder in addition to wheat will be facilitated. For the purpose of reducing risks of businesses in land cultivation and assure their running, measures to allow land ownership and possession will be taken. This is an important action for not only crop producers but also the poor to cultivate vegetables and berries to improve their living. The law on land ownership was adopted in June of 2002 by the Parliament and will enter into force from May of 2003.

\section{Environment}

4.184 The socio-economic development of Mongolia is dependant on the utilization of natural resources. The principle that the sustainable use and management of natural environment will help to create jobs, to improve human health and maintain biodiversity, is being pursued. The main sectors of our economy such as nomadic livestock breeding, agriculture and mining are largely dependent on natural resources. During the transition to the market economy, many Mongolians who lost their jobs turned to the natural resource for their livelihood through livestock breeding, mining, hunting, and collection of natural by-products such as nuts and berries. Their intense interaction with natural environment has led to depletion of natural resources and increase in environmental deterioration. Meanwhile, natural disasters such as drought and severe winter, desertification, sand movement caused by global warming, and overgrazing have hit the lives of herders harshly, forcing them to abandon their traditional lifestyle of herding and move to cities. Over-concentration of the population in cities in turn has caused unemployment, poverty, environmental degradation, waste production, and soil and water pollution. It is, therefore, essential to incorporate the issue of improving people's livelihood with environmental protection when defining the strategy for poverty alleviation.

4.185 Due to global climate change, desertification has increased in Mongolia: lakes and rivers have dried up, vegetation cover has decreased dramatically, soil has lost its fertility and there is increased desiccation and sand movement. Overgrazing has caused threat to the livelihood of herders, who make up 40 percent of the population. 70 percent of the pasturelands of Mongolia are used for livestock grazing to certain degree. Yet the biomass/yield of one acre area has decreased by 19- 24 percent during last 30 years. Due to bare lands and lack of grazing areas herders were forced to settle along rivers and other surface water sources. As a result, areas near settlements, water sources in forest steppe region were severely degraded. Thousands of herders having lost their livestock - their only livelihood means, due to overgrazing, shortage of forage and water resources, and natural disasters such as drought and heavy snowfall. The soil protection will be improved by combating the desertification and sand movement through rational utilization and re-productivity of pastureland, increase of the green grass-lands in dessert areas, improvement of fuel supplies in medium and long-terms. Therefore the activities aimed to combat desertification and overgrazing, to intensify land reform policy, sustainable pastureland and natural resource management, and to establish green zones to prevent sand movement, plant endemic plants which endure drought, to utilize pasturelands in rotation and to improve the quality of livestock will be undertaken. All activities will be implemented jointly with local administration and local people.

4.186 The measures to plant bushes in dessert areas will be taken in order to prevent sand movements. The large utilization of sexual forests as fuel has caused the sand movements and desertification. Therefore, it is important to supply the Gobi zones with cheap fuel by producing them. 
The policy to intensify forestation and ensure plantation and proper use of semi-natural resources will be pursued.

4.187 Approximately 8.1 percent of Mongolian territory is covered by forests. According to the Food Agricultural Organization study, Mongolia is considered to have poor forest resources. In relation to unemployment and poverty, illegal tree felling has increased dramatically in the last decade. Since 1996, areas of 6.0 million ha were affected by forest fires. Thus, forest resources have been reduced dramatically. It is essential to provide jobs for low income families and poor households mobilizing them in activities such as to establish tree nursery, forestation, utilization of half burned wood and tree coals and prevent fire. It is also important to increase livelihoods by training them in planting semi- natural resources (such as berries, nuts and medical plants) and proper utilization of them. The same issue remains with UB city municipality to maintain green zones through mobilization and involvement of low income households in rehabilitation and maintenance of the city's green zones, assigning the responsibility for protection of green zones to district authorities, business entities and associations of housing owners.

4.188 Solid waste management is one of the critical problems facing Mongolia. Solid wastes are kept in and around 447 waste points covering a total of 3145 ha area. Some area of 11115 ha has been polluted by waste. Wastes are disposed to open waste points near settlements. Therefore, it is a priority to remove or re-process solid waste. All ideas and initiations of people, non-government organizations and business enterprises to reduce air pollution, to improve solid waste management in long and medium-term will be encouraged. Factories designed to classify/sort out and recycling waste will be built. The UB city municipality will draw a special attention on a removal and processing of solid waste, including collection, sorting and separation of hard waste and garbage.

4.189 The public initiations and active participation of poor in management of collection, sorting, re-use, transportation and removal of waste will be highly encouraged.

4.190 There are 4113 small and large rivers stretching 67000 kilometers, 3060 small and large lakes with 500 cubic kilometers water resources, and about 7000 spurting out springs, 262 ice rivers, stretching 659 square kilometers, 120 mineral waters, 139 underground water resources in Mongolia. Total water resources of Mongolia are 38.8 cubic kilometers and of which 34.6 cubic kilometers of water resources are available for utilization. 64 percent or 22 cubic kilometers of out of usable water resources are surface water, and 36 percent or 12.6 cubic kilometers are underground water.

4.191 The water consumption in the capital city is increasing due to a number of reasons such as increase of population and factories, watering of plants and connection of suburban areas to the capital water supply network. It is estimated that the amount of water consumption in 2010 will reach 218 cubic meters per day. The survey conducted among households residing on the outskirts showed that their consumption of water ranges from 8-10 liters, which is 5 times lower than the required health standard. Water supply in steppe and Gobi is much more scarce. The quality of water in soum centers does not meet health standards, and it is established that the quality of water consumed by people does not meet health requirements in 38percent of soum and rural areas. Thus, it is very urgent to address the issue of improving water quality and 
reducing incidence of water related diseases. Besides, due to scarce water resources and supply, a quite large number of hectares of pasture and crop land left without exploitation. The water shortage causes the desertification, flora degradation, and even serves as a main cause for households to fall into poverty. Therefore, it is a critical to improve the quality of drinking water and reduce disease rates. Lack of water resources limits the usage of pasturelands and crop fields which in turn leads to overgrazing, loss of livestock number, and poverty. Most of poor people are unable to use water which meets health standards.

4.192 Rational utilization of water resources, improvement of water quality and reproductive capability of natural water resources are to be encouraged. The policy to supply people, particularly poor people with purified water will be pursued.

4.193 Air pollution threatens people's right to live in healthy and safe environment. In Ulaanbaatar city 75 thousand households in ger area use 200 thousand tons of coal and 160. 0 thousand cubic meters of wood for fire per year. They throw ashes and waste in open places which pollutes air and increases diseases among the population. According to some estimation, one resident in Ulaanbaatar breathes $90 \mathrm{~kg}$ of harmful gases/toxic gas. Respiratory diseases are predominant among citizens, especially children. The measures are being taken to enhance the basis of the legal environment to reduce pollution, to minimize consumption of fuel by poor households in ger area, to supply with stoves with fuel-efficient stoves, to control car emissions and to require the power stations to have stoves with gas filters. Fuel-efficient stoves meeting national standards should be distributed to poor households at discounted prices to save fuel and reduce household expenses, especially for the poor people in ger areas of Ulaanbaatar city. The Government's priority is to provide required funding resources to obtain stoves that consume less fuel and emit less smoke. The distribution of fuel-efficient stoves to poor households is aimed to save their fuel consumption and to increase their income.

4.194 Within the framework of reducing of air pollution in Ulaanbaatar city the actions such as recovery of green planting areas, involvement of people with low income in to plant-caring activities, protection of plants and ownership responsibilities will be carried out with support of apartment-ownership associations. The strategy on environment protection and improvement will set up more possibilities for population, especially for poor people, to live in healthy environment, to utilize clean drinking water and to use natural resources rationally. 


\section{CHAPTER 5: ENSURING SUSTAINABLE HUMAN DEVELOPMENT}

5.1 Although achievement of the sustainable livelihood and reduction of poverty depends on the level of economic growth, it is also closely associated and interrelated with the ensuring sustainable human development, improvement of the access to and quality of public services, and creation of sound governance. The human development objectives as they relate to the economic growth and poverty reduction strategy, are aimed at creating income-generation opportunities for the poor, engaging them in decision-making processes and thus securing their social protection. The policies for social services by various sectors are:

1. Creation of job and business opportunities for the population, especially the poor, aiming at enhancing the income of the poor.

2. Improvement of the access to and quality of social and infrastructure services and involvement of the poor and vulnerable groups in the decision-making process for resource utilization and management, which is one of the ways to alleviate poverty.

3. Prevention of poverty and vulnerability by encouraging civic engagement, especially of the poor, in decision-making.

5.2 The current programs, projects and the social welfare system may in some ways create a sense of dependency in the population, particularly in the poor. Therefore, the poverty reduction efforts to achieve sustainable livelihood of the population should be driven by the initiatives of the people to whom these efforts are dedicated. A Project for Sustainable Livelihood began in September 2002 with the purpose of implementing the national poverty reduction strategies and fostering sustainable and reliable livelihood of the rural population. The project is underway in 8 pilot aimags and has the following three main components:

5.3 Pastoral risk management: development and application of an integral strategy to mitigate pastoral risks such as the "dzud", drought, livestock diseases, and price fluctuation. This component will be integrated with other components in determining the main causes of the herders being heavily affected by the "dzud" and drought, supporting initiatives for risk management and developing hay and fodder activities.

5.4 Expanding the scope of micro finance services: provision of financial and micro credit services to the rural individuals and families of the poor and vulnerable groups through the Micro finance Development Fund and the earlier Revolving Credit Fund. Various tools for mitigating micro credit risks, forms of credit collaterals and a small-scale credit insurance system will be tested out.

5.5 Local development initiatives fund aimed at increasing investments for the development of local infrastructure and social services, prioritizing the investment allocation, cofinancing, and defining the most effective and transparent instruments maximizing local 
participation. The Local Development Initiatives Fund efforts are to be coordinated with the government investments.

5.6 The three project components are well-integrated to build the capacity of poor and vulnerable families and individuals, create opportunities for income generation, invest into the local infrastructure and the social sector and improve the access to the social services. Therefore, it is hoped that implementation of the programs, projects and activities supporting sustainable livelihood will help alleviate poverty in Mongolia.

5.7 Human development level. The global trend has changed attitudes towards assessing national performance from economic prospects only. The national development and prosperity depends on how big human deprivations are big. Therefore the government of Mongolia focuses on issues of social development.

5.8 Human development means expanding people's choices and opportunities. These choices include the choice to exercise healthy and long life, to obtain good education, to own assets and money, to participate in decision making and to be empowered, to use efficiently natural resources and pass them to future generations, to enjoy political freedom, to respect each others, etc. An indicator that measures human development is the Human Development Index (HDI). Mongolia's Human Development Index was 0.737 in 1990, which then subsequently declined to 0.604 in 1995, 0.669 in 1998, 0.618 in 1999 and 0.628 in 2000. In 2002, the Human Development Index reached 0.628 and Mongolia was placed the 113 th among 173 countries.

5.9 At the beginning of 20th century the Mongolian society was one a traditional and underdeveloped one with literacy rate below 10 percent, average life expectancy below 40 years, high child mortality and almost without any formal education, health services. The People's Revolution of 1921, created opportunities to people to obtain education and health services free of charge with equal access without any ethnic, gender, wealth, and religious considerations. At the beginning of 1990s prior to the transition period the human development indicators have been improved substantially with 100 percent literacy rate, average life expectancy of 60 years and relatively low child mortality.

5.10 The Government's objective to enhance economic growth and reduce poverty will be based on broad participation of the private sector in the economy and reform of the public sector. The reform will depend on the access and quality of government services and appropriate public expenditure management. The reform process will be based on newly passed Public Finance and Management Law.

5.11 The Government's policy is to raise the efficiency of budget resources allocated to the social sector. Expenditures on the social sector, and their performance in the past 6 years is shown in the following table: 
Table 5:1: Fiscal Expenditures on the Social Sector

\begin{tabular}{|c|c|c|c|c|c|c|c|c|c|c|c|c|c|c|}
\hline & \multicolumn{7}{|c|}{ percent in total budget expenditures } & \multicolumn{7}{|c|}{ percent in GDP } \\
\hline & 1995 & 1996 & 1997 & 1998 & 1999 & 2000 & 2001 & 1995 & 1996 & 1997 & 1998 & 1999 & 2000 & 2001 \\
\hline $\begin{array}{l}\text { Total expenditures } \\
\text { on the social } \\
\text { sector }\end{array}$ & 49.1 & 44.4 & 45.5 & 46.2 & 48.4 & 52.3 & 55.9 & 13.3 & 11.3 & 16.0 & 19.4 & 19.1 & 21.5 & 24.2 \\
\hline Education & 17.0 & 15.9 & 16.2 & 17.1 & 17.8 & 19.1 & 20.4 & 4.6 & 4.0 & 5.7 & 7.1 & 7.0 & 7.9 & 8.9 \\
\hline Health & 11.3 & 10.6 & 9.9 & 9.6 & 9.8 & 10.5 & 12.1 & 3.1 & 2.7 & 3.5 & 4.0 & 3.9 & 4.3 & 5.2 \\
\hline $\begin{array}{l}\text { Social insurance } \\
\text { and social } \\
\text { assistance }\end{array}$ & 15.7 & 13.6 & 14.9 & 15.1 & 16.4 & 17.2 & 17.6 & 4.3 & 3.4 & 5.2 & 6.3 & 6.5 & 7.3 & 7.6 \\
\hline $\begin{array}{l}\text { Housing and } \\
\text { public services } \\
\text { Recreation, sports, } \\
\text { culture and arts }\end{array}$ & 1.6 & 1.1 & 1.2 & 1.1 & 1.3 & 1.6 & 2.8 & 0.4 & 0.3 & 0.4 & 0.5 & 0.5 & 0.7 & 1.2 \\
\hline
\end{tabular}

5.12 One of the key priorities of the Government is improvement of the quality and access to basic education and health services, to support employment and income-generating activities, thereby improving the social safety net and supporting sustainable human development. In implementing these activities, the Government will ensure that the poor and vulnerable groups of the society have equal access to basic social services, thus supporting their opportunities for employment and participation in economic activities. It means that having a person reach satisfactory levels in terms of education level, food availability and health is the prerequisite to prevention and escaping from poverty and vulnerability, especially inter-generational poverty.

5.13 Participants of the Regional seminar on "From I-PRSP to F-PRSP" expressed their criticism about issues of education and gender. For instance, Hovsgol, Zavkhan aimag participants mentioned that "Intellectual poverty is emerging in rural areas. It is especially important to consider the issue of making boys leave schools in order to herd the livestock. It is necessary to improve conditions in dormitories and the supply of professional teaching staff in order to increase enrollment in rural areas. The Government should also regulate the issue of enrollment in higher education and support employment of graduates in rural areas through government policy. It is necessary to ensure gender equality in professional training." 


\section{Box 5-1: Human Development Index (HDI)}

The Human Development Index is based on three criteria: life expectancy, educational achievements and income level, which measures social progress and achievements. Life expectancy is the average life expectancy of the population, which is 65 years in Mongolia (men 62.7 years and women 67.6 years).

The educational achievement is determined by literacy level of adults, and the overall enrollment rate in secondary and tertiary education. The adult literacy level was 97.8 according to the population and housing census of 2000 (men 98.0 and women 97.5), the overall enrollment rate 69.6 (men 63.7percent and women 75.5), which gives the educational achievement index of 0.884 ( 0.865 for men and 0.901 for women).

The income index is measured by the income in purchasing power parity and adjusted real GDP per capita. The real GDP per capita in Mongolia is about US dollars 400.

5.14 As a result of long and medium term policy priorities implementation, the Human development index will be improved over time.

\section{Education}

5.15 According to educational statistics of 2002-2003 there are 83.6 thousand children in 665 pre-school institutions, 510.3 thousand pupils attend 700 schools and another 15.1 thousand students are engaged in vocational training institutions. Many studies conducted in previous years how that although there is no big gender discrepancy in terms of educational achievements, there are significant differences between the levels of education of urban and rural citizens. Therefore, it is important for educational policies to aim at closing the gap between levels of education in rural and urban areas.

Table Basic education indicators, by regions, 2001-2002

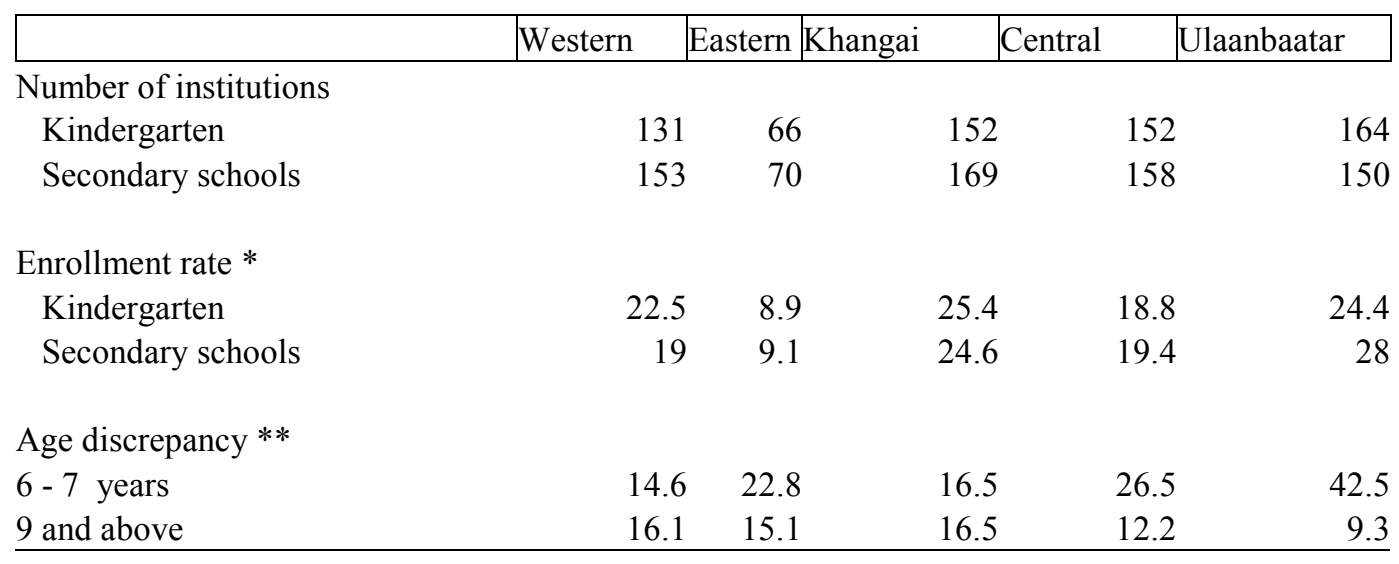

Source: compiled based on MOESC annual report

* percentage of pupils enrolled among designated age

** percentage of enrolled in grade 1 among aged 6-7 years and 9 and above years 
5.16 Before 1990, education coverage level of Mongolia was the highest and it is confirmed by the fact that Mongolia was among the countries with the highest literacy rate. However, at the beginning of 1990, when the country started to transfer to the market economy, the enrollment rate was sharply declined. Main reason of this decline was the boys who were from herder families living in the remote aimags and who dropped out of the schools to help their parents to look after the privatized livestock.

5.17 As of 2002-2003 academic year, there are 510.3 thousand students who are studying in the general secondary schools and this number is higher than the 1990 level. Despite this positive figure, the coverage rate in the distanced local areas is still lower than in the urban places.

5.18 Last several year migration to the capital city and aimag centers resulted in increased number of population and density in these places. In contrast, it led to the sharp decrease in the number of students in the rural schools.

5.19 In the lower and upper secondary schools, number of girls is more than the boys' and their gender ratio is 56:44 in the secondary schools and 2:1 in the higher education institutions which is rare even in international practices.

5.20 In 1990, there were 97.2 thousand children in the pre-school education institutions, however, this number went down to 64.1 thousand in 1995. During the last years, number of kindergarten students is increasing and reached 87.6 thousand. Although, only $33.4 \%$ of total pre-school age children is in the main class of the kindergarten and $8.1 \%$ is covered under other types of training. As the kindergartens are located in the centers of aimag and soum, rural, especially, herders' children cannot be covered under the preschool education.

5.21 Number of students in the technical and vocational schools was 31.2 thousand in 1989 , but this number decreased up to 7.6 thousand in 1994. In the last years, the number of VTS students is gradually increasing and now over 19.0 thousand students are studying in the technical and vocational training schools.

5.22 In 1990, there were 13.8 thousand students studying in the universities and colleges for bachelor degree and during 1997-2001, this number has increased from 44.9 thousand up to 83.2 thousand. However, the number of graduates with higher education diploma is going down.

5.23 In the first half of 1990, over 30 thousand children dropped out of the schools and it took $8.8 \%$ of total students. Boys took more than $70 \%$ of total drop outs. Such increased rate of drop outs formed a condition to increase the number of illiterate population in Mongolia.

5.24 Although the drop out is decreasing in the latter years, annually 12-13.0 thousand children are still dropping out of the schools and this fact shows that the drop out rate is not substantially declining. Poverty and inappropriate activities of schools and teachers are somehow affecting the drop out rate.

5.25 Annual repitition rate for total students is $0.11 \%$ and this is $1.0 \%$ for the first grade and $0.6 \%$ for the second grade which are considered the highest repitition rates. Those who 
dropped out of the schools are basically leaving school. Eighty six per cent of total first grade enrollment has received primary education and $66.3 \%$ have had basic education within the specified period and that is considered as very unsatisfactory performance.

5.26 Extension of 26 schools with most work overload and building of new schools are done through public investment and assistance of donors' support and loan. This measure created additional 11.5 thousand seats in the schools. In addition, over 300 schools, kindergartens and dormitories were maintained. All these measures are creating more favorable education environment.

5.27 Parents and relatives used to provide their children in the dormitory with meat, but now the government is recovering total food cost for the students living in the dormitories. The government is also giving school supplies to the students from a family where four and more children go to the general secondary school at the same time and the very poor families free of charge and this measure positively effected to decrease the drop outs.

5.28 Teacher supply in the general secondary schools is substantially improving. The government took measures such as sending over supplied teachers to the place with shortage of teachers on volunteer appointment, enroll the students to the teacher training institutes with more favorable requirements and increasing salary of teachers etc.

5.29 Content, standards and curriculum for the preschool, primary and secondary education were revised and compliance of them were provided. Textbooks were also renewed. As a result of these actions, drop out was declined and education value is increasing.

5.30 Quality and efficiency of education is below the sufficient level. There is a big gap in between of the rural and urban school performance. According to the school performance monitoring analysis in 1999-2000, performance of soum level students is over 10\% lower than the performance of aimag and capital city students' performance. There are certain factors that are effecting this:

1. Shortage of teachers in rural schools. In the academic year of 2002-2003, rural schools are lacking 495 teachers. Processes as teacher training, retraining and increasing their qualification are still weak.

2. Teachers are in lack of sufficient class methodology skill, thus they cannot introduce modern comprehensive pedagogical approaches in the training process.

3. Quality of kindergarten, school and dormitory buildings is getting worse and worse. In the last years, many school, kindergarten and dormitory buildings are being maintained, however, there is still a long list of such buildings waiting for the maintenance.

4. Training facilities and equipment of the general secondary schools got worse and there was basically no reform in this field during the last 10 years.

5. Most education sector budget is spent on indirect expenditures such as heating, electricity and water etc. In other words, the budget cannot be considered as an incentive to increase education quality and efficiency.

6. Training curriculum and plan for all stage of schools are not yet strengthened and quality and supply of the textbooks are not meeting the increasing demand. 
7. Although the number of students in the VTSs is increasing, we cannot still train the professional workers who can meet the market demand and need.

8. Training of children with some development difficulties (disabled, deaf, blind etc), providing them with sufficient social welfare services is still out of control and such children are out of the schools.

5.31 The Law on Education states that not less than 20 percent of the annual budget is to be spent on educational sector. In last years 113.9-126.8 billion tugrugs were spent on educational sector, and 64.7-72.6 billion tugrugs were spent on secondary schools and kindergartens. Although the financing of educational sector is being increased every year, the budgetary funding are not always sufficient to meet increasing needs of all stage of schools and kindergartens.

5.32 In last years, the Government determined variable cost norms per a student and it is improving the sector cost planning. The fact that the variable cost norms are determined differently depending on school's qualifications and locations of the aimags or capital, causes the lack of resources and the budget allocation for some schools is becoming inefficient depending on the number of students. The management capacity of central and local educational institutions is not good enough. In last years, it has been difficult to find people who would work as principals and heads of schools and kindergartens in rural areas. There is a need to have a comprehensive system of training and re-training of senior educational managers, and it is necessary to improve their professional skills.

5.33 One of the instruments to alleviate poverty is to improve the educational level of the population. For this, the government aims to create favorable conditions for the population to obtain high-quality education by expanding the scope of educational services and improving the quality of education. The following policy objectives are being set up to develop the educational sector:

5.34 First, to upgrade the education quality of all stages of schools and to educate a citizen capable to live in the society with a market economy. Based on certain assessments, it is required to take systematic actions on improvement of training quality. It is appropriate to start these actions from conducting diagnosis through monitoring, analyzing and evaluating the performances of students and activities of schools and teachers, and through assessing the conditions and the environment which influence the education quality. This work can help to realistically determine the main factors which impact on the quality of training, and will give an opportunity to make corrections and to rationally plan and implement regulatory actions.

5.35 Second, to set up a system where educational services are accessible in all areas, particularly in rural areas, and to support the need of the low income group to obtain education and the possibility to provide them with education services.

5.36 Third, to improve the management capacity of central and local educational institutions of all levels.

5.37 In order to implement the policy objectives, the following strategy is to be considered: 
1. To strengthen management capacity of state central administrative organization in charge of educational issues and of educational institutions in aimag and local areas.

2. To reduce the drop outs, and to increase the coverage of basic education up to $90.5 \%$ by 2006. Gender disparities in secondary and higher education should be addressed by increasing the enrollment rates of both sexes. In this regard, education facilities, teachers and other personnel need to be motivated and trained more effectively and actions should be taken to improve access and quality of services. It is necessary to aggregate efforts of government, public organizations, community institutions, business entities, citizens, parents, teachers and schools in this work.

3. To improve the teacher training system, to fully provide the rural schools and kindergartens with teachers, to rationalize the actions to improve their professional skills and to upgrade their methodological skills.

4. To improve the education content of all stage schools and kindergarten so that it can give professional and job orientation and life skills to the students and to transfer the secondary schools towards 11-grade system starting 2005.

5. To expand the coverage of pre-school education by achieving $62.0 \%$ by 2006 , to improve the training environment of rural kindergartens, to describe rational methods and forms of preparing children of herder family for a school.

6. To expand conditions and possibilities of fully cover the children from herder and poor families, and the children with development difficulties (such as deaf, blind, disabled, etc.) in the schools, to improve dormitory supply and provision, upgrade service quality.

7. To provide literacy education for children, youth and citizens dropped out from the schools, to encourage and expand all methods and forms of obtaining professions.

8. To expand the scope of training professional workers that can meet the market demand through improving education content and material environment VTCs and to involve unemployed young people in the vocational trainings.

9. To improve quality of accreditation process for the higher education institutions, to upgrade the level of higher education up to the international standards.

10. To continue the renewal of the general secondary school textbooks, to fully supply the students with handbooks and textbooks.

11. To improve training environment by maintaining, expanding and newly building the schools, kindergartens and dormitories, to strengthen the training material base, to computerize and connect the schools to the Internet.

12. To monitor and evaluate the performance of students in the general secondary schools, study the basic factors effecting their performance and to improve the quality of basic education.

5.38 In order to implement the education sector objectives and strategy, we consider that assistance of donor countries and international institutions plays significant role. 
Table 5:2: Preliminary Cost Estimates, US\$ thousands

\begin{tabular}{|l|l|l|l|l|}
\hline Item & 2003 & 2004 & 2005 & 2006 \\
\hline $\begin{array}{l}\text { 1. Maintenance, extension and innovation of school, } \\
\text { kindergarten and dormitory buildings }\end{array}$ & 5000 & 6500 & 7000 & 7500 \\
\hline 2. Reform the education content & 40 & 50 & 60 & 60 \\
\hline $\begin{array}{l}\text { 3. Teacher training, retraining and increase their } \\
\text { qualification }\end{array}$ & 250 & 250 & 280 & 280 \\
\hline 4. Renew the textbooks & 200 & 220 & 230 & 240 \\
\hline $\begin{array}{l}\text { 5. Computer technology, accessories and connection to } \\
\text { the Internet }\end{array}$ & 200 & 220 & 220 & 220 \\
\hline $\begin{array}{l}\text { 6. Training facilities, equipment and other technical } \\
\text { supplies }\end{array}$ & 150 & 150 & 180 & 180 \\
\hline 7. distance learning, no formal education & 50 & 50 & 60 & 60 \\
\hline 8. Monitoring and evaluation of the training performance & 30 & 40 & 40 & 40 \\
\hline Amount & 5920 & 7480 & 8070 & 8580 \\
\hline $\begin{array}{l}\text { Of which: - from foreign sources } \\
\text { - domestic sources }\end{array}$ & $\begin{array}{l}4950 \\
970\end{array}$ & 6430 & 6870 & 7230 \\
1050 & 1200 & 1350 \\
\hline
\end{tabular}

\section{Health}

$5.39 \quad$ "Health services are very poor. There is a shortage of medical doctors, and hospitals provide very poor, symbolic services. If you are hospitalized, then you will have to buy medicines and syringes by yourself. Since we cannot always travel to Ulaanbaatar, we buy medicines and syringes from private traders, however, sometimes, what we buy turns out to be already expired and of low quality. I think that selling expired medicines to rural people is extremely dangerous. It seems to me that unlicensed private traders, who do not have any quality assurance tests, are selling such items in the rural areas" - says a woman in Builsen bag of Sevrei soum of Umnogovi aimag.

5.40 The transition process started since 1990 affected all social and economic spheres and sectors. Health sector was hit more severely than other sectors by the transition. The number of people employed in the sector, particularly, the number of midwives reduced by 32percent, nurses - by 31 percent and of medical doctors - by 11 percent respectively. The number of health institutions also reduced in size and some of them such as maternal rest homes closed their doors. Under such harsh conditions, thanks to the professional commitment and dedication of the medical personnel, and their mobilization of their potential resources, the health sector was prevented from a sweeping failure. The rapid recovery of the health sector since 1995 laid down a firm foundation to further development of the sector.

5.41 The health sector financing was shown on the previous table. It slightly reduced since the transition period began, but then in 2001-2002 it increased. This pattern is explained by the fiscal constraints and the reduction of the medical personnel as mentioned above. The health sector financing originates from three sources: state budget, paid services and medical insurance. The funds generates through paid services is relatively low. In 1990, 70.3 percent of the health sector finance came from the state budget, 29.7 percent was covered by the health insurance contributions whereas in 200253.9 percent was financed from the state budget, 41.8 percent was 
covered by health insurance contributions and the remaining 4.3 percent was financed from the proceeds of paid services.

5.42 Birthrate has been on reducing trend over the last 20 years with an ever sharp reduction since 1990. In 1998, a woman of reproductive age would have a fertility rate of 3 births. The fertility rate varies by regions and level of education of women. For instance, this indicator was high in remote western aimags (3.85), and was lower in Ulaanbaatar (2.17).

5.43 In 1980 the average life-expectancy was recorded to be 58, and increased to 67 in 2000, approaching a similar level with most of the countries with similar level of income. However, the women's average life-expectancy is below compared with that of the women of other transition economies.

5.44 Despite the difficulties of the transition years, over the last 10 years Mongolia has achieved certain progress in reducing infant mortality and mortality of children aged under 5 . For example, infant mortality rate reduced twice from 63 to 31 in the period between 1992-2000. Although this indicator is below the rate of the countries with similar income level, it is above the average of transition countries. This could be associated with relatively higher level of poverty in Mongolia.

5.45 Infant and below 5 years old child mortality rate in the rural areas is higher than in urban areas. For instance, a survey conducted in 1998 showed that the mortality rate in the rural areas was 50percent higher than the rate of urban areas. Dornod aimag recorded the highest rate, which was twice more than the rate of the lowest record, shown in Dundgovi aimag.

5.46 The above rate tends to be higher in less-educated and poor households. A survey conducted in 1997 suggested that the death probability of children in poor households was 16 times higher than the child death probability in rich families. Besides the poverty level, the level of education of fathers, lack of medical control during pregnancy, inaccessibility to medical consultation services are highly correlated with the mortality rate. Acute respiratory diseases, gastro-intestinal infections, complicated by diarrhea caused by malnutrition, and other easily preventable and treatable diseases become the major causes of child mortality.

5.47 In 1985-1990, maternal mortality rate fluctuated between 120-175 per 100000 live births. Since 1990 this indicator sharply increased and reached its apex in 1993 totaling to 240. Since then, this indicator has shown a trend of gradual decline comprising 160 deaths per 100000 live births over the period of the last 5 years. Although Mongolia recorded a declining birthrate since 1990, the total birth coefficient compared with that of the countries of transition economies and some other countries, is higher. Induced abortion account to be 230.8percent per 1000 live births, and this seriously affects reproductive health, especially the birth of young girls. As of today, 9percent of girls aged below 19 have become mothers. Of the total number of women, 33.4percent use contraceptives, and 45.7percent of married women use contraceptives.

5.48 A survey conducted in 2000 indicates that almost the half of maternal deaths constitute women from herding households. Women of herding households comprise 29percent of the total birthrate. Besides, unemployed women account for 28 percent of total mortality rate, which is quite a high indicator. A survey carried out in 2001 established that the causes of 
maternal mortality are associated with decreasing level and quality of medical services (36percent), delay of emergency medical aid (28percent) and living far from medical institutions. Sexually transmitted diseases lead to pregnancy complications, thus becoming one of the causes of maternal mortality.

5.49 Malnutrition is another issue of concern for both adults and children of Mongolia. Malnutrition and anemia is very common among pregnant women and children. For instance, at least 40percent of pregnant women have chronic anemia. Compared with incidence of anemia in urban areas (45percent), anemia is prevailing among rural women (71percent). In the result of measures to support breast-feeding, malnutrition among infants has reduced, however, wrong diet for children aged 2-5 at home leads to malnutrition. As of 2000, 25percent of children aged under 5 had growth problem, and 13percent were underweight, which is high than the same indicator for 1997.

5.50 Compared with countries with a similar income level, malnutrition is not a prevailing incidence in Mongolia, however, it still exists among poor, and rural population. The children of poor families suffer from protein-deficiency malnutrition and are more affected by growth defects and delays and mineral deficiency. According to a 2000 survey, 39.3percent of the members of households under extreme poverty, 13percent of poor households and 5percent of non-poor families have food deficiency. Of the underweight children, covered in the study, 7.1percent in urban areas, 15.7 percent in aimag centers and 19.4percent in soums. Though modest success was achieved in reducing the incidence of diseases, prompted by malnutrition, a lot remains to be done. Because of lack of proper knowledge and education and even money to buy iodinated salt, the poor people are more affected by thyroid.

5.51 Poor people tend to be more affected by infectious diseases, with higher incidence of respiratory and gastro-intestinal diseases, which as was said above could be easily prevented. Mongolia is one of the 7 WHO Asia-Pacific countries with high incidence of tuberculosis, and this indicator comprised 7.4 per 10000 population in 1991 and increased to 14.1 in 2001. Most of the people with tuberculosis are unemployed, poor and extremely poor people. Though the medical treatment has been relatively successful, because the poverty level is increasing, the tuberculosis incidences do not decline.

5.52 STDS and poverty have a strong correlation. In the period between 1989-1998, the incidence of syphilis increased by 66percent and of gonorrhea - by 56 percent respectively. As of 2001, syphilis incidence per 10000 population was 7.1 and of gonorrhea was 23.0. Almost the half of the total infected people were unemployed and homeless people.

5.53 National vaccination program to control severe cough, poliomyelitis, chicken pox and etc. is being implemented successfully, however, incidences between rural and urban areas, poor and non-poor children are different and uneven. For instance, Edstam and others conducted a survey on Hepatitis B vaccination coverage and immunization among children under age 2, showed that the percentage of children of herding households which received full dosage of the vaccine was considerably low that the number of vaccinated children in Ulaanbaatar.

5.54 Cardiac diseases, cancers and traumas - the non-infectious diseases - have also been major causes of morbidity and mortality over the last 10 years. 
5.55 Living conditions. Poverty and health degradation are directly related with poor living conditions. Most poor people live in gers and gers do not meet hygienic requirements in some aspects. Particularly, a recent survey has proven that there is a direct correlation between get heating and incidence of respiratory diseases among children. Poor people resort to improper ways and means to heat the ger, and this affects the health of aged and children living in the ger.

5.56 Although a host of measures have been undertaken to reduce the cost of medical aid and services, poor citizens are spending the bigger portion of their income for their health. For example, the 1998 Livelihood Measurement Survey established poor household spend 3percent of their income for medical and pharmaceutical purposes whereas for non-poor household this expenditure comprises 2 percent. This survey also concluded that the second major reason of impoverishment is diseases.

5.57 According to Janes survey (2000), 15percent of the household covered in the survey are impoverished or on the brink of impoverishment due to serious diseases; and 20percent were households, which were not able to follow medical prescriptions or delayed the prescriptions due to financial constraints. These are prevailing difficulties among the poor and vulnerable group citizens.

5.58 Consumption of medical aid. The level of consumption of medical aid remains high in Mongolia. Children and pregnant women are almost fully covered in vaccination, and most deliveries are carried out under control of professional medical staff. For example, 77percent of children with acute respiratory diseases, 67 percent of children with diarrhea were taken to hospitals for medical consultancy and/or treatment. Besides, the reports of state hospitals indicate that on average a person visits ambulatories at least 5 times a year. Although the level of consumption of medical services is high, the morbidity rate remains high, which suggests that the quality and scope of medical aid needs to be further improved.

5.59 The difference in the consumption level of medical aid is clearly seen. Compared with richer people, the consumption of medical services by poor people is considerably low. Besides, poor people tend to be served by district hospitals because of location proximity and lower costs of services, whereas people from families with higher income are served by central clinics, private hospitals and aimag center hospitals.

5.60 Because of their disability to pay for the services in cash, the poor people's consumption of medical services is low. A survey of 1999 indicated that among the total number of clients, the number of poor people was low at all levels of medical establishments. The indoor medical treatment of extremely poor citizens is 2.5 times less than the number of indoor treatment of members of richer households.

5.61 However, a survey on family medical services, carried out in 2001, showed positive changes in the established patterns. People registered as "Poor" received almost the same amount of family medical services with non-poor citizens. For people of some categories (aged citizens, single mothers) family doctor services have been recorded as the major source of medical assistance. 
5.62 However, it is impossible to deliver all necessary medical services through family doctors, and the clients complain that in most cases they are transferred to the higher level of medical establishments. This incurs additional (non-medical) expenditures such as absence of the necessary doctor, or the hospital does not accept the client, and the client is forced to wait for a long time etc.

5.63 As of September 2002, there were operating 234 family hospitals serving 56percent of the total population of Mongolia. These family hospitals employed 940 physicians. On average one family hospitals serves 5540 persons and 1250 families.

5.64 Soum hospital aid. The issue of increasing the quality of public health services and first medical aid, provided by soum hospitals is one of the core objectives of the health sector of Mongolia.

5.65 Soum hospitals account for 27.7percent of total hospital beds, 32.1percent of indoor clients, and 39.4percent of pregnant women deliver babies at soum hospitals.

5.66 The incidences of major 5 diseases, which are causes of population morbidity and mortality are increasing among rural population year by year; 40.5 percent of maternal deaths in the last 3 years occurred in soums and bags. This demonstrates that the quality and availability of medical services in rural areas is poor and inadequate. The following factors contribute to the emergence of such a situation. These are:

5.67 Buildings, heating, electricity and water supply at soum hospitals do not meet the minimum hygienic requirements.

5.68 The inspection by a relevant state administrative organization over the utilization and maintenance of buildings and facilities of 370 soum hospitals, conducted in 2001, established that the initial quality of construction of the most of the buildings was poor, no repair works had been carried out for a long period of time, 109 hospitals were providing medical services in buildings constructed for non-medical purposes. It was also established that 83.6percent of soum hospitals heat their hospital buildings with manually assembled low-pressure stoves, and 80 percent receive electricity from soum diesel station with some limitations. All soum hospitals consume portable water for their services and do not have a clean and waster water sewerage system.

\section{Soum hospitals lack necessary equipment and medicines.}

5.69 In the last 10 years the work to supply soum hospitals with necessary equipment and medicines practically stopped. The technical equipment that were in use earlier became obsolete and cannot be used in medical practices any longer. Thus, 92.5percent of total soum hospitals are in shortage of necessary equipment and devices to carry out medical services and aid. However, during this period, with the aid and assistance of some foreign countries and international organizations, most of the soum hospitals were supplied with sets of obstetric devices and some other equipment. Soum hospitals use 174 types of medicines in their medical practices, and currently the supply of these medicines comprise on average 30-40percent. Due to the failure of the delivery of pharmaceutical services to rural population, rural residents do not have access to 
reliable supply of quality and inexpensive medicines. Besides, there are cases when the rural citizens pay for medical services themselves, and cannot buy medicines at discounted prices even though they are covered by medical insurance.

5.70 Soum hospitals do not have sufficient professional personnel, and the capacities and skills of existing staff is inadequate.

5.71 Soum hospitals still lack medical doctors and mid-level professional staff. Rural doctors are not covered in post-graduate studies and training, have limited possibilities to acquire new information and are not ensured adequate living standards and remuneration. These factors adversely affect doctors' commitment to reside in one location permanently and their ability to deliver high-quality and accessible public health and primary medical aid.

5.72 Soum hospitals do not receive financing on time, and the allocated budget is insufficient.

5.73 Because of the failure to provide for financing of soum hospitals on time and insufficiency of the approved budget, there have been constant pressures and difficulties in organizing training activities for the medical personnel, treating the clients according to approved standards and paying the salaries and wages to the personnel on time. This leads such improper practices as requiring the patients to bring medicines with themselves, ask the clients to pay for the fuel of ambulance cars, thus leading to accumulation of arrears between and among hospitals and pharmaceutical organizations. The financing of soum hospitals, calculated by normative costs for medical services per person in soum is not fully made on time. Thus, as of the expected performance for 2001, 10 billion $\mathrm{Tg}$ was spent which is 21 percent of the total expenditures of the health sector.

5.74 There remain many issues that need to be addressed such as optimizing the structure and organization of rural health organizations, improving the capacities of professional management, improving the coordination and regulation of rural administrative organizations and increasing support for their activities.

5.75 Availability and location of medical doctors and personnel. It was mentioned earlier that in the period between 1990-1995, the number of medical doctors, nurses, midwives and other personnel reduced sharply. In 1995-2000, the number of nurses and midwives continued to decline, and reduced by 5-20percent. At the same time, the number of doctors increased by 18 percent. As of 2000, the number of doctors and nurses almost equaled.

5.76 The geographic location and dispersal of medical personnel attracts attention. In Ulaanbaatar one doctor accounts for 206 clients, whereas in Zavhan this number comprises 794 people. In Ulaanbaatar, one nurse accounts for 393 patients, whereas in Zavhan this number equals to 502. This demonstrates that the location of medical staff is not even, and the number of medical staff in rural areas is limited, which makes poor, and regular citizens at large, unable to receive medical services and assistance. Some remote soums do not have physician at all.

5.77 Policy changes implemented recently. Due to economic difficulties since 1990, the budget for the health sector sharply reduced, and the quantitative and qualitative indicators of health services drastically worsened. The situation improved since 1995 to some extent, 
however, health expenditures in GDP comprised 5.3percent in 1990, reduced to 3.1percent in 1995, and to 4.6percent in 2001.

5.78 The sectoral investment since 1990 fluctuated, and as of 2000, health sector investment accounted for 4percent of social sector expenditures. The breakdown of expenditures by categories shows that hospital aid, specifically, hospitalization of clients tends to prevail among others.

5.79 With the aim to create new financial sources, a health insurance system was introduced in 1994. The contributions of people from vulnerable groups are paid by the Government, and because the vulnerable group members do not make collective payments, this insurance system is a poor-friendly system.

5.80 Beginning from 2003 family hospital services are covered by health insurance, and since the poor citizens are broadly consuming and are likely to remain to widely refer to family hospital services, these changes are beneficial for poor citizens. The collective payment to be made at the moment of hospitalization is 5percent at soum hospitals, 10percent at aimag hospitals and 15percent at the third level hospitals. This is to reduce the cases to refer to the third level hospitals when deemed necessary. On the other hand, this could potentially reduce the referral of poor citizens for the third level services, who already rarely use this level of medical services.

5.81 Privatization of health sector. Privatization of the health sector tends to be not beneficial for poor. Particularly, because the more experienced renowned doctors and physicians are allowed to practice privately, their services seem to target richer citizens. Privatization experience of one hospital shows that now this hospital practically doesn't serve poor.

5.82 According to the Public Sector Finance and Management Act, an output-based financing scheme is being prepared, and this will create favorable conditions to increase the efficiency of health sector expenditure.

5.83 The strategy to reduce maternal mortality has been pursued since 2002. Because the incidence of maternal mortality is high among poor and vulnerable group citizens, the implementation of this program shall contribute to a certain extent to reduction of poverty. This year the National Program to Reduce Infectious Diseases has been adopted. This program is expected to be beneficial for the vulnerable groups as the incidence of infectious diseases among vulnerable groups is high. In November 2001 the State Policy on Public Health has been approved. This program creates possibilities to reduce poverty and increase the efficiency of the health sector. The newly endorsed National Program on Mental Health will be directed towards ensuring efficiency, accessibility and availability of medical aid and services to the population.

5.84 The rural poor residents and members of vulnerable groups are the core clients of soum medical aid and services, and within the framework of soum hospital programs, we aim at ensuring even, accessible health services in rural areas. Regional Diagnosis and Treatment Centers were established in 2001, which will be directed towards reducing the gap between medical aid and services in rural and urban areas. There are many other important programs 
implemented in the area of combating iodine deficiency, reproductive health, food security and nutrition.

5.85 Policies and actions implemented in the health sector in 2000-2002, their results

5.86 With the aim to improve medical aid and services by covering the majority of the population by health insurance, the Law on Citizens' Health Insurance has been revised. This created conducive conditions for shifting from individual health insurance to household insurance system. It has become possible for poor people to receive cheap health services. Besides, a new environment to foster competition among health organizations is built, which would further enhance quality and expand the scope of health services.

5.87 The Government is actively supporting private health sector. The privatization is being carried out within two venues: to acquire material base for health service delivery, and on the other hand, and to partially shift financing to private sector (through volunteer insurance and/or paid services).

5.88 A new system of family hospitals has been introduced to provide the major part of health services. Independent family hospitals have been set up with the location close to their serving districts. Family hospitals are financed through a contract based on norms calculated for a unit of service (for one client). According to the revised law on health insurance, the current expenditures of family hospitals will be paid by health insurance contributions and capital expenditures - from the budget.

5.89 Mongolia has achieved certain success in vaccination in the result of its years-long efforts. Tuberculosis, chicken pox, hepatitis B vaccination rate comprise over 90percent.

5.90 However, there are many issues challenging the health sector. Maternal mortality rate remains high and does not show any sign of drastic reduction. The quality of primary health care and services is poor, and they cannot reach the vulnerable groups. Health sector has limited financial capacities. Health sector does not yield sufficient efficiency. There is a need to organize information dissemination and training activities using radio and information and communication technology for rural residents, particularly housewives.

5.91 The following objectives are aspired at mid and long terms. These include:

- By sustainable implementing the Strategies to Reduce Maternal Mortality, the National Program on Reproductive Health and the Child Health Program, to achieve substantial reduction of maternal and child mortality and meet the bottom-line set by the Millennium Development Agenda.

- To improve the quality of and accessibility to basic health services for the population of Mongolia and the rural population in particular through strengthening family hospitals, ensuring conditions for normal functioning of soum hospitals and regional diagnosis and treatment centers and ensuring conditions for settled employment of personnel.

- By expanding the scope of coverage of the health insurance system, to improve to conditions for providing free medical aid and services to poor and members of the vulnerable groups.

- To reduce the incidence of infectious diseases. 
5.92 Within the framework of the above long-term strategies, the following mid-term actions shall be undertaken:

1. Within the framework of the goal to reduce maternal mortality:

- to revise and enforce the procedures to provide free medical professional assistance to mothers and children in conformity with the changes and amendments made to the Health Law

- to undertake measures to make the central clinics of Arhangai and Selenge aimag, and some soum hospitals Mother Friendly Hospitals. Furthermore, the scope of coverage will be expanded

- to expand government and civil society involvement on increasing public awareness on preventive measures of birth control - especially at the community and family levels.

- to activate reproductive health activities in Hovd, Bayan-Ulgii, Uvs and Huvsgul aimag and at two districts of Ulaanbaatar; to expand and strengthen reproductive health care and services in rural areas

2. Within the framework of the goal to improve the quality and accessibility of medical services for poor and vulnerable groups in rural areas:

- to undertake measures to increase the funding for family hospitals and other health services

- to improve the capacities of soum hospitals, train the personnel and ensure conditions for settled employment

- to improve the health knowledge and education of the population and train volunteer assistant-workers. To improve the material base and supply at rural and family hospitals.

- To improve the quality of professional medical assistance to the population by health organizations and medical doctors

- To upgrade the accreditation of public and private sector health organizations. To create favorable conditions and support the operation of private clinics and hospitals.

- To develop and implement programs on enhancing quality of services at accredited health organizations

- To train and retrain accredited officers, dealing with and specializing at licensed activities

- To develop and start implementing the health sector privatization program

3. Within the framework of the goal to improve the quality of medical services and strengthening financial capacities:

- to undertake measures to supply with necessary equipment and medicines

- to improve the diagnosing capabilities of state owned hospitals

- to create incentives to use financial resources for improving the quality of medical services

- to introduce a new health cost accounting system

- to develop and enforce new procedures and instructions to regulate health insurance financing 
- to establish a unified health database

- to improve the efficiency and promptness of provision of health service. To undertake measures to ensure prompt operation of rural ambulance services.

4. Within the framework of the goal to ensure food security and nutrition:

- to improve nutrition, food security and supply of mothers and children by implementing a national program

- by implementing a National Program to Combat Infectious Diseases to reduce the incidence of infectious diseases, tuberculosis and STDs.

- To undertake measures to combat AIDS.

5.93 The implementation of the strategic objectives for the health sector, Mongolia will upgrade the population health guarantee and the opportunities and possibilities for the poor and vulnerable groups to be fully covered by health services and aid will be created. Implementation of the strategic objectives shall necessitate full and complete mobilization of financial sources, ensure their optimal use and require support of donors.

\begin{tabular}{|rl|l|l|}
\hline Table 5:3: Health Sector Financial Requirements Summary \\
\hline \multicolumn{2}{|l|}{} & $2003-2006$ & $2007-2010$ \\
\hline 1. & $\begin{array}{l}\text { Repair, expansion and rehabilitation of buildings of } \\
\text { family hospitals, soum, aimag and capital hospitals }\end{array}$ & 5190.0 & 5150 \\
2. & $\begin{array}{l}\text { Provision of all necessary equipment, devices and tools } \\
\text { necessary for health organizations }\end{array}$ & 1645 & 2950 \\
3. & To rehabilitate the supply of ambulance cars \\
4. To retrain medical staff, specialization of medical & 1575 & 575 \\
professionals & Funds necessary for implementation of programs & 2262 & 250 \\
& & 224.8 & 280 \\
\hline
\end{tabular}

\section{Employment}

"Many people lost their jobs because of bankruptcy of factories and downsizing of budget entities. Some smart people moved away and those who are not-stayed in the country," said a group of women of Eson Bulag sum of Gobi Altai aimag.

"The living standards of people who were in normal condition 8 years ago are becoming worse and worse. These people are entering the ranks of the poor. The fact that privatization had been done in a wrong way is the main reason of closure of many industries, which increased a number of unemployed" said the residents of the Dalanzadgad city of the Omnogobi aimag on the current decrease of employment.

5.94 The main goals of labor and social welfare sector are reduction of unemployment and poverty, improvement of the living standards, ensuring social guarantees and improvement of the quality and access of caring services. According to the Millennium program of development, the 
reduction of poverty and hunger is a priority of the actions to be taken by of the Government of Mongolia in the social protection.

5.95 The main cause of poverty, malnutrition, deficiency of food and low income of the population is a high rate of unemployment in Mongolia which is the main reason of the fact that people are becoming poor. According to the statistics of the Population and Housing Census 2000,51 per cent of the population group aged above 15 is employed and actual unemployment or whose who are not employed constitute 17:5 per cent of labor forces. 54 per cent of all unemployed are females, more than 60 per cent are youngsters aged 16-35 and more than half of them are the people without professional education. One of the reasons of increasing of unemployment is a lack of vocational training.

5.96 As of January 1, 2003 the number of labor-age population was 1,402.8 thousand, while number of employed reached 832.6 thousand. The labor force participation rate was 61.5 per cent at the end of 2002. A survey of the labor market status has revealed a large migration of labor force and low labor productivity. This shows a necessity to develop the labor force of Mongolia and to enhance its capacity.

5.97 The migration of population from the countryside to city and urban settlements has a significant impact on employment. This impact is realized through the concentration of population and expansion of the informal sector in cities and urban settlements.

5.98 The resolution of the Minister of Social Welfare and Labor and the Head of the National Statistics Office No. 207/103 dated October 4th, 2002, on main definitions of employment was issued in order to correlate definitions and norms of employment, database on labor force, reporting, assessment and the main labor indicators with the definitions set by the International Labor Organization.

5.99 At the end of 2002, the number of unemployed that are of labor age, have the capability and possibility to work, registered with the employment office and actively looking for a job reached 30.8 thousand with the unemployment rate reaching 3.6 per cent, 1.1 point short from that in the same period of the previous year. The report on economic development, employment and training prepared by the International Labor Organization in 1999 within the framework of the assistance of UNDP on development of policy and programs of UNDP concluded that 10 per cent of economically active population are unemployed, and the Government of Mongolia has the same opinion. Informal entrepreneurs, who prefer to be registered as officially unemployed, are included in this number. Since 1995 our country has a system of insurance on unemployment. 
Table 5:4: Employment Status of the Population at the year- end, 1995-2001, (thousand people)

\begin{tabular}{|l|r|r|r|r|r|r|r|}
\hline Indicator & \multicolumn{1}{|c|}{1995} & \multicolumn{1}{|c|}{1996} & \multicolumn{1}{|c|}{1997} & \multicolumn{1}{|c|}{1998} & \multicolumn{1}{|c|}{1999} & \multicolumn{1}{c|}{2000} & \multicolumn{1}{c|}{2001} \\
\hline 1.Population of labor- age & 1186.7 & 1212.8 & 1229.9 & 1256.8 & 1279.3 & 1347.4 & 1402.8 \\
\hline Out of which: females & 590.4 & 599.5 & 612.3 & 625.8 & 637.0 & 676.5 & 719.9 \\
\hline \multicolumn{1}{|c|}{ percentage } & 49.8 & 49.4 & 49.8 & 49.8 & 49.8 & 50.2 & 51.3 \\
\hline 2. Economically active population & 812.7 & 825.0 & 828.8 & 842.4 & 853.4 & 847.6 & 872.6 \\
\hline Out of which: females & 384.2 & 393.1 & 396.4 & 404.4 & 408.3 & 412.8 & 429.7 \\
\hline 2.1. Employed (official) & 767.6 & 769.6 & 765.1 & 792.6 & 813.6 & 809.0 & 832.3 \\
\hline \multicolumn{1}{|c|}{ Out of which: females } & 360.6 & 365.0 & 363.8 & 378.4 & 386.7 & 392.1 & 407.8 \\
\hline 2.2.Unemployed (registered) & 45.1 & 55.4 & 63.7 & 49.8 & 39.8 & 38.6 & 40.3 \\
\hline \multicolumn{1}{|c|}{ Out of which: females } & 23.6 & 28.1 & 32.6 & 26.0 & 21.6 & 20.7 & 21.9 \\
\hline 3. Unemployment rate (percentage) & 5.5 & 6.7 & 7.7 & 5.9 & 4.7 & 4.6 & 4,6 \\
\hline Out of which: females (percentage) & 6.1 & 7.1 & 8.2 & 6.4 & 5.3 & 5.0 & 5.1 \\
\hline $\begin{array}{l}\text { 4. Participation rate of the labor force } \\
\text { (percentage) }\end{array}$ & 68.5 & 68.0 & 67.4 & 67.0 & 66.7 & 62.9 & 62.2 \\
\hline Out of which: females (percentage) & 65.1 & 65.6 & 64.7 & 64.6 & 64.1 & 61.0 & 59.7 \\
\hline 5. Employment rate (percentage) & 64.7 & 63.5 & 62.2 & 63.1 & 63.6 & 60.0 & 59.3 \\
\hline Out of which: females (percentage) & 61.1 & 60.9 & 59.4 & 60.5 & 60.7 & 58.0 & 56.6 \\
\hline
\end{tabular}

Note: excluding people working abroad

Source: National Statistics Office

It should be noted that in relation to employment, women have fewer opportunities for employment and income, the main mechanisms for escaping poverty, than men. Discrimination against women in job recruitment based on age, appearance and resistance because of childbirth and child care duties should be taken account of. In addition, women have disproportionately suffered as a result of restructuring in the formal labor market during economic transition-many women working in light industries and services were forced to move to the informal sector with little preparation. More women (63\%) than men (37\%) lost their jobs in the economic restructuring that took place from 1992 to 1995 , (according to a to study conducted by the then MOHSW). Women's higher levels of unemployment, high reliance on the informal sector for employment and income mean that many women fall outside of the state social protection and benefits system, increasing their vulnerability to economic and health problems.

5.100 The evaluation of the labor market status revealed that although the labor force flow is large, there is low productivity, weak competitiveness in the market, lack of floating capacity, high percentage of unskilled unemployed and duration of being unemployed is too long.

5.101 In light of the fact that almost 60 per cent of unemployed is not skilled at all and 6 per cent has primary education, the training in vocational orientation and new skills is a critical issue. The vocational training system has not been updated, the curriculum and education adequacy is not sufficient, and the quality still remains weak. There is a lack of qualified and skilled personnel that fits employers' subscription and needs.

5.102 The private sector has made certain contributions to increasing the population income and jobs since the beginning of the transition or at the time of large-scale social and economic 
difficulties, resulting in establishment of the informal sector. Informal sector is an economic activity aimed to gain a profit, but not registered in statistics, tax offices and in the state register list of enterprises and its income can't be determined." In the assessment done with the assistance of the World Bank in 1997 it is stated that "Informal sector comprises of small-sized economic activity generally based on a family unit which is not registered in formal statistics, and its taxes and other figures cannot be regulated the same way as other formal entities." In 1999 the USAID issued the same conclusion from the assessment on the project to support employment policy. Within the framework of informal economy employees don't have an official registration, the range of operations is small and not consistent, labor organization and conditions are bad, productivity and income is low, and micro business entities consist of small number of people.

5.103 60 per cent of the informal sector is engaged in retail trading. Most of those employed here are female and middle aged people.

5.104 Informal economic operations show a trend of increasing the number of employees with little income and low productivity. Most of them were laid off from state organizations and enterprises under job-cuts and are considered to be old to be recruited by the formal sector. The remaining part is those who could not get a job in the formal sector after their graduation of university and are registered with the labor market.

5.105 The survey estimated that informally employed build up 10.2 per cent of total labor resource and 13 per cent of the economic structure. And this shows a need for the Government to work out and implement policies and programs regarding the future development of the sector. First of all, protection of employee interests, enhancement of labor relations and social welfare, and provision of opportunities to switch into the formal sector are required.

5.106 The build-up an intensive policy for the labor market, operational legal framework, and economic environment have been addressed; the Parliament of Mongolia adopted the Laws on Unemployment Insurance, Employment Promotion, and Exporting labor force and importing labor force and specialists in 1995-2001. In 2002 the Government has developed and is implementing a National Program for Employment Promotion. In addition, drafts on the midand long-term government policy towards the informal economy and migration has been worked out.

5.107 Within the framework of employment promotion, the Government is attaching an importance to creating a legal and favorable environment. The Parliament ratified Employment Promotion Law and it is in force effective June1, 2001. The law aims at providing training, information and counseling, as well as conducting vocational training and retraining, promoting cooperatives and private entities, promoting employers and public works.

5.108 The utilization of the Employment Promotion Fund, which is established under this law and composed of allocations from the central and local budgets, as well as loans and assistance of international and domestic organizations, is started. It is envisaged to allocate 0,3 per cent of the budget revenue to the Employment Promotion fund and planned to allocate 200 million tugrugs in 2001, 800 million tugrugs and in 2002. In 2003 the budget reflects 1200 million tugrugs. The proceeds of working place payments paid by foreigners working in 
Mongolia go to this fund. In 2001 it was accumulated 400 million tugrugs from this source and 600 million tugrugs in 2002. It is expected to collect 800 million tugrugs in 2003.

5.109 In 2002 MNT 1.850.9 mil was mobilized into the Employment Promotion Fund and spent for financing employment promotion activities. As a result, in 200233.0 thousand people were hired under labor intermediary service, 15,431 people received vocational training and retraining. It can be considered as the result of the build-up of a favorable legal environment for the employment promotion policy.

5.110 In coming years, the annual growth rate of population of Mongolia is expected to remain at 1.4 per cent per year.

5.111 Although there is a downward trend for birth, a forecast of population and labor resource is under development using the stabilization of death by age groups as foundation. For instance, the comparison of age pyramid delivered a decline in the percentage share of young children accompanied by a rise in the percentage share of labor-age people, which is a favorable trend from the perspective of creative resources.

5.112 The labor resource growth rate is over pacing the rate of population growth by 15-20 points reveals a fact that the labor resource is being re-charged with thousands of youth and that the Mongolian community is faced with a tough goal of establishing job for and training them.

5.113 Only for 2002, 64 per cent of secondary school graduates enrolled universities and colleges while only 2 per cent went to vocational training and production centers. The rest 33 per cent moved into the labor market. The latter two issues are the ones that are closely linked to labor and social welfare.

5.114 The labor market strategy has been defined taking into account current situation of the labor market, vocational training system, unemployment, evaluations and recommendations by ILO and donors with regard to the informal sector status.

5.115 Within the framework of long- and mid-term policy for employment, the following two issues are set out as main goals:

1. Employment policy that is implemented under close coordination with the economic growth and investment measures;

2. intensive policy for the labor market oriented towards regulating the labor demand and supply efficiently.

5.116 To attain the above, the following strategic objectives are set out with regard to employment generation, unemployment and poverty reduction:

- Priority issues:

- Promote employment with priority in the fields of processing and exploitation industry, household service for the population, infrastructure development, and environmental protection and restoration; 
- Enhance the informal sector and gradually attach into the formal sector by establishing favorable economic and legal environment and conditions for setting up and engaging in animal husbandry, land cultivation, mowing and feed procurement cooperatives and trading, household and farmer businesses;

- Work out and implement mid- and long-term policies and programs with regard to the informal sector, enhance its labor capacity;

- Intensify labor market policies and measures, upgrade the quality and availability of employment services;

- Expand vocational and skills training (voucher program) for the youth, poor and vulnerable consistent with the labor market demand and supply, enhance the quality and outcomes of the training;

- Expand labor market specialized surveys, information provision and promotion efforts, increase the civil community participation.

5.117 The following actions will be implemented in coming years in a prior order:

- Establish conditions for sustainable job creation in the fields of infrastructure development and information and communication technology introduction, support small and medium sized enterprises with consideration of specifics of economic development, resources, and advantages of regions;

- Carry out measures of organizing public works with temporary employment opportunity to improve parts of infrastructure, community facilitates, public roads and squares under contract.

- Introduce a healthy job promotion movement consistent with the decent work agenda.

5.118 These objectives will be attained through implementation of the following measures in the mid term:

- Within the Millennium Road project, organize the provision of temporary and permanent jobs to the unemployed through intermediary services of central and local employment offices.

- Run livestock husbandry of good breeds and selected local breeds, develop and provide support to farmer businesses, establish research-analysis frame in this field;

- Provide temporary and permanent jobs by setting up a wholesale network for collection and sale of export products and raw materials and by promoting the establishment of primary processing of animal-originated raw materials;

- Submit a draft on the government mid- and long-term policy towards the informal economy to the Parliament for adoption. An importance is given to the development and implementation of a program to transfer those individuals working in the mining sector informally into the formal sector.

- Promote rural employment by assisting in launch of community service facilities including public bath, hairdresser, tailor shop, and shoe repair in soums and bagh centers and establishment of mobile facilities;

- Get local people deeply involved in forest, water source, and rare animal protection, forest cleaning, furnishiment of wells and springs, and forest restoration, expand the provision of temporary and permanent jobs and production and services that uses natural resources; 
- Expand and organize manufacturing and services with utilization of natural resources, involve local people in protective activities of forests, water springs, rare animals and in forest cleaning and fixing of wells, springs and rivers by providing temporary and permanent jobs;

- Organize activities to involve unemployed people to protect soil by preventing the deterioration of desert and steppe and setting up forest stripes;

- Consistent with the labor market demand and supply, organize the intermediation between the unemployed and job-seekers and job vacancies through the employment office;

- Support employers that organize on-the-job training for the unemployed to provide new qualification and upgrade skills;

- Set up business incubators in aimag centers and UB districts to enhance the capacity of micro businesses;

- Upgrade facilities, learning environment, and curriculum of vocational training and production centers;

- Extend vocational and skills training consistent with the market demand to individuals in the socially vulnerable group that are not covered by unemployment insurance and have been unemployed for an extensive period, those with potential of becoming unemployed, and incomplete and complete secondary school graduates left without work and school, improve training outcomes;

- Under the decent work agenda, provide with a working environment that satisfies the labor and health safety of employees;

- Carry out measures to include the unemployed and those in the informal sector in the labor market database, build up a statistics system under the ILO methodology;

- Strengthen the capacity of central and local labor offices, improve the organizational structure, expand the labor market information and surveys, establish an adequate mechanism for monitoring-evaluation-analysis;

- Conduct a business environment survey of the formal sector, establish a system of periodical surveys in the future. In cooperation with employer and employee representative organizations implement a program of improving qualifications of those employed in the formal sector.

5.119 With implementation of the employment generation policy thereby, people will have higher income, and poverty will be reduced. The main way of poverty reduction is employment.

5.120 Financing needs for the implementation of the employment enhance strategy are estimated as follows: 


\begin{tabular}{|l|l|l|l|}
\hline & Actions & Funding needs (USD mil) \\
\cline { 3 - 4 } & & $2003-2006$ & $2006-2010$ \\
\hline 1 & $\begin{array}{l}\text { Establishment of public work jobs and permanent } \\
\text { and temporary jobs }\end{array}$ & 10.0 & 10.0 \\
\hline 2 & Promotion of informal employment & 3.0 & 5.0 \\
\hline 3 & $\begin{array}{l}\text { Upgrade facilities to improve vocational training and } \\
\text { skills }\end{array}$ & 5.0 & 5.0 \\
\hline 4 & $\begin{array}{l}\text { Implement an intensive labor market policy and } \\
\text { activities }\end{array}$ & 3.0 & 3.0 \\
\hline 5 & Expand labor market information and surveys & 2.0 & 2.0 \\
\hline & Total & $\mathbf{2 3 . 0}$ & $\mathbf{2 5 . 0}$ \\
\hline & Of which: - domestic & 10.0 & 12.0 \\
\hline & \multicolumn{1}{|c}{ foreign } & 13.0 & 13.0 \\
\hline
\end{tabular}

\section{Social Welfare}

5.121 The preparation works of the project on survey of family income and expenditures based on living standards has been carried out since the end of 2001 . This survey will be conducted in 2002-2003 involving more than 11200 families. This survey on family income and expenditures will include many features such age, sex, status of employment of family members, amount of income and expenditures, consuming and living conditions. According to the survey done in 2002 on family income and expenditures, an average family cash income per month was 141.0 thousand tugrugs, which shows an increase by 27 percent in comparison with 2001. In average in the country salary consists 24.6 percent, and income from family manufacturing, commercial and trading activities consists 44.3 percent out of the total income structure. Within expenditures food expenses consist 42.9percent, non-food expenses - 26.8percent and service expenses - 27.3percent. In 2002 family savings increased by 2.5 in comparison with 2001. The survey on family income and expenditures is the basis to determine the living standards of the population, and according to the Law on establishment of the minimum of living standards, the National Statistics Office declared the minimum of living standards in its survey. In 2002 according the National Statistics Office the minimum of living standards for Ulaanbaatar city was fixed to be 24600 tugrugs and for 5 rural zones it would be 19100-20200 tugrugs. In near future the measures to enhance the contents of consumer basket, which are the main indicators of living standards, are planned to be taken. The method of determination of the level of poverty based on living standards has to be improved and inclusion of real estate such as cattle, vehicles, motorcycles and houses shall be considered.

5.122 During 1996-2000, the market economy has seen an increased need for social welfare of the population associated with a 4.4-7.3 percent growth in its funding, equal to 17.7 percent of total budget expenditures. Also the share of expenses for the social sector has increased from 13 percent to 20 percent of GDP. In 1997-2000 the amount of pensions and benefits spent from Social Welfare Fund increased by 2 times. In 1998, the share of social assistance pensions and benefits in the total income of middle-income households was only 0.75 percent, while it was 1.3 percent for poor and 3.6 percent for very poor households. Problems encountered in financing of 
the social welfare have been deteriorating due to challenges in the state budget such as constituting of funds and financial sources.

5.123 Social insurance: Social insurance plays a major role in the social welfare sector. Today the pay-as-you-go system is in effect, which provides an establishment of a pension fund through contributions paid by insured and employers, to be used for disbursement of pensions to pensioners.

5.124 As of today, 92 percent of all employed under labor contract are covered by compulsory insurance, 22,5 percent of herdsman and self-employed are covered by voluntary insurance and 92,2 of the total population are covered by health insurance. The average pension of 263.8 thous. pensioners is 25.7 thous. tugrugs.(as of the end of 2002).

5.125 According to the 2000 Population and Housing Census results, population aged 60 and above was 124.3 thous., constituting 5.2 percent of the total population. In the next 25 years, the population of Mongolia is expected to grow by 24 percent, while the share of people aged 65 and above in the total population is expected to have almost doubled from 2.4 percent to 6.4 percent by 2025 .

5.126 There is a trend that an increase in the share of the elderly in the total population results in an increased number of pensioners per the insured, causing adverse effects to the pension insurance fund.

5.127 In addition, pensions of those people covered by the pensions system have lagged behind the price rises from 1990 roughly by two times due to the economic circumstances of the country, necessitating rises in pensions and benefits. This fact is causing the need to increase the pension insurance fund as well as other problems.

5.128 Therefore, the challenging goal is to improve the pension system by way of implementation of the pension reform policy, which is to ensure conditions for transformation from the "pay-as-you-go" system of the pension insurance into a "partially-funded" system.

5.129 In addition, the facts, that a number of people covered by the social insurance is decreasing and deficit in the pension insurance fund is increasing are the major issues that should be resolved in the frame of the social insurance reform of Mongolia. The present pension system would continue to cause burdens to the budget unless number of the insured increases further. 
Table 5:5: Pensions met by the Social Insurance Fund, (as of January 1, 2003)

\begin{tabular}{|l|l|l|l|l|l|l|}
\hline $\begin{array}{l}\text { Types of social } \\
\text { insurance } \\
\text { pensions }\end{array}$ & Old age & Survivors & Disability & Military & $\begin{array}{l}\text { Industrial accident and } \\
\text { occupational } \\
\text { decease }\end{array}$ & Total \\
\hline $\begin{array}{l}\text { Number of } \\
\text { people } \\
\text { (thousand) }\end{array}$ & 174.6 & 35.5 & 36.3 & 9.7 & 6.7 & 262.8 \\
\hline $\begin{array}{l}\text { Average } \\
\text { pension } \\
\text { thousand } \\
\text { tugrugs) }\end{array}$ & 25.1 & 18.0 & 18.5 & 36.8 & 30.5 & 25.7 \\
\hline
\end{tabular}

Source: SSIGO

5.130 Within the framework of activities that will be organized to improve the present social insurance system and build up the capacity of the insurance fund, the following priorities are put forward:

- Ensure preparatory conditions for transformation from the pay-as-you-go scheme to the partially-funded system (roughly, from 2021), study and resolve elimination of possible negative effects that may arise in that time. Enroll all insured born after 1960 in to individual account network of pension insurance, develop an efficient system of informing insured on an amount of accumulated funds and interest rates.

- The present minimum retirement age is between 50-60, which makes the social insurance system costly, thus creating inequity among people covered by the individual account network and the insured, who would get pensions and benefits according to the present law. Lower minimum pension age means lesser pensions for them. This, on the other hand, may create burdens to pension aged people, who are incapable of earning additional profits, thus deepening the poverty among them. A survey and analysis on setting out prudent minimum retirement age and reducing age gap between women and men needs to be carried out. Although the present Social Insurance Law provides that the citizens of Mongolia are entitled to retire at the age of 60, a survey of foreign consultants revealed that only 25 per cent of them have retired after 60 . People get retired at different ages depending on their job conditions and gender. For example:

- If working conditions were extraordinary difficult, retirement age is between 45-50.

- Females with 4 or more children retire at 50, other females - at the age of 55 . Under the amendment to the Pension Law (1990), women with four and more children could be pensioned off from work without necessarily reaching the pension age. This was an organized effort to downsize the labor force under the pretext that these who were "occupied in social care". This amendment has made women more vulnerable to job losses and poverty during the transition years.

- For military servants of middle and lower positions with 20-25 years of employment, the retirement age is between 40-45.

- If civil servants wish and their supervisors agree to it, males and females can retire at the ages of 65 and 60, respectively. These figures show that this issue needs to be carefully studied and resolved. 
- Establish a legal environment for full social insurance coverage of herdsman and selfemployed in informal sector as well for a sectoral insurance system for employees working under extraordinary difficult or specific working conditions. As of today, over 300 thous. herdsmen and over 100 thous. self-employed haven't been covered by social insurance. These people are at a risk to remain with no rights to receive pensions and benefits from the social insurance system and with no social protection. However, these citizens may enjoy the rights to social assistance pensions, which are lesser than pensions paid from the social insurance fund, but in this case, the state budget would be burdened with more load. Herdsmen and self-employed, who were either employed for certain period before or were insured with the pension fund on the voluntary basis may enjoy rights to low level pensions from the social insurance fund. The majority part of funding for this is deemed to be financed through premium income of other insured people or through an establishment of a special fund from the state budget and other sources. Therefore, it is necessary to study and resolve feasibility to find initial sources of funding for the special fund of the pension insurance of herdsmen and self-employed.

- For instance, as long as the present legislation is replaced by a new one, there would be a significantly large difference between pension levels of the present Law on Social Insurance and the new Law on Personal Account of Pension Insurance Premiums. It is estimated that old-age pension levels of the insured, which were born after 1960 would sharply decrease. Pensions of the insured who will reach the age of 60 in 2020 (according to the new Law on Personal Account) are expected to receive barely half of pensions of the insured who reached the age of 60 in a previous year. (according to the present Law on Social Insurance). Therefore, the goal is to revise and renew a method for calculation of pensions of the insured, who were born before 1960, by way of gradually reducing the ratio of pensions to pay levels before the retirement ages of people of similar ages. Within the frame of this goal to reduce the difference, it is necessary to define policy proposals and results to be achieved, as well as to calculate pension levels for the disabled and survivors that are to be allocated in accordance with the Pension Insurance Fund in comparison with old-age pension levels to be paid also according to the same law, revise a method for calculation of these pensions and make necessary estimation regarding their results.

- Establish a mechanism, which monitors operations of the Social Insurance Fund by way of procurement of goods and services from the Social Insurance Body, in accordance with the Public Sector Management and Finance Act.

- All Social insurance funds will be joined into one system of the State Fund.

- The capacity of social insurance should be strengthen and the information network will be improved.

5.131 Social assistance: The main objective of social assistance, which is an integral part of social protection, is to ensure livelihood safety of vulnerable groups, very poor and those who are incapable to live without social support services, by providing nursing and assistance to them.

5.132 Under the Social Assistance Law, more than 30 thous. people, who are not subject to exercise the rights to receive pensions and benefits from the social insurance fund, those who are incapable of living independently, or the elderly and the disabled without relatives and children 
to take care of them, have been receiving assistance benefits from the social insurance fund. More than 200 thousand people including mothers with many children, mothers on maternity or child care leave, or nursing, orphan children and others are provided benefits and assistance from the social assistance fund. More than 400 thous. people of the social vulnerable group are receiving social welfare services.

5.133 The present social welfare benefit system has a tendency to create a "poverty trap" over time, and it pushes people to become poorer. The amount of services per person is relatively small, and the impact on their lives is not sufficient, and according to the calculations it has a bad side of having a lot of expenses. In 1997, 7.0 billion tugrugs were spent for social welfare pensions and benefits, while this amount almost tripled in 2001, reaching over 20 billion tugrugs. However, the actual benefit per person hasn't increased substantially. The management of assistance is vertically-organized, the participation of people and non-government organizations is low, and it is necessary to reform this system.

\subsection{The present social assistance system has 3 weak points:}

5.135 First, the rate of capital deficit spent in the social assistance system is high, i.e. there are cases when many not poor families receive pensions and benefits.

5.136 Second, the range of involvement into the assistance system is not sufficient; there are many poor families, which stay out without assistance.

5.137 Third, the present assistance system has a tendency to create a "poverty trap" over time. In other words, households have wrong attitudes to prefer to remain as members of poor and vulnerable groups in order to maintain the rights for benefits.

5.138 The reform of the social assistance has to resolve the above issues and alleviate poverty by enhancing criteria of providing pensions and benefits, reducing the number of groups eligible to receive pensions and benefits and increasing the average size of benefits.

5.139 Activities undertaken by the social assistance organizations are limited to determination of eligibility the citizens to receive pensions and benefits. There is a room for social works which are aimed at improving living conditions of citizens covered by social assistance pensions and benefits and ensuring equal social coverage.

5.140 The Master Plan for the Social Welfare Sector, which is planned to be implemented in the next decade, would cover an issue of reform in social assistance pensions and benefits. It is envisioned that this plan would provide support the goal of poverty alleviation through improving criteria for allocation of social assistance pensions and benefits, properly defining groups to receive social assistance and increasing average pension levels.

5.141 A group of young people of Bayantsogt soum of Tuv aimag outlined "Only our elderly and pensioners-relatives feed us. Thus we want to work ", while a group of men and women of Tariat soum of Arkhangai aimag said, "Many unemployed young adults still live with their parents and live on their pensions, because of high cost of marriage." 
5.142 The following goals are set up to promote poverty elimination, upgrade the quality and benefit of the social welfare services and to improve their access:

- Reform the institutional structure of the social assistance management through pursuing the principle of community based services and establishing Social service centers at soum and khoroo levels. The current structure is based at the aimag and district levels and most of the activities have been focused on distribution of pensions and benefits, thus, lacking access to the community as a whole. However, it needs to be carefully studied and tested in order to foresee pros and cons.

- Social assistance agencies need to shift from their current services to allocate pensions and benefits into methods and forms for providing services for the vulnerable groups. In order to do so, there are challenges of restructuring the system, improving institutional capacity building and training of social workers to achieve this objective.

- Carefully study reform measures on optimizing selection criteria and actual benefits of reproductive type of benefits under the Social Assistance Law such as pregnancy, maternity, child and infant care, twins and triplets, adoption and raising of orphan child and disabled child, and find and implement optimal options in line with the specific features of the country. For revising the existing legal relations, the policy is not to step backward from the level reached at the moment.

- Review benefits and services extended to the elderly under the Law on Discounts and Services for the Elderly, and adopt a new type of household assistance benefits, study feasibility of this issue and come to a decision with support of the international community.

- For reviewing non-monetary benefits, assistance, scope of services and access for the disabled, their quality of life and specific features will be taken into account. It is necessary to develop an assistance system which relies on a community or household based services. In connection with this, the goal is to decentralize operation of the nursing centers and promote involvement of the community and NGOs.

- For improving usage of funding with social services purposes, public monitoring and participation is crucial. In order to conduct monitoring of this sector, it is important to increase public participation, centralize powers at local levels and allow them to conduct selection and distribution.

5.143 There are risks in the reform of the social welfare system, such as a lack of funding, failure in achievement of some goals because of the specifics of Mongolia and professional level of population. Although there is a high necessity for involvement and assistance of foreign countries and international organizations that support Mongolia's development, the fact that currently there is a relatively small number of adopted projects and programs with pledged and approved budget sources, adds more risks.

\section{Gender Equality}

5.144 A newly established National Gender Council is headed by the Vice-Director of the Cabinet Secretariat and the members represent various government and non-governmental 
organizations and the civil society. The gender situation in Mongolia in comparison with other countries is quite unique. The rights of women are equal to the rights of men in Mongolia. The level of education of women is comparatively high and women widely dominate in the education, culture, health and other social sectors, while male participation is rather low.

5.145 According to the statistical data of the 2000-2001 school year, 30.6 percent of all kindergarten age children were enrolled in kindergartens and the percentages of boys and girls were comparatively similar (boys 29.4, girls 31.9). However, the gross primary enrolment of children aged 8-11 shows some change in gender equality, represented by 119 thousand girls and 117 thousand boys enrolled in school. 23.3 percent of junior youth (age 12-15) drop-outs in provinces are boys and 13.2 percent are girls. In the 2000-2001 school year girls constituted 52.3 percent of all the students in primary and secondary education, 50.1 percent of all the students in grades 1-3, 53.4 percent- in grades 4-7, and 59.4 per cent of all the students in grades 8-10. 61.7 percent of children aged 8-15 who dropped out of school are boys, which shows great disparity in gender among the school drop-outs. As a result, the overall majority of the undergraduates in tertiary education are women.

5.146 Women's access to credit, financial services and business opportunities is more limited than men's, in part because property and other assets that can be used as collateral for loans is typically registered in the name of the head of household. In the restructuring financial and banking system, the government should ensure that significant measures are taken to improve women's access to credit. Commercial Bank annual reports should be required to disclose the gender composition of loan beneficiaries.

5.147 Gender related legislation. Mongolia is a signatory to a number of international treaties and conventions, including Civil and Political Rights Pact, Convention on Women's Political Rights, Convention on Elimination of All Forms of Discrimination of Women, Convention on Equal Remuneration of Working Men and Women and others; and has been taking a series of measures to ensure gender equality. However, family violence, violence against women and children remain an issue of particular concern. Courts' statistics indicate that in the last 2 years, violent crimes account for 25.2 percent of total crimes, and the victims are mostly women and children. In the last 5 years, 639 women with 641 children found a shelter in the National Center to Protect Against Violence. Of these, 82.2 percent were under others' pressure and 28.9percent had some injuries. Some of the laws and regulations adopted in the name of transition were and remain, very unfavorable to women - e.g., the recently passed Land Law, which specifies that land be given to households rather to individuals, potentially with negative effects on single women and men.

5.148 To ensure equal benefits of males and females in the implementation of restructuring policies, gender analysis of those policies and programs should be conducted, special and urgent attention should be given to the land reforms to avoid any possible negative impacts. Over 80 percent of education sector staff and 90 percent of total judges are women. These statistics demonstrate the role of women in the society and the burden and responsibilities they are bound with. However, the fact that the number of positions held by women at top political, social and economic management levels does not increase is yet another example manifesting the level of implementation of policies on improving the women's status. 
5.149 In 1991-1992 the women's representation in the Mongolian parliament constituted 23 percent, which dropped to 3.9 percent after the 1992 elections, picking up to 10.5 percent in 1996 and 11.8 percent in 2002. However, at the level of political decision-making there is little women's participation. The election results of the last few years show that people vote more for the parties rather than for individual nominees. Therefore, in order to increase the level of participation of women in the political decision-making processes, one of the important strategies may be collaborating with political parties to ensure that the party policies are gendersensitive.

5.150 The sound governance implies sensitivity to gender issues, increase of women's participation in the political life and eradication of violence on women. To improve the representation of females in decision making process to promote equality of opportunity and the empowerment of males and females in society. The National Forum on Gender and Developed organized in October 2002 recommended that the law on political parties be amended and include a provision "to have at least 40 per cent presence of both males and females at political party decision making positions and in selecting candidates for elections. This will enable women to be elected for management and decision making positions.

5.151 Additional measures to promote good governance and gender equality are to encourage community leaders and local bodies to include more women in local decision-making, and promote awareness of existing legal rights (eg relating to land, employment and personal security) among women. In the medium term within this strategy a legal framework will be created to fight family violence through adoption of state policies on family development.

5.152 One of the objectives is also to abolish the widespread physical and emotional desolation and despair resulting from the economic conditions and family violence. The participants in a survey conducted in 6 districts of Ulaanbaatar by the National Centre Against Violence, voted that family violence was one of the negative factors preventing women's participation in social life. 30 percent replied that family violence makes women lose their interest in their work, one second replied that women lose their self-confidence and as a result lose their social standing.

5.153 The Government of Mongolia adopted in December 2002 a National Program for Gender Equality with a view to implement the policies for increasing the level of employment, reducing poverty, acquisition of education, ensuring appropriate gender equity at the level of decision-making and in asset relations, reducing family violence and to reflect them in the national social and economic policies and programs. The program includes strategic objectives for achieving gender equity. Within the National Program activities will be undertaken to resolve the issue of family violence, family asset-ownership, and equitable decision-making through strengthening family values, raising children, ensuring equitable participation of men and women in household work, developing laws and regulations, and raising awareness. Also, a gender-sensitive approach will be adopted in developing macroeconomic policies, budgets and statistical data as well as in creating opportunities for asset-ownership, access to health and social insurance services and in ensuring gender equality in the household economy. Rural children, especially boys, will have better access to education, the level of grassroots 
participation in the regional development will be improved, the maternal and infant mortality rates will drop and the gender quality will be ensured in employment and small businesses. Conditions will be created in which men and women will have equal opportunities at the government decision-making level and in obtaining political and civil service positions in the government. The activities of the National Gender Council will be continued with more scope to conduct gender-based surveys, reflect gender issues in ongoing policies, programs and projects, improve the monitoring mechanism for the implementation of gender-related objectives and programs. Also, the capacity and competency of the National Gender Council and the staff of government agencies working with gender issues will be raised. 


\section{CHAPTER 6: IMPLEMENTING AND MONITORING THE STRATEGY}

"We, soum administrators must do a lot in our work. But we can not even reach out to everyone" said a citizen of a bagh of Tuv province.

\section{Good Governance}

6.1 Extending Participation of the Civil Society. Further participation of the civil society will be sought in the process of making regular adjustments to the PRSP and in ensuring its sustainable implementation. Implementation of any government strategy depends on overall capacity of government to formulate, implement and monitor the particular program.

6.2 In particular, "bottom-up" process will be used to regularly collect feedback on the impact of the strategy from civil society and business community on aimag and soum levels. The public views and comments on the effectiveness and impact of the strategy will be used for further adjustments of EGSPRS. This feedback will serve as main ground for adjustments and refinement in the EGSPRS as well as in planning for its implementation. Also, mechanisms and avenues will be set up to enable non-governmental organizations to participate in the implementation of the EGSPRS on national, regional, sector and local levels. Central and sector agencies/ministries, local authorities will design and develop concepts on engaging nongovernmental and business sectors in carrying out the strategy.

6.3 Special attention will be given to such forms of civil society engagement as outsourcing to NGOs of delivery of some public services. Government agencies will develop lists of potential services and activities within their jurisdictions that can be contracted out and have them approved by the national government. Relevant procedures and regulations will have to also be developed that would enable agencies to partner with the rest of the society in the implementation of EGPRS. To develop such lists and procedures, ministries/agencies will have consultations with the non-governmental sector to inform themselves fully on interest, capacities, and perspectives of NGOs in delivery of public services on various levels and communities.

6.4 Such streamlining of NGO participation in the implementation of the EGSPRS on ministerial and local government levels is planned to be initially supported from a special PRSP Trust fund administered jointly with the World Bank and set up for a specific purpose of institutionalizing civic engagement and participation. The government understands that this way it will mobilize social capital for ensuring sustainable development. 
6.5 To do so effectively, the government will cooperate with civil society organizations in capacity building of NGOs and government agencies. PRSP Trust Fund resources will be sought to support such capacity building not only for implementation but also for evaluation and monitoring of the EGSPRS.

6.6 Cooperation with media will be sought in every step and aspect of civic engagement in the EGSPRS process: dissemination to the public of information on development, status and implementation of the strategy, its concept, content and action plans; collection of bottom-up information from the public, consultations with the civil society and local communities, reporting on the performance of government and NGO involvement in the implementation, monitoring and evaluation of the EGSPRS, etc.

6.7 The following priority areas were identified within the framework of ensuring sound governance:

- To improve efficiency of government organizations and business processes, to improve operations, finances, planning, reporting, the system of accountability and management mechanisms, to improve the quality and access to social services, and to raise their status.

- To create a management information system for public services, ensuring its reliability using modern technologies, and to improve decision-making and implementation mechanisms of the executive governance.

- To institute appropriate methods of internal and external monitoring, analyses and assessment of government organizations.

- To strengthen the legislative framework for the authority and organization of the legislative and judicial bodies, to further the judicial reform, to ensure independence of the judiciary, and to raise its reputation.

- To ensure better delivery of government policies to the people, and to create a system of providing public comments or voices to the government using the media by improving the legislation on the freedom of media, and strengthening the accountability mechanism of media.

- To improve the accountability of social services, and to accelerate actions to fight against corruption, bribes and crimes. To provide a legal environment against domestic violence as a part of policies to ensure gender equality.

- To strengthen the management of public relations, to ensure transparency of government organizations, to encourage establishment of various business contacts with nongovernment organizations, and to increase outsourcing of some government functions to non-government organizations. Instituting good governance will result not only in creation of conditions to reduce poverty, but will also lead to eradication of poverty.

6.8 One of the key requisites for the successful implementation of the EGSPRS is donor coordination. The government is responsible for maintaining such coordination and integration of the donor efforts for effective and efficient allocation of the financial aid. The government shall show leadership in adopting appropriate policies and decisions, involve participation of the stakeholders in their implementation and ensure transparency in aid coordination. 


\section{Implementation and Operational Management}

6.9 The Government of Mongolia as the highest executive body of the State will undertake implementation and monitoring of the EGSPRS in the country. The current of the government of Mongolia consists of 11 ministries with defined inter-sectoral and sectoral responsibilities, including

- to organize and ensure nation-wide implementation of the Constitution and other laws;

- to work out a comprehensive policy on economic and social development, the State budget, credit and fiscal plans, to submit these to the Parliament, and to execute decisions taken thereon;

- to elaborate and implement comprehensive measures on sectoral, intersectoral, as well as regional development;

- to undertake measures on the protection of the environment and on the rational use and restoration of natural resources;

- to provide efficient leadership of central state administrative bodies and to direct the activities of local administrations;

- to strengthen the country's defense capabilities and to ensure national security;

- to take measures for the protection of human rights and freedoms, enforcement of public order, and prevention of crime;

- to realize the State foreign policy;

- to conclude and implement international treaties with the consent of and subsequent ratification by the Parliament as well as to conclude and abrogate intergovernmental treaties.

- the specific powers, structure, and procedure of the Government are determined by law.

Ministries and other government offices are constituted in accordance with the law. The implementation of the EGSPRS will re-orient the policies and activities of each ministry towards achieving the goals and objectives stated in the strategy and build mechanisms to ensure the participation of all stakeholders.

6.10 The overall implementation and monitoring of the EGSPRS will be coordinated by the MOFE. Within MOFE the Poverty Research Group (PRG) will be a main acting body to coordinate implementation, monitoring and reporting for the EGSPRSP. The line ministries will be responsible for attaining of targets set for particular time period and implementation of specific programs within the framework of objectives. The local government and civil society will be involved through the working groups established during the I-PRSP dissemination. The involved ministry, agency or NGO will be responsible for implementation and monitoring of 
specific projects or programs included in the EGSPRSP. The PRG will consolidate, evaluate and prepare Progress report to the higher instances, including Ministers, Parliamentarians, the World Bank and other concerned bodies. The progress report will be prepared on an annual basis and the strategy itself will be revised every three years and presented along with progress report at the donor meetings to coordinate activities and funds of the donor community.

6.11 Alignment of government policy documents. The government medium term main policy documents are the Government Action Plan, Medium term budget framework, the SocioEconomic Guidelines, sectoral papers and other policy papers / programs, signed agreements with international agencies. In addition following to the international practice the Government of Mongolia started an active participation in global initiatives such as PRSP process, MDG attainment, and Millennium Challenge accounts, specific programs to address greatest obstacles to the national development to spur economic growth and reduce poverty with an active participation of national stakeholders and coordination of external assistance. The MOFE will be a leading coordinating body to formulate, adopt, implement, and monitor these programs. Successful implementation of programs depends on efficient coordination of policy documents, reporting and alignment of processes, in particular the budgetary allocation in line with development priorities plays an important role in overall macroeconomic and sectoral management.

Chart 1. Current policy making process

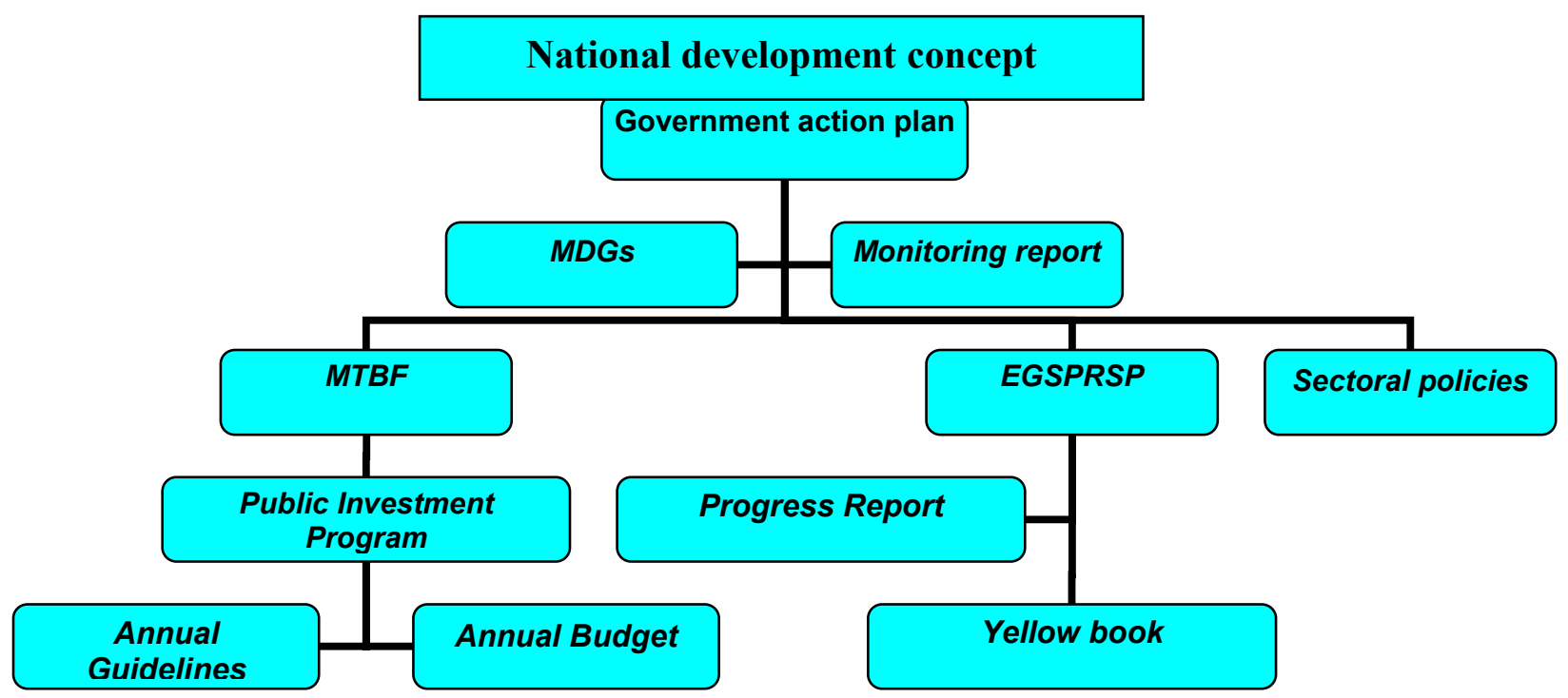

In order to improve policy coordination in the process will be modified: at the late stage the annual socio-economic guidelines will be a main monitoring document and basis for government 
action plan, MDGs and PRSP progress report. The following chart describes the improved policy making process:

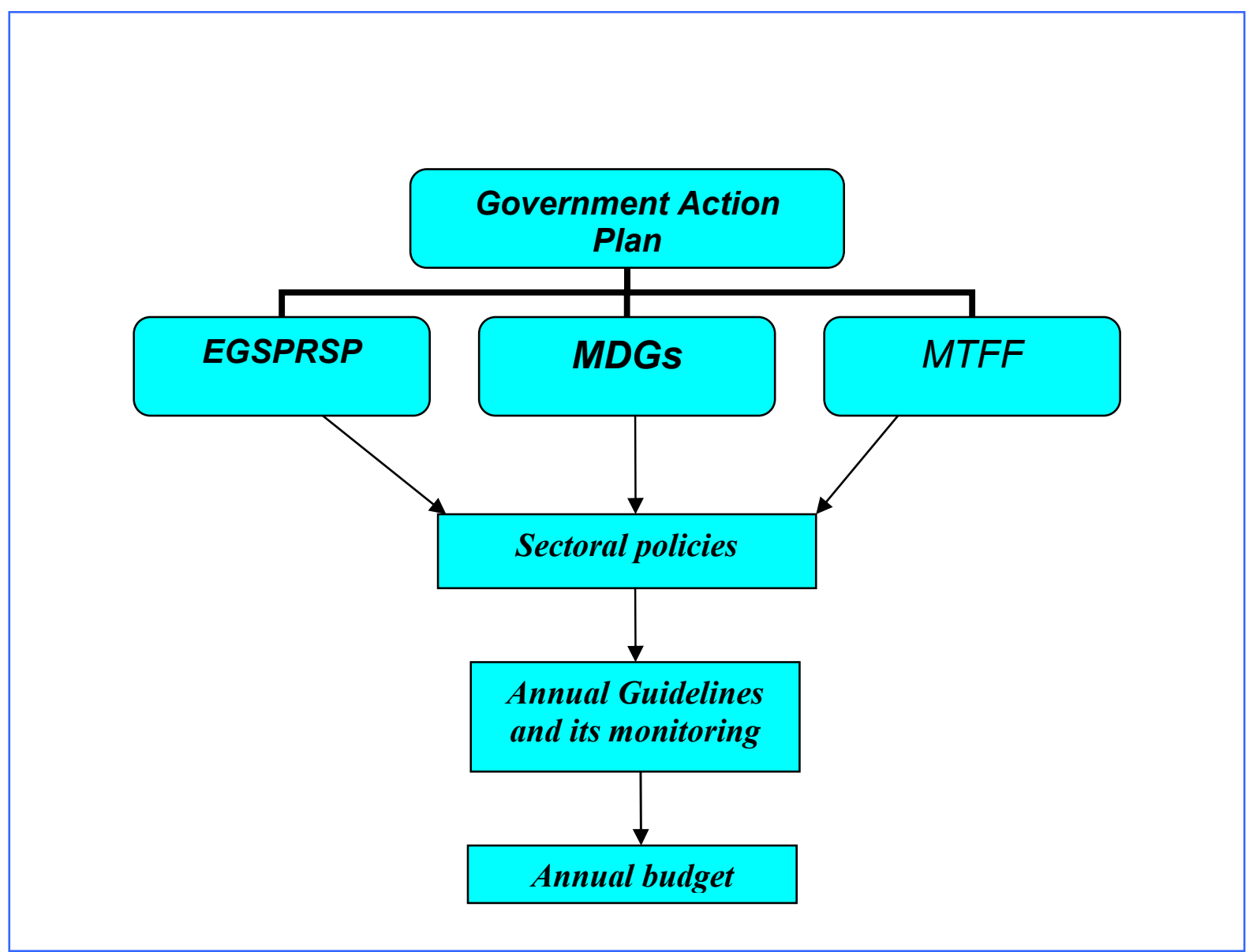

6.12 Relationship with Socio-economic Guidelines: The main mechanism for implementation of EGSPRSP is the annual national socio-economic guidelines. These guidelines are approved by the parliament of Mongolia every year and implemented through government ministries and agencies. Although policies and instructions which are introduced in EGSPRSP will be specifically conducted through the socio-economic guidelines it will also require the annual approval of the Mongolian Parliament for implementation. This action will take effect from the preparation of the 2004 guidelines.

\section{Extending Participation}

6.13 During the evaluation of the I-PRSP, the World Bank and the IMF recommended to fully provide for the participation of the community in developing the full PRSP. Therefore, the Social Development Center was involved in the F-PRSP Working Group as a civil society representative. The Social Development Center established a sub Working Group consisting of 
12 NGOs to develop the participation section of he PRSP. At the initial stage of the PRSP development, regional seminar was organized in the local area and the civil society representatives did also participated in that workshop. (see the table)

\begin{tabular}{|c|c|c|}
\hline & Total participants & $\begin{array}{ll}\text { Of which: } & \text { NGO } \\
\text { representatives (\%) }\end{array}$ \\
\hline 1. Tuv & 16.3 & 5.5 \\
\hline 2. Dornogobi & 15.9 & 24.7 \\
\hline 3. Dornod & 13.3 & 25.7 \\
\hline 4. Bayanhongor & 11.8 & 33.3 \\
\hline 5. Huvsgul & 20.1 & 28.6 \\
\hline 6. Zavkhan & 7.9 & 38.6 \\
\hline 7. Khovd & 14.7 & 12.2 \\
\hline Amount & 100.0 & 22.8 \\
\hline
\end{tabular}

6.14 The Parliament of Mongolia annually approves and implements the socio-economic guidelines. Therefore, the policies and actions that are reflected in the EGPRSP shall be specifically considered in the annual socio-economic guidelines, approved by the Parliament and be implemented as such. This work shall begin with the development of the 2004 socioeconomic guidelines. In addition, several meetings were organized with the NGO working group in order to introduce the PRSP development process and draft versions and their opinions were also reflected in the PRSP. The NGO WG also provided their comments in written form. The NGO representatives also participated in the WB organized poverty workshops for the Asian region. The NGO representatives took part in the video and telephone conferences organized by the World Bank.

6.15 Further participation of the civil society will be sought in the process of making adjustments to the PRSP after a certain period of time and ensuring its sustainable implementation. In particular, working groups could be formed at aimag and soum levels with civil society and business representation to monitor and intensify the process of implementation of the PRS. Also, non-governmental organizations will be involved in monitoring and evaluation of the process of PRS implementation.

6.16 In order to ensure participation of the public in the development and implementation of the strategy, the contents, the direction of the strategy and planned actions will be advertised through media, and we will cooperate with the media in order to find our the views and hear voices of the public. As initial support to streamline the participatory process the project will be implemented under the PRSP Trust fund which aimed to institutionalize the participatory process through capacity building, information dissemination using IT and mass media, extensive consultations.

\section{Monitoring and Evaluation}

6.17 Monitoring and evaluation. The prerequisite for the successful strategy is implementation of efficient monitoring and evaluation by two types of assessment, namely 
through monitoring benchmarks set by the government and civil society oversight. The Government, in order to monitor and evaluate the implementation of the poverty reduction strategy, will develop a system appropriate tools and benchmarks for regular collection, monitoring, publishing of statistical indicators on the level of livelihood. These indicators were selected based on MDGs adopted for Mongolia. Data availability, measurability, coverage were considered as main criteria for building of benchmark indicators. In addition some indicators were included the assumption that they be estimated in the future. For instance, some data will be available based on socio-economic impact analysis. Civil society oversight, including NGOs, private sector, parliamentarians, citizens, donor representatives, will be conducted through various methods and approaches for monitoring and evaluation. However, government priority on this area is to assist in building of capacities to undertake monitoring and carry out the relevant assessments. For instance, in the medium term the institutionalization of participatory process with focus on strategy dissemination, expansion of experience with Citizens reporting card, Blue ger painting, scope cards will be undertaken. The coordination of monitoring activities and collection of relevant information will be done through Poverty Research Group under the MOFE. The Poverty Research Group will assist in organization of various evaluation surveys on the specific components of the PRS implementation with the help of nongovernmental organizations and researchers. The National Statistical Office will conduct assessments of the level of livelihood on the basis of the various surveys and studies and will enrich poverty-related information with qualitative indicators. The expanded Household and Expenditure survey will be a main source for the poverty monitoring. This information will be transparent and available for users.

6.18 The monitoring indicators of the EGSPRS will be closely linked with the Millennium Development Goals. Apart from the dissemination of the statistical indicators, the implementation of the objectives of the EGSPRS will be monitored and evaluated according to the benchmarks developed in synchronization with the Millennium Development Goals indicators. These benchmarks include economic growth, unemployment rate, average life expectancy of men and women, infant and maternal mortality, mortality of children under five, enrollment in primary and secondary schools, vaccination, etc. As well, the intermediate benchmarks were identified regarding poverty reduction. (Monitoring and assessment benchmarks and Technical notes on monitoring indicators are attached).

6.19 The new global initiative of Millennium Challenge Account will be another approach to monitor and evaluate progress towards economic growth enhancement and poverty reduction. The MOEA will undertake a lead role in joining the MCA following guiding principles, including government commitment, ownership, partnership, investment needs, and available capacity to manage funds.

6.20 The UNDP has assisted the government in establishing the Poverty Research Group which will be a main institution to carry out monitoring and produce concerned reports. Some non-governmental organizations with appropriate experience and expertise will be called on to contribute to the implementation of the PRS on a voluntary basis.

6.21 A mechanism for monitoring the process of PRS implementation based on the outcomes of the Citizen's Control Card system widely used in Asian countries will be utilized, 
which will ensure larger scale engagement of the civil society. Also the Community-based Monitoring System introduced within a UNICEF project will be extended for the locally run assessment of the level of livelihood.

6.22 The coordination of monitoring of gender sensitivity will be done through Poverty Research Group allocated within the MOFE. The statistical authorities will enhance data dissemination on living standards and poverty based on qualitative and quantitative assessments. The information will be transparent and available for the public. Sex-disaggregated data related to poverty reduction and other national goals should be collected. Gender sensitive methodologies for monitoring and evaluation will be developed.

6.23 Financing requirements. An implementation of the policy objectives included in the Economic Growth Support and Poverty Reduction Strategy require resources equal to 40-45 percent of GDP per annum. These estimates are made based on targets included in the Medium term budget framework. 


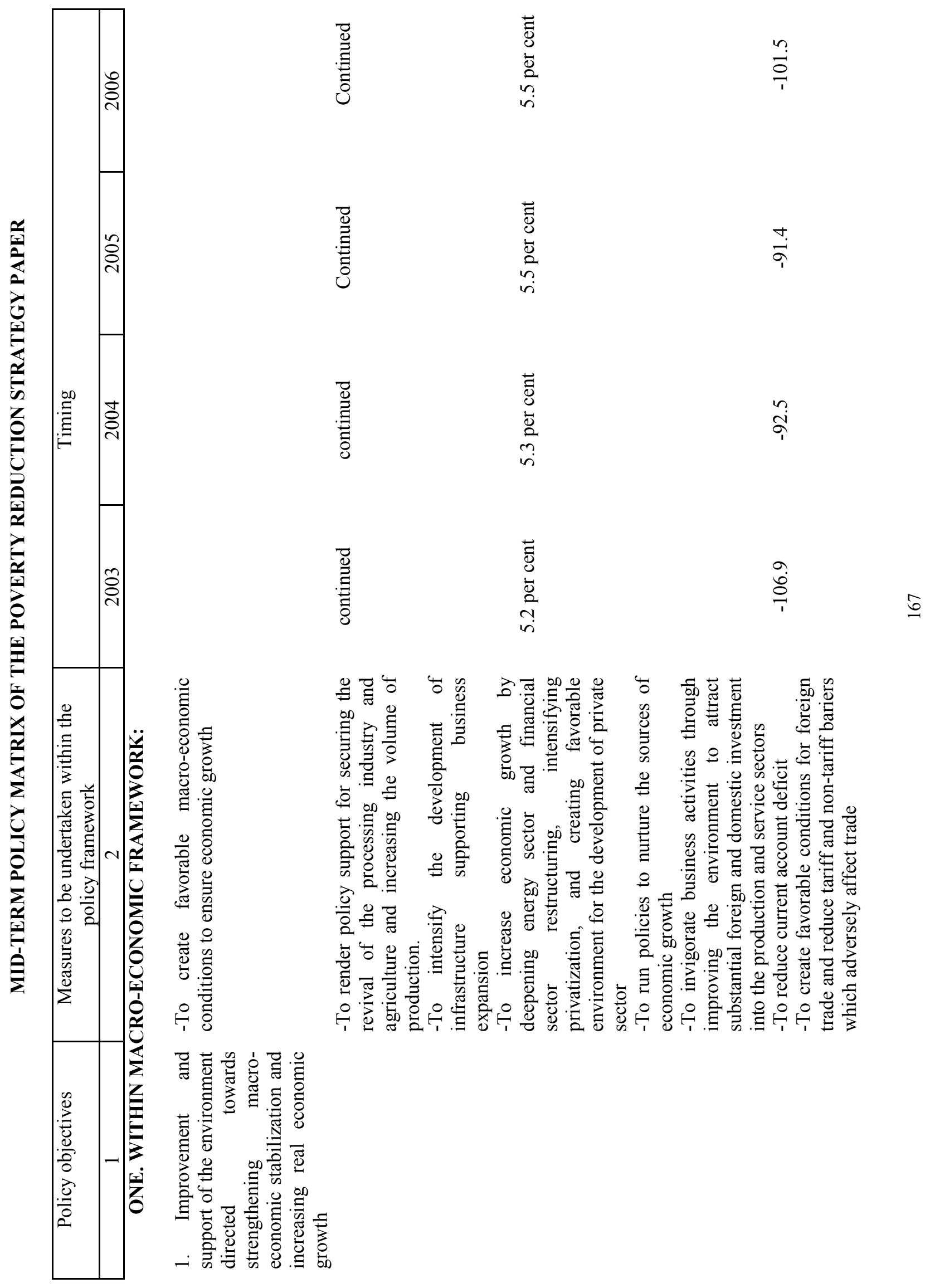




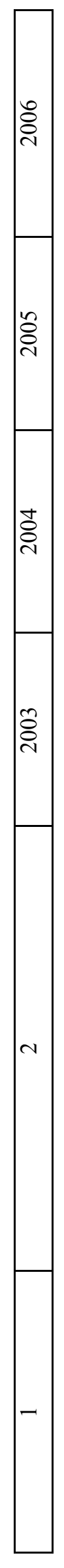

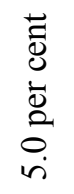

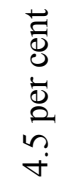

$\overrightarrow{0}$
0
$\dot{0}$
0
0
$\dot{0}$

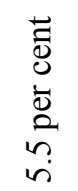

$\overrightarrow{0}$
0
$\dot{0}$
0
0
$\dot{0}$

$\overrightarrow{0}$
8
$\dot{0}$
$\stackrel{\Xi}{\sigma}$
के

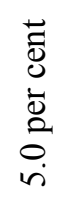

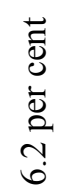

$\underset{0}{\infty}$

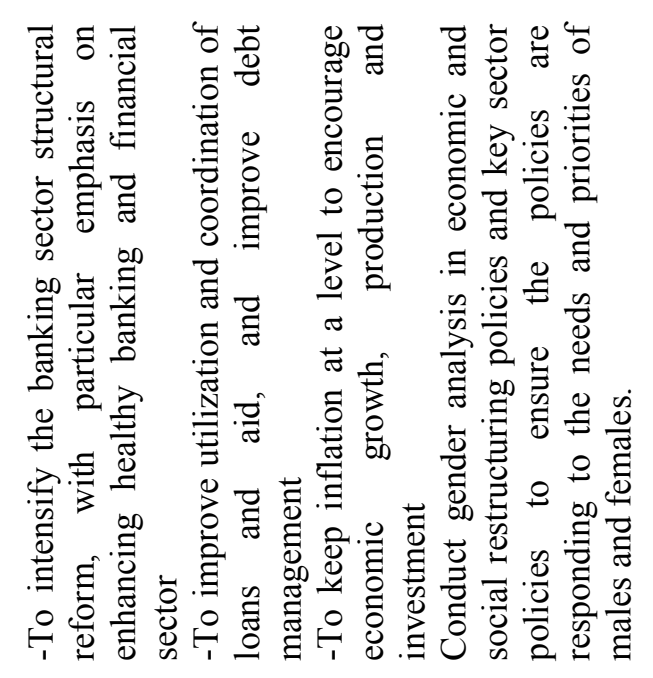

.

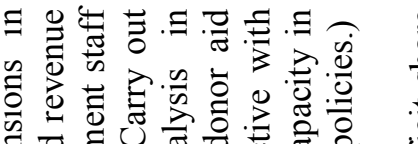

离

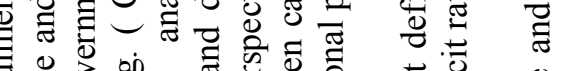

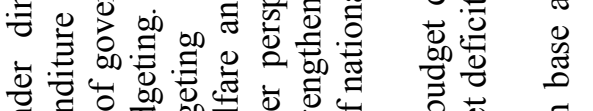

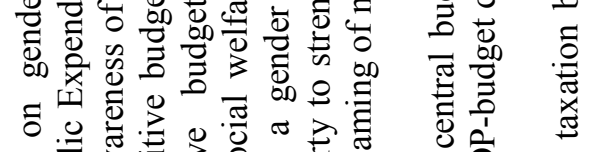

入े 引े

웡

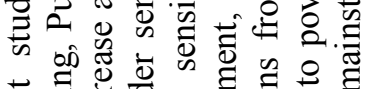

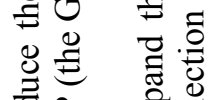

氖育 这

可

$\stackrel{0}{\ominus} \stackrel{0}{\oplus}$

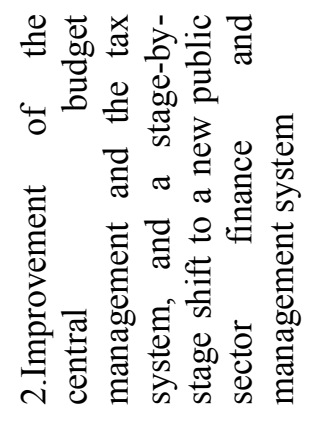




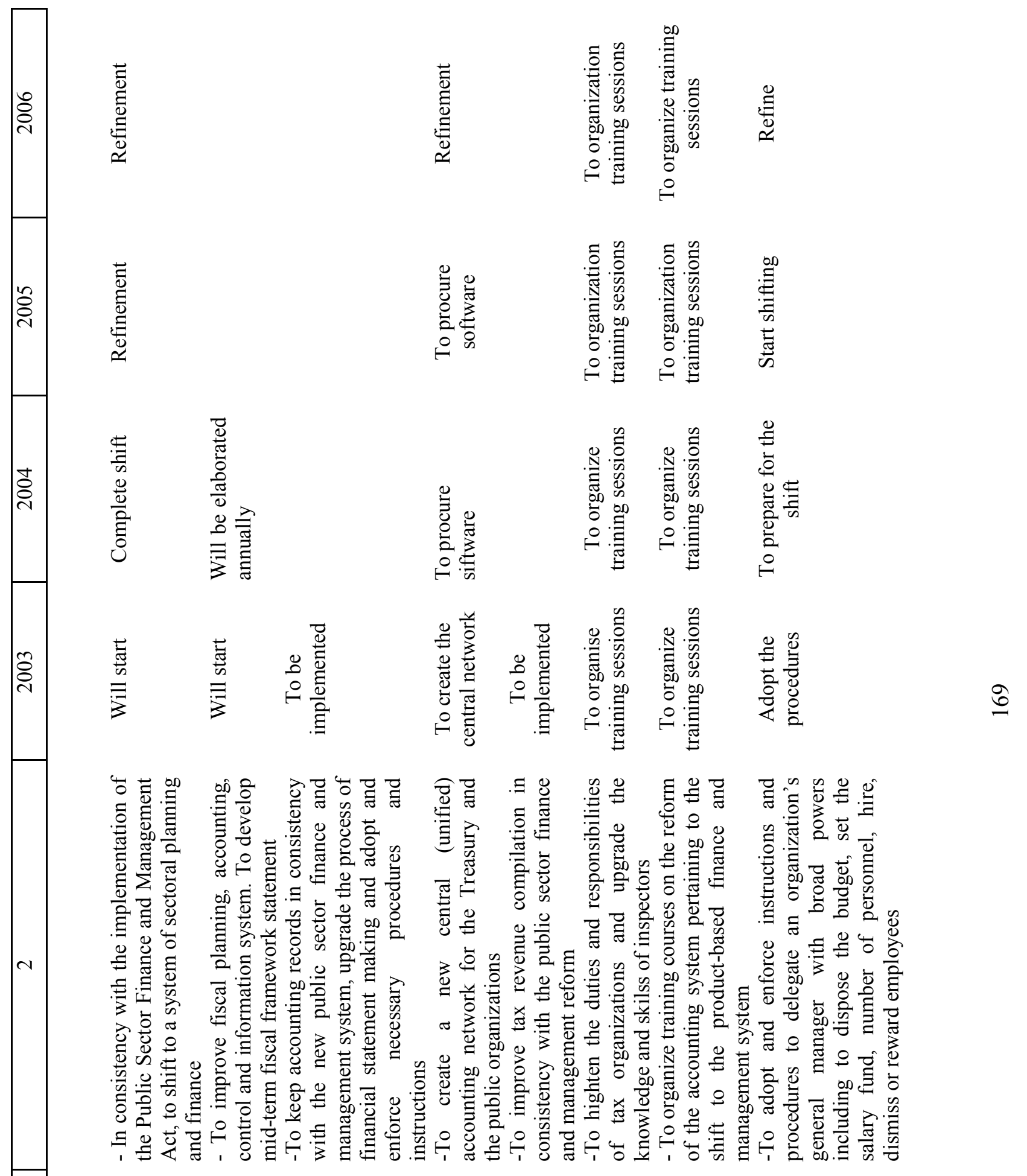




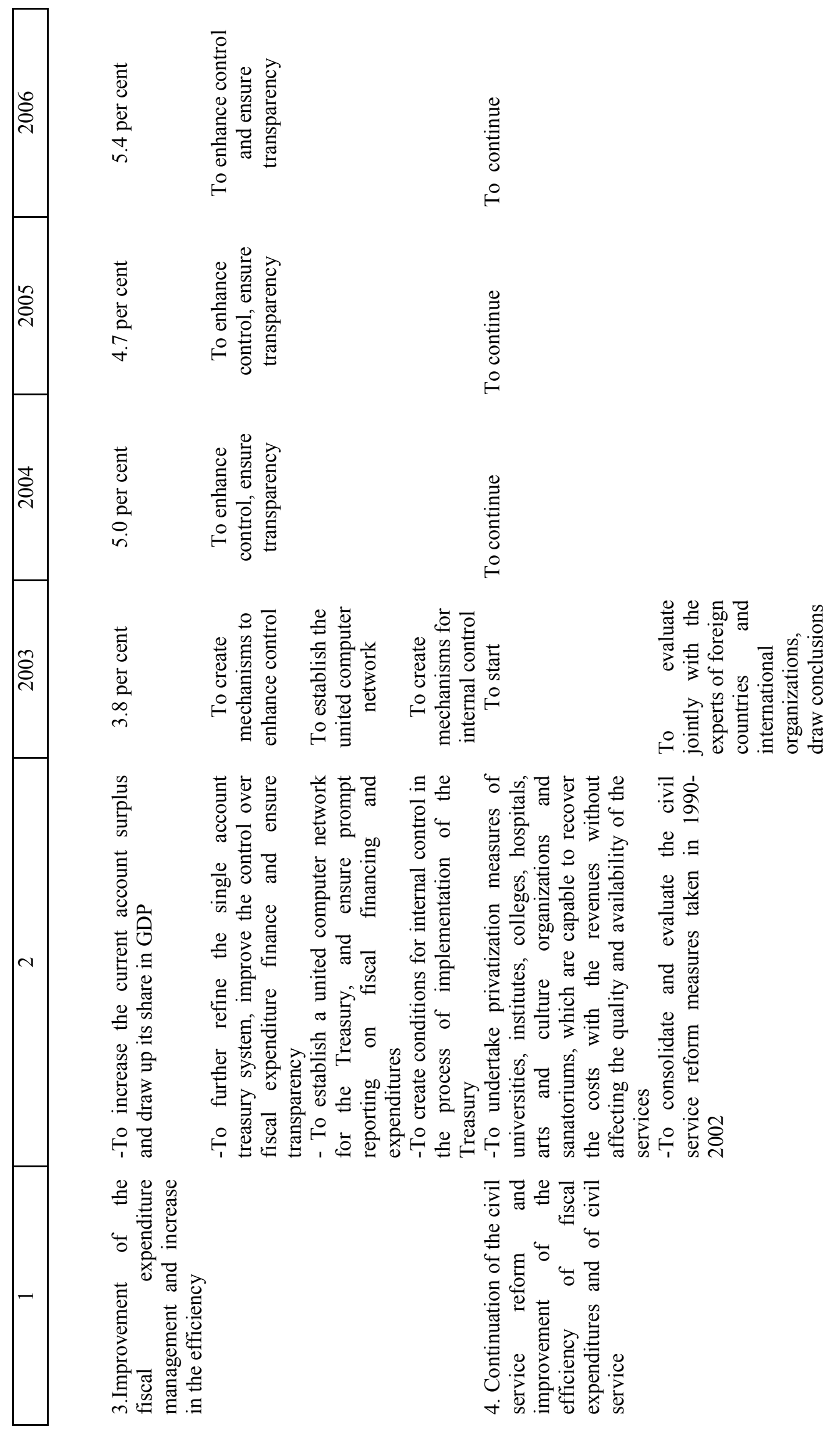




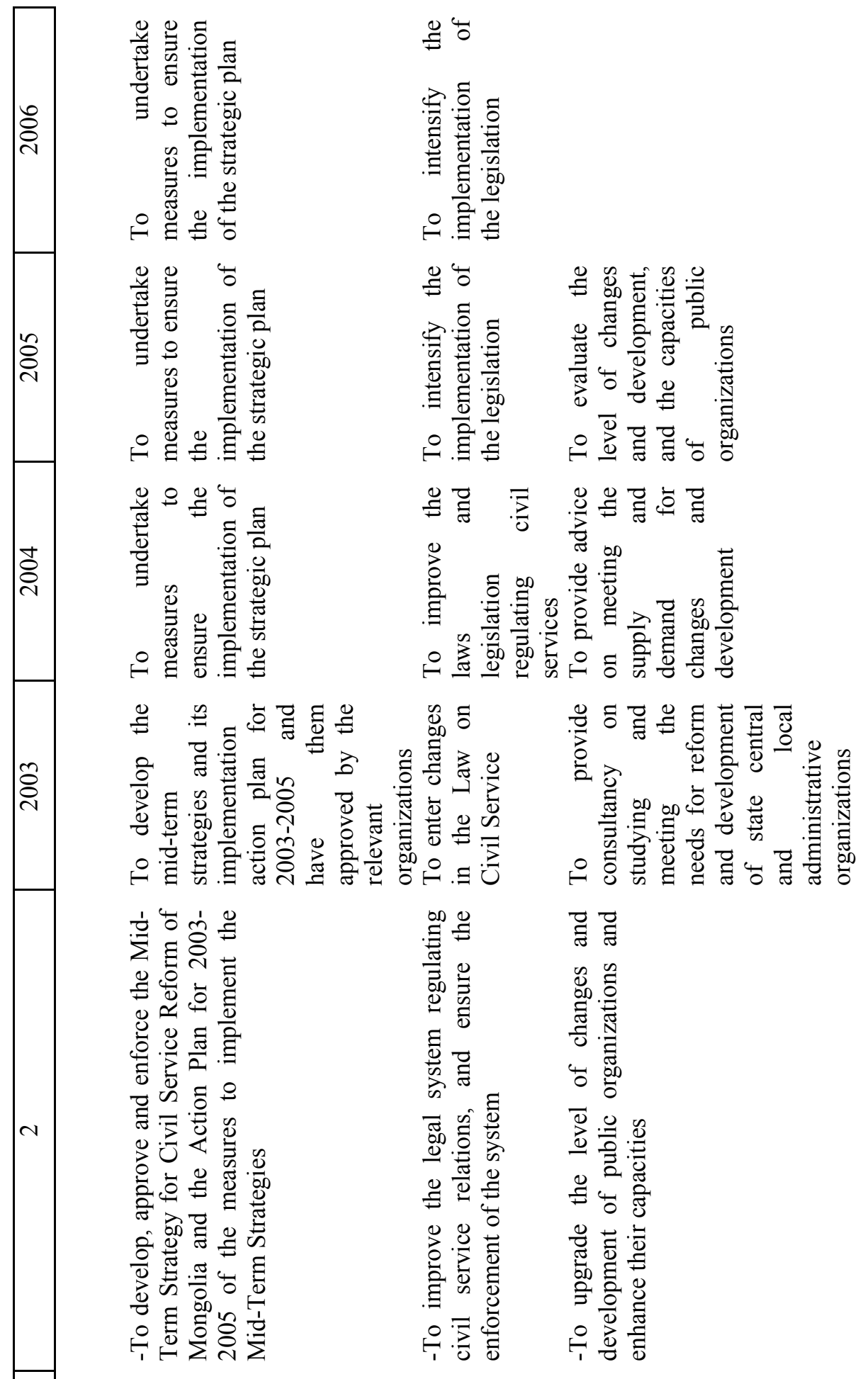




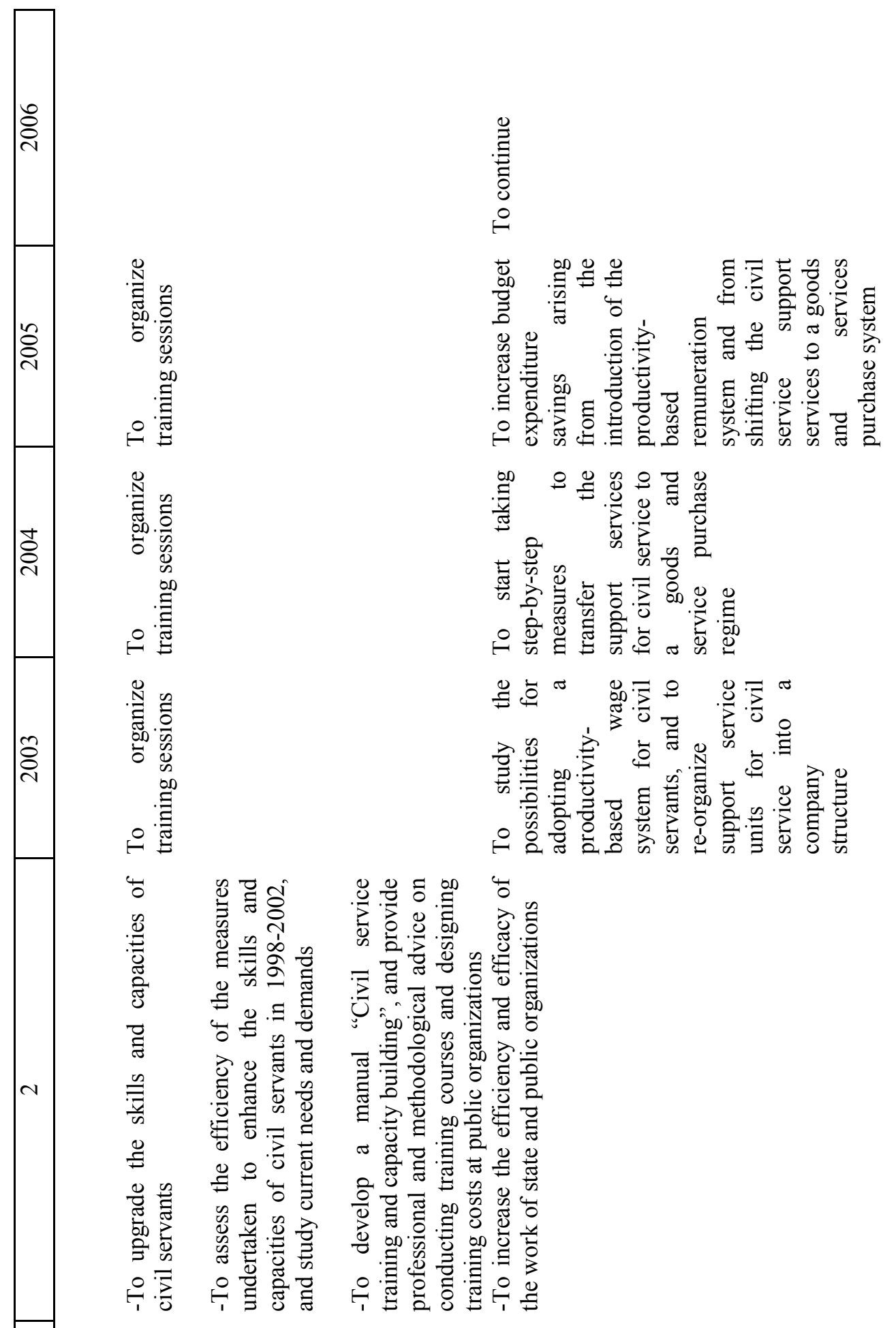




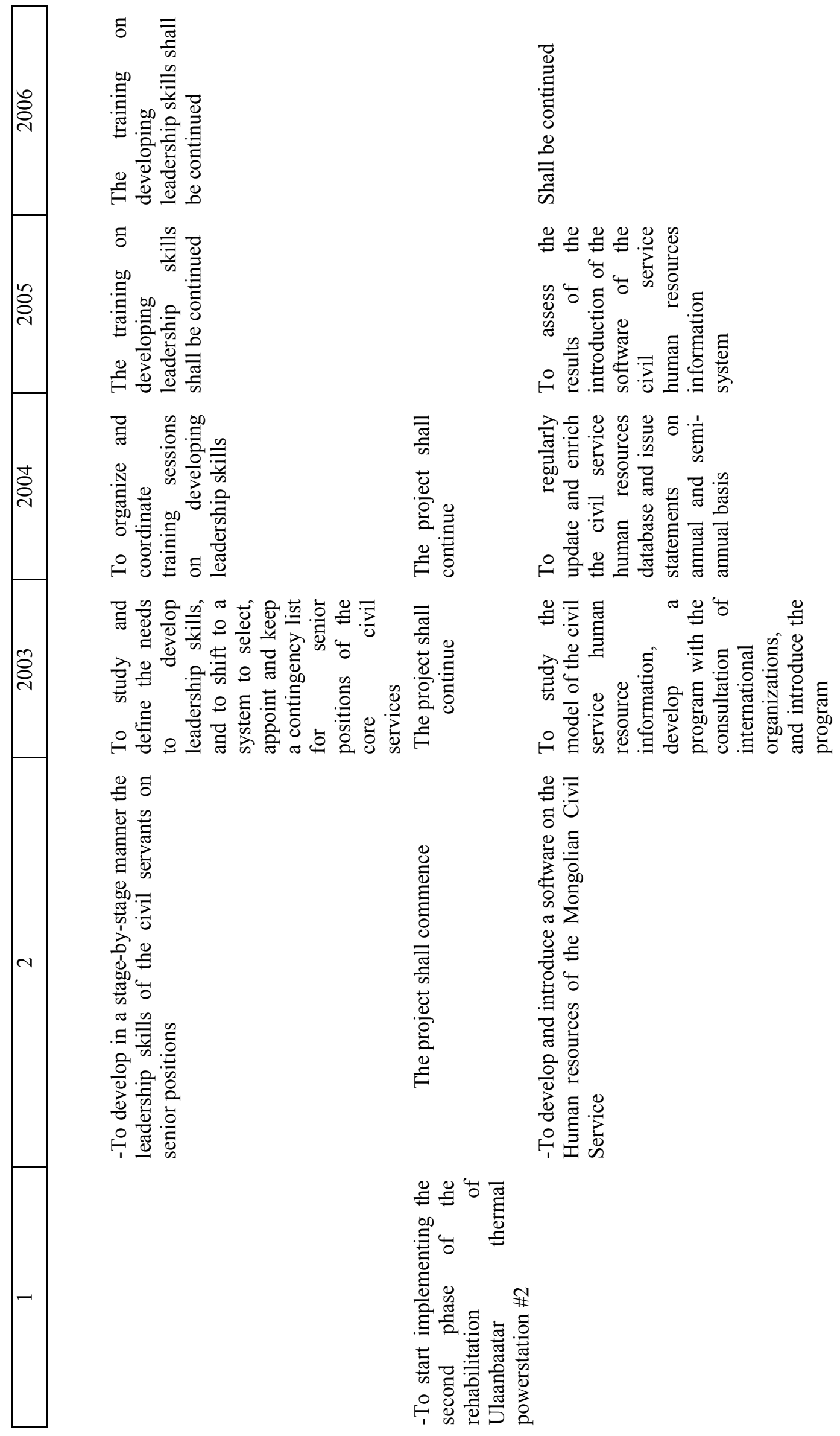




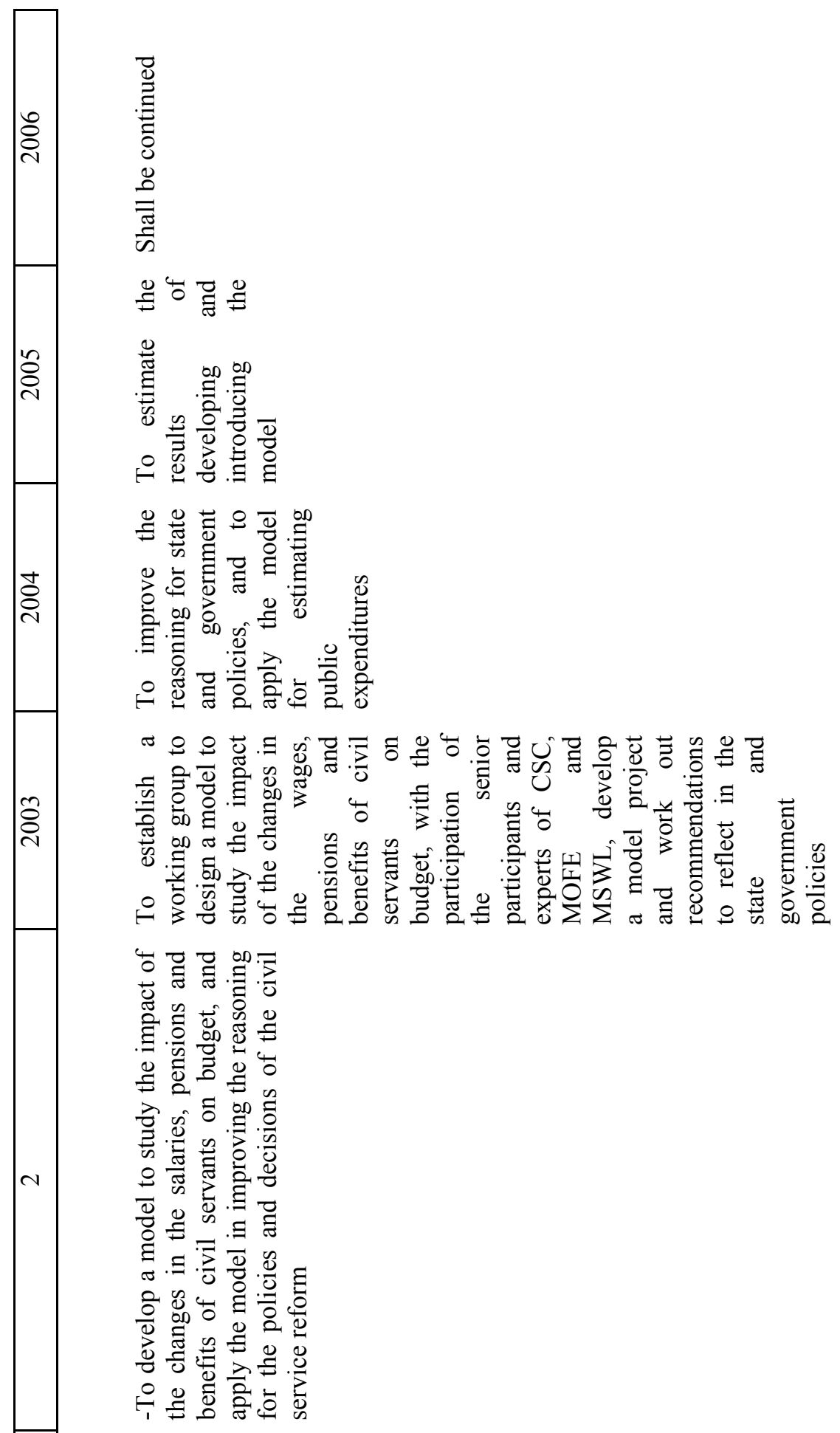




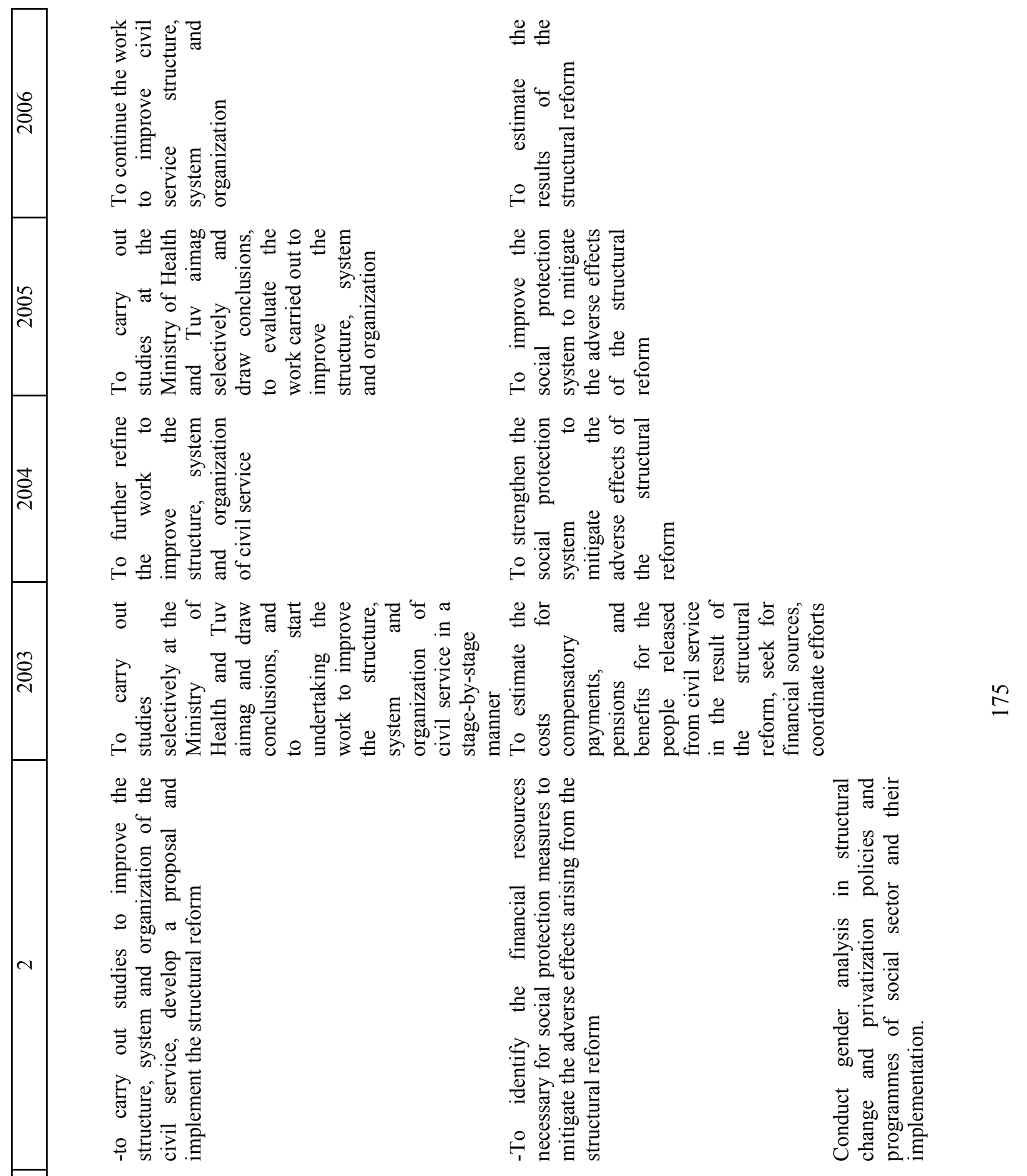




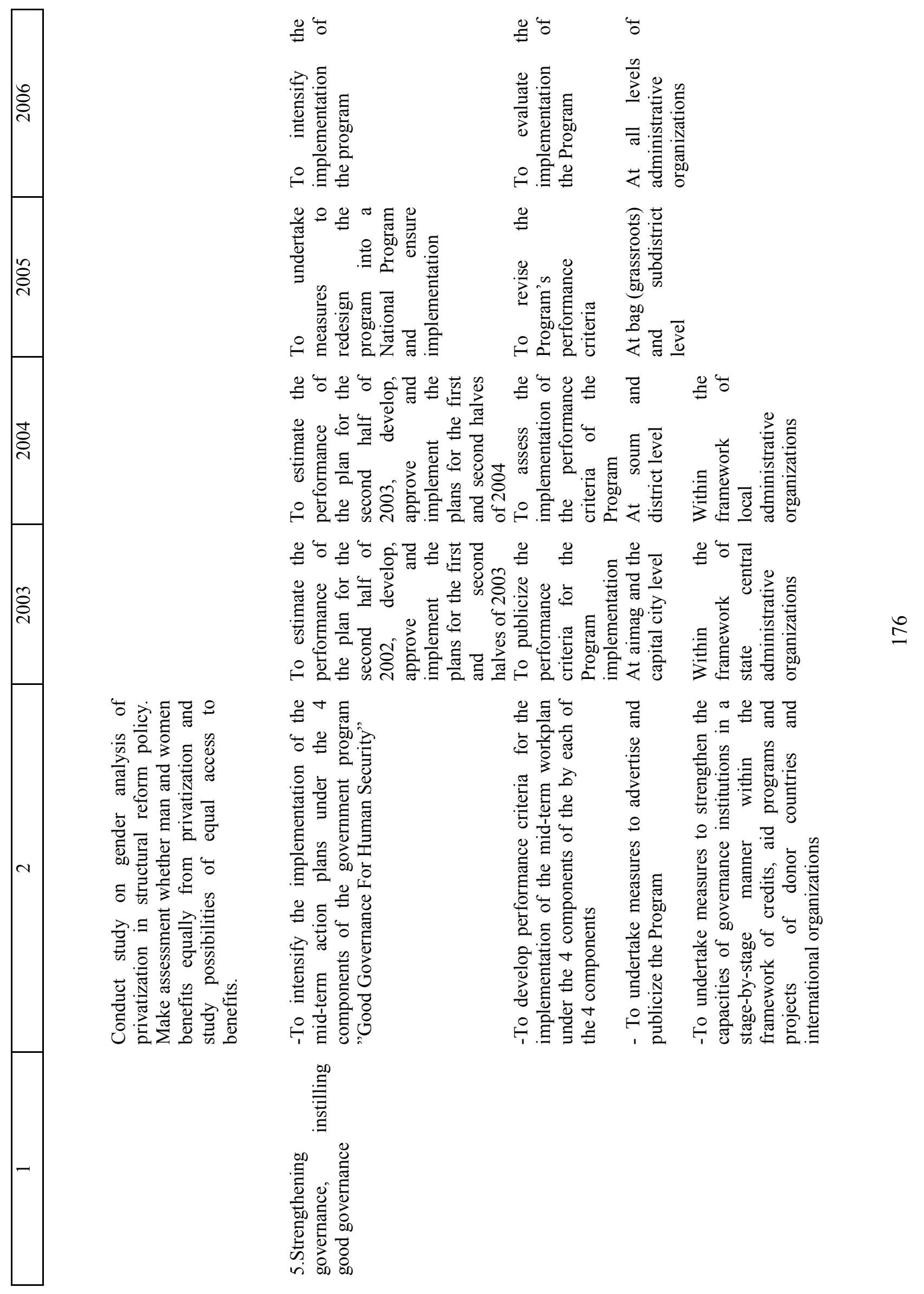




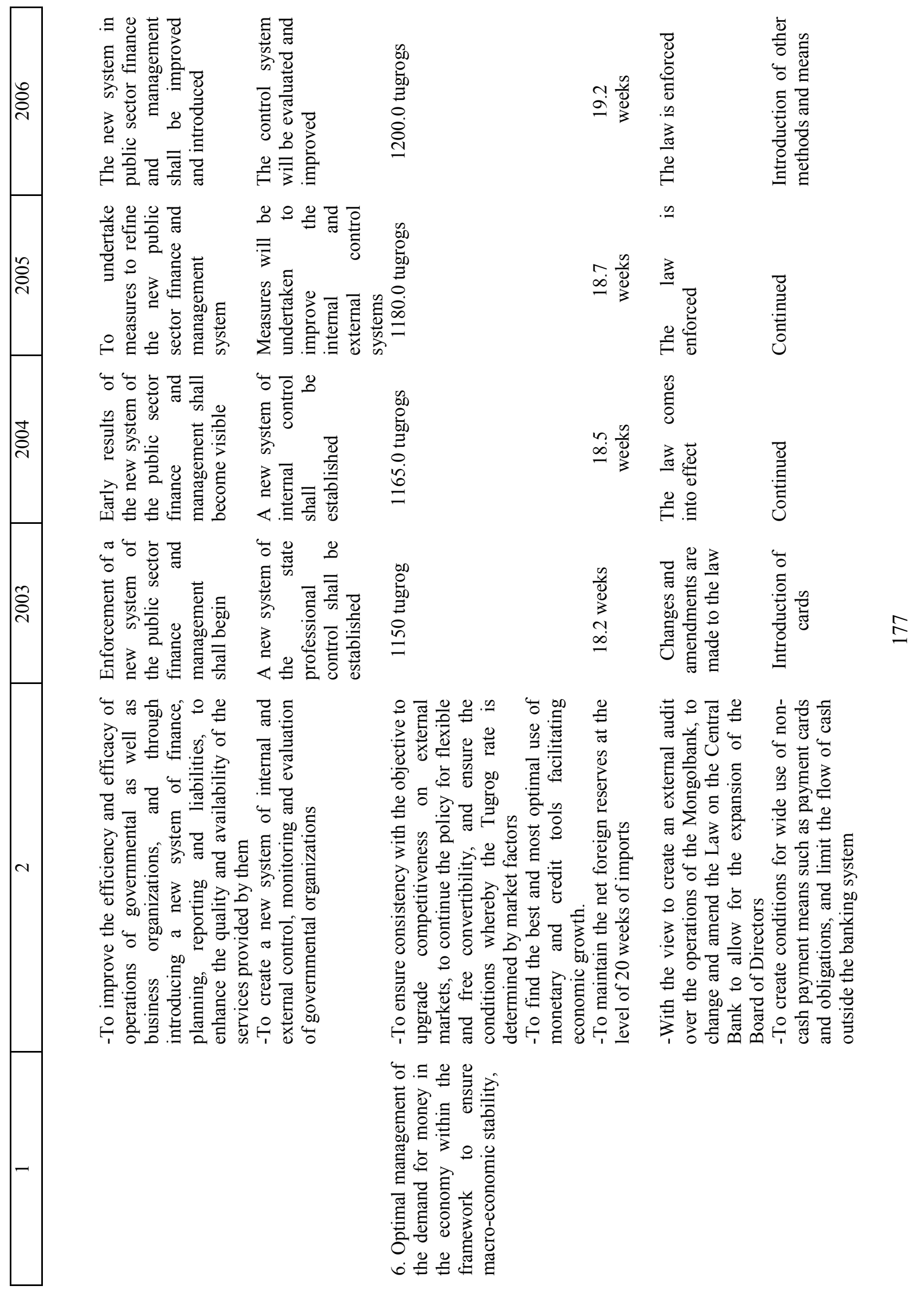




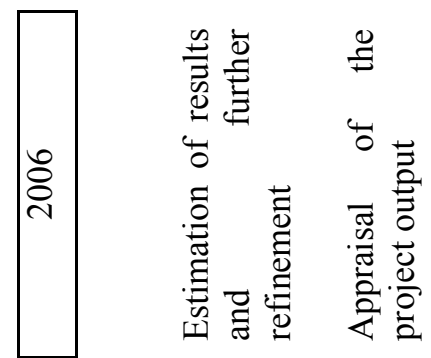

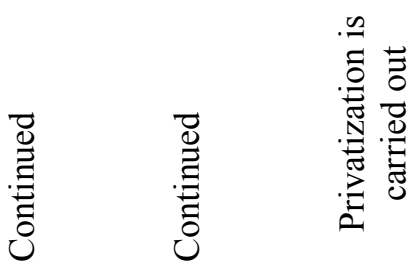

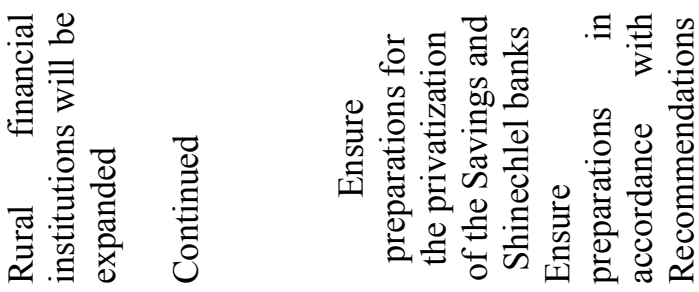

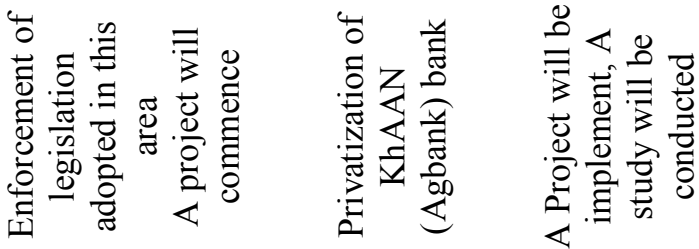
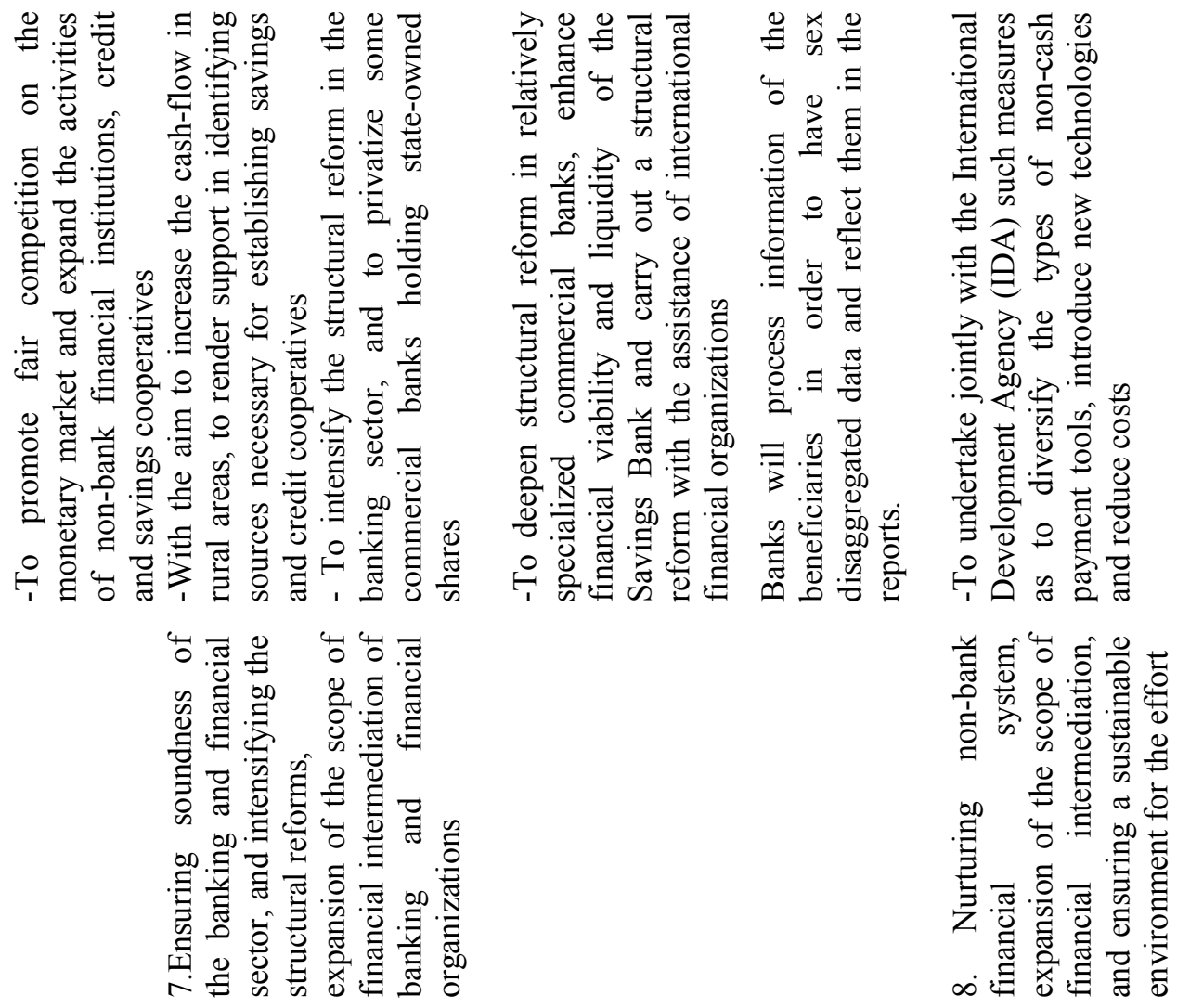


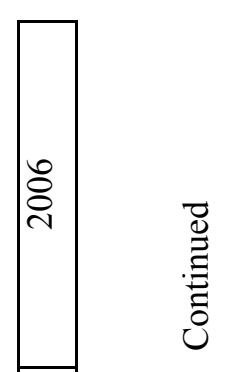

总

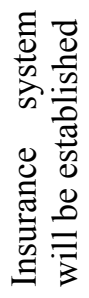

莺

8 를

苍

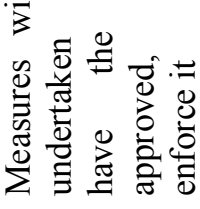

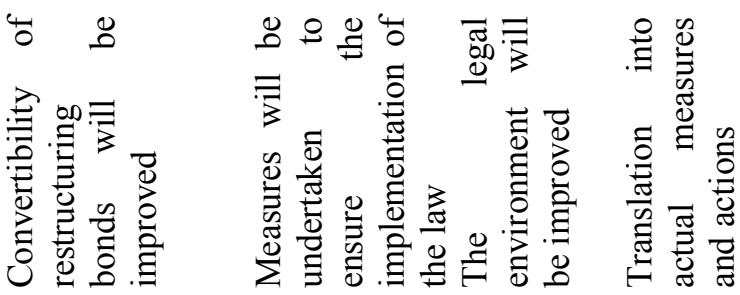

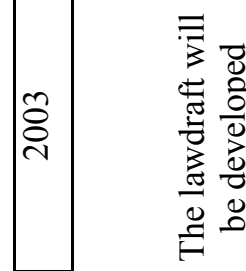

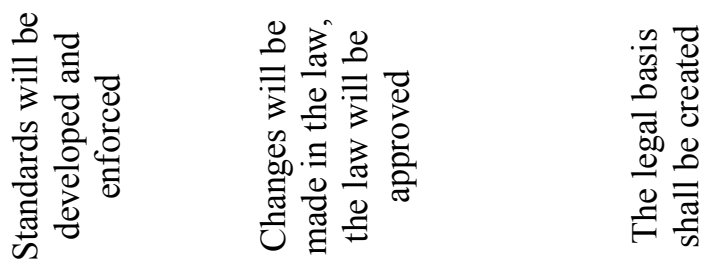

$\stackrel{1}{2}$

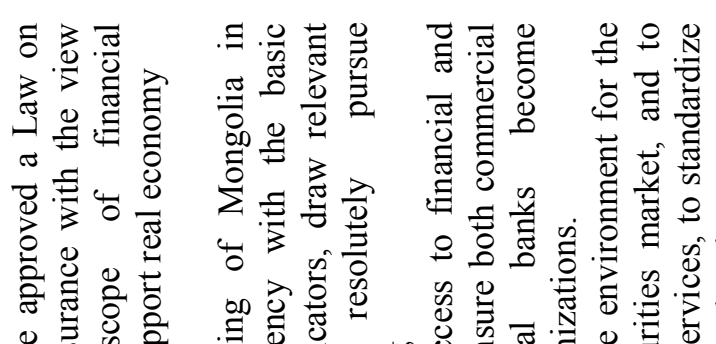

N

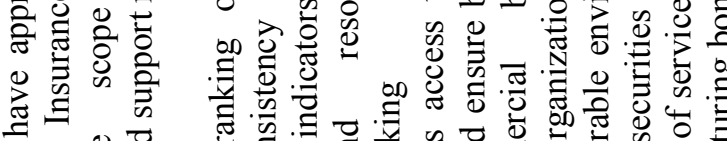

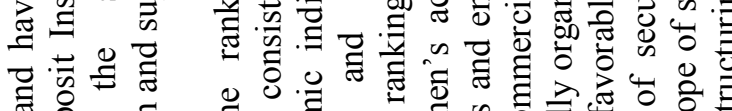

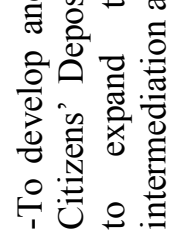

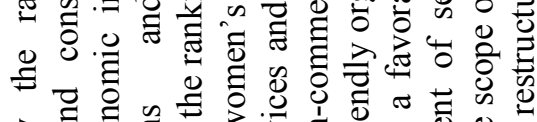

خ

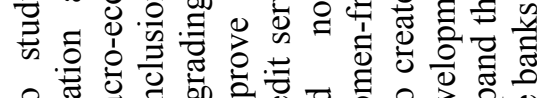

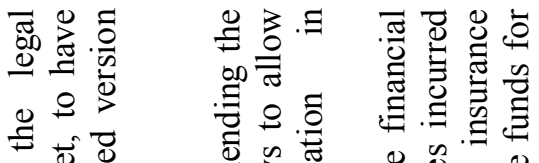

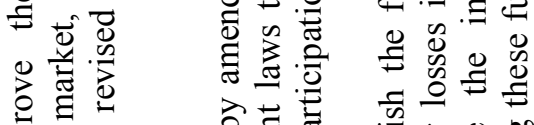

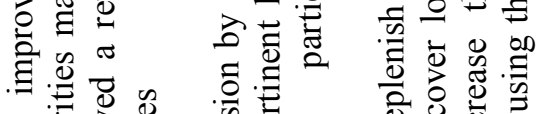

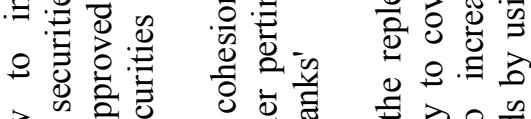

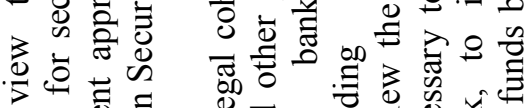

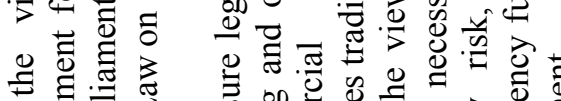

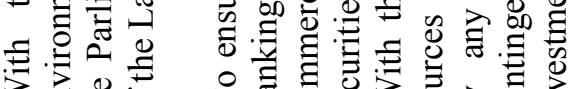

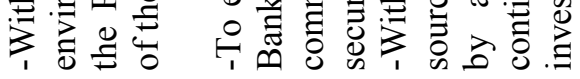
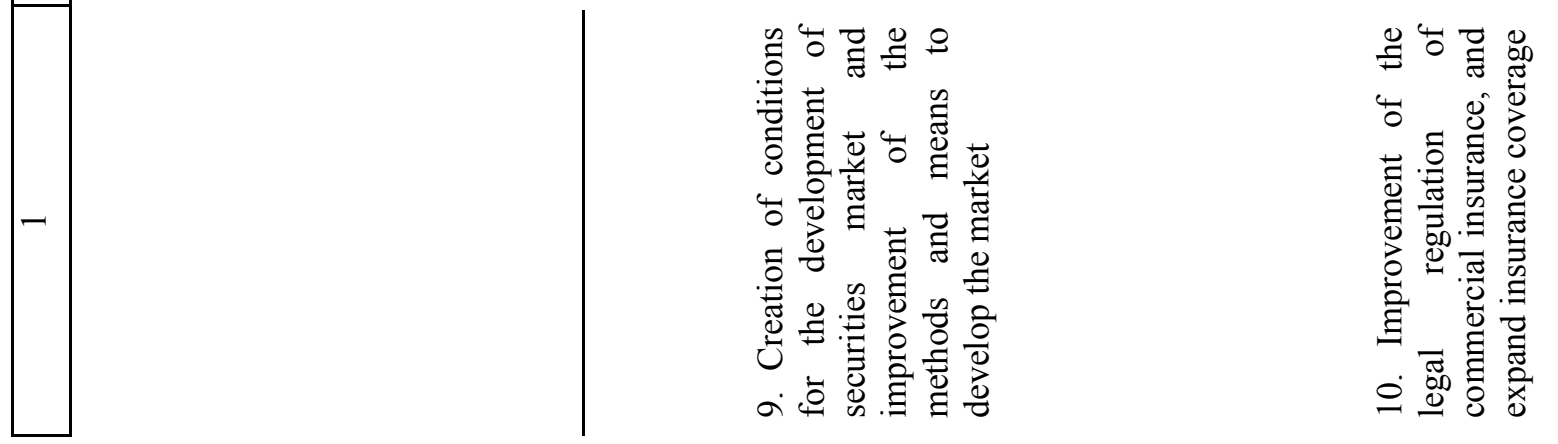


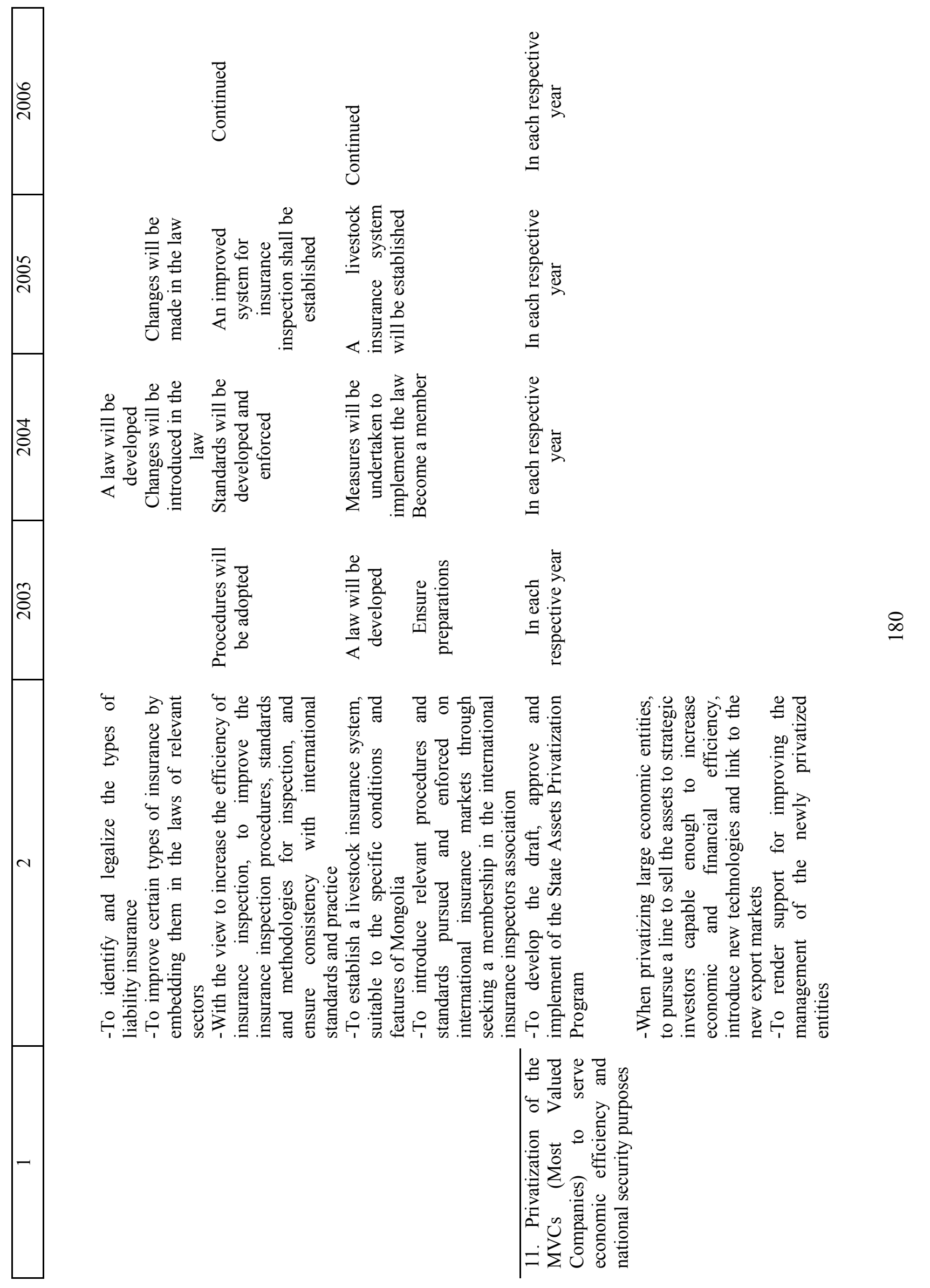




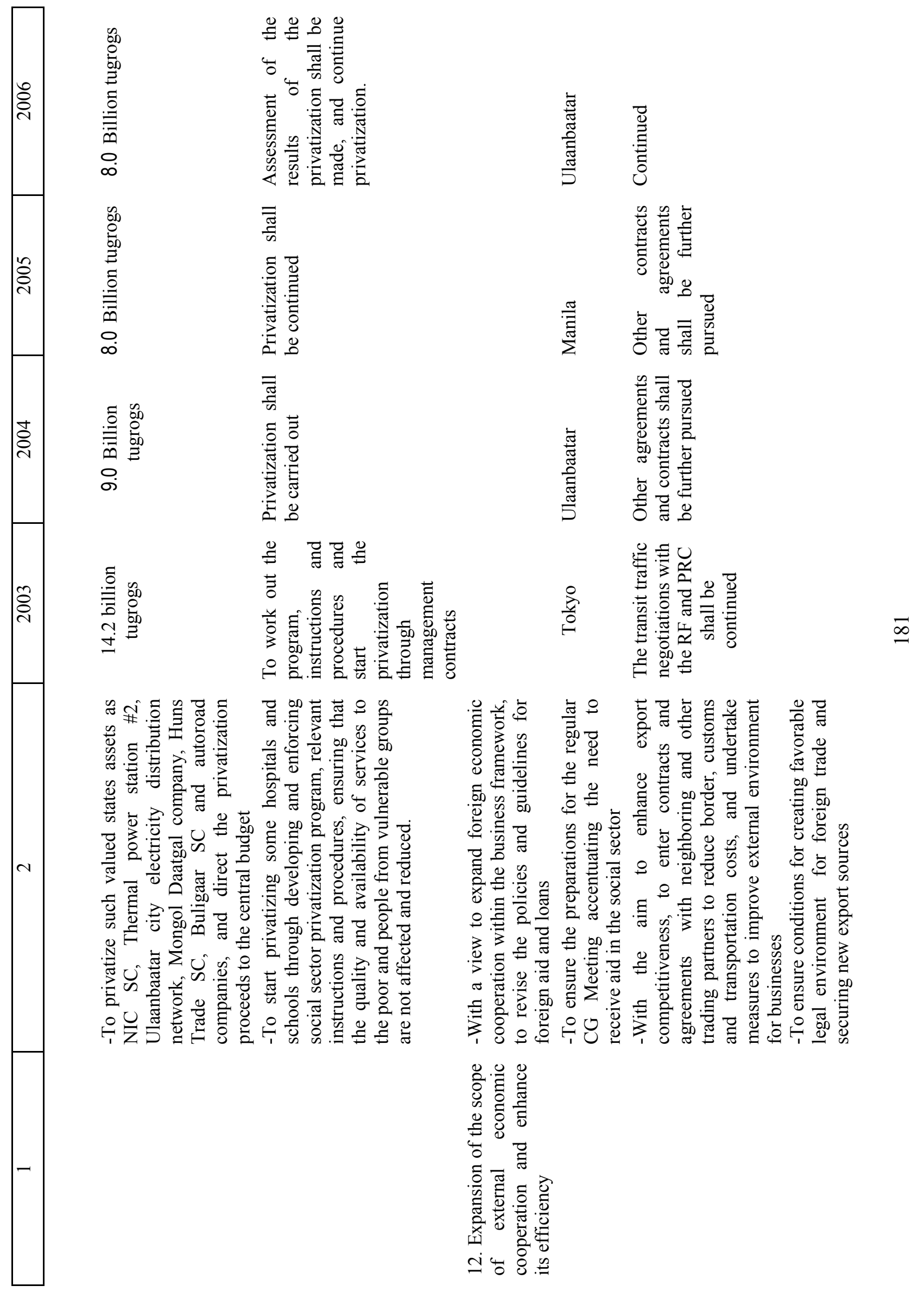



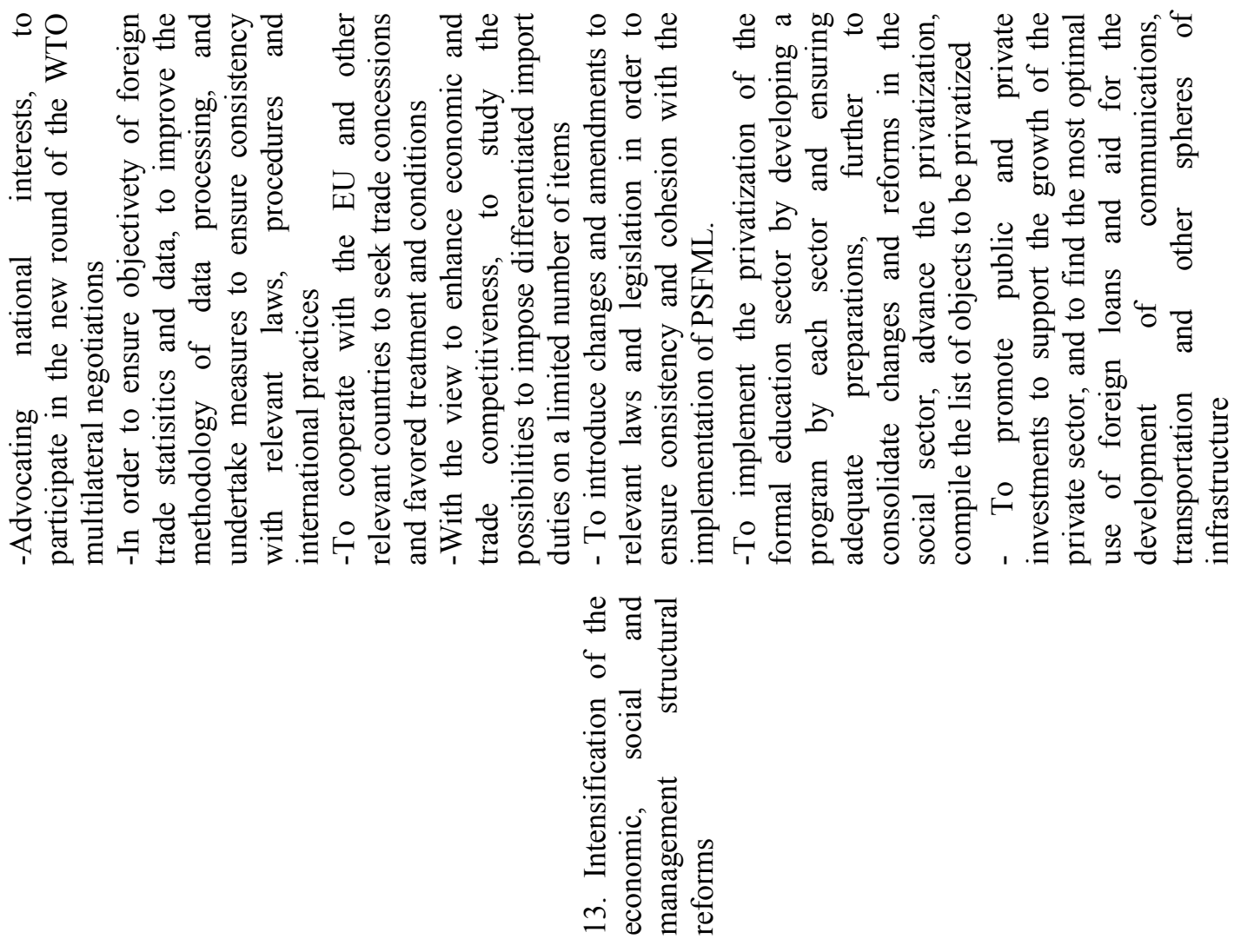


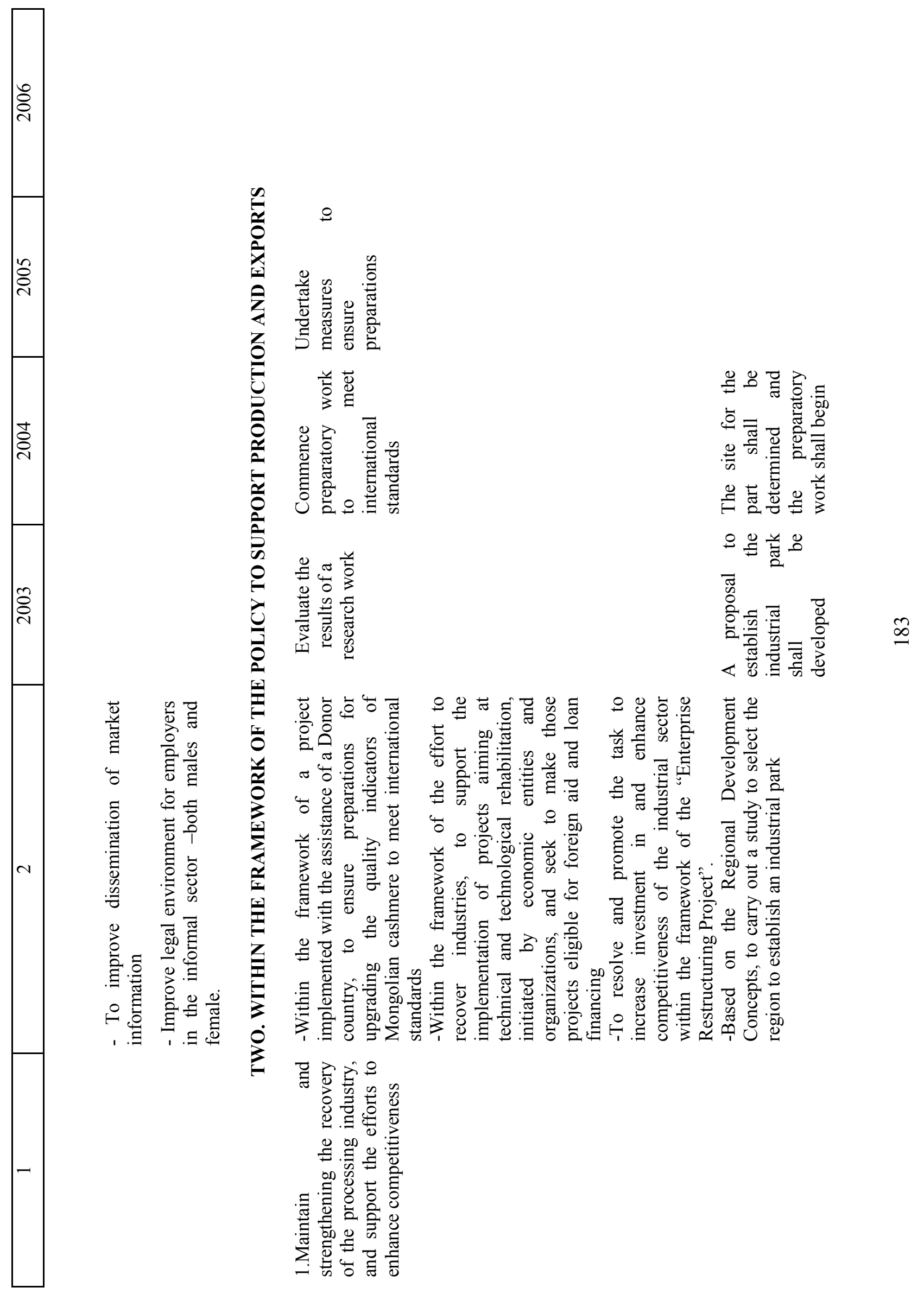




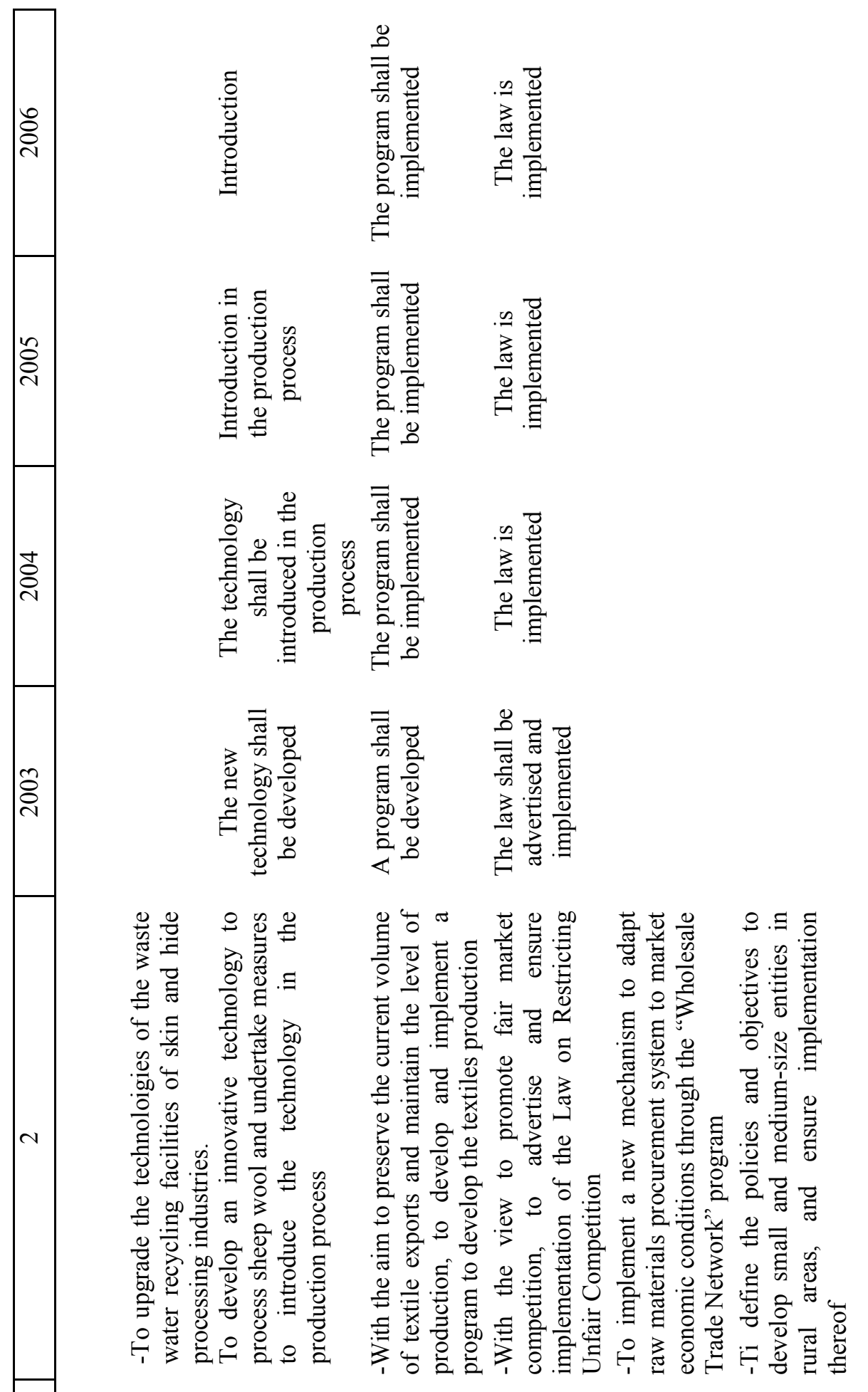




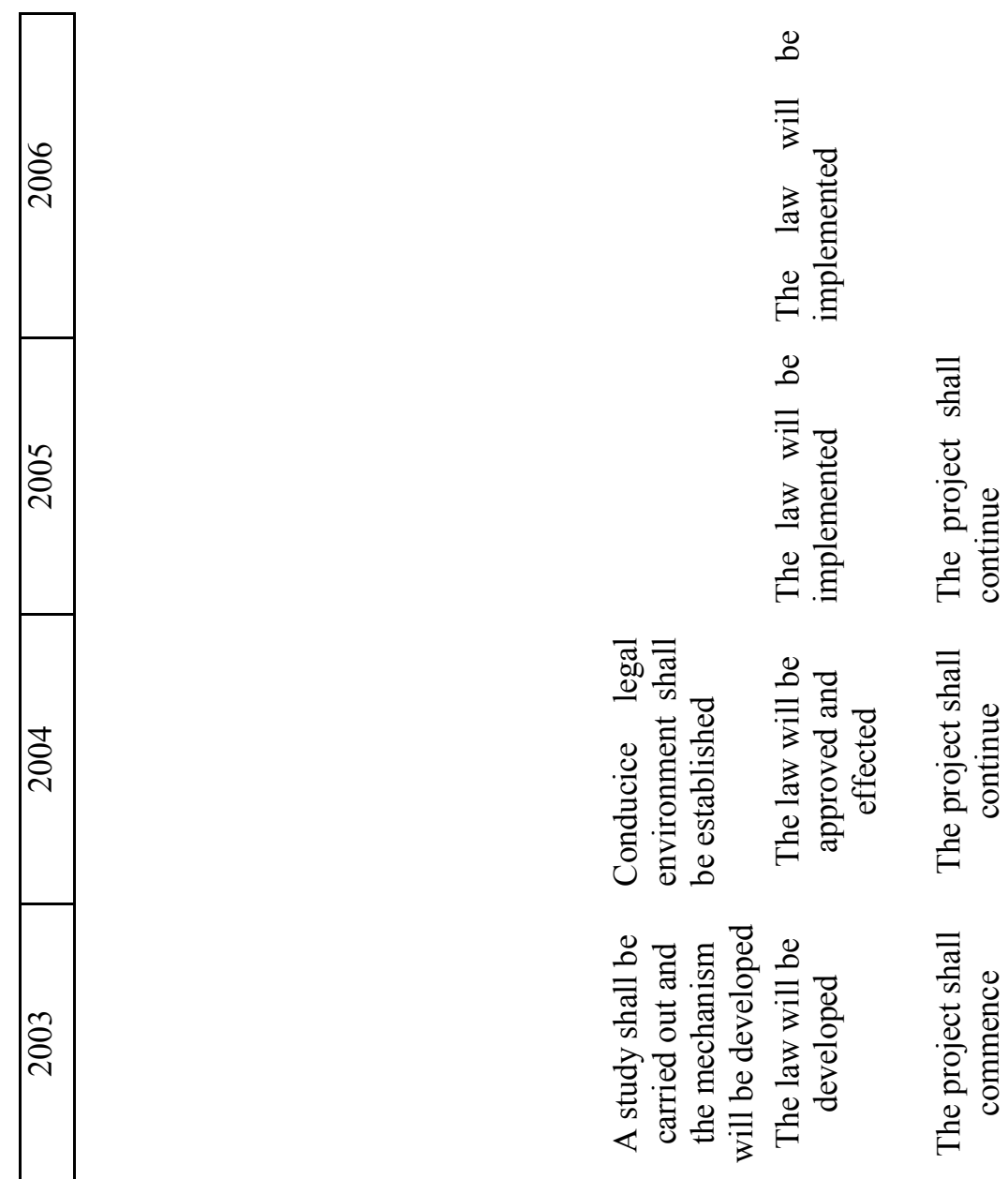

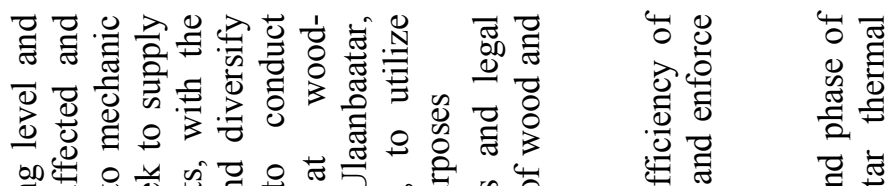

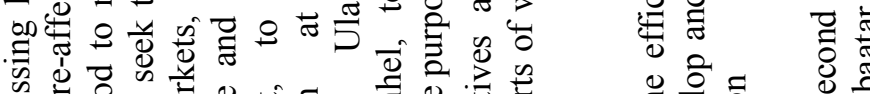

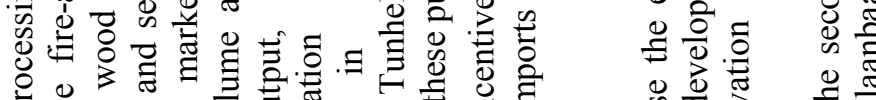

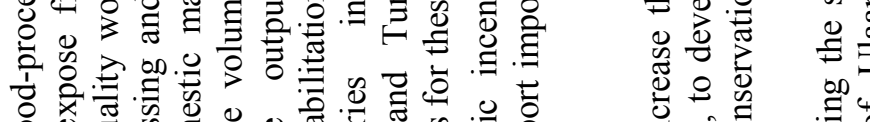

㖊

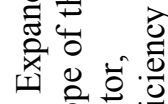

त 


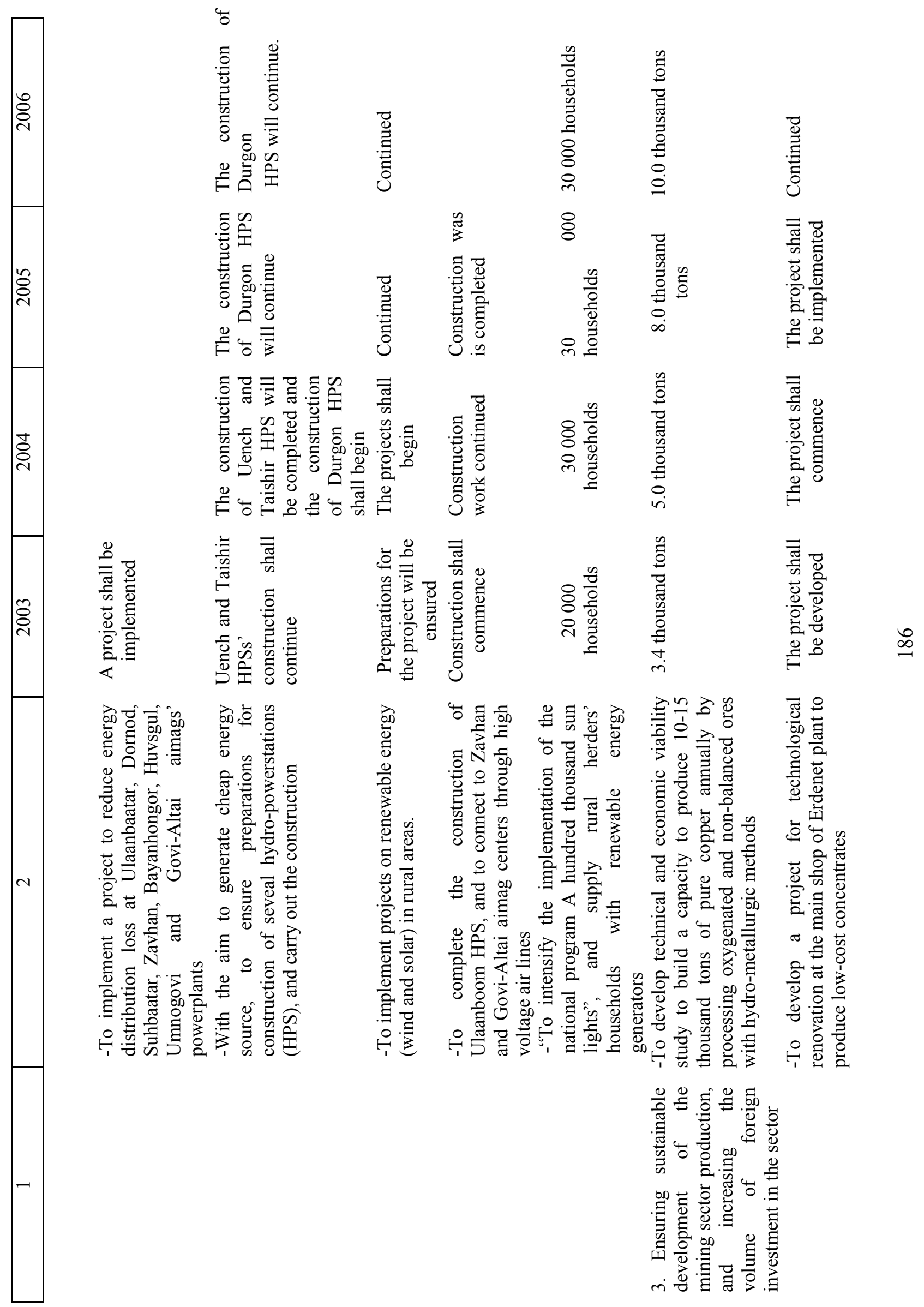




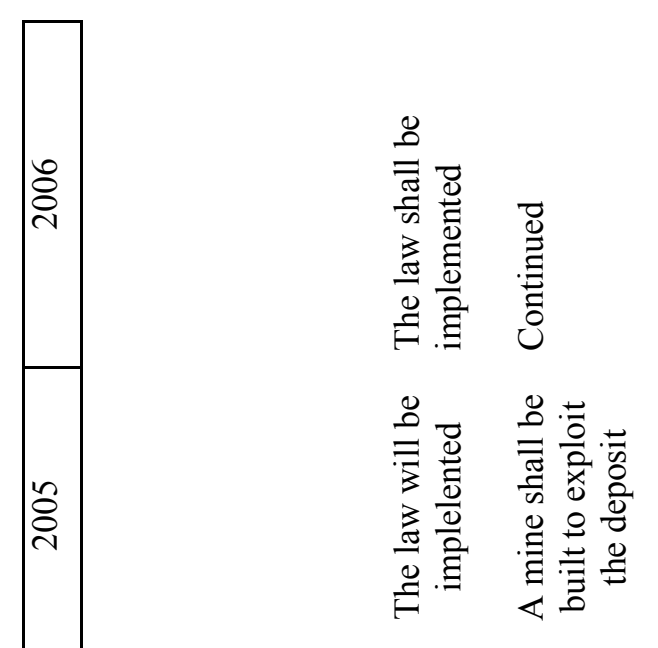

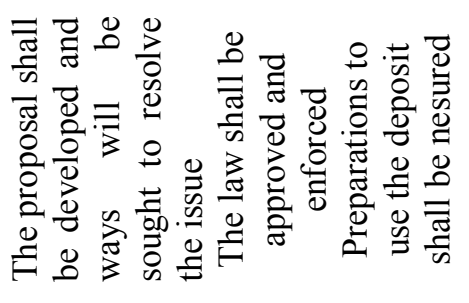
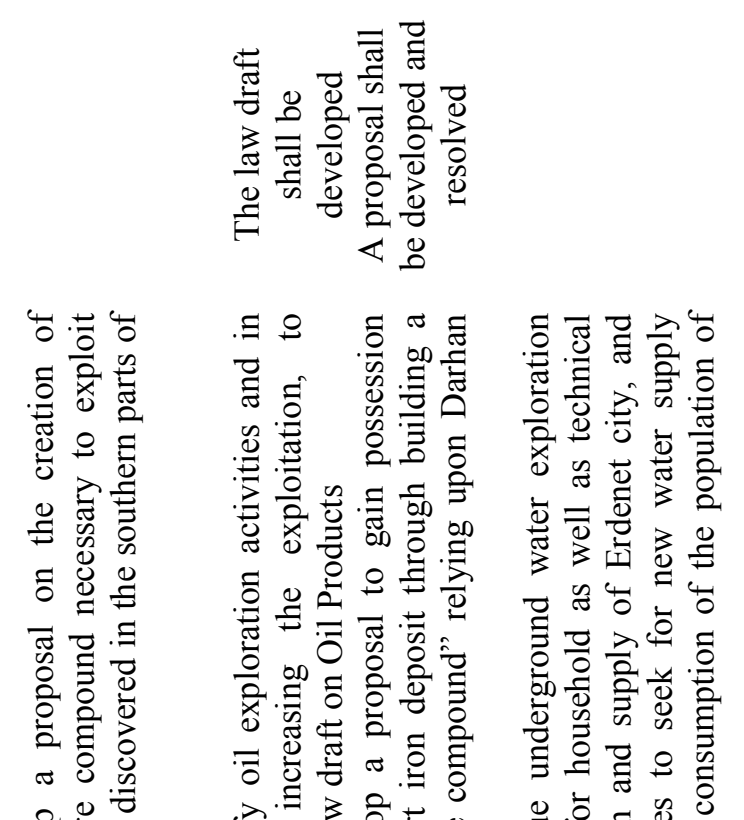

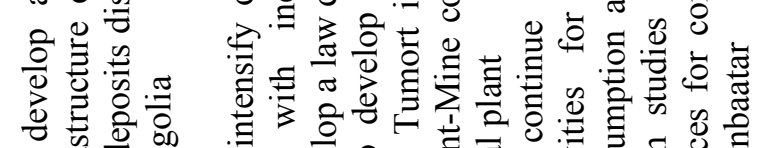

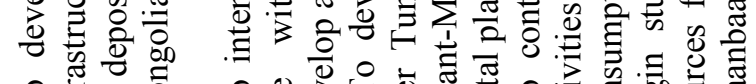

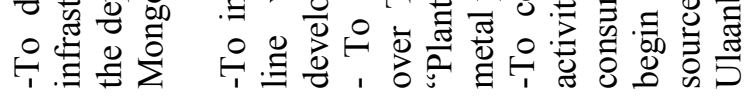

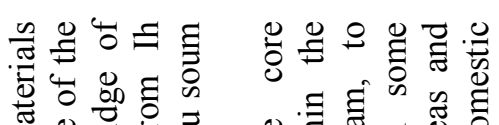

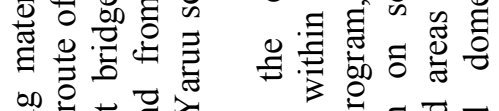

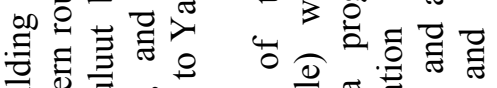

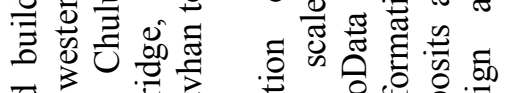

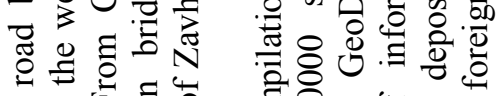

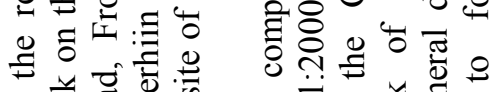

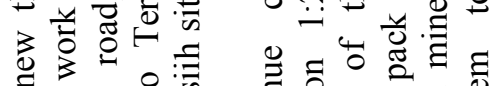

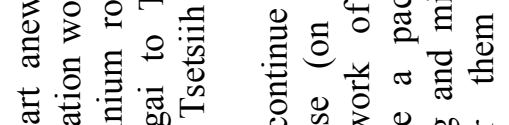

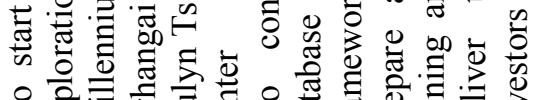

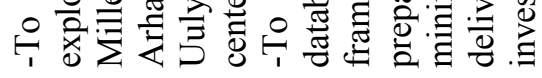

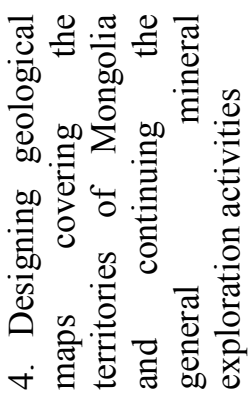




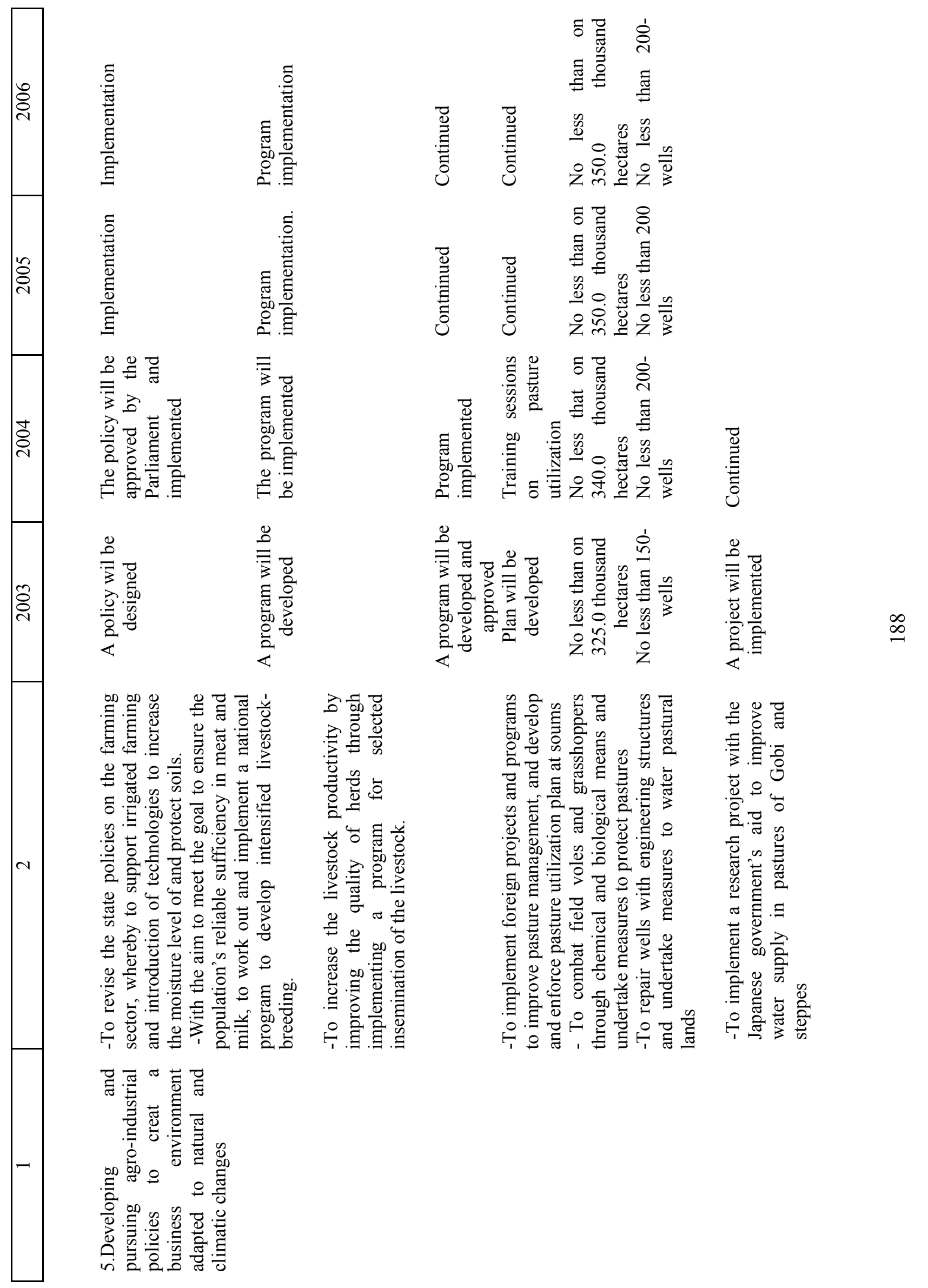




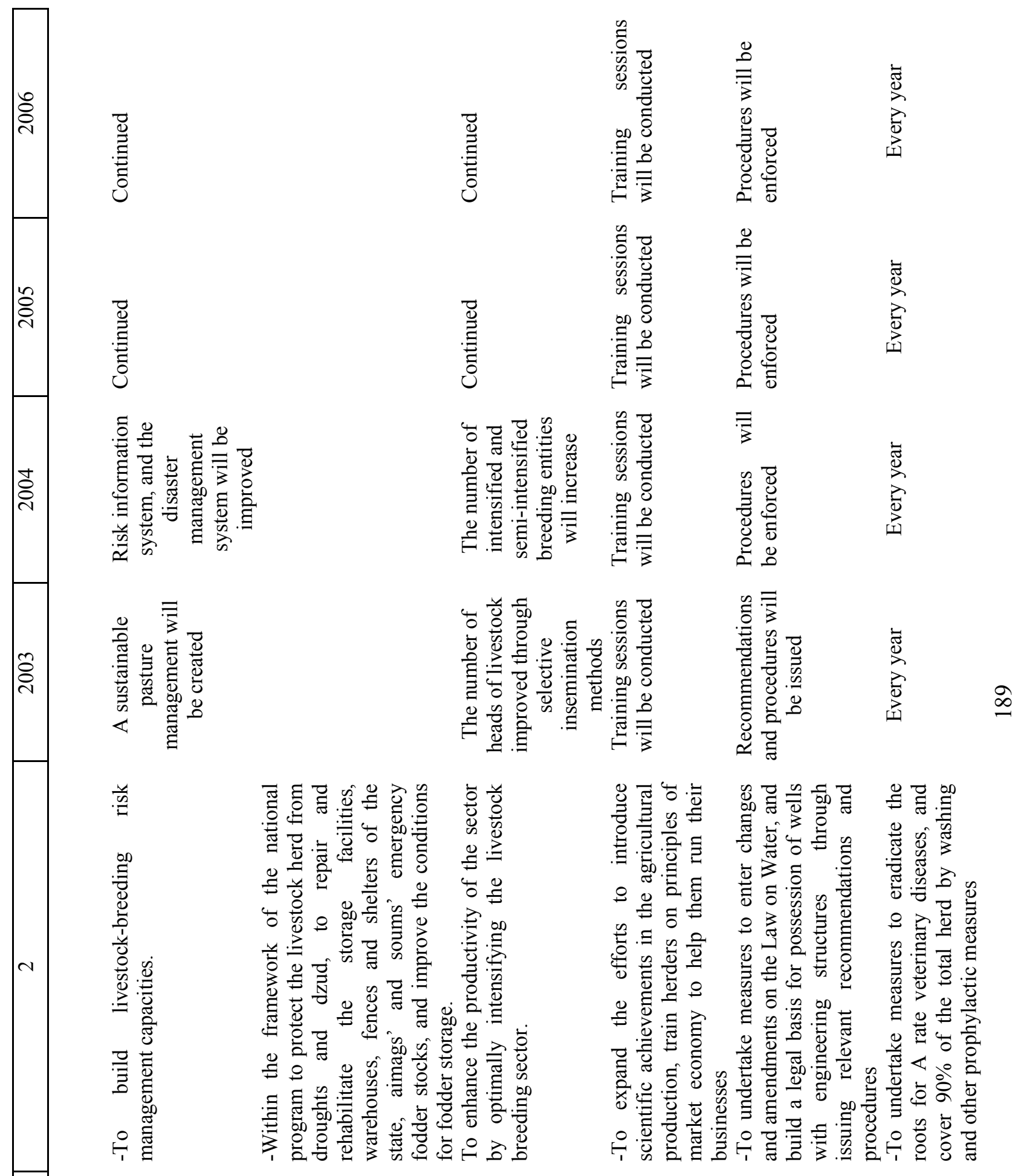




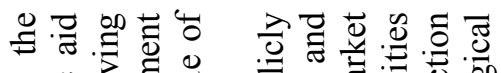

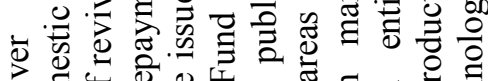

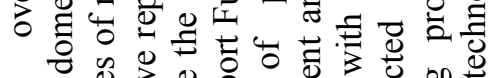

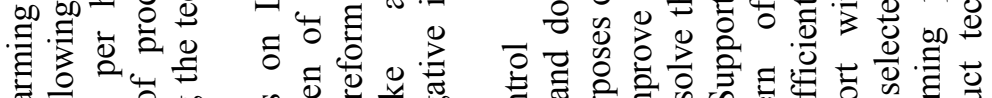




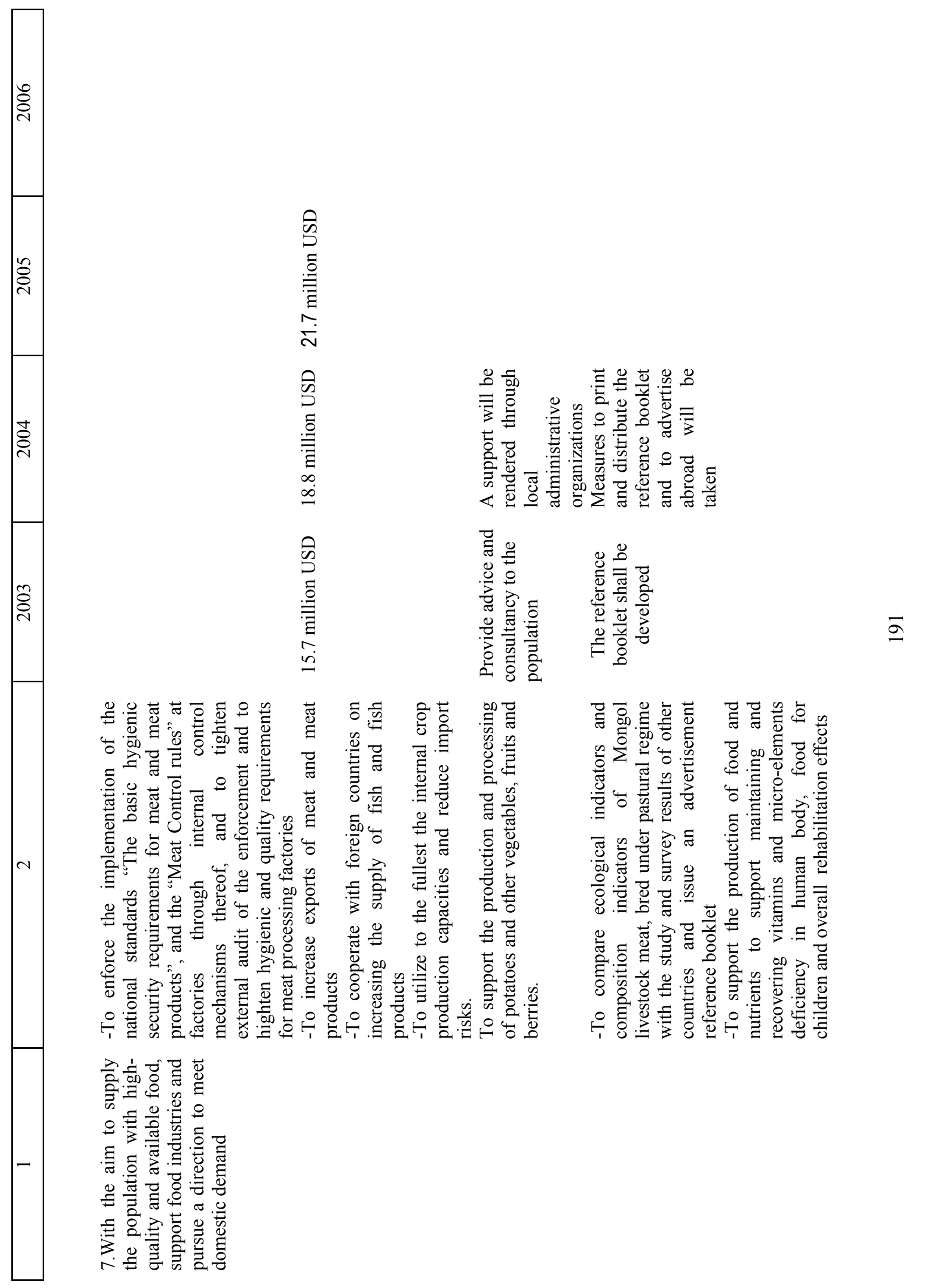




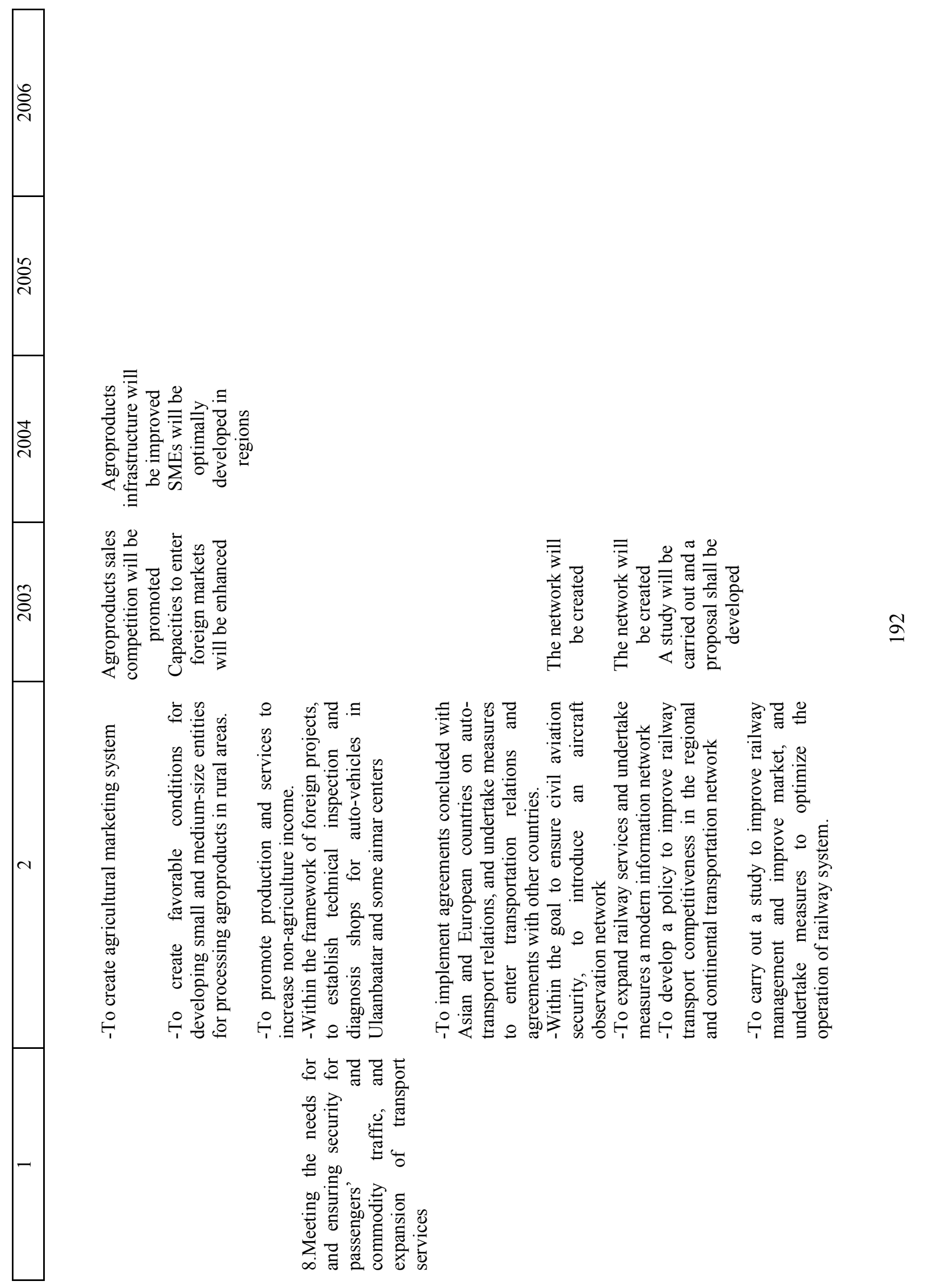




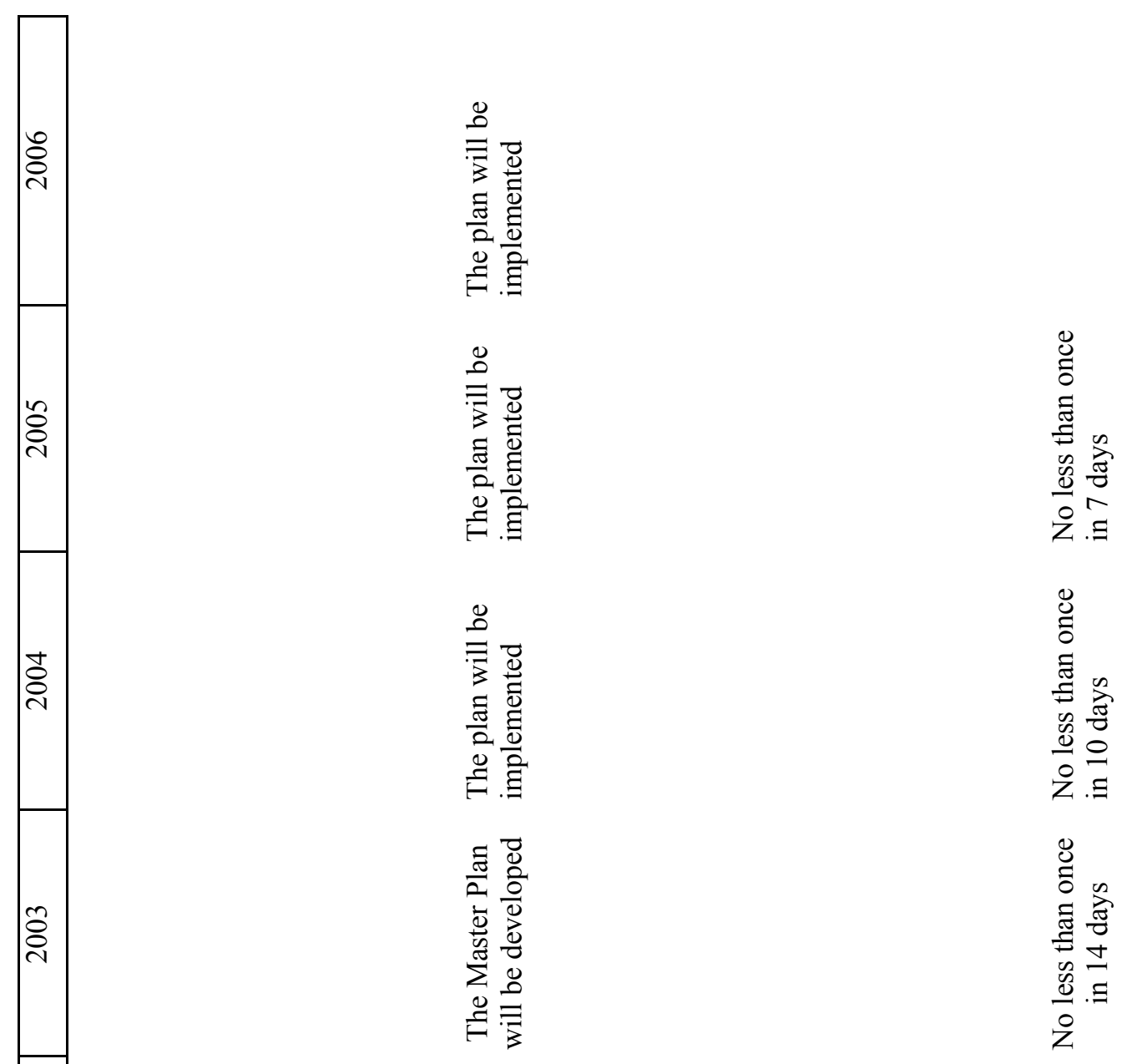

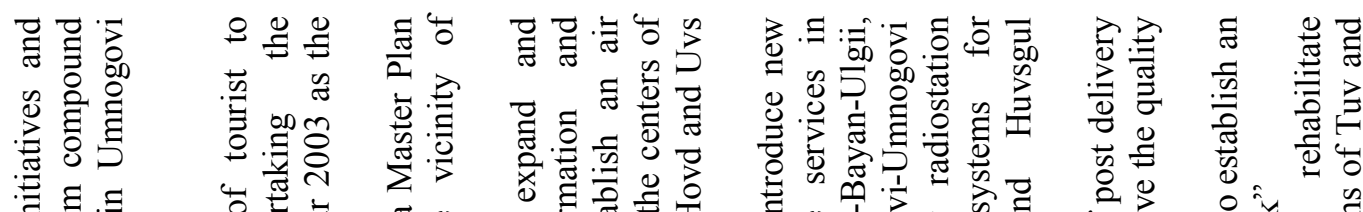

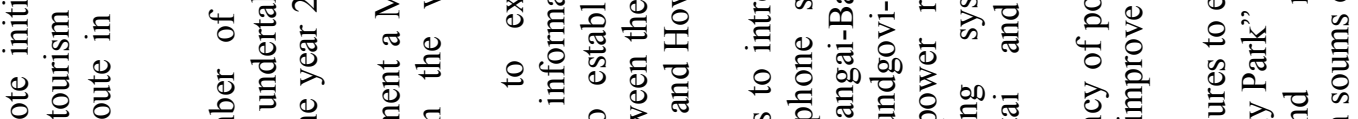

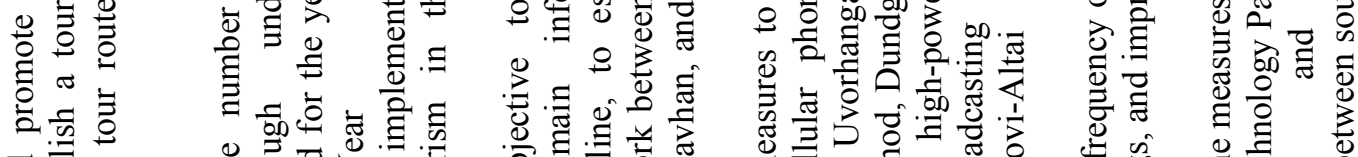

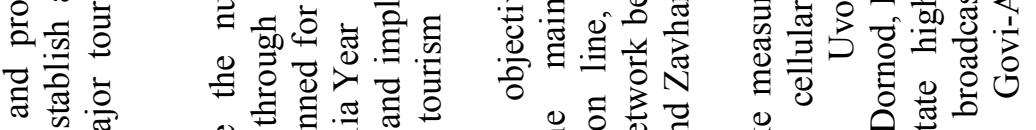

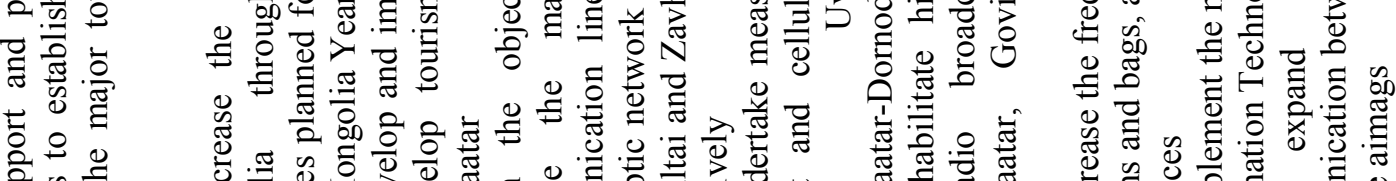

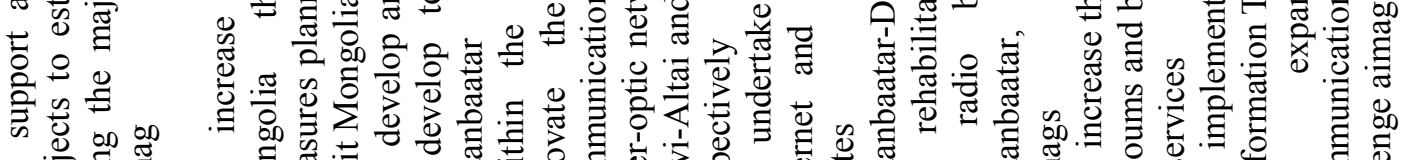

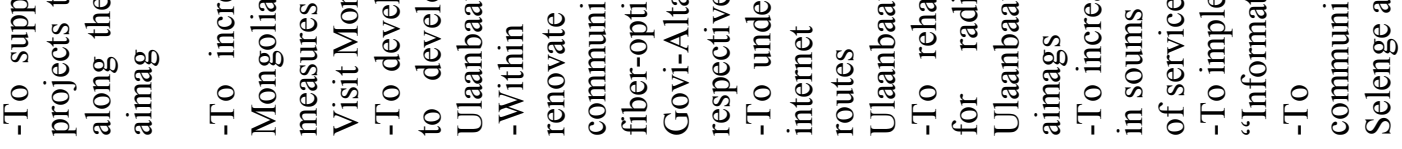

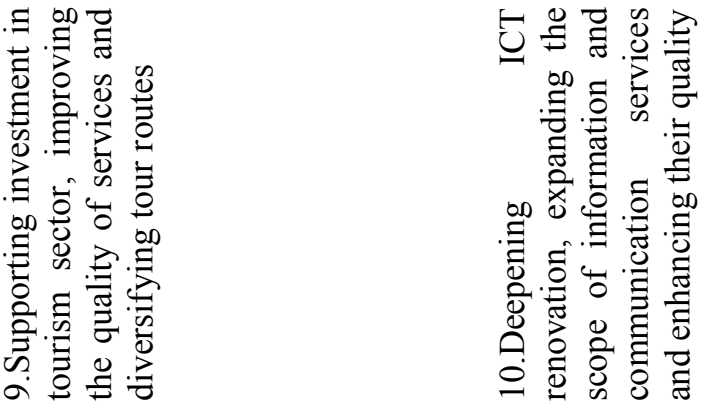




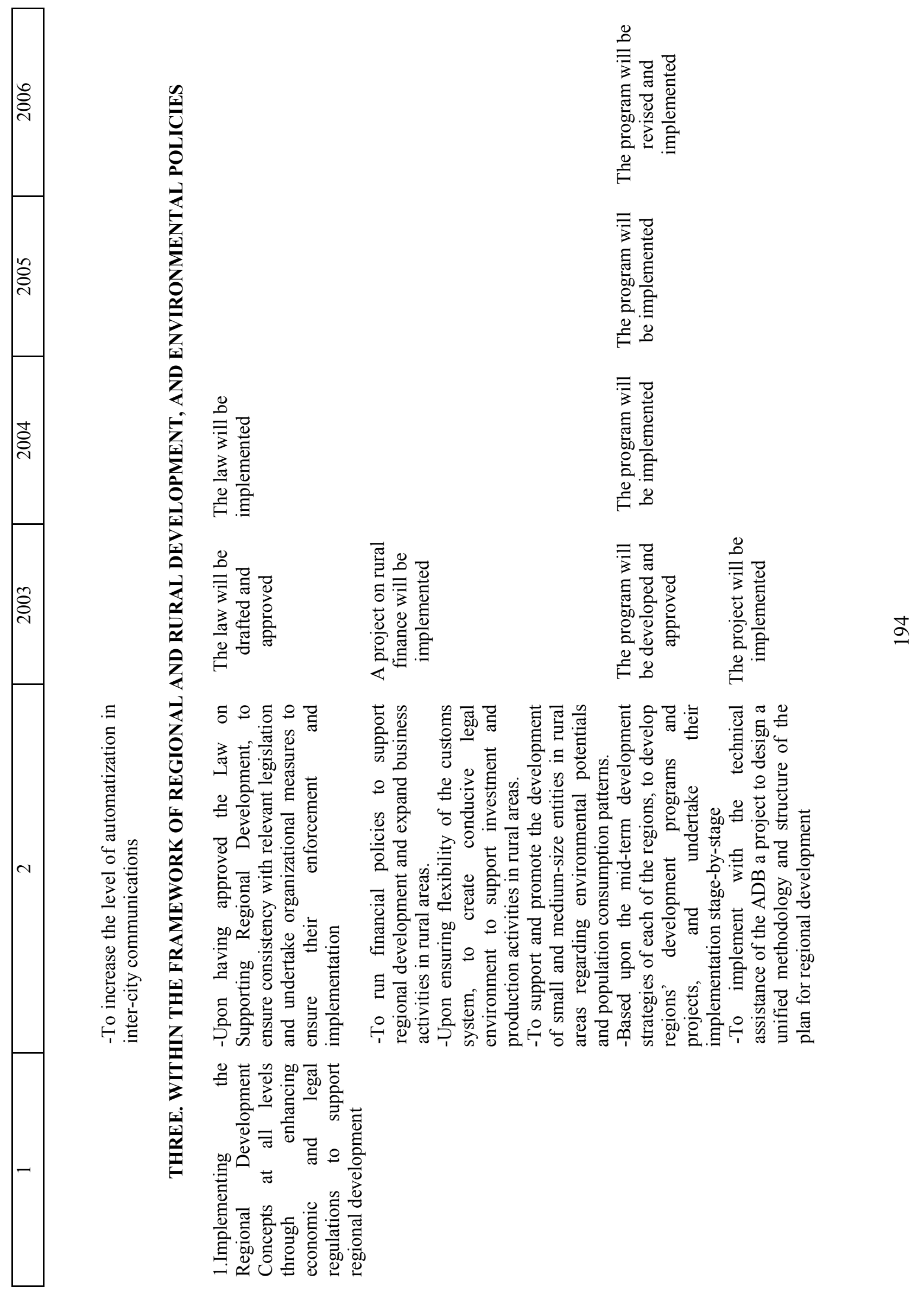




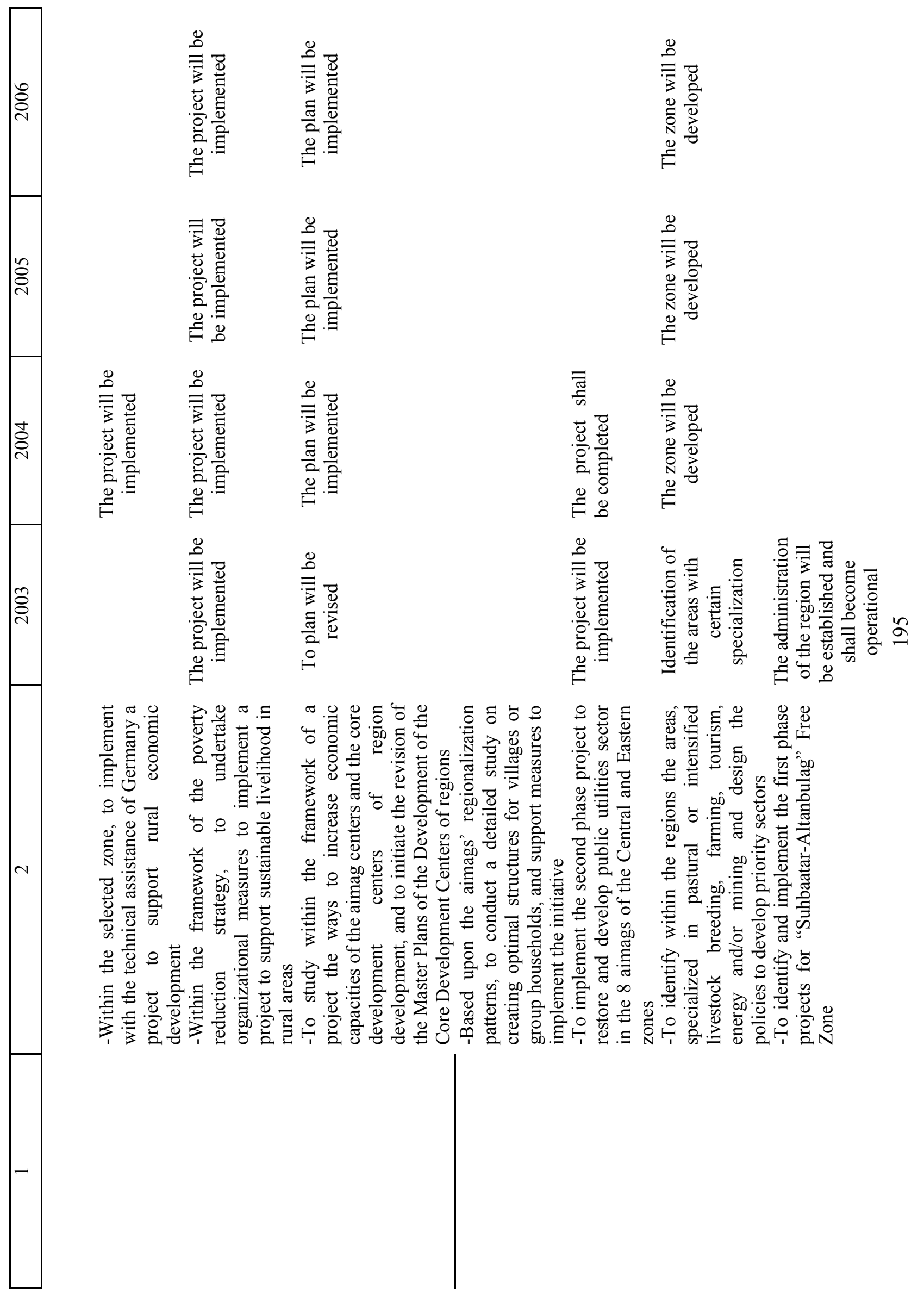




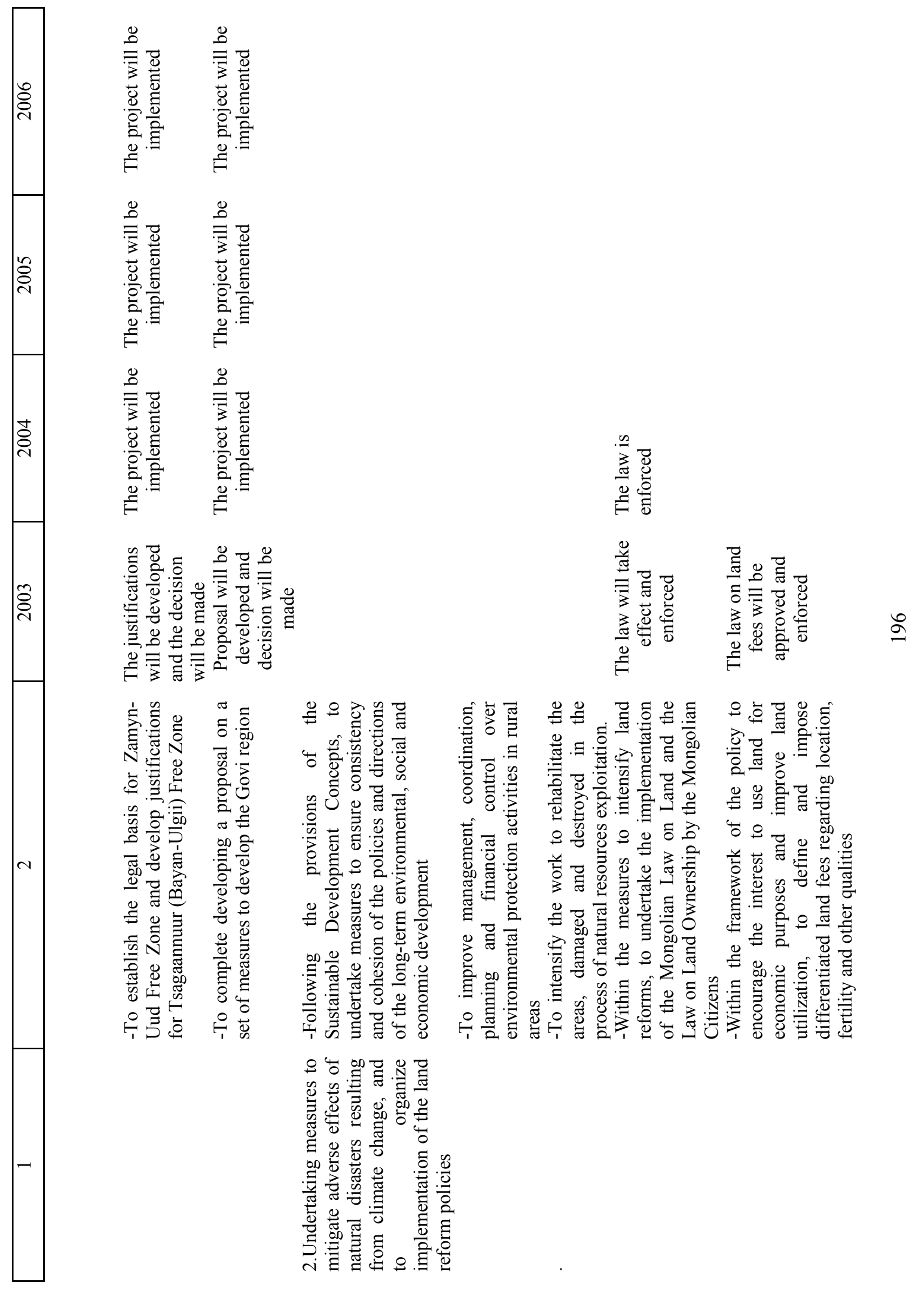




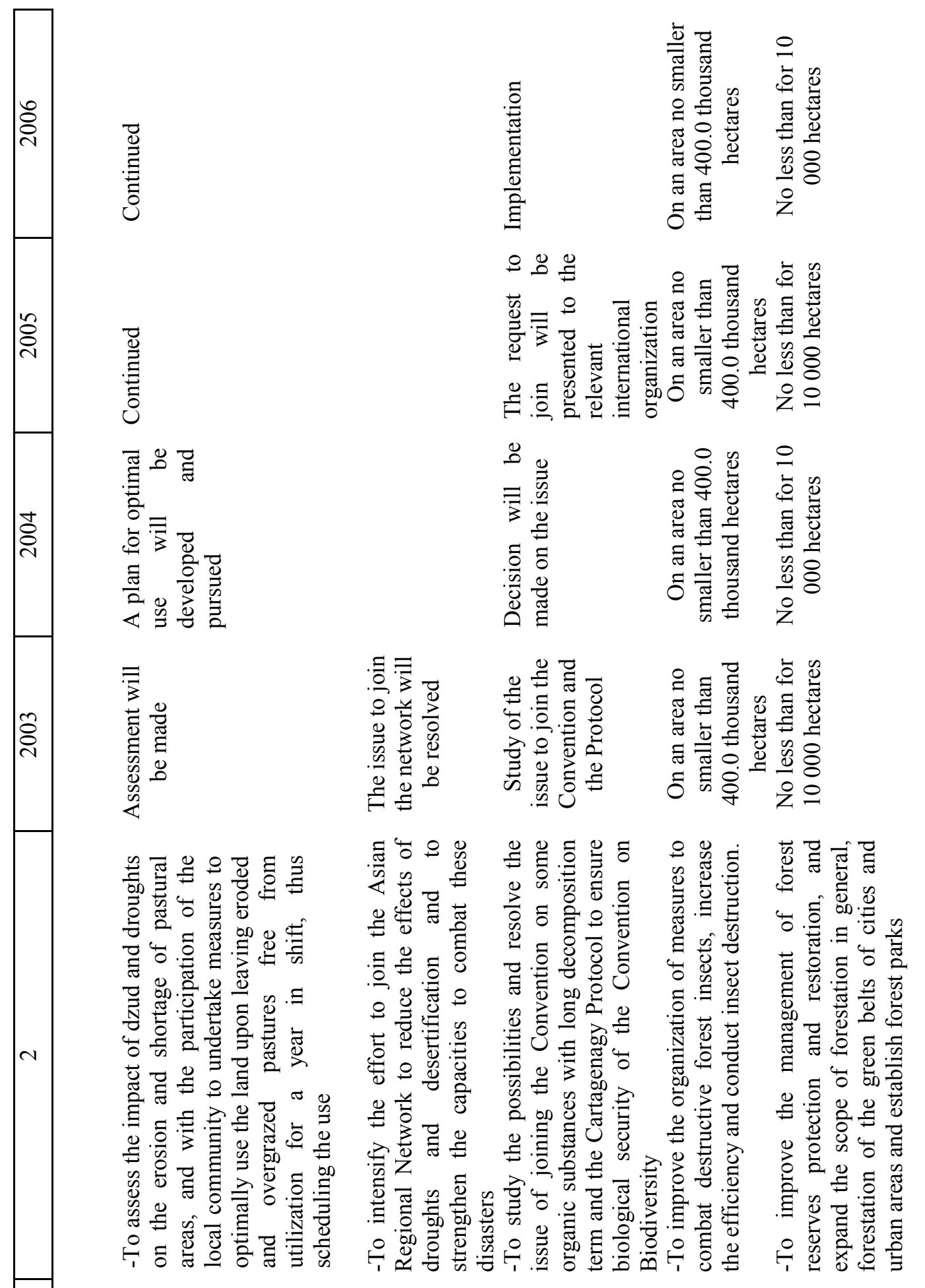




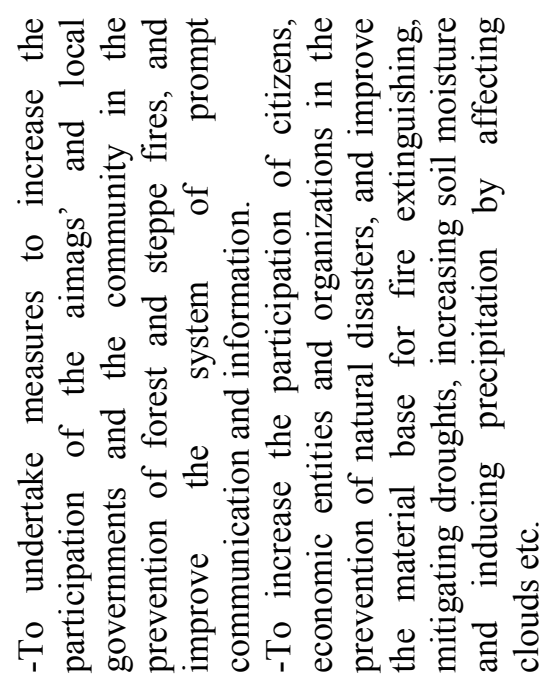




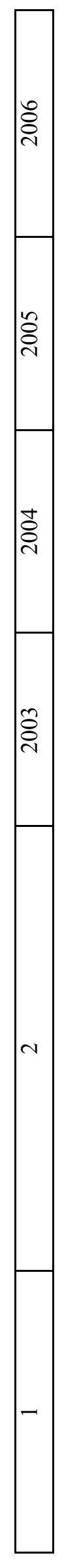

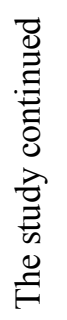

옿용

论

웡

«

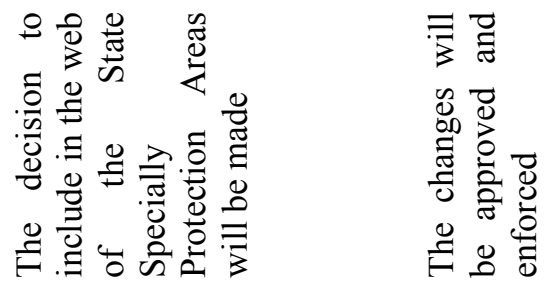

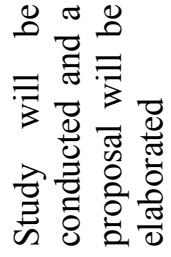

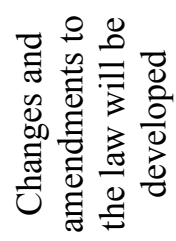

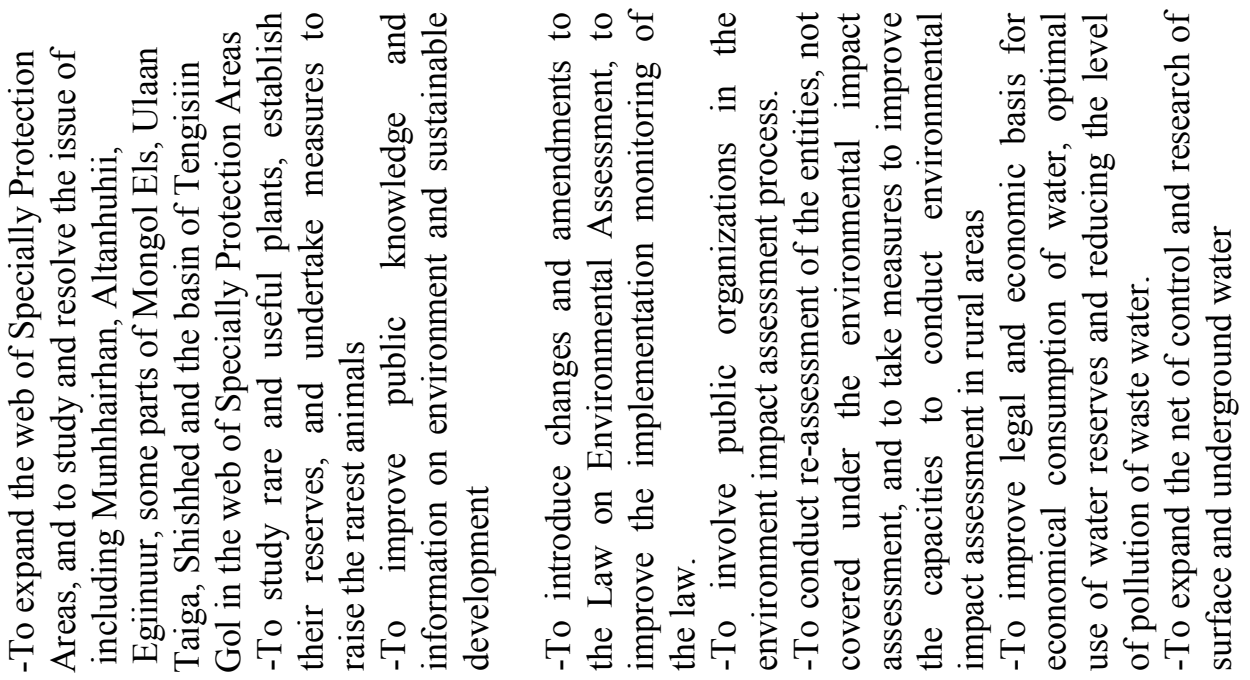

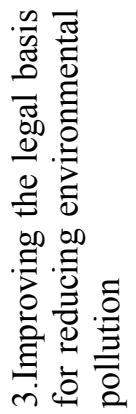



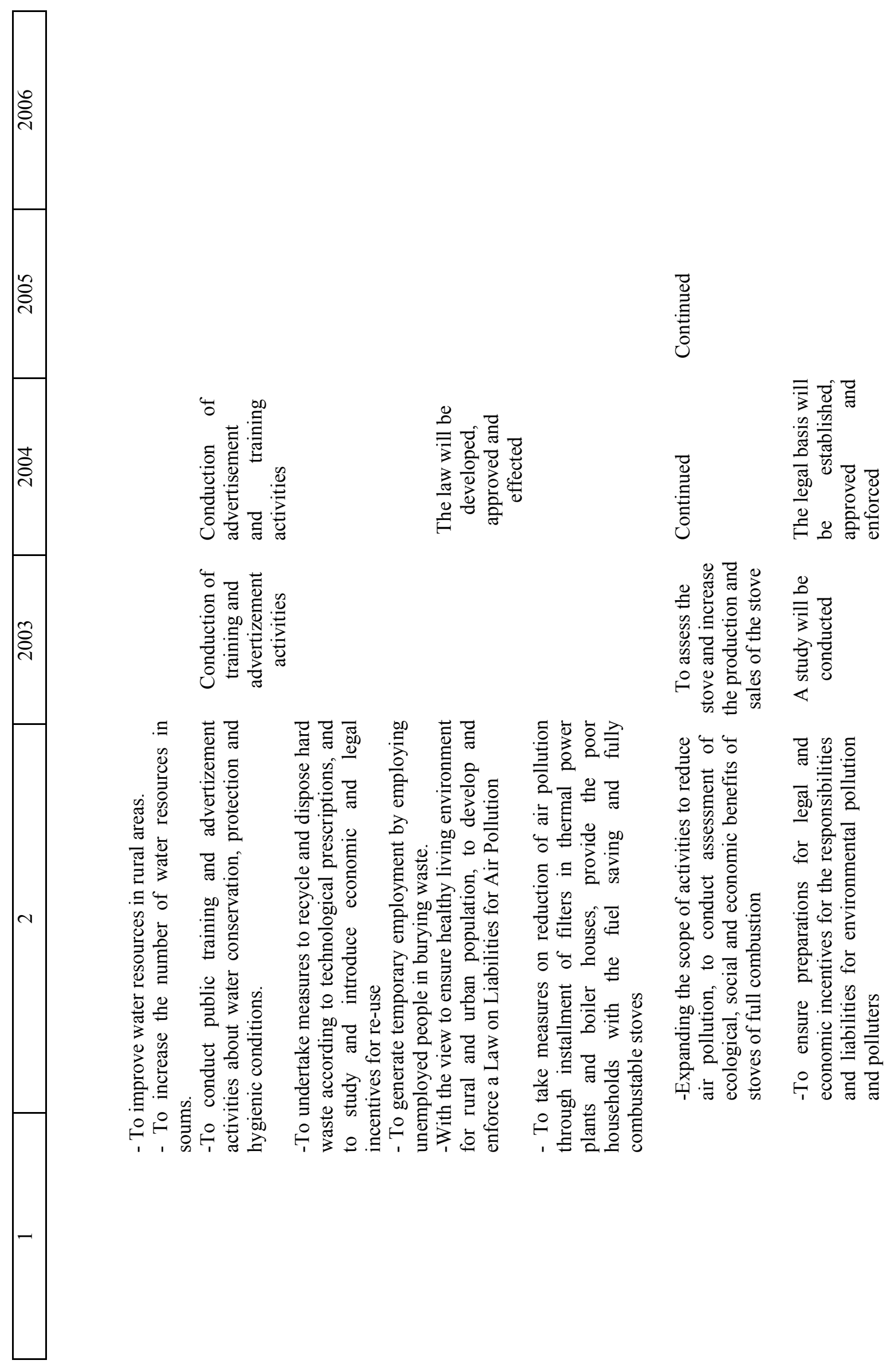

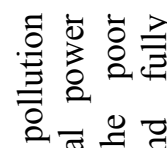

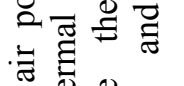

त है

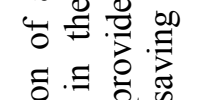

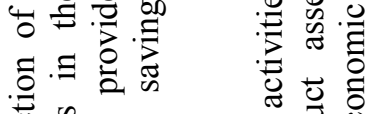

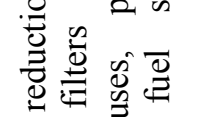

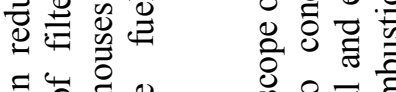

뚱용

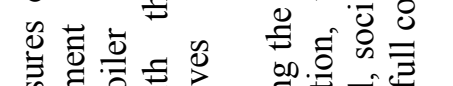

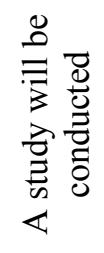

유

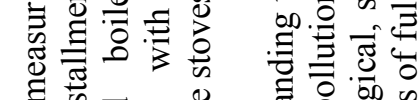

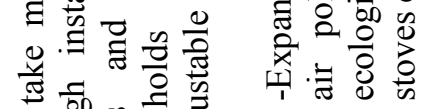

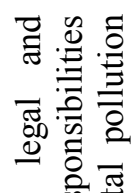

क्ष

电

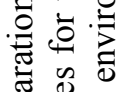

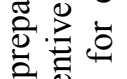

过

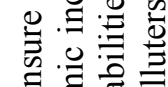

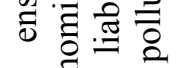

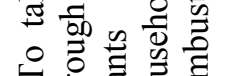

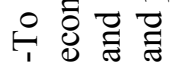




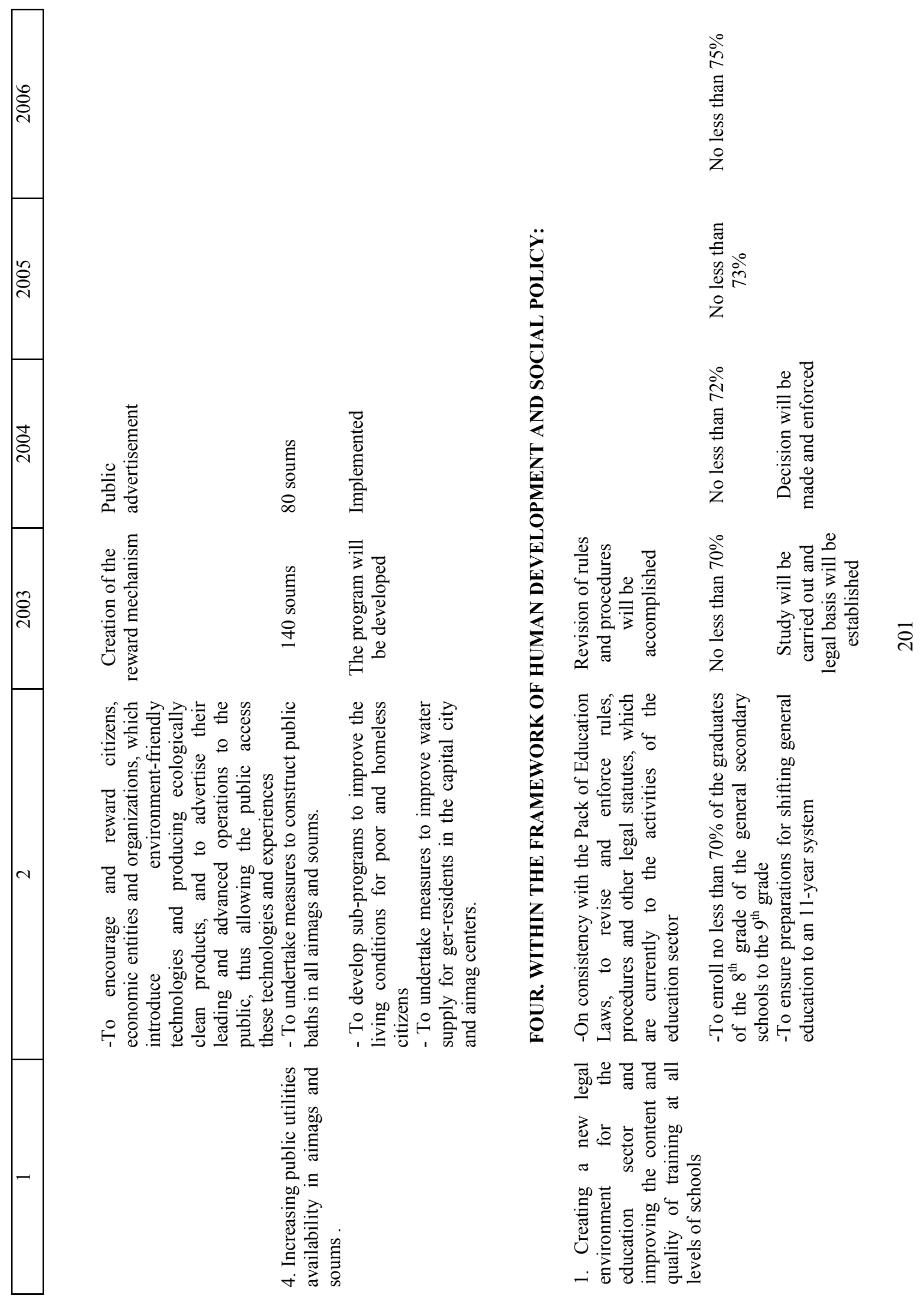




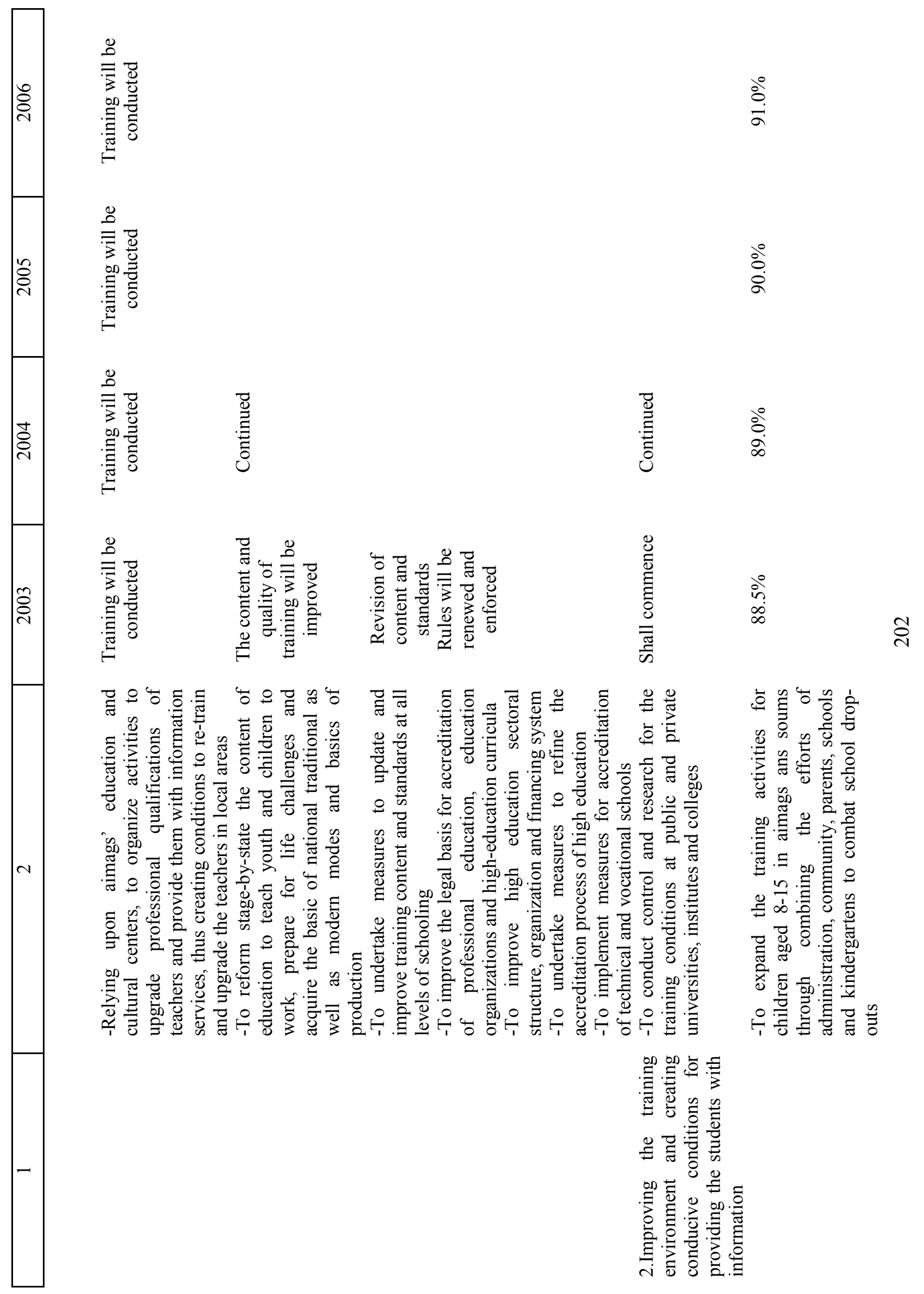




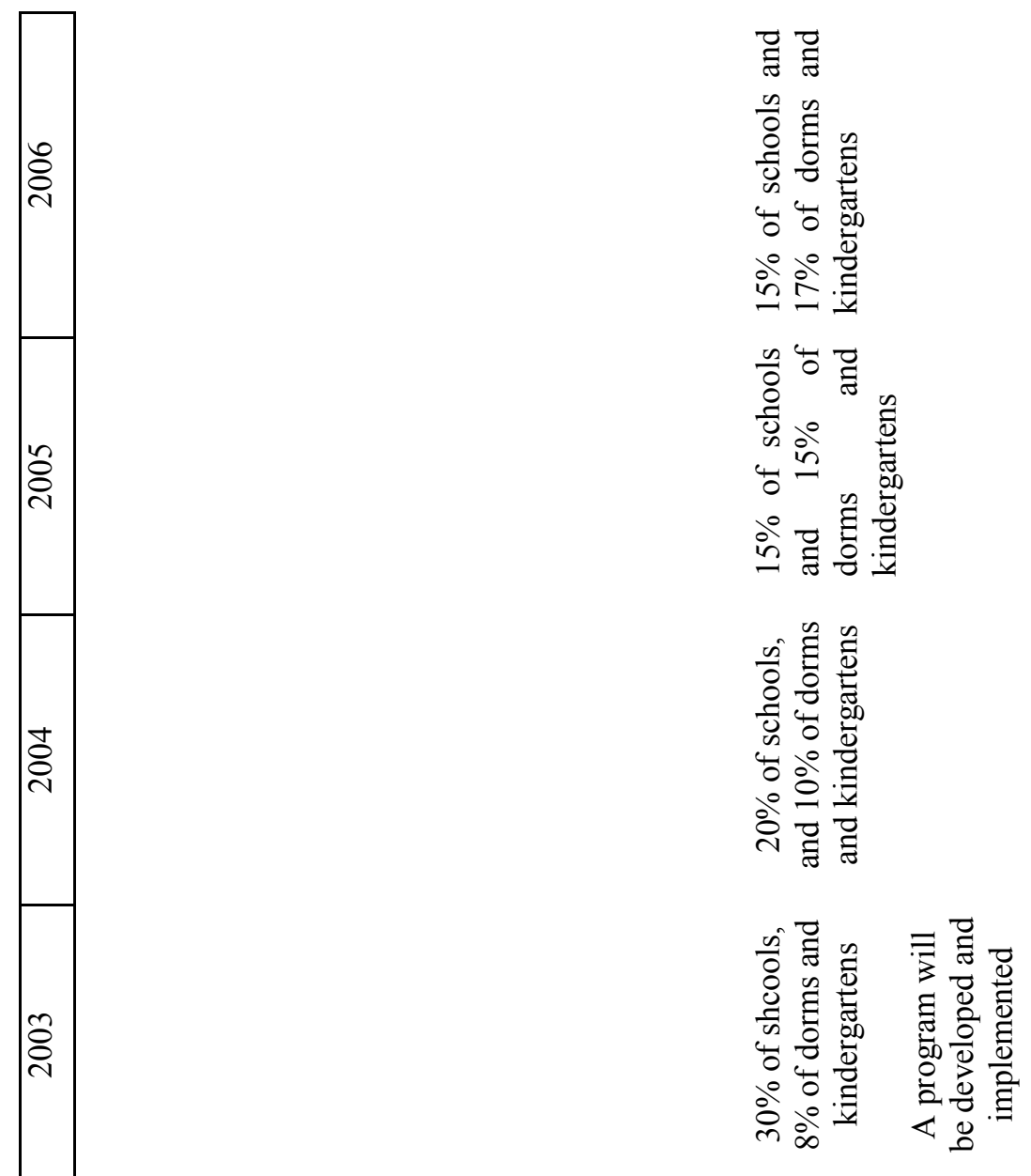

ชิ

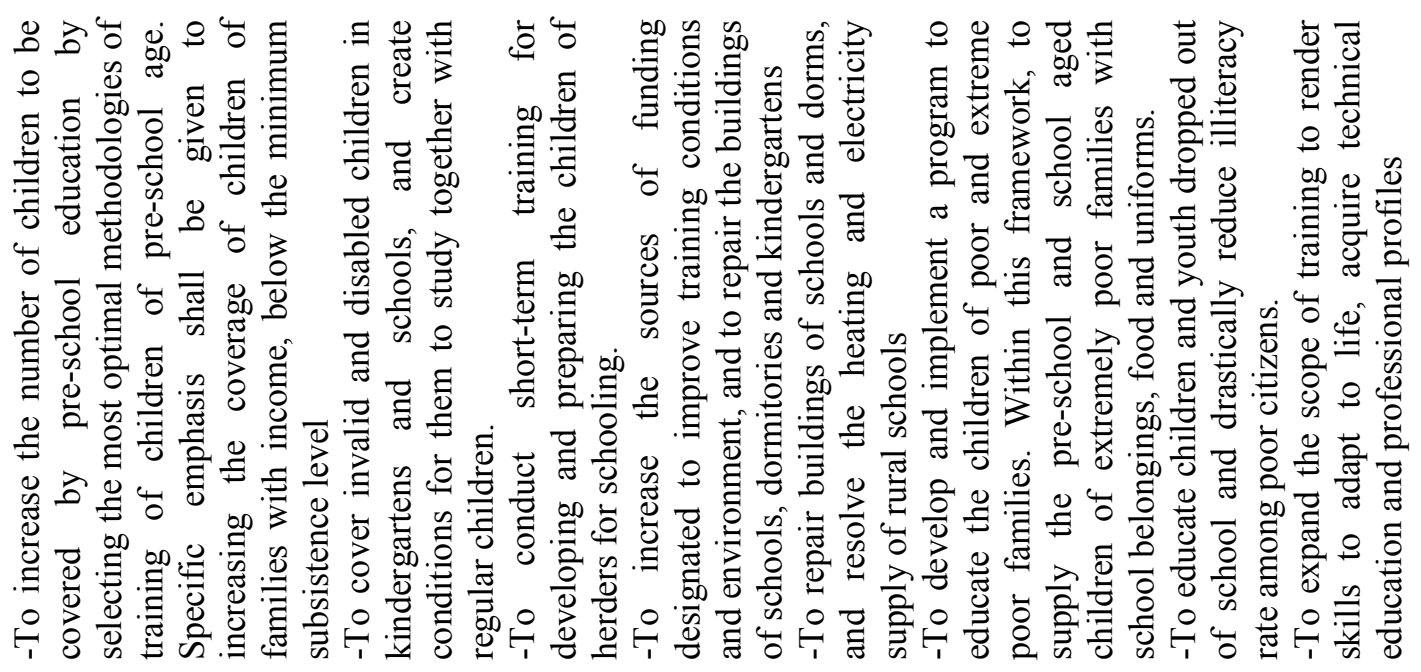




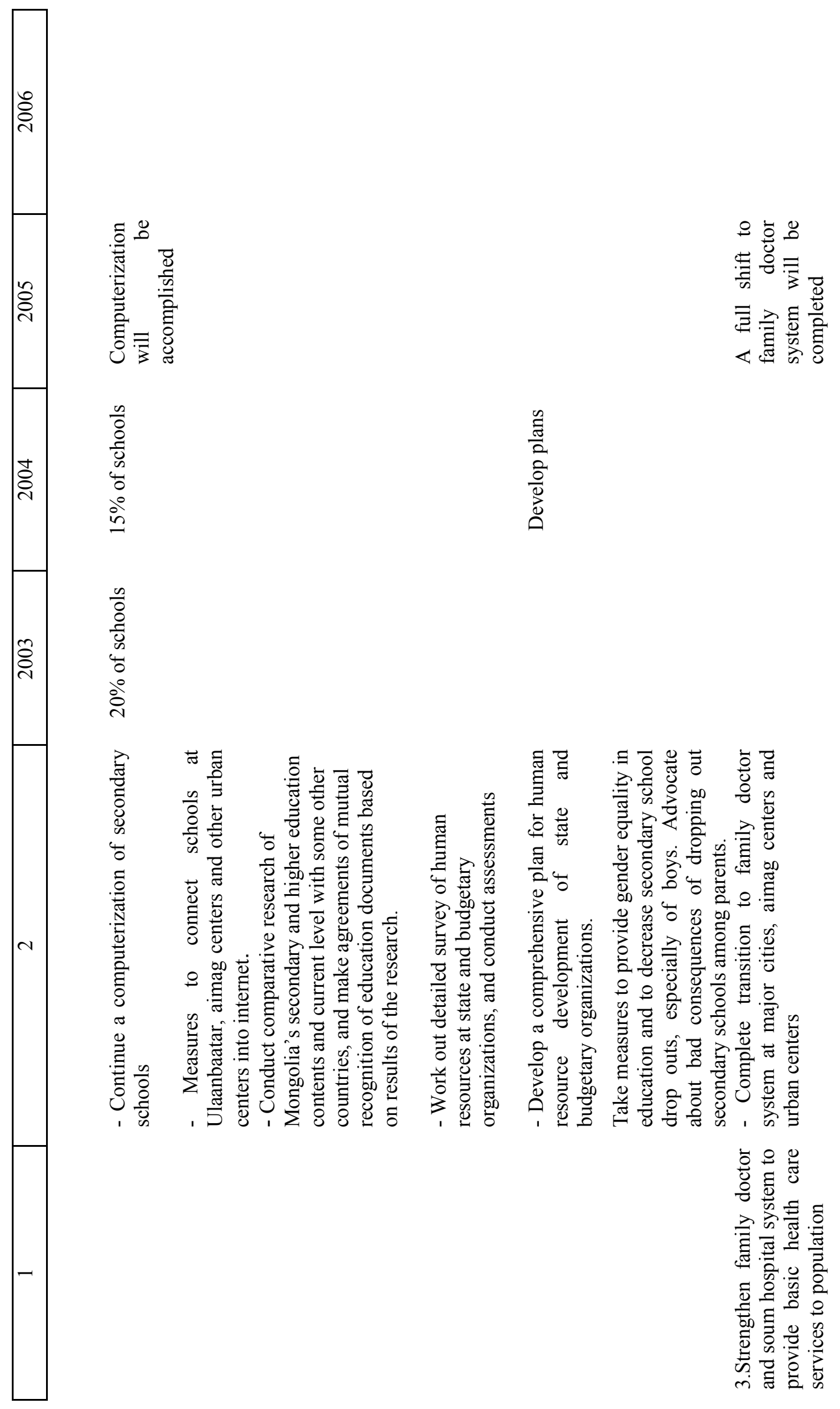

옹 


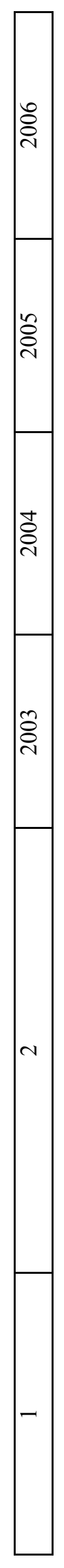

$\frac{0}{0}$
$\frac{0}{0}$
$\frac{1}{2}$
$N$

$\frac{0}{0}$
$\frac{0}{3}$
0
0
0
0

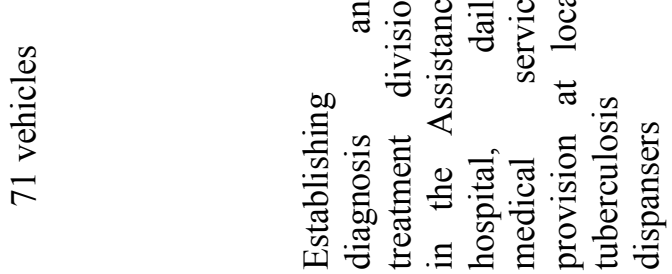

0
$\frac{0}{0}$
$\frac{1}{0}$
0
0
0

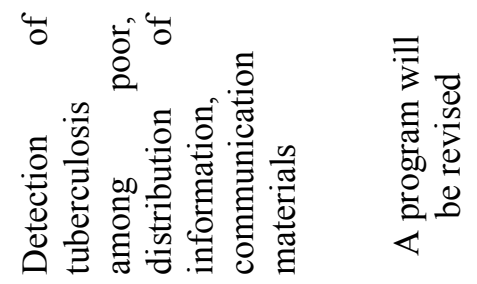

ำ

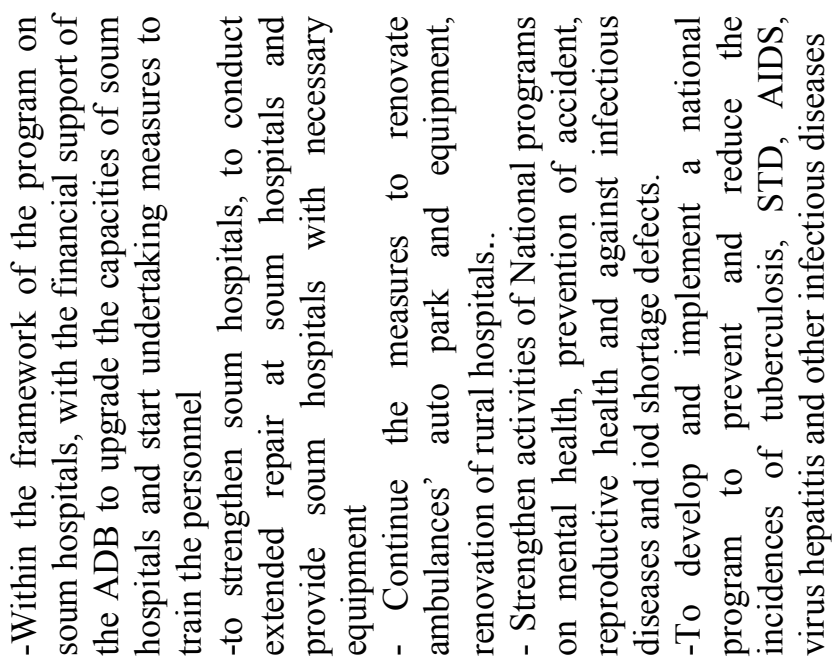

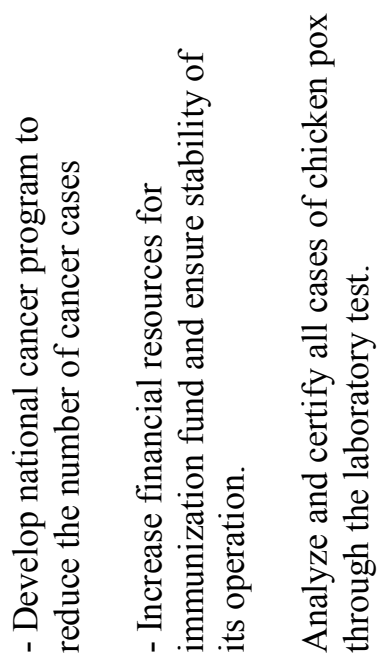

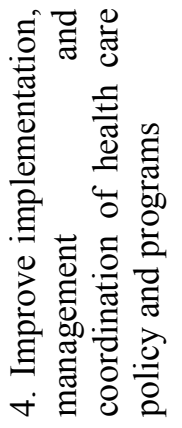




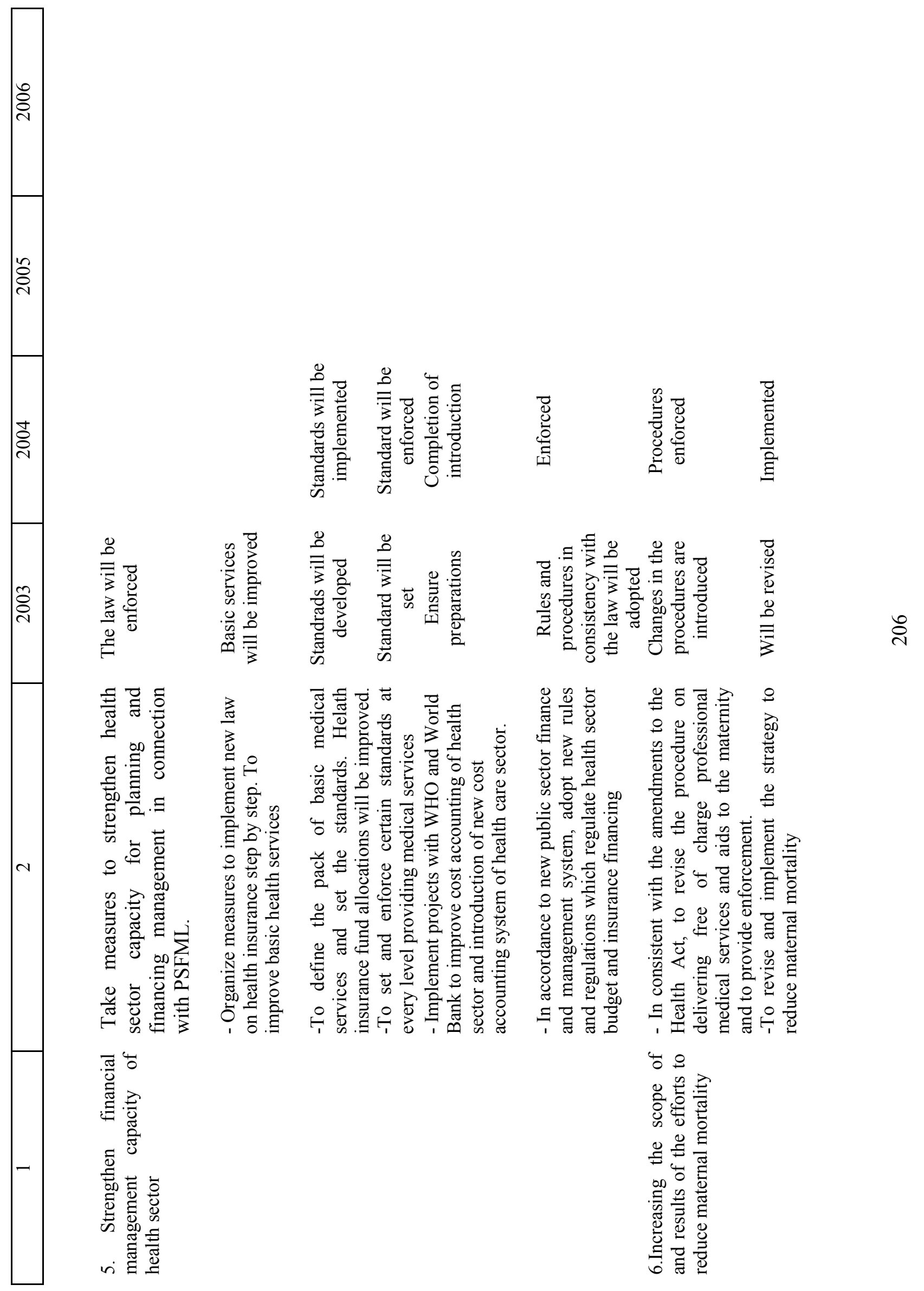




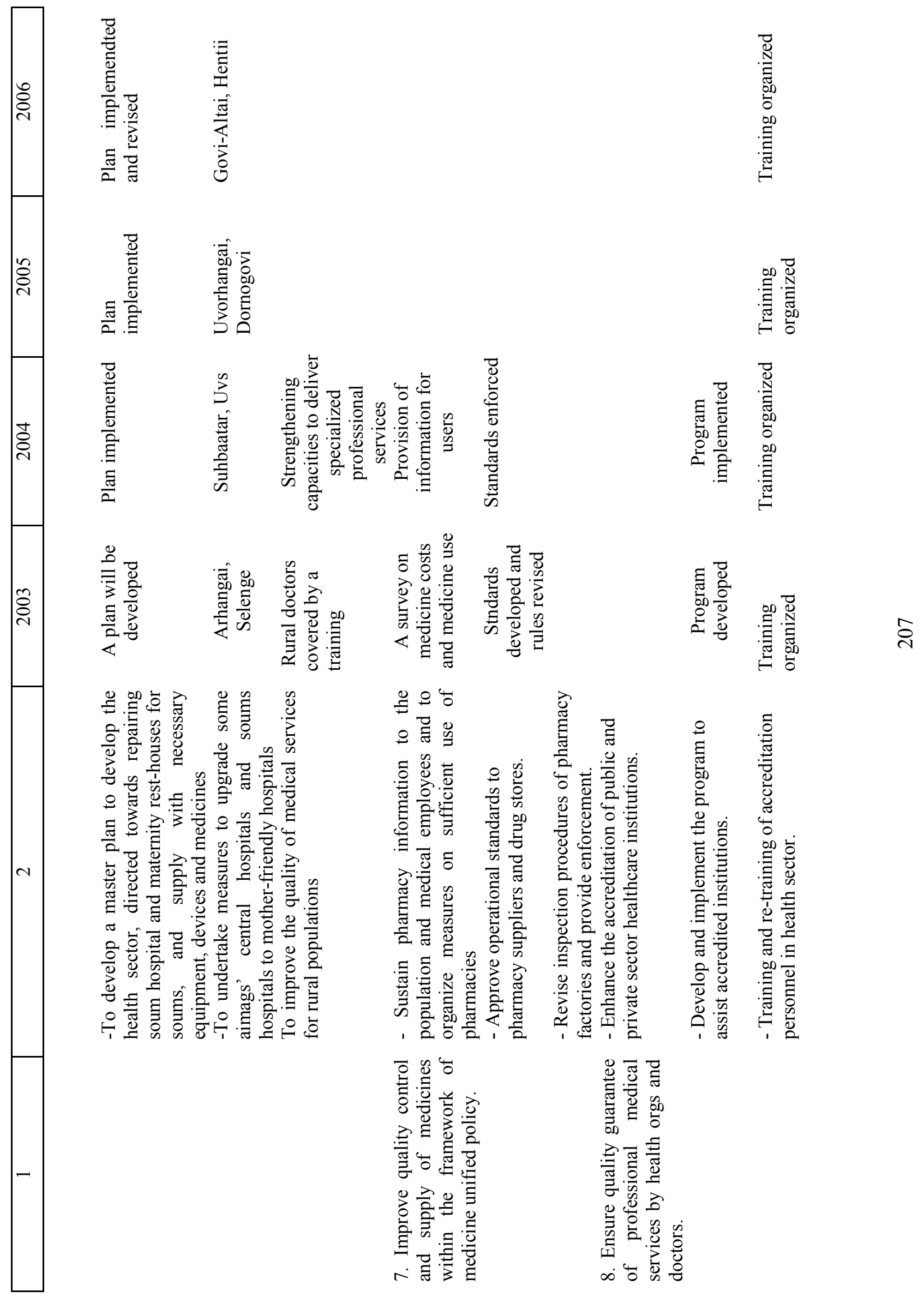




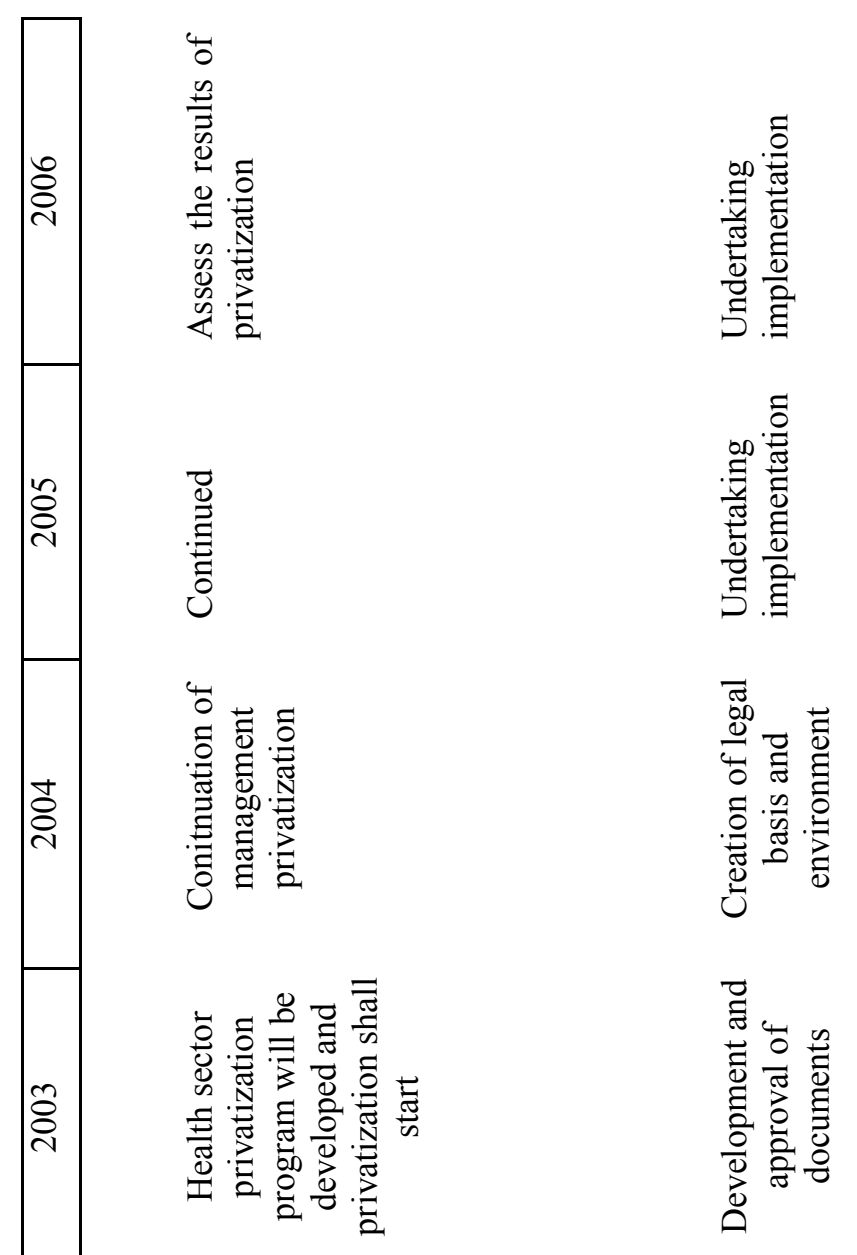

웅

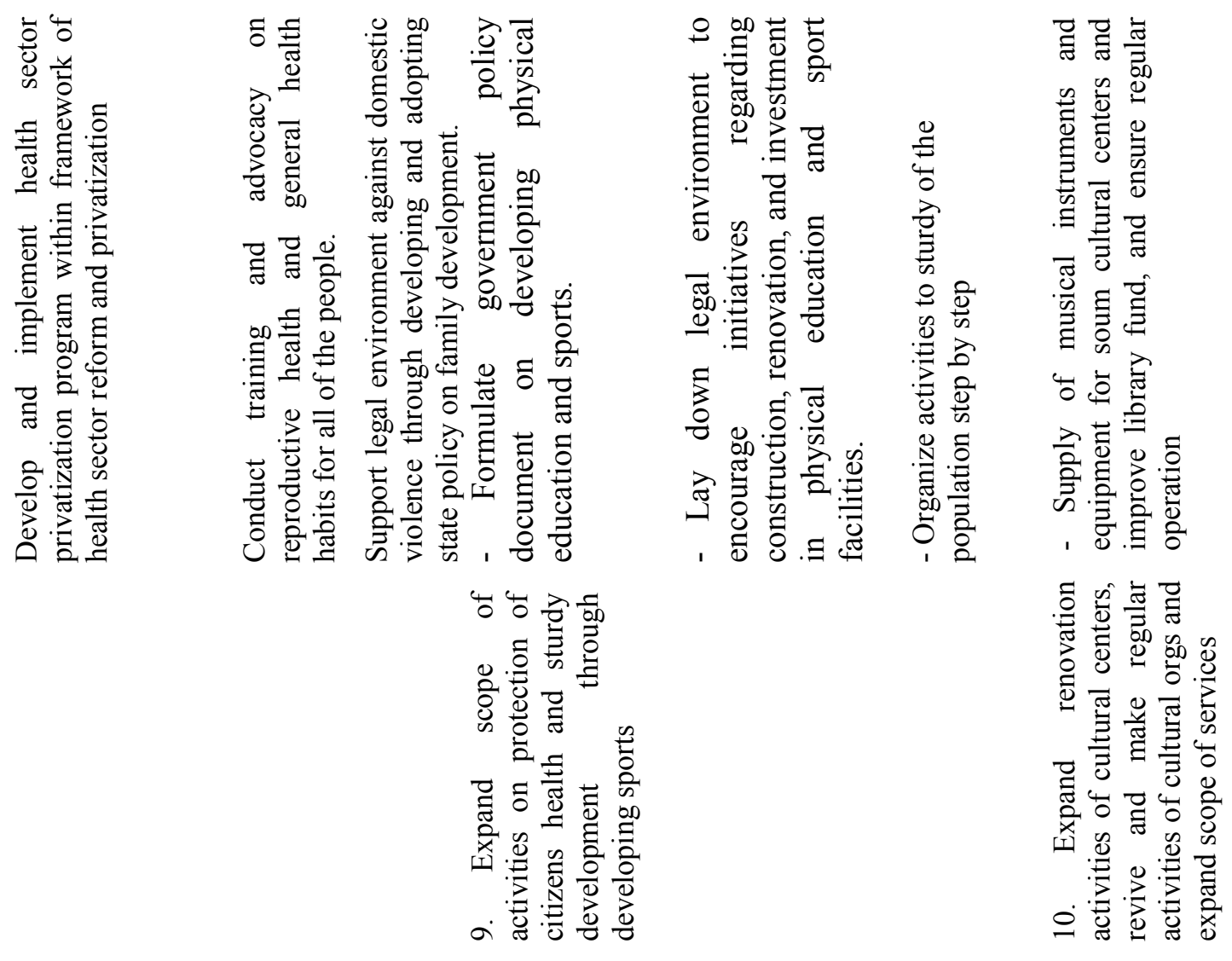




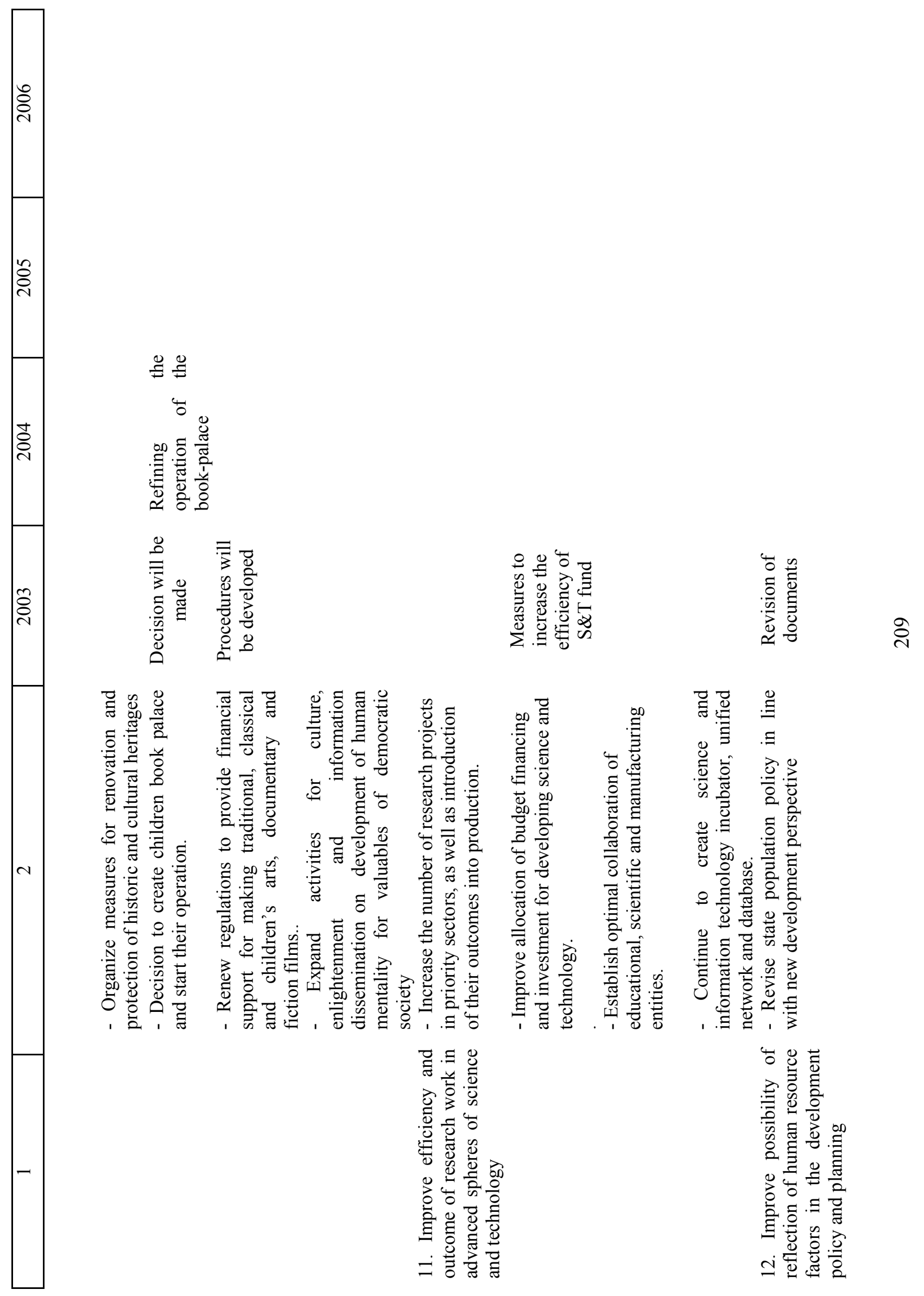



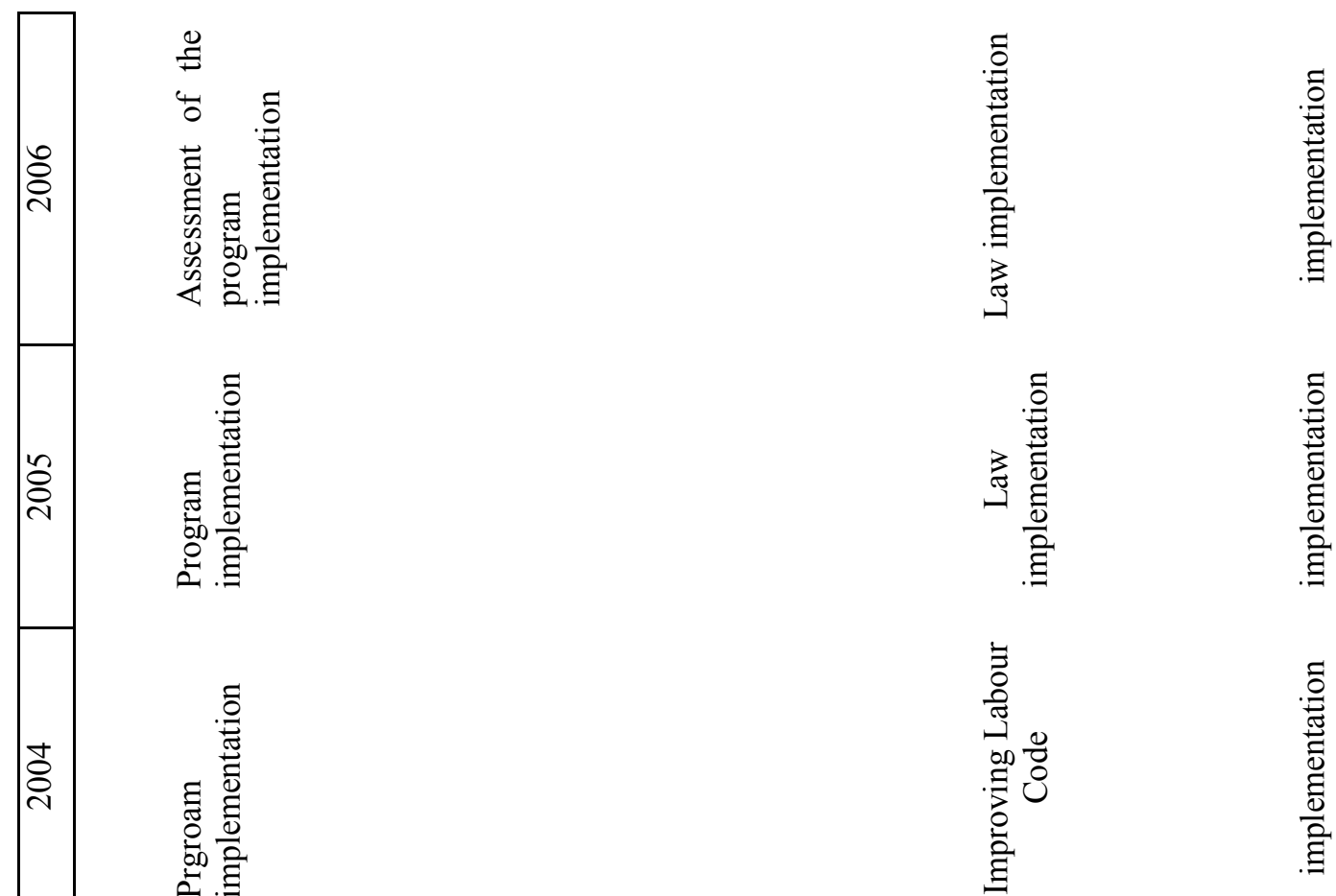

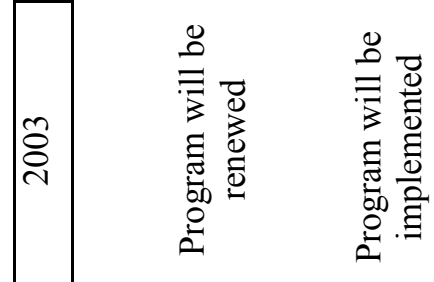
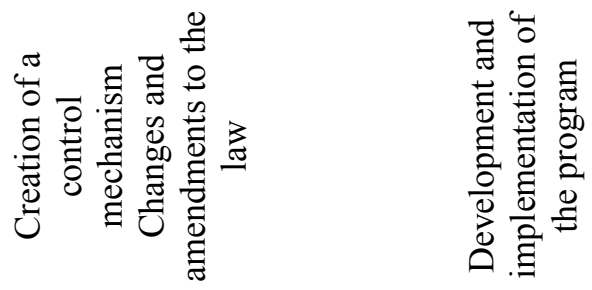

$\frac{0}{N}$
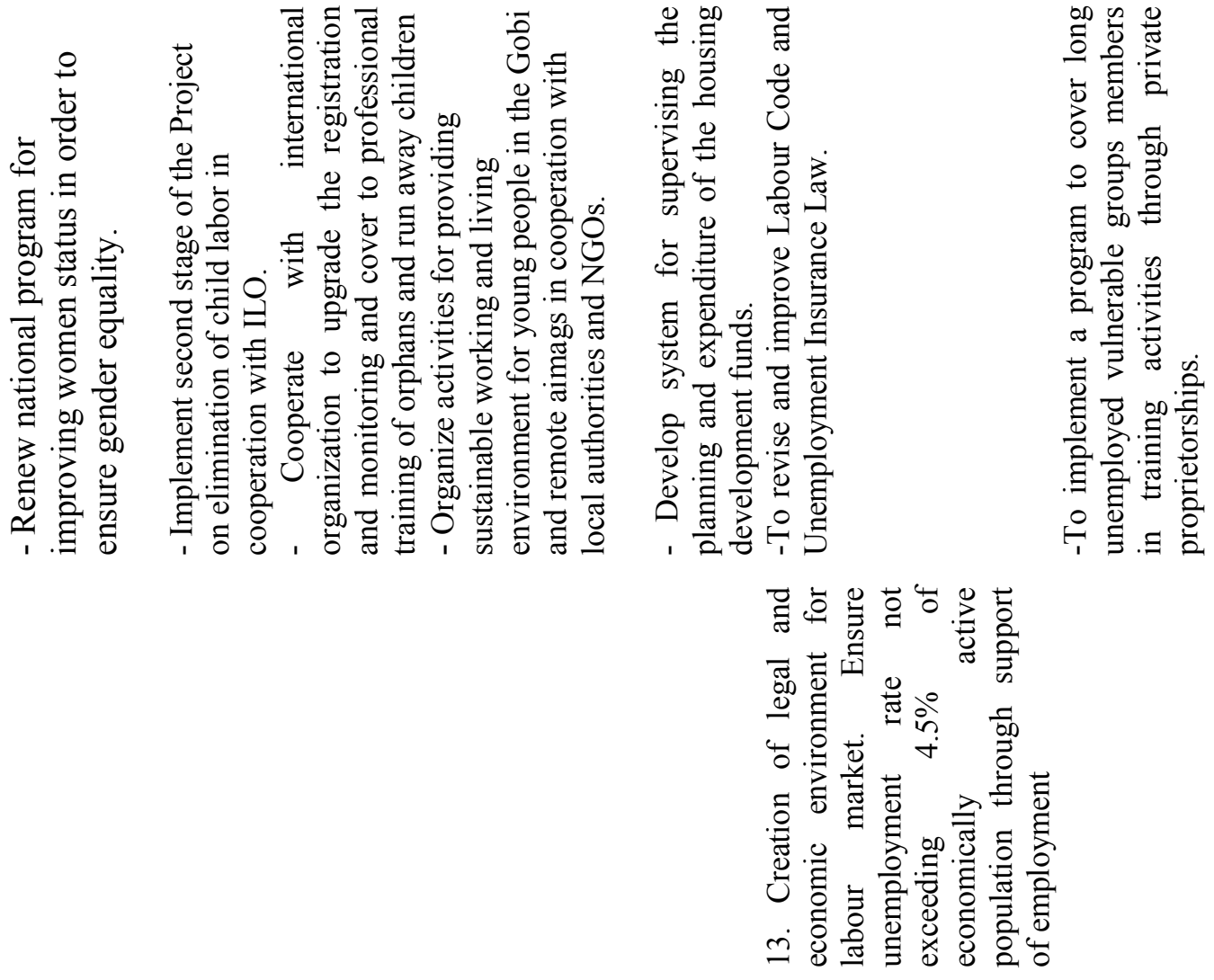


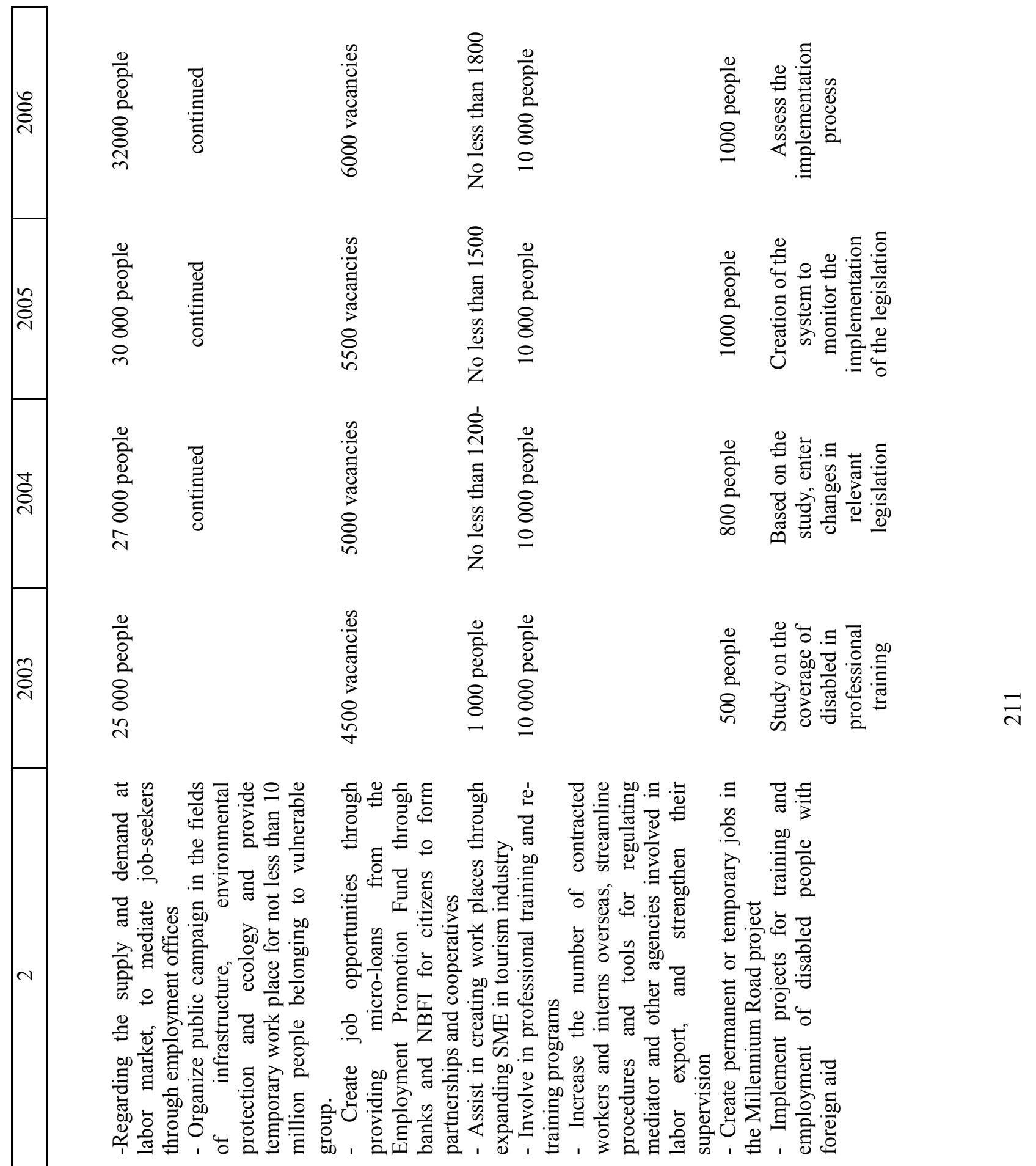




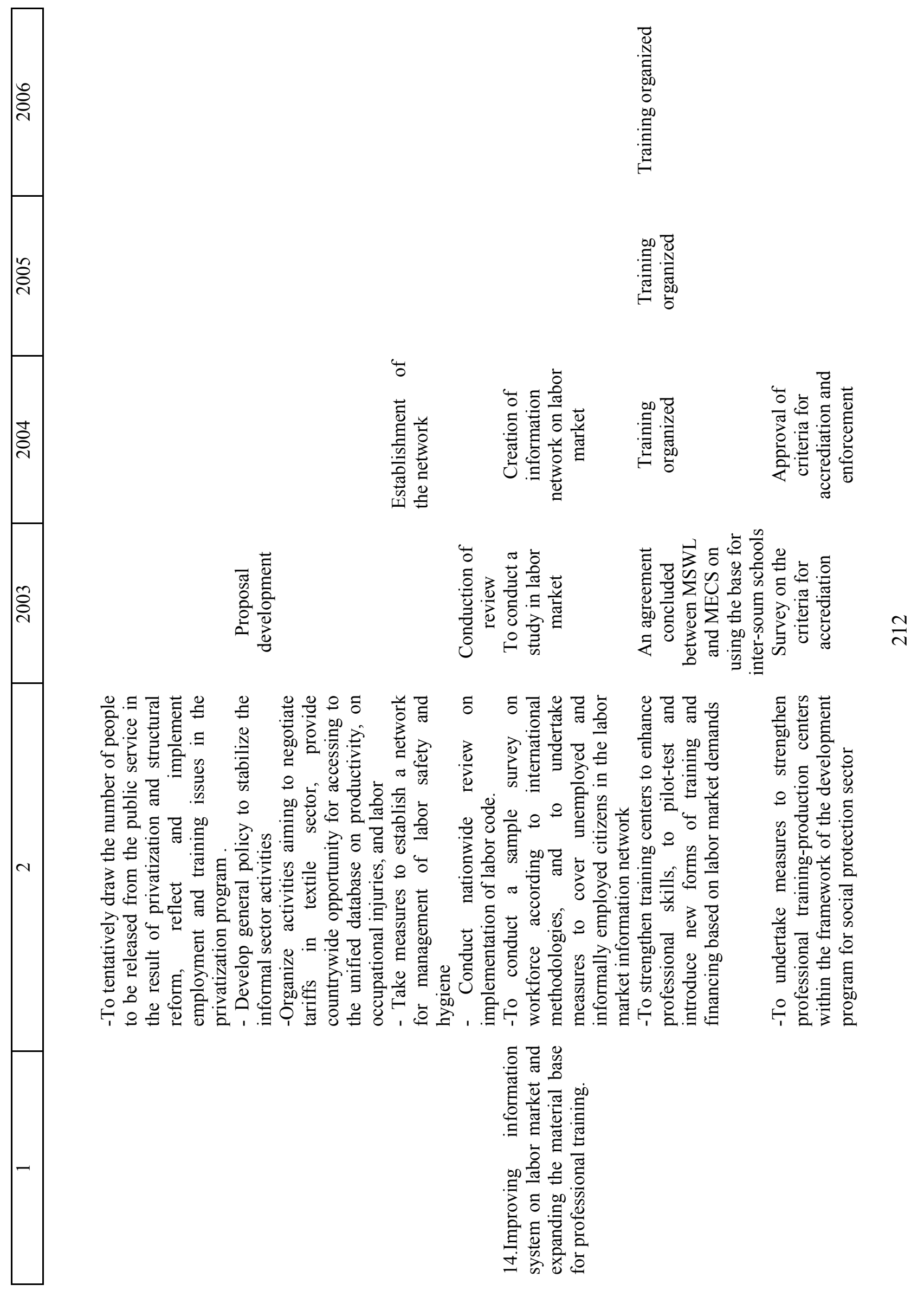




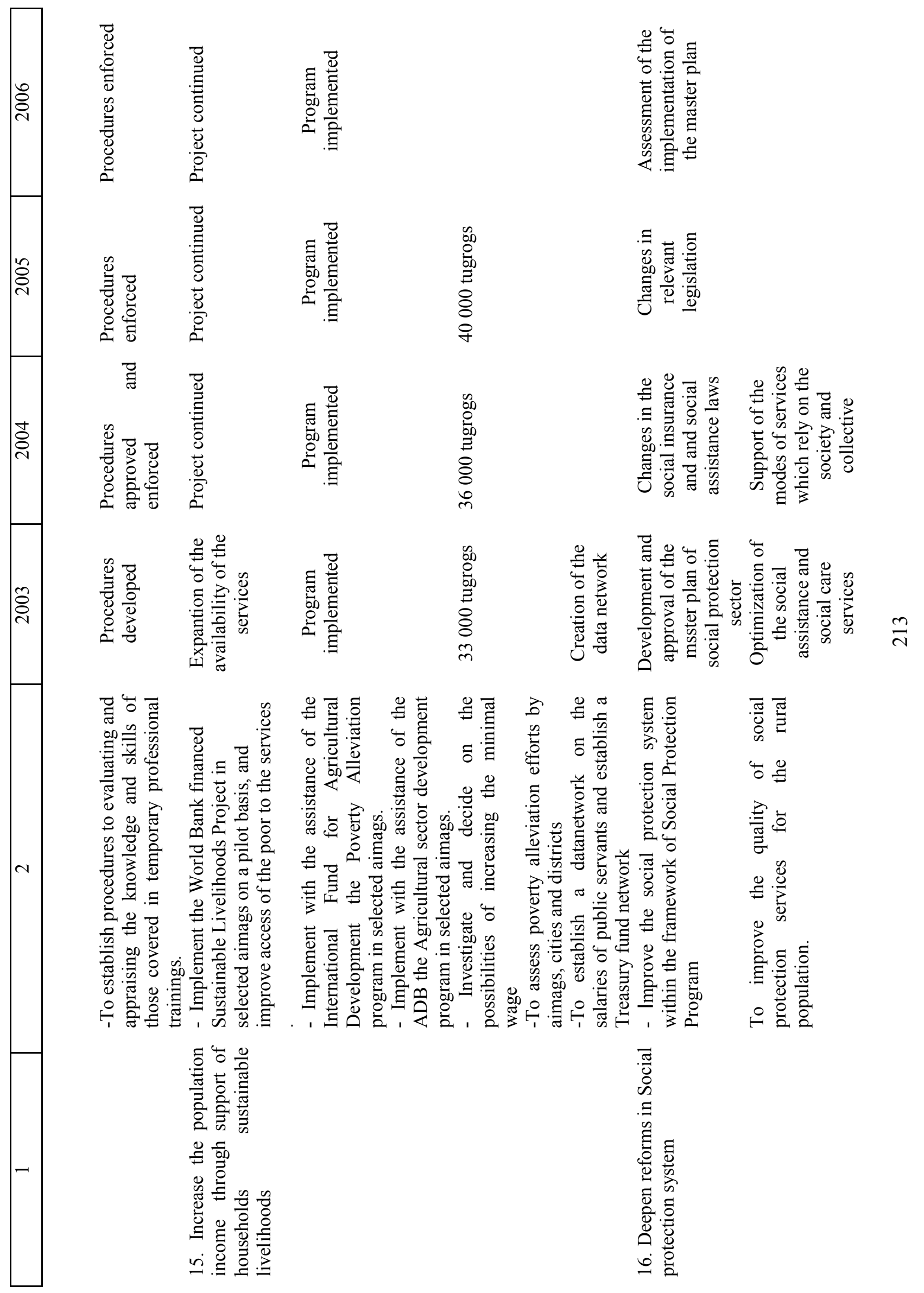




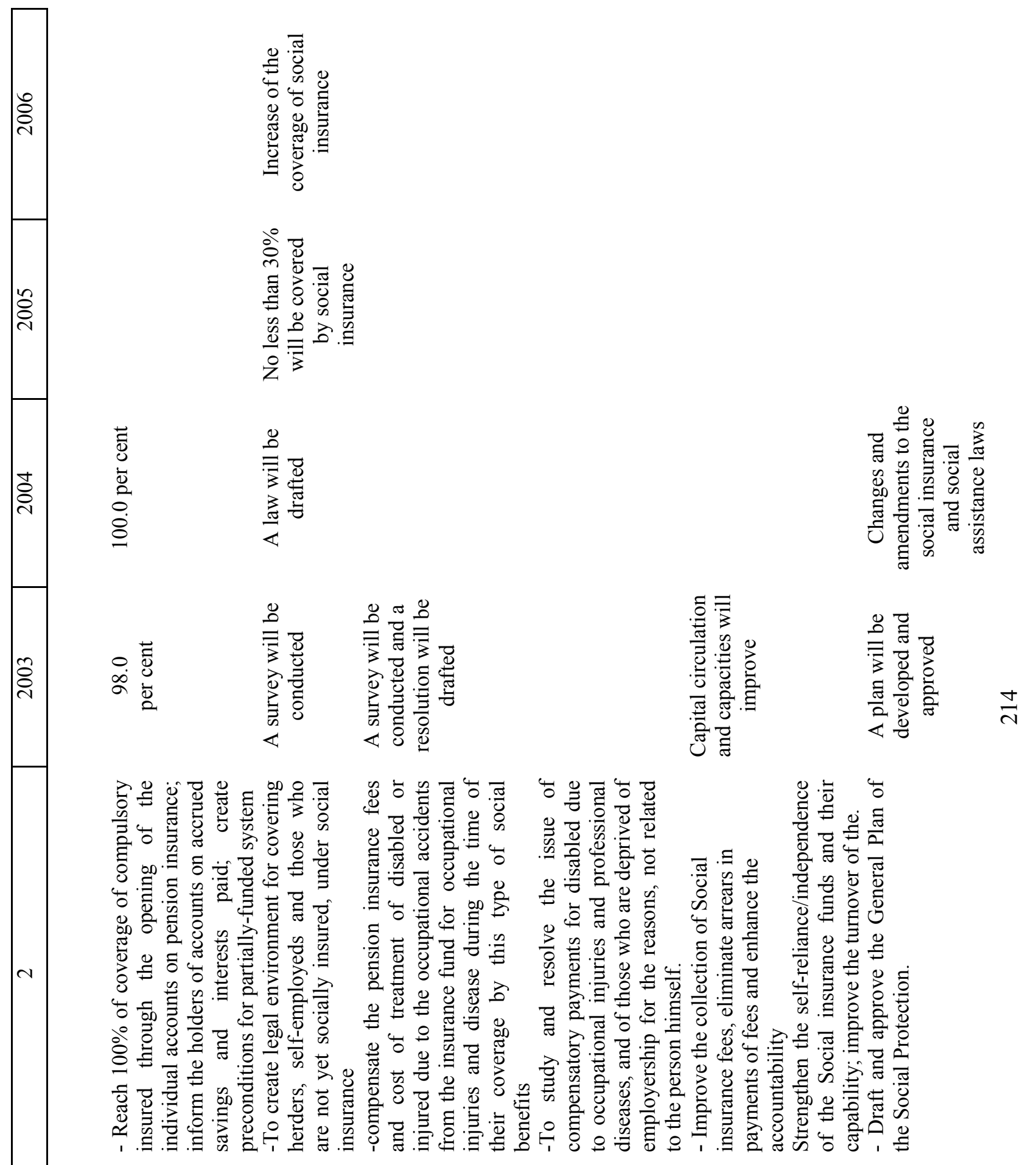



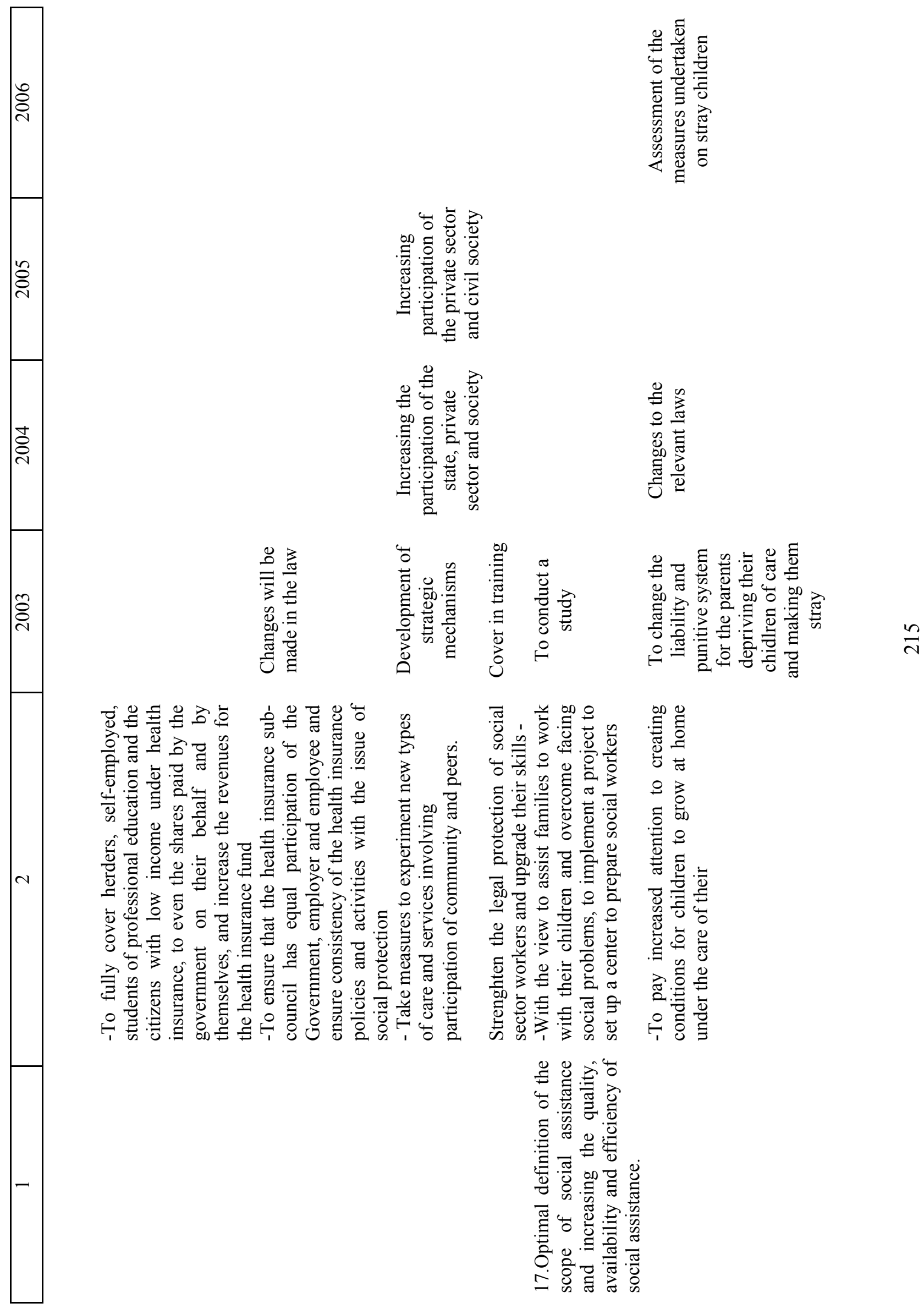

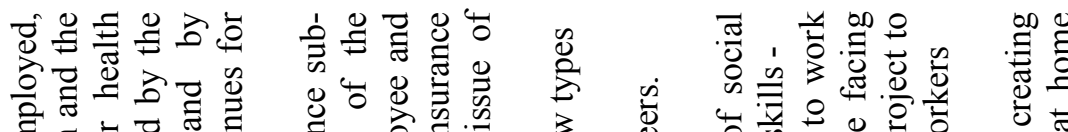

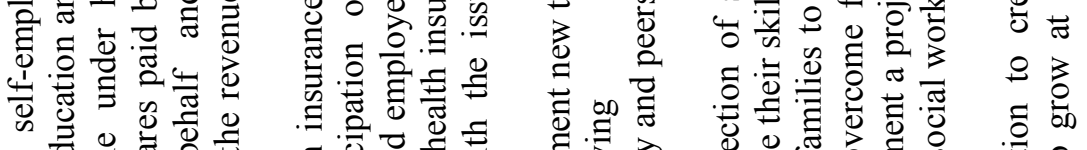
क्ञ

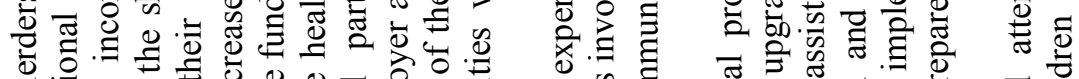

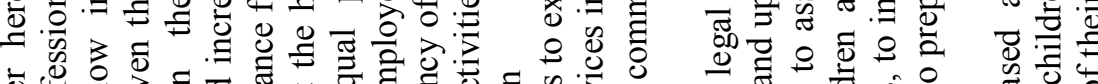

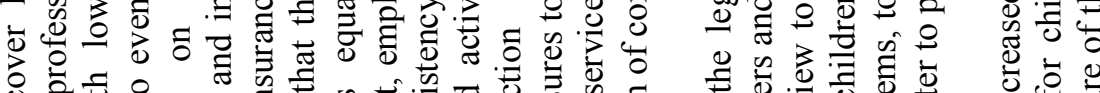

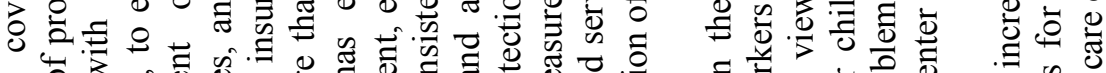

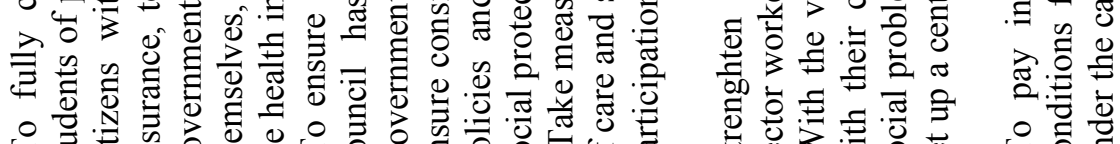

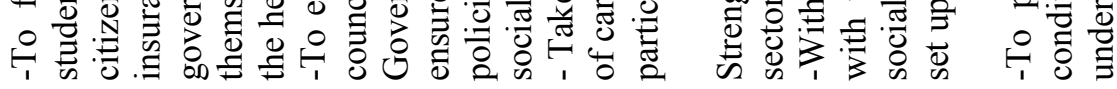

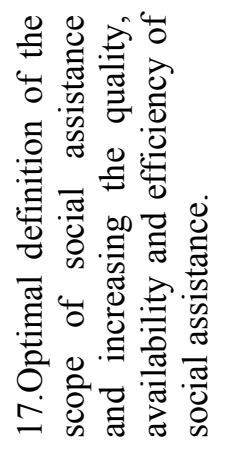




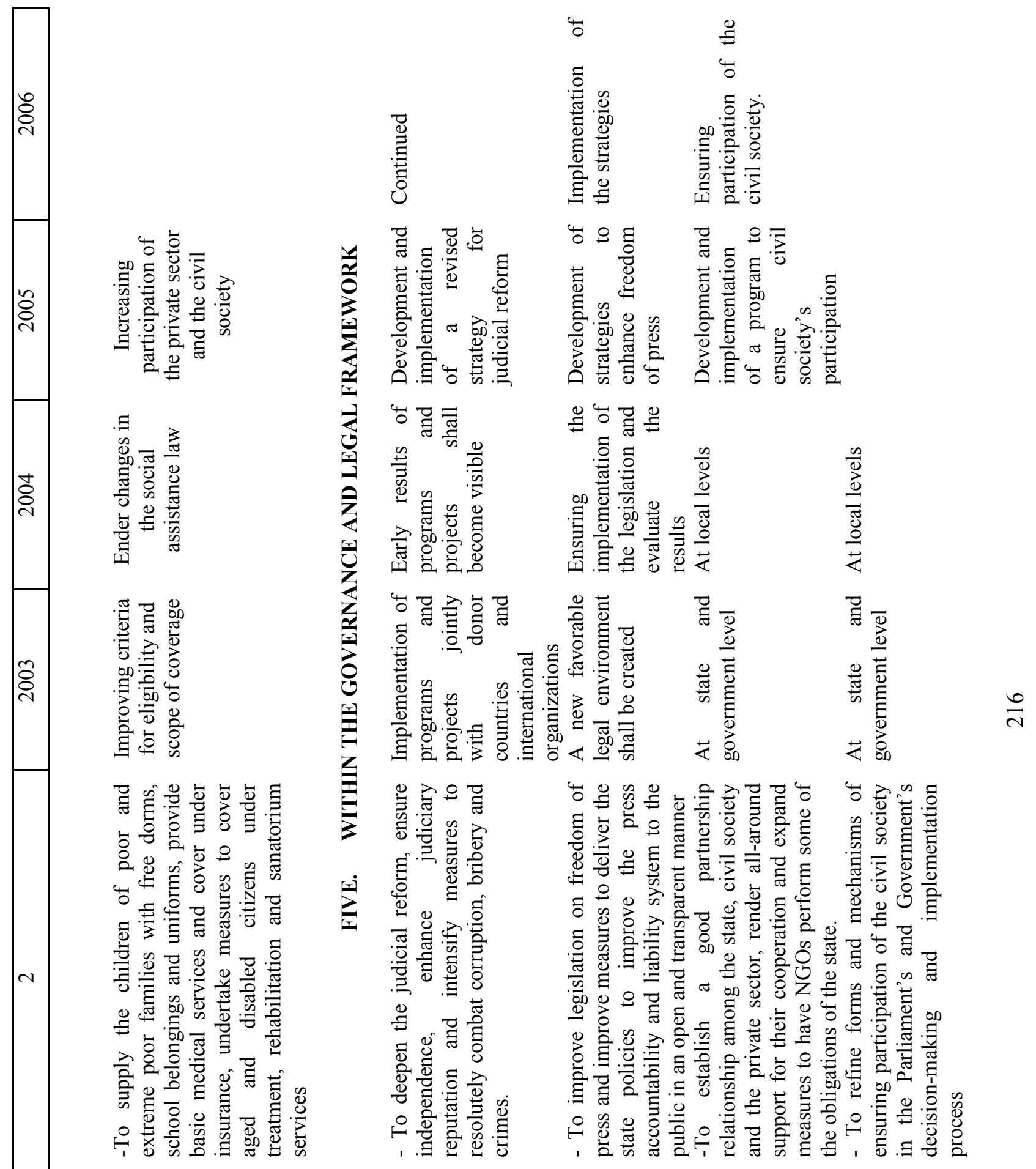




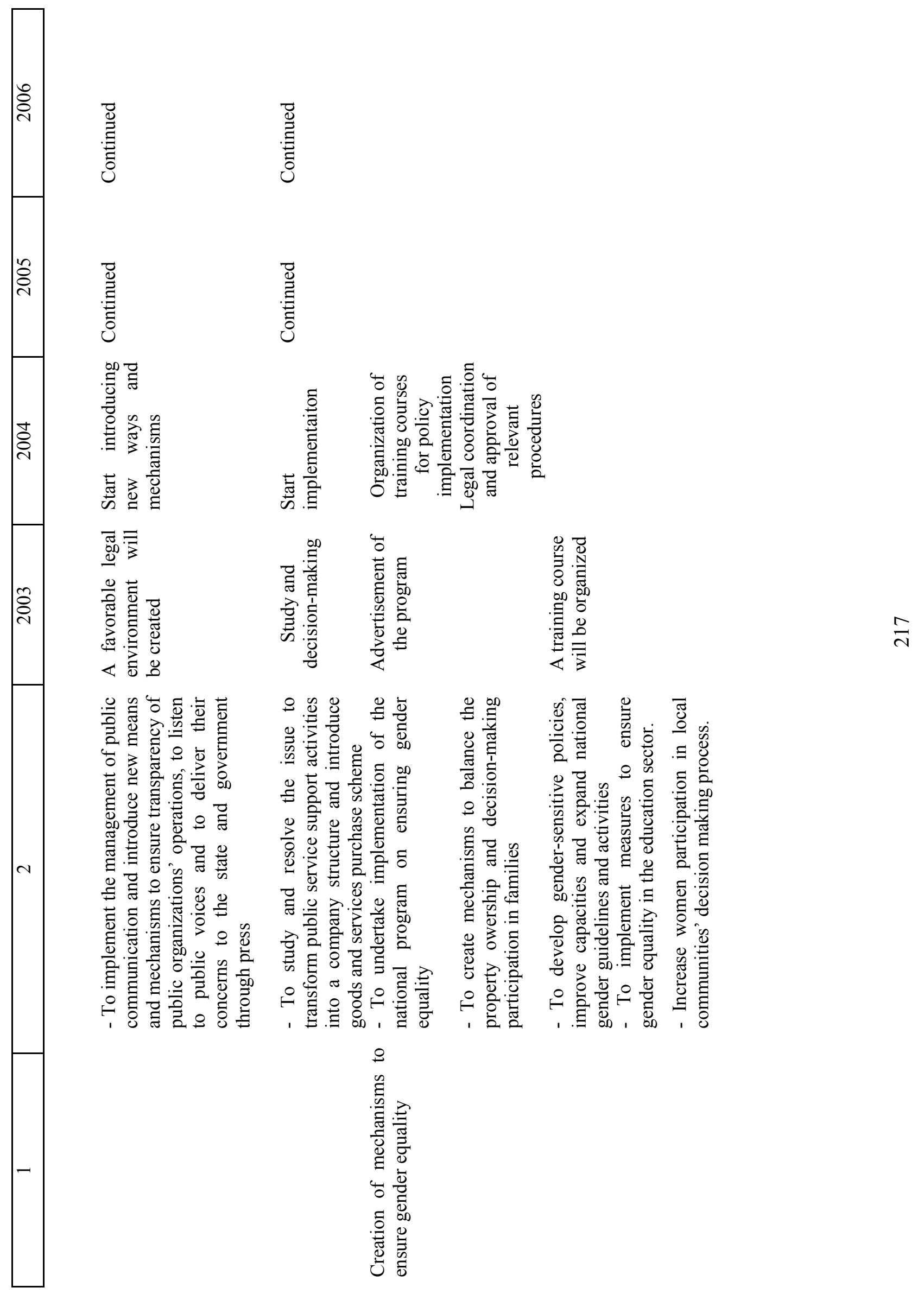




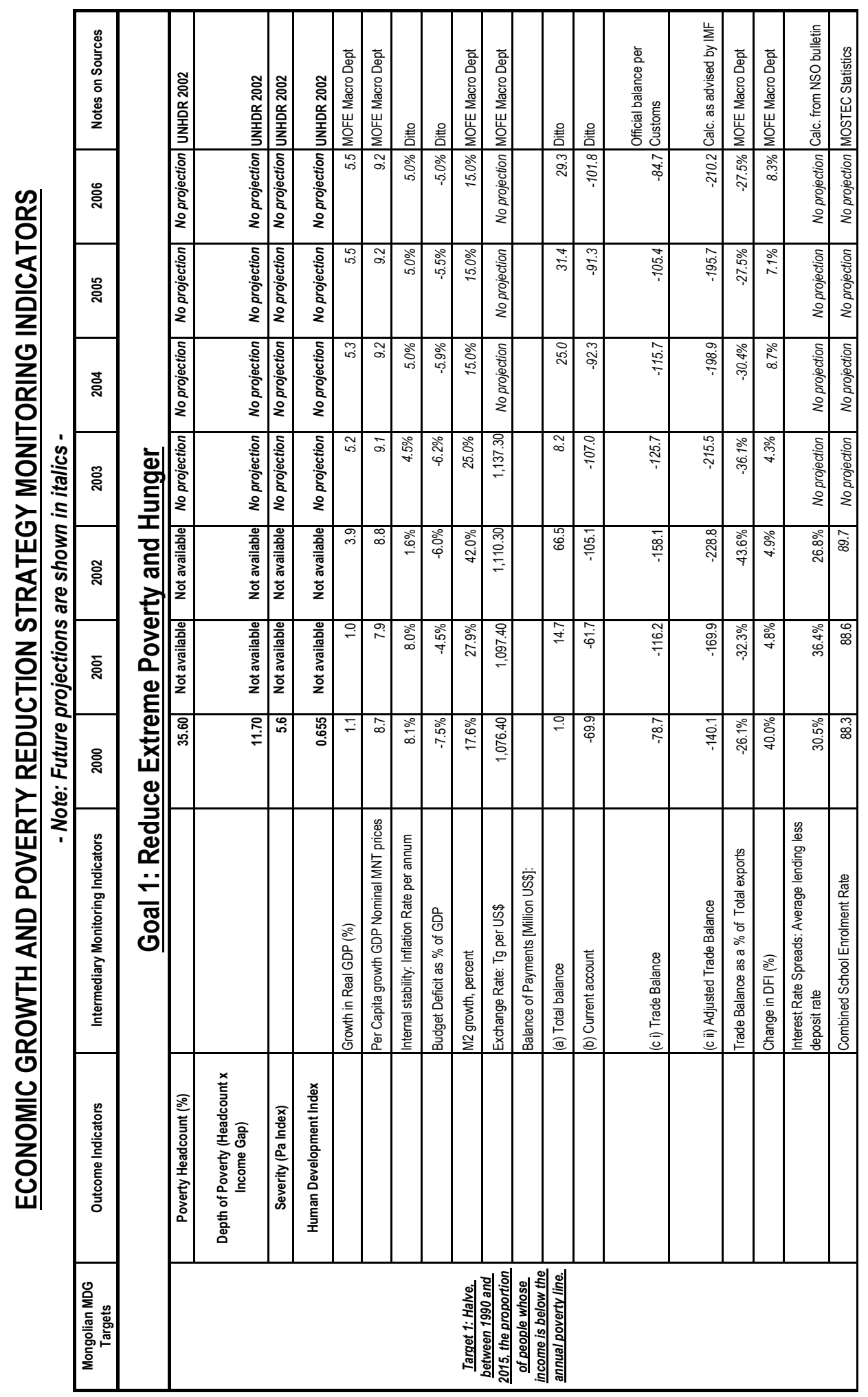




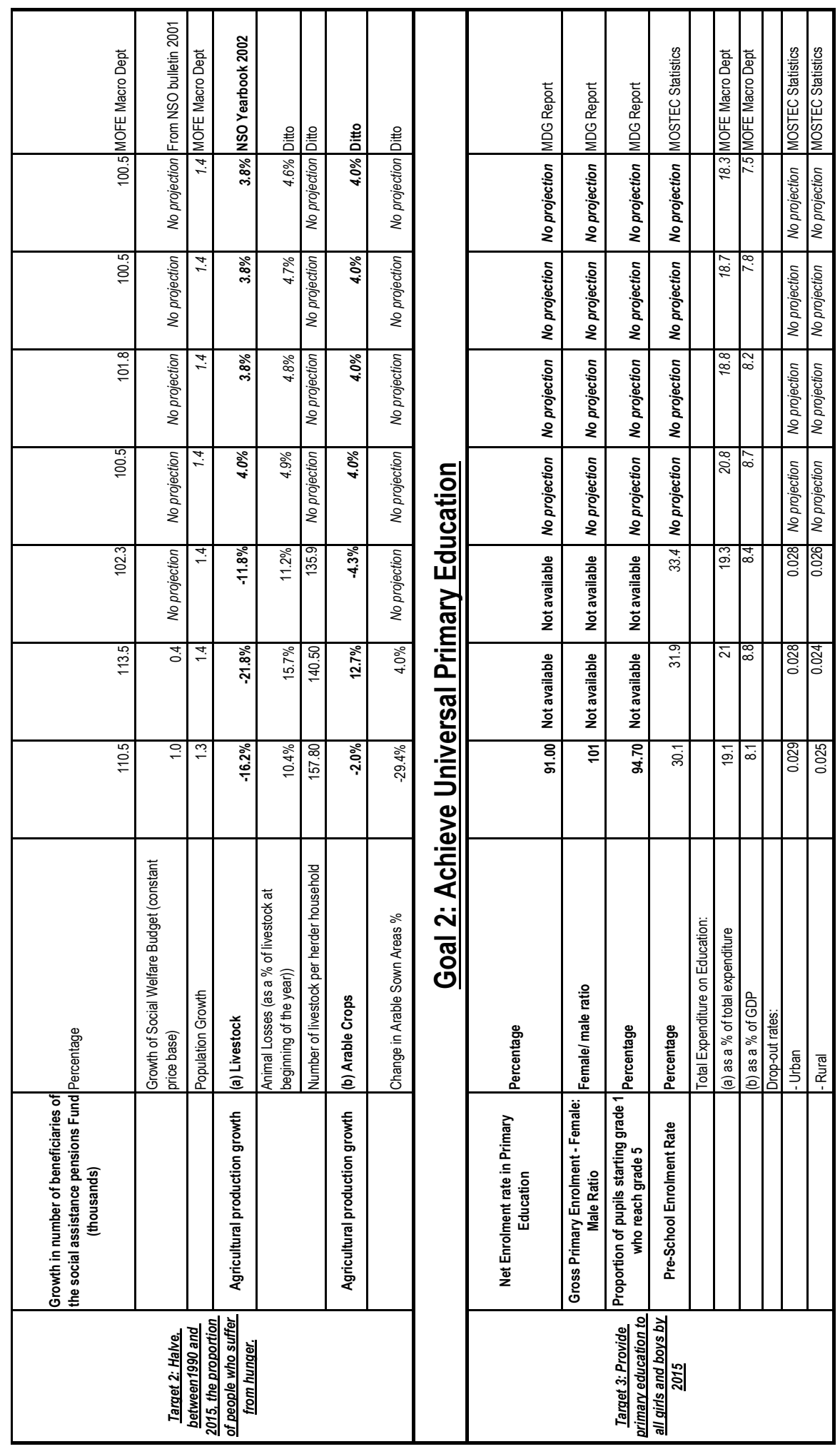




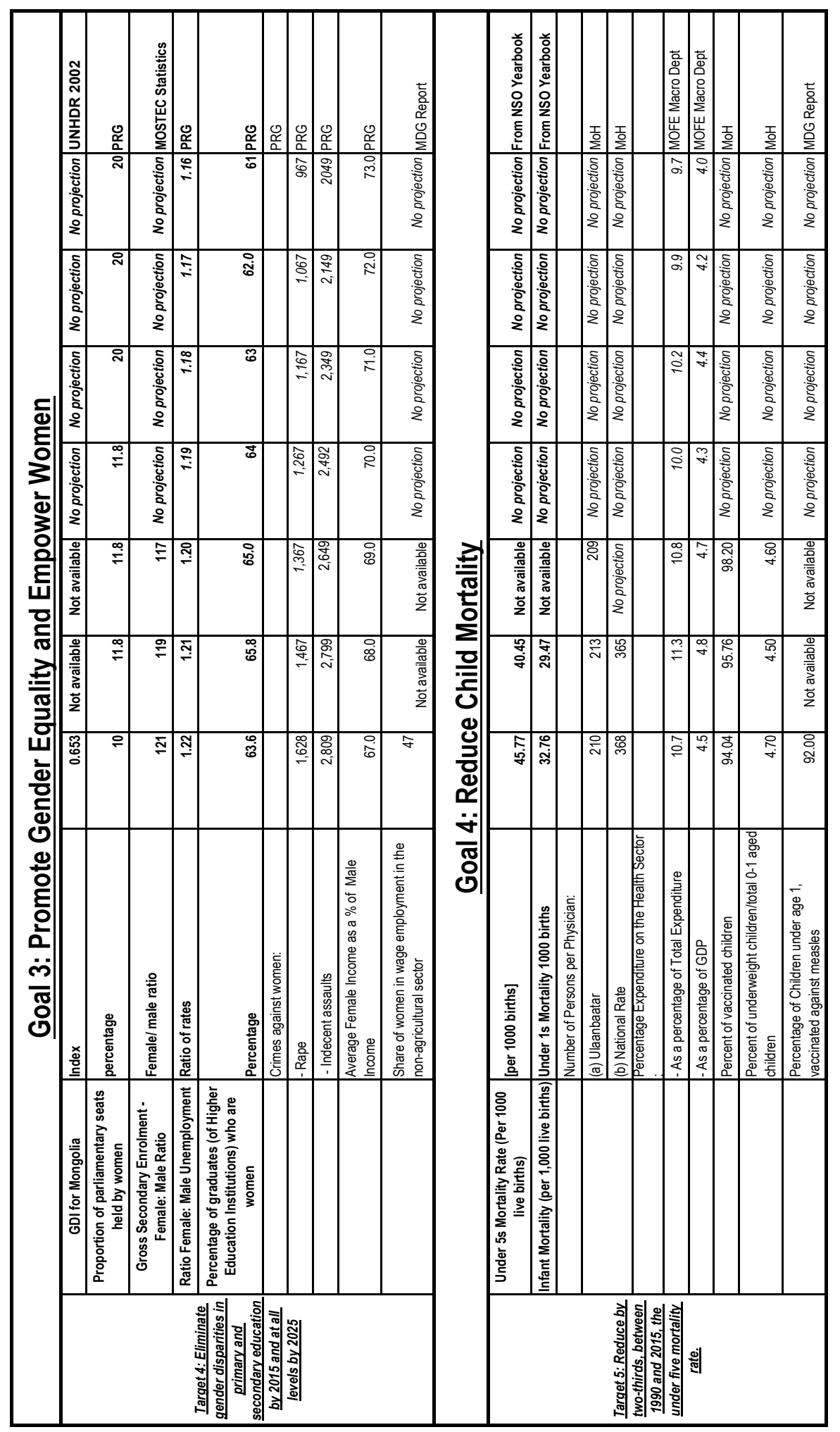




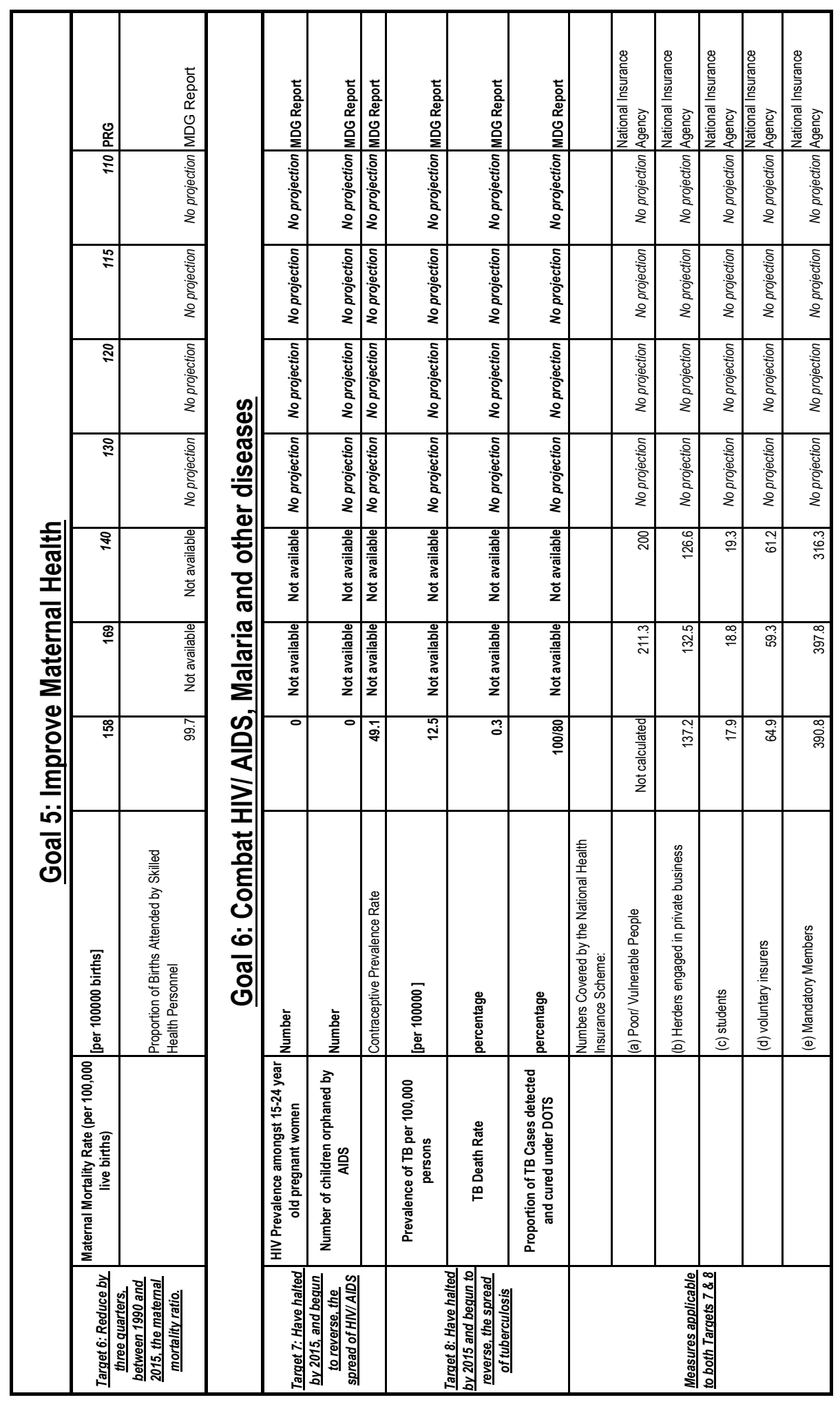




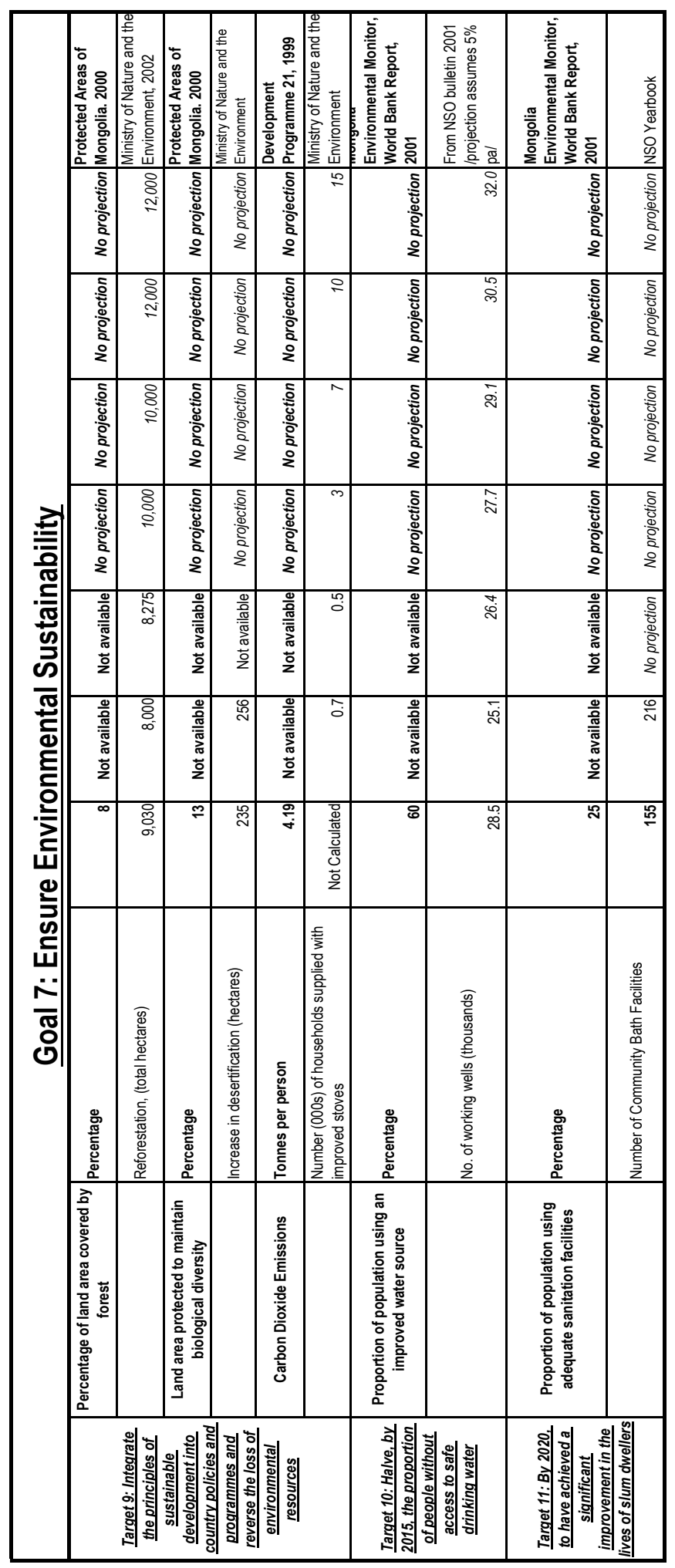




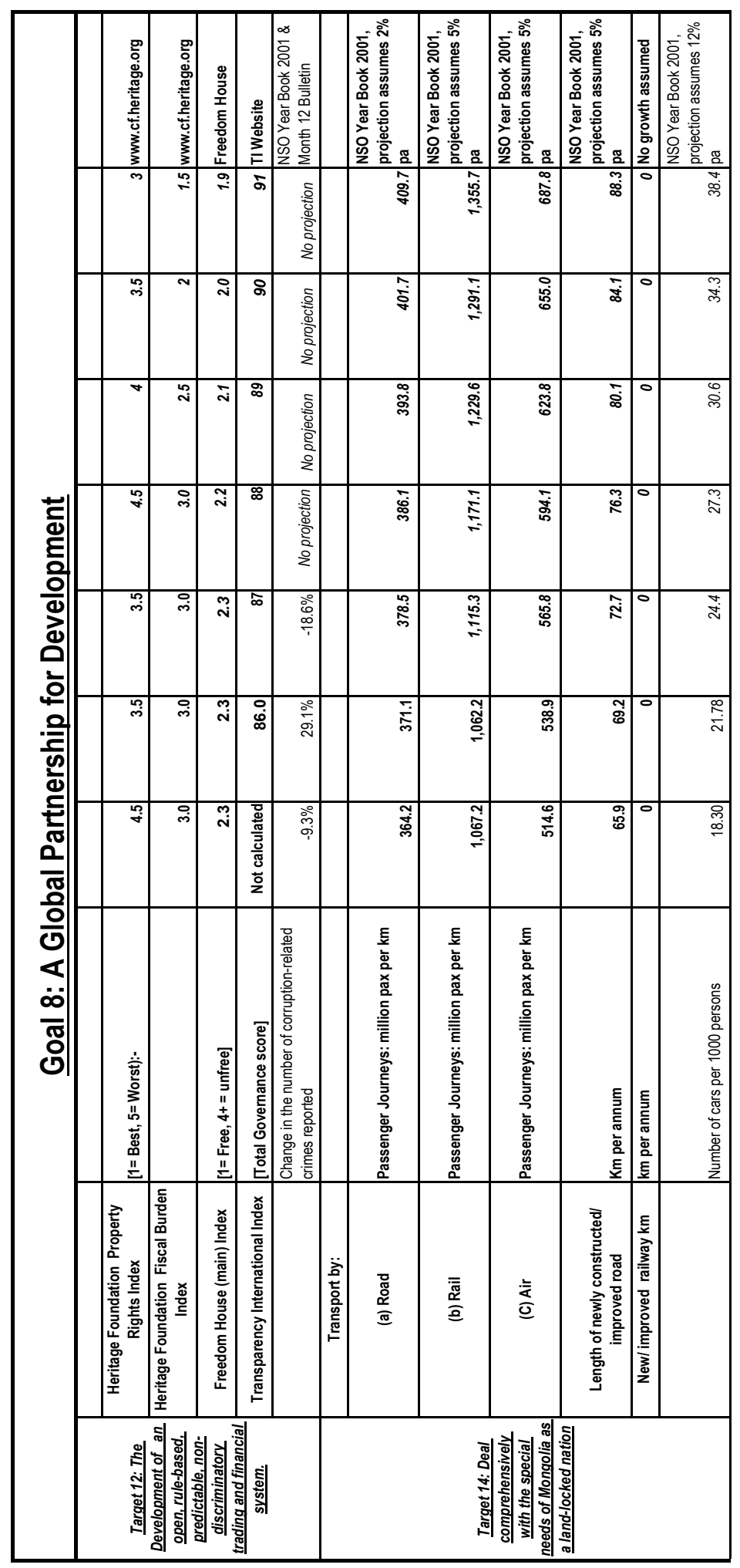




\begin{tabular}{|c|c|c|c|c|c|c|c|c|c|c|}
\hline 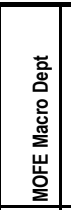 & 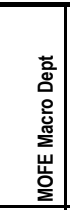 & 高 & 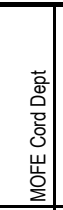 & 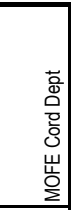 & $\begin{array}{l}\frac{t}{0} \\
\frac{0}{0} \\
0 \\
0 \\
\end{array}$ & 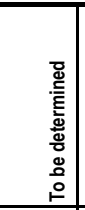 & 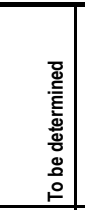 & 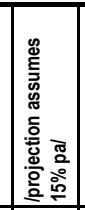 & 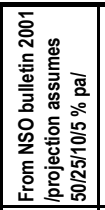 & 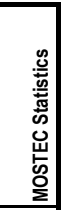 \\
\hline 灾 & D. & 年 & 审 & 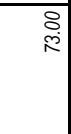 & 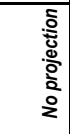 & 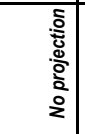 & 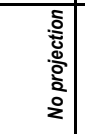 & $\mathbb{Z}$ & \begin{tabular}{l}
\multirow{2}{*}{} \\
$\mathrm{N}$
\end{tabular} & 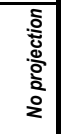 \\
\hline ๙̊. & $\stackrel{\sim}{\sim}$ & 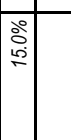 & 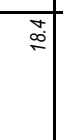 & 胥 & 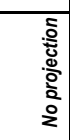 & 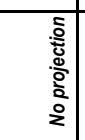 & 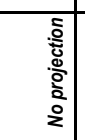 & 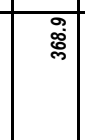 & 管 & $\begin{array}{l} \\
\frac{5}{8} \\
\frac{0}{0} \\
\frac{0}{2} \\
2\end{array}$ \\
\hline के & $\stackrel{\sim}{\sim}$ & 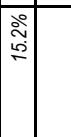 & 竞 & 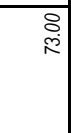 & 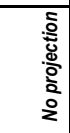 & 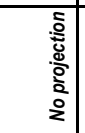 & 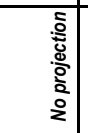 & 焉 & (5) & 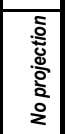 \\
\hline 产. & స్ల & 年 & $\begin{array}{l}8 \\
\end{array}$ & 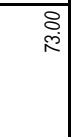 & 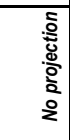 & 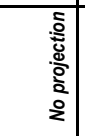 & 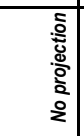 & 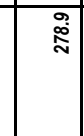 & (5) & న్ల \\
\hline \begin{tabular}{l|l}
0 \\
$\dot{\infty}$
\end{tabular} & งิ & 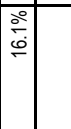 & 它 & त्रి & 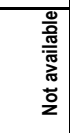 & 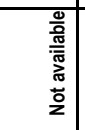 & 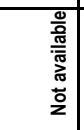 & : & $\begin{array}{l}2 \\
3 \\
2 \\
2\end{array}$ & ग्ञ \\
\hline 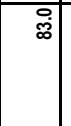 & 胥 & | & i্ & 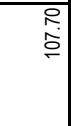 & 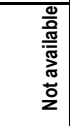 & 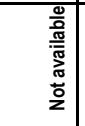 & 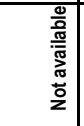 & 势 & 管 & 吕 \\
\hline \begin{tabular}{l|l|l|l|l|} 
& \\
$\infty$
\end{tabular} & iñ & | & $\stackrel{\infty}{\circ}$ & \begin{tabular}{l|} 
\\
\\
$\infty$ \\
$\infty$ \\
0
\end{tabular} & \begin{tabular}{|c|}
\multirow{8}{\circ}{} \\
$\stackrel{\circ}{\circ}$
\end{tabular} & 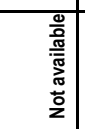 & 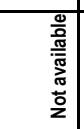 & $\stackrel{\substack{0 \\
\infty \\
\infty}}{-10}$ & जी & 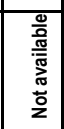 \\
\hline 蒿 & 号 & 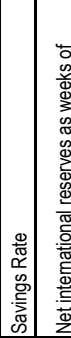 & 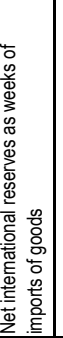 & 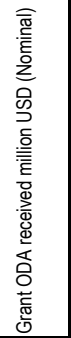 & 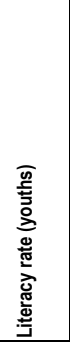 & & & & & \\
\hline 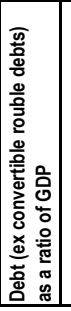 & 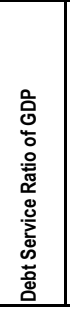 & & & & 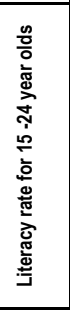 & 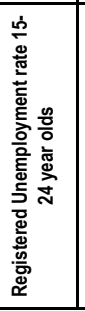 & 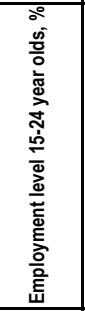 & 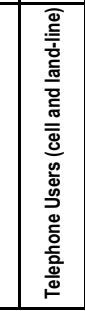 & 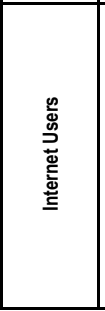 & 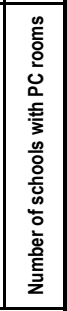 \\
\hline \multicolumn{5}{|c|}{ 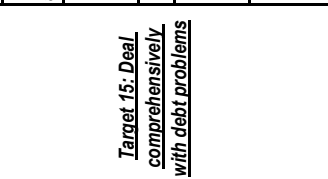 } & \multicolumn{3}{|c|}{ 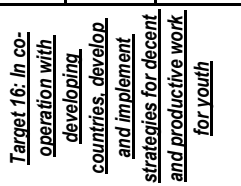 } & \multicolumn{3}{|c|}{ 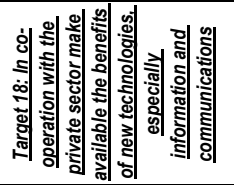 } \\
\hline
\end{tabular}




\section{EGPRS MONITORING INDICATORS (QUALITY OF) DATA SOURCES ASSESSMENT}

- Note: Future projections are shown in italics -

\begin{tabular}{|c|c|c|c|c|c|c|}
\hline $\begin{array}{l}\text { Mongolian MDG } \\
\text { Targets }\end{array}$ & Outcome Indicators & Intermediary Monitoring Indicators & Responsible & Time & $\begin{array}{l}\text { Ability to } \\
\text { obtain } \\
\text { a statistical } \\
\text { data }\end{array}$ & Notes \\
\hline \multirow{10}{*}{$\begin{array}{l}\frac{\text { Target 1: Halve, }}{\text { between } 1990 \text { and }} \\
2015 \text {, the proportion of }\end{array}$} & Poverty Headcount (\%) & & NSO & every 5 years & good & from LSMS \\
\hline & $\begin{array}{l}\text { Depth of Poverty (Headcount x Income } \\
\text { Gap) }\end{array}$ & & NSO & every 5 years & good & from LSMS \\
\hline & Severity (Pa Index) & & NSO & every 5 years & good & from LSMS \\
\hline & Human Development Index & & NSO & every year & good & \\
\hline & & Growth in Gross GDP (\%) & MOFE and NSO & every year & good & \\
\hline & & Per Capita growth GDP & MOFE and NSO & every year & good & \\
\hline & & Internal stability: Inflation Rate per annum & MOFE and MB & every year & good & \\
\hline & & Budget Deficit as $\%$ of GDP & MOFE & every year & good & \\
\hline & & M2 growth, percent & $M B$ & every year & good & \\
\hline & & Exchange Rate: Tg per US\$ & $M B$ & every year & good & \\
\hline \multirow{9}{*}{$\frac{\text { people whose income }}{\frac{\text { is below the annual }}{\text { poverty line. }}}$} & & Balance of Payments [Million US\$]: & MOFE and MB & every year & good & \\
\hline & & (a) Total balance & MOFE and MB & every year & good & \\
\hline & & (b) Current account & MOFE and MB & every year & good & \\
\hline & & (c i) Trade Balance & MOFE and MB & every year & good & \\
\hline & & (c ii) Adjusted Trade Balance & MOFE and MB & every year & good & \\
\hline & & Trade Balance as a \% of Total exports & MOFE and MB & every year & good & \\
\hline & & Change in DFI (\%) & MOFE & every year & good & \\
\hline & & $\begin{array}{l}\text { Interest Rate Spreads: Average lending less } \\
\text { deposit rate }\end{array}$ & MOFE and MB & every year & good & \\
\hline & & Combined School Enrolment Rate & MOSTEC & every year & good & \\
\hline \multirow[b]{2}{*}{$\frac{\text { Target 2: Halve, }}{\text { between1990 and 2015, }}$} & $\begin{array}{l}\text { Growth in number of beneficiaries of } \\
\text { the social assistance pensions Fund } \\
\text { (thousands) }\end{array}$ & Percentage & MOWL & every year & good & \\
\hline & & $\begin{array}{l}\text { Growth of Social Welfare Budget (constant price } \\
\text { base) }\end{array}$ & MOFE and MOWL & every year & good & \\
\hline \multirow{6}{*}{$\begin{array}{c}\frac{\text { the proportion of }}{\text { people who suffer from }} \\
\text { hunger. }\end{array}$} & & Population Growth & NSO & every year & good & \\
\hline & Agricultural production growth & (a) Livestock & MOFA & every year & good & \\
\hline & & Animal Losses (000 numbers) & MOFA & every year & good & \\
\hline & & Number of livestock per herder household & MOFA & every year & good & \\
\hline & Agricultural production growth & (b) Arable Crops & MOFA and NSO & every year & good & \\
\hline & & Change in Arable Sown Areas \% & MOFA and NSO & every year & good & \\
\hline
\end{tabular}




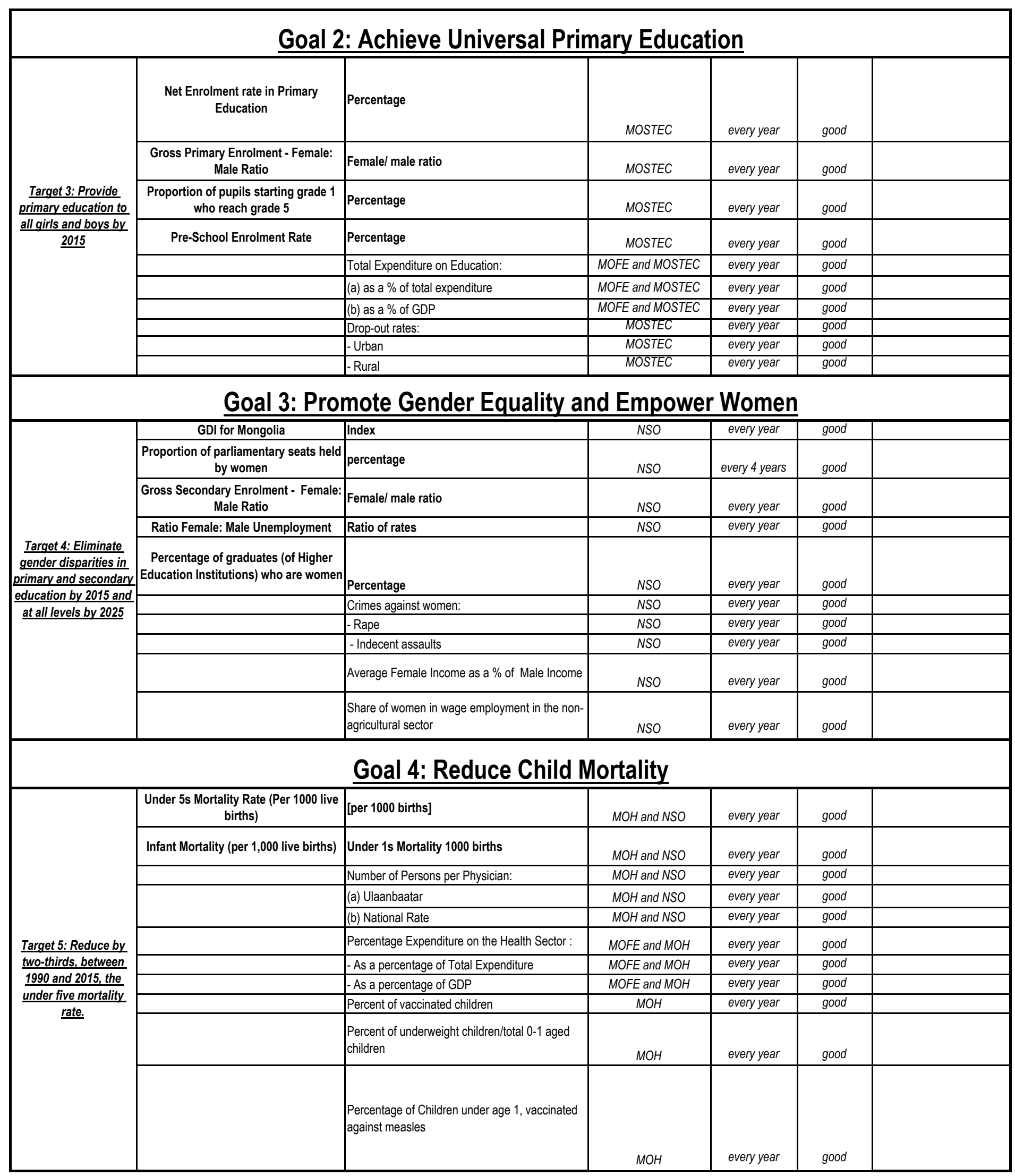




\begin{tabular}{|c|c|c|c|c|c|c|}
\hline \multicolumn{7}{|c|}{ Goal 5: Improve Maternal Health } \\
\hline \multirow{2}{*}{$\begin{array}{l}\frac{\text { Target 6: Reduce by }}{\text { three quarters, }} \\
\frac{\text { between } 1990 \text { and }}{2015, \text { the maternal }} \\
\frac{\text { mortality ratio. }}{\text {. }}\end{array}$} & $\begin{array}{l}\text { Maternal Mortality Rate (per 100,000 } \\
\text { live births) }\end{array}$ & [per 100000 births] & $\mathrm{MOH}$ & every year & good & \\
\hline & & $\begin{array}{l}\text { Proportion of Births Attended by Skilled Health } \\
\text { Personnel }\end{array}$ & $\mathrm{MOH}$ & every year & good & \\
\hline \multicolumn{7}{|c|}{ Goal 6: Combat HIV/ AIDS, Malaria and other diseases } \\
\hline \multirow{3}{*}{$\frac{\frac{\text { Target 7: Have halted }}{\text { by 2015, and begun to }}}{\frac{\text { reverse, the spread of }}{\text { HIV/ AIDS }}}$} & $\begin{array}{c}\text { HIV Prevalence amongst } 15-24 \text { year old } \\
\text { pregnant women }\end{array}$ & Number & $\mathrm{MOH}$ & every year & good & \\
\hline & Number of children orphaned by AIDS & Number & $\mathrm{MOH}$ & every year & good & \\
\hline & & Contraceptive Prevalence Rate & $\mathrm{MOH}$ & every year & good & \\
\hline \multirow{3}{*}{$\frac{\frac{\text { Target 8: Have halted }}{\text { by 2015 and begun to }}}{\frac{\text { reverse, the spread of }}{\text { tuberculosis }}}$} & Prevalence of TB per 100,000 persons & [per 100000 ] & $\mathrm{MOH}$ & every year & good & \\
\hline & TB Death Rate & percentage & $\mathrm{MOH}$ & every year & good & \\
\hline & $\begin{array}{l}\text { Proportion of TB Cases detected and } \\
\text { cured under DOTS }\end{array}$ & percentage & $\mathrm{MOH}$ & every year & good & \\
\hline \multirow{6}{*}{$\frac{\text { Measures applicable to }}{\underline{\text { both Targets } 7 \& 8}}$} & & $\begin{array}{l}\text { Numbers Covered by the National Health } \\
\text { Insurance Scheme: }\end{array}$ & & & & \\
\hline & & (a) Poor/ Vulnerable People & $\begin{array}{r}\text { National Insurance } \\
\text { Agency }\end{array}$ & every year & good & \\
\hline & & (b) Herders engaged in private business & \begin{tabular}{r|} 
National Insurance \\
Agency
\end{tabular} & every year & good & \\
\hline & & (c) students & $\begin{array}{r}\text { National Insurance } \\
\text { Agency }\end{array}$ & every year & good & \\
\hline & & (d) voluntary insurers & $\begin{array}{r}\text { National Insurance } \\
\text { Agency }\end{array}$ & every year & good & \\
\hline & & (e) Mandatory Members & $\begin{array}{r}\text { National Insurance } \\
\text { Agency }\end{array}$ & every year & good & \\
\hline \multicolumn{7}{|c|}{ Goal 7: Ensure Environmental Sustainability } \\
\hline \multirow{6}{*}{$\begin{array}{l}\frac{\text { Target 9: Integrate the }}{\text { principles of }} \\
\text { sustainable } \\
\frac{\text { development into }}{\text { country policies and }} \\
\frac{\text { programmes and }}{\text { reverse the loss of }} \\
\frac{\text { environmental }}{\text { resources }}\end{array}$} & $\begin{array}{l}\text { Percentage of land area covered by } \\
\text { forest }\end{array}$ & Percentage & MONE & every year & good & \\
\hline & & Reforestation, (total hectares) & MONE & every year & good & \\
\hline & $\begin{array}{l}\text { Land area protected to maintain } \\
\text { biological diversity }\end{array}$ & Percentage & MONE & every year & good & \\
\hline & & Increase in desertification (hectares) & MONE & every year & good & \\
\hline & Carbon Dioxide Emissions & Tonnes per person & MONE & every year & good & \\
\hline & & $\begin{array}{l}\text { Number (000s) of households supplied with } \\
\text { improved stoves }\end{array}$ & MONE & every year & good & \\
\hline \multirow{2}{*}{$\begin{array}{l}\frac{\text { Target 10: Halve, by }}{2015, \text { the proportion of }} \\
\text { people without access } \\
\text { to safe drinking water } \\
\end{array}$} & $\begin{array}{l}\text { Proportion of population using an } \\
\text { improved water source }\end{array}$ & Percentage & MONE and MOI & every year & good & \\
\hline & & No. of working wells (thousands) & NSO & every year & good & \\
\hline \multirow{2}{*}{$\begin{array}{l}\frac{\text { Target 11: By 2020, to }}{\frac{\text { have achieved a }}{\text { significant }}} \\
\text { improvement in the } \\
\text { lives of slum dwellers }\end{array}$} & $\begin{array}{l}\text { Proportion of population using } \\
\text { adequate sanitation facilities }\end{array}$ & Percentage & NSO and MONE & every year & good & \\
\hline & & Number of Community Bath Facilities & NSO & every year & good & \\
\hline
\end{tabular}




\begin{tabular}{|c|c|c|c|c|c|c|}
\hline \multicolumn{7}{|c|}{ Goal 8: A Global Partnership for Development } \\
\hline \multirow{5}{*}{$\begin{array}{l}\frac{\text { Target 12: The }}{\text { Development of an }} \\
\frac{\text { open, rule-based, }}{\text { predictable, non- }} \\
\text { discriminatory trading } \\
\text { and financial system. }\end{array}$} & $\begin{array}{l}\text { Heritage Foundation Property Rights } \\
\text { Index }\end{array}$ & {$[1=$ Best, $5=$ Worst):- } & $P R G$ & every year & meddium & www.cf.heritage.org \\
\hline & $\begin{array}{l}\text { Heritage Foundation Fiscal Burden } \\
\text { Index }\end{array}$ & & $P R G$ & every year & meddium & www.cf.heritage.org \\
\hline & Freedom House (main) Index & {$[1=$ Free, $4+=$ unfree $]$} & $P R G$ & every year & meddium & Freedom House \\
\hline & Transparency International Index & [Total Governance score] & $P R G$ & every year & meddium & TI Website \\
\hline & & $\begin{array}{l}\text { Change in the number of corruption-related } \\
\text { crimes reported }\end{array}$ & NSO & every year & meddium & \\
\hline \multirow{7}{*}{$\begin{array}{l}\frac{\text { Target 14: Deal }}{\text { comprehensively with }} \\
\frac{\text { the special needs of }}{\text { Mongolia as a land- }} \\
\frac{\text { locked nation }}{}\end{array}$} & Transport by: & & & & & \\
\hline & (a) Road & Passenger Journeys: million pax per km & $\mathrm{MOI}$ and NSO & every year & good & \\
\hline & (b) Rail & Passenger Journeys: million pax per km & $\mathrm{MOl}$ and $\mathrm{NSO}$ & every year & good & \\
\hline & (C) Air & Passenger Journeys: million pax per $\mathrm{km}$ & $\mathrm{MOl}$ and $\mathrm{NSO}$ & every year & good & \\
\hline & $\begin{array}{c}\text { Length of newly constructed/ improved } \\
\text { road }\end{array}$ & Km per annum & $\mathrm{MOI}$ and $\mathrm{NSO}$ & every year & good & \\
\hline & \begin{tabular}{|l|} 
New/ improved railway $\mathrm{km}$ \\
\end{tabular} & $\mathrm{km}$ per annum & $\mathrm{MOI}$ and $\mathrm{NSO}$ & every year & good & \\
\hline & & Number of cars per 1000 persons & $\mathrm{MOI}$ and $\mathrm{NSO}$ & every year & good & \\
\hline \multirow{6}{*}{$\frac{\frac{\text { Target 15: Deal }}{\text { comprehensively with }}}{\underline{\text { debt problems }}}$} & & & & & & \\
\hline & $\begin{array}{l}\text { Debt (ex convertible rouble debts) as a } \\
\text { ratio of GDP }\end{array}$ & Ratio & MOFE & every year & good & \\
\hline & Debt Service Ratio of GDP & Ratio & MOFE & every year & good & \\
\hline & & Savings Rate & $M B$ & every year & good & \\
\hline & & Gross international reserves as weeks of imports & MB & every year & good & \\
\hline & & Grant ODA received million USD (Nominal) & MOFE and MB & every year & good & \\
\hline \multirow{3}{*}{$\begin{array}{c}\begin{array}{c}\text { Target 16: In co- } \\
\text { operation with } \\
\text { developing countries, }\end{array} \\
\frac{\text { develop and }}{\text { implement strategies }} \\
\frac{\text { for decent and }}{\text { productive work for }} \\
\text { youth }\end{array}$} & Literacy rate for $15-24$ year olds & Literacy rate (youths) & MOSTEC & every year & good & \\
\hline & $\begin{array}{l}\text { Registered Unemployment rate 15-24 } \\
\text { year olds }\end{array}$ & & NSO & every year & good & \\
\hline & Employment level $15-24$ year olds, \% & & NSO & every year & good & \\
\hline \multirow{4}{*}{ 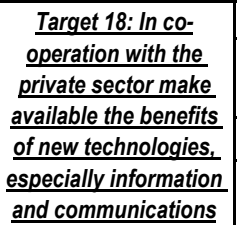 } & & & & & & \\
\hline & Telephone Users (cell and land-line) & & $\mathrm{MOI}$ and NSO & every year & good & \\
\hline & Internet Users & & $\mathrm{MOI}$ and NSO & every year & good & \\
\hline & Number of schools with PC rooms & & MOSTEC & every year & good & \\
\hline
\end{tabular}

MOFA

MOWL

MOFE

NSO

MB

MOSTEC

MONE

$\mathrm{MOI}$
Ministry of Food and Agriculture

Ministry of Welfare and Labour

Ministry of Finance and Economy

National Statistical Office

Mongolbank

Ministry of Since and Tehnology and Education and Culture

Ministry of Nature and the Environment

Ministry of Infrastructure 